\title{
lus Soli, lus Sanguinis, lus Linguae, or lus Mundi: Living, Understanding, and Building Transnational Citizenship in a Transnational Multilingual Family in the U.S
}

Natalya Kuznetsova

Follow this and additional works at: https://researchrepository.wvu.edu/etd

\section{Recommended Citation}

Kuznetsova, Natalya, "lus Soli, lus Sanguinis, lus Linguae, or lus Mundi: Living, Understanding, and Building Transnational Citizenship in a Transnational Multilingual Family in the U.S" (2018). Graduate Theses, Dissertations, and Problem Reports. 6024.

https://researchrepository.wvu.edu/etd/6024

This Dissertation is protected by copyright and/or related rights. It has been brought to you by the The Research Repository @ WVU with permission from the rights-holder(s). You are free to use this Dissertation in any way that is permitted by the copyright and related rights legislation that applies to your use. For other uses you must obtain permission from the rights-holder(s) directly, unless additional rights are indicated by a Creative Commons license in the record and/ or on the work itself. This Dissertation has been accepted for inclusion in WVU Graduate Theses, Dissertations, and Problem Reports collection by an authorized administrator of The Research Repository @ WVU.

For more information, please contact researchrepository@mail.wvu.edu. 
Ius Soli, Ius Sanguinis, Ius Linguae, or Ius Mundi: Living, Understanding, and Building Transnational Citizenship in a Transnational Multilingual Family in the U.S.

Natalya Kuznetsova

\author{
Dissertation submitted \\ to the College of Education and Human Services \\ at West Virginia University \\ in partial fulfillment of the requirements for the degree of \\ Doctor of Philosophy in Education
}

\author{
Malayna Bernstein, Ph.D., Co-chair \\ Audra Slocum, Ph.D., Co-chair \\ Melissa Sherfinski, Ph.D. \\ Marjorie Orellana, Ph.D. \\ Samuel Stack, Ph.D. \\ Lisa Di Bartolomeo, Ph.D.
}

Department of Curriculum and Instruction/ Literacy Studies

\author{
Morgantown, West Virginia \\ 2018
}

Keywords: transnational families, family language policy, heritage, language socialization Copyright 2018 Natalya Kuznetsova 


\section{ABSTRACT \\ Ius Soli, Ius Sanguinis, Ius Linguae, or Ius Mundi: Living, Understanding, and Building Transnational Citizenship in a Transnational Multilingual Family in the U.S.}

\section{Natalya Kuznetsova}

Through the case of a multilingual Estonian family of sojourners in the U.S., this ethnographic study examines the ways in which a multilingual family lives, understands, and constructs their transnational experiences, negotiating their language practices and identities in the context of their family space and globally. With an intention to respond to and to reflect the complexity of the phenomenon of language ecology in a multilingual transnational family, the study draws on and merges three conceptual frameworks: language socialization, family language policy, and transnational social spaces. Through the analysis of ethnographic observations, recordings of naturally occurring conversations, interviews with family members, and parents' graphic representations of their language selves, this thesis explores (1) family beliefs and attitudes about languages and language learning, (2) family language and cultural behaviors and practices, (3) family language management and overall language policy, and (4) family identities.

The analysis revealed that the parents' beliefs about language as a tool, as a resource, and as a social practice, and their beleifs about language learning originated from their personal experiences and broader ideological context. Those beliefs were translated into the family's rich multilingual discursive practices through which they constructed experiences for their children as multilingual "global elites" with flexible language and cultural citizenships. The family created a complex network of language and cultural spaces which encompassed the links to the home country through parents' languages and their memory, the connections to the Russian-speaking diaspora in the U.S. and relatives in Estonia, and the immediate context of the host country, the U.S.

The study illustrates that the notions of "heritage", "first", and "family" languages are contested, and in their individual realizations, embody the relationship between spacio-temporal context and individual experience. The momentum of the language choice, practice, and identification lies in one particular "standing point", beyond which is multiplicity of other developing scenarios of language choices, practices, and identifications. The "standing point" grounds in either the land where someone is born or resides (ius soli), or through the parents (ius sanguinis), or via the ways of "being and becoming" through languages learning (ius lingue), or through developing a feeling of being a product of the global world (ius mundi).

The study aspires to contribute to the existing scholarship on language and society, language and identity, the ecology of multilingualism, heritage language socialization. This work advances the notion of language as a social practice, and provides illustrative support for conceptualizing multilingualism as a tool, a resource, and a social practice. The results of the study will be of interest to heritage language linguists, anthropologists, literacy studies and family studies scholars, and sociologists of language. 


\section{DEDICATION}

To my parents, Nina and Vladimir,

not only for their endless and selfless love and support,

but most importantly for their immense patience

to calmly accept all adventures

of their little world explorer, me 


\section{ACKNOWLEDGMENTS}

This work is the outcome of many years of a long process of personal and professional inquiries, and there are many people who have contributed to this work by their knowledge, guidance, support, wisdom, advise, kindness, love, and understanding, and of course by direct participation in the project. Some people were near, some happen or have to be far, but always in heart.

I am grateful for having met Kristina and Meelis Kiisks, who agreed to participate in this project, heartily welcomed me in their house, and generously shared the secrets of their "language being". It was a real discovery to turn our friendship into a scientific inquiry and be observing the development of multiple languages and the dynamics of language socialization together. The little multilinguals, Annemarii and Keiriin, are also getting special thanks, as the time with them was the most stimulating experience of the whole project. Their language learning and socializing patterns informed me a lot scientifically, and taught me not to be afraid of mistakes and be open to discoveries, to always test and try, and to believe. Who knew that children would be the best teachers. I was growing together with those little girls.

My deep gratitude goes to the members of my dissertation committee, who had provided me with personal and professional guidance, nourished me intellectually and supported me overall personally. You are all great scholars, educators, and wonderful human beings. I am indebted more than once to Dr. Malayna Bernstein, my academic advisor and a professional mentor, a co-chair of this research project and my academic mother. I am very grateful to you for your unwavering trust in me when I was losing confidence in myself. The stimulating discussion of language and literacy as a social practice in Dr. Audra Slocum's class became the creek that gave life to this inquiry. I have been extremely fortunate to work with Dr. Lisa DiBartolomeo, 
who has been my Russian program supervisor and a wonderful colleague for many years. How many blinis and pelmeni we have made together, and how many high-achieving students we have graduated! I am honored to have Dr. Marjorie Orellana as my external examiner, whose academic works on transnational children were insightful for me in many ways. And, of course, I ma grateful to Dr. Melissa Sherfinski and Dr. Sam Stack who jumped on the committee offering their help.

My American hostparents, Marcia Stoutjesdyk and John Kennedy, whose welcoming house became my first American home back in 2007-2008, in Davidson, NC, contributed greatly to who I am now: Marcia with her cheerful spark in her eyes and witty comments and John with his serenity and wisdom. It was in a house of Magnolia Street that my U.S. journey started. Marc and John opened an American life to me with the first cup of latte and a soup bread bowl in far away August 2007, and were the ones who packed me up and travelled with me to begin my Morgantown chapter. Thank you for letting me become a part of your life. This work is indebted to you for your generosity and overabounding kindness.

I am grateful for my WVU community, the faculty and my student-colleagues, with whom I had a pleasure to work, study, and learn from in my two homes, the department of World Languages, Literatures, and Linguistics and the College of Education and Human Services. My tea-solemates Ayaka, Margarita, Olga, and many others who provided me with energizing or calming tea, cookies, and endless conversations and laughs. I thank my academic twin-sister Nathalie Ruamba, for supporting and encouraging me immensely all the way since our first day of graduate student orientation back in 2009, when we started our MA. I am also grateful to my other wonderful colleagues whom I met during my doctoral studies. 
To all my Russian students, and there are nine full years of them, who kept me sane through all these years. Teaching them and learning from them was a pleasure and the best leisure to ask for during my writing journey.

I would like to thank College of Education and Human Services for providing me with an opportunity to receive a Wirt C. and Mae S. Belcher Graduate Education Award. This work became possible thanks to this generous support.

Lastly, but most importantly, nobody is always as supportive of my life endeavors as my family: my parents, Nina and Vladimir, my elder sister, Elena, and my two nephews. Their unconditional love, kindness, and an example of hard work have been always my anchor in happiness and challenging times. They might be the happiest, as they have hoped wholeheartedly, that my academic journey of long 26 years - since they ribboned my two ponytails tight, gave me an Азбука (an $\mathrm{ABC}$ book) and sent me to school when I was 6 years old - is coming to an end with the completion of this dissertation. My sister has always been my pillar of wisdom and comfort. I also cannot imagine going through this transformative intellectual process without the most patient person in the world, my multilingual and multicultural multi-citizen husband Ricardo. Many ideas and inquires were born out of our endless philosophical discussions of his own heritage, languages and cultures, art and life, and what not. You came into my life five years ago, in the right time, and you know every step I made in this journey; you wiped down every sob I made and backed up my excitement when I was finding solutions to my research puzzles. Thank you for encouraging me, and pushing me to write one more line, one more paragraph.

To all who made this work possible, with my deep appreciation of your support, I present you with this piece... 


\section{TABLE OF CONTENTS}

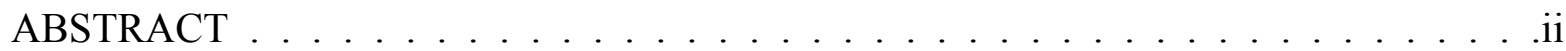

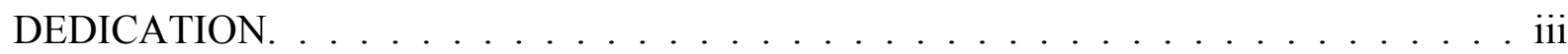

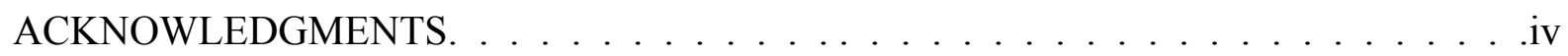

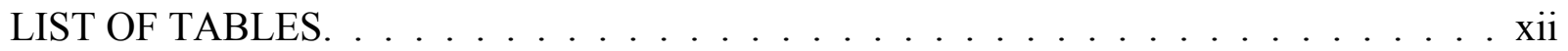

LIST OF FIGURES. . . . . . . . . . . . . . . . . . . . xiii

LIST OF EXCERPTS. . . . . . . . . . . . . . . . . xiv

KEY TO TRANSCRIPTION CONVENTIONS. . . . . . . . . . . . . . . . xvi

CHAPTER 2: INTRODUCTION . . . . . . . . . . . . . . . . . 1

Introductory Vignette $\ldots \ldots \ldots \ldots \ldots$

Migration, Language, and Family. . . . . . . . . . . . . . . . . . 2

Statement of Purpose. . . . . . . . . . . . . . . . . 10

Guiding Questions. . . . . . . . . . . . . . . . . . . 13

An Overview of the Dissertation. . . . . . . . . . . . . . . . 14

CHAPTER 2: REVIEW OF LITERATURE. . . . . . . . . . . . . . . . . . . . . 16

Introduction. . . . . . . . . . . . . . . . 15

Language Socialization in the Contemporary World . . . . . . . . . . . . 19

Theoretical Overview. ................... 19

Language Socialization in Multilingual Settings. . . . . . . . . . . . . 22

Agents of Language Socialization. . . . . . . . . . . . . . . . . 24

Family Language Behavior. . . . . . . . . . . . . . . . . . . 27

Language, Heritage, and Identity. . . . . . . . . . . . . . . . . . . 32

Summary. . . . . . . . . . . . . . . . . . . 37 
Family Language Policy. . . . . . . . . . . . . . . . . . . . . . . . . . . 39

Theoretical Overview. . . . . . . . . . . . . . . 40

Family Language Ideology. . . . . . . . . . . . . . . . . . . . . . . . . 39

Family Language Practices and Management. . . . . . . . . . . . . . . 56

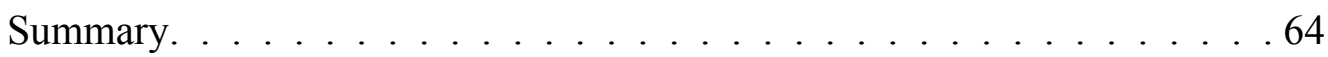

Transnational Spaces. . . . . . . . . . . . . . . . 65

Theoretical Overview. . . . . . . . . . . . . . . . . 65

“Transnationalism" in Family Language Socialization. . . . . . . . . . . . .67

Socio-Cultural Context of The Study. . . . . . . . . . . . . . . . 70

The Russian-Speaking Context in the U.S. . . . . . . . . . . . . . . 70

The Russian Language in the Estonian Context. . . . . . . . . . . . . . . . 73

U.S. Educational Context for Russian and Estonian. . . . . . . . . . . . . 77

Putting Frameworks Together. . . . . . . . . . . . . . . . . . . . 78

Summary of Literature Review. . . . . . . . . . . . . . . . . . . . 80

CHAPTER 3: METHODOLOGY . . . . . . . . . . . . . . . . . 82

Research Design. . . . . . . . . . . . . . . . . . . . . . . . .

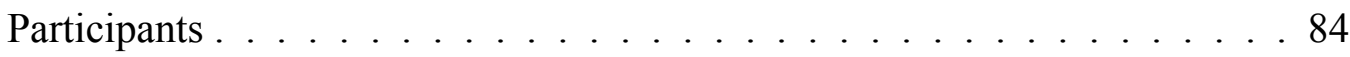

Data Collection Tools. . . . . . . . . . . . . . . . . . . 84

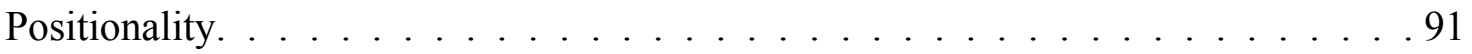

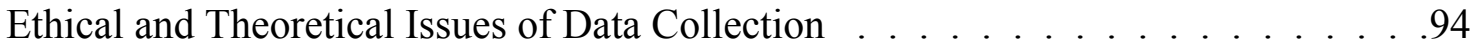

Data Analysis. . . . . . . . . . . . . . . . . . 96

Data Preparation and Organization of Data. . . . . . . . . . . . 95

Coding. . . . . . . . . . . . . . . . . . . 100 
Limitations and Challenges of Data Collection and Data Analysis. . . . . . . . . 104

CHAPTER 4: FINDINGS. . . . . . . . . . . . . . . . . . . . . 107

Family Profiles . . . . . . . . . . . . . . . . . 105

The Kiisks. . . . . . . . . . . . . . . . . . . . . . . . . 105

Children: Annemarii and Keiriin. . . . . . . . . . . . . . . . . . . 110

Kristina. . . . . . . . . . . . . . . . 116

Meelis. . . . . . . . . . . . . . . . . . . . 121

Baba Olya, Olga, Kristina's Mother. . . . . . . . . . . . . . . . 125

Eveline, Eve, Meelis's Mother. . . . . . . . . . . . . . . . . . . . . . 128

Family Language Policies. . . . . . . . . . . . . . . . . . . . . . . . 129

Family Ideologies. . . . . . . . . . . . . . . . . . . . . 129

Beliefs about the Language. . . . . . . . . . . . . . . . 130

Beliefs about Language Learning . . . . . . . . . . . . . . . . 141

Beliefs about Children's Linguistic and Cultural Citizenship . . . . . 144

Comparing Beliefs at Macrolevel and Microlevel. . . . . . . . . . . 145

Values of Being Multilingual. . . . . . . . . . . . . . . . 146

Family Language Practices. . . . . . . . . . . . . . . . . . . . . 148

Parents' Discourses: Parents Teaching. . . . . . . . . . . . . . . 149

Children's Discourses: Children Learning. . . . . . . . . . . . . 200

Defining the Kiisk's Family Language System. . . . . . . . . . . . . . . . . . 224

The Kiisk' Family Language Policy . . . . . . . . . . . . . . . . . . . . . .224

Language Spaces. . . . . . . . . . . . . . . . 225

Constructing Family Language Policy. . . . . . . . . . . . . . . 228 
Summary of the Kiisk's Family Language Policy Principles . . . . . . . . . 225

Negotiating Identity through Family Language Policy . . . . . . . . . . . 232

Parents' Identities. . . . . . . . . . . . . . . . . 233

Constructing Children Identity. . . . . . . . . . . . . . . . . 242

Children Constructing Identity. . . . . . . . . . . . . . . 244

Summary of Findings. . . . . . . . . . . . . . . . . . 245

CHAPTER 5: DISCUSSION, CONTRIBUTIONS, AND FURTHER RESEARCH . . . 248

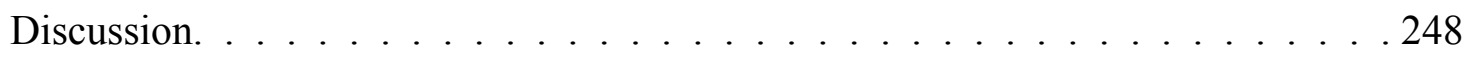

Family Portrait. . . . . . . . . . . . . . . . . . . . . 249

The Kiisk's Family Language system . . . . . . . . . . . . . . . . . . . 251

Heritage, First, or Family Language? . . . . . . . . . . . . . . . . . . . 254

Place Vs. Space.. . . . . . . . . . . . . . . . . . . . . . . . . . 258

Revised Language Socialization Framework. . . . . . . . . . . . . . . . 262

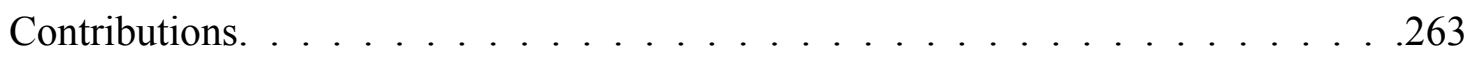

Empirical Contributions. . . . . . . . . . . . . . 263

Methodological Contributions. . . . . . . . . . . . . . 266

Conceptual Contributions. . . . . . . . . . . . . . . . . . . . . . . . . . . . . .

Directions for Further Research. . . . . . . . . . . . . . . . . . . 270

AFTERWORD . . . . . . . . . . . . . . . . . . . . . . . . . . . . . . . . . . . .

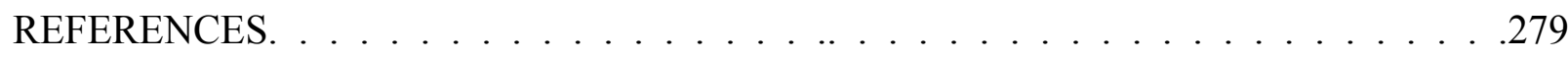

APPENDIX A: IRB Approval Letter. . . . . . . . . . . . . . . . . . . . . . . . . 299

APPENDIX B: Interview Protocol (Parents) . . . . . . . . . . . . . . 300

APPENDIX C: Trip-Journal Guiding Questions. . . . . . . . . . . . . . . . . 302 
APPENDIX D: Essay Questions for Grandmothers. . . . . . . . . . . . . . . . . 303

APPENDIX E: Skype Interview Protocol (Russian Speaking Grandparent) . . . . . . . . . .304

APPENDIX F: Interview with the Elder Child . . . . . . . . . . . . . . 305

APPENDIX G: Language Ego-maps Protocol (parents) . . . . . . . . . . . . . . . . 306

APPENDIX H: Parents Ego-maps (examples) . . . . . . . . . . . . . . . . . . . 307

APPENDIX I: Emergent Themes. . . . . . . . . . . . . . . . . . 308

APPENDIX J: Ethnography of Place (visuals) . . . . . . . . . . . . . . . . 310 


\section{LIST OF TABLES}

Table 1. Number and share speaking language other than English at home 1980-2013 . . . . 3

Table 2. The comparison of analytical focus in conceptualizing code-switching and translanguaging. . . . . . . . . . . . . . . . . . . . . . . . 29

Table 3. Data collection timeline . . . . . . . . . . . . . . . . . . . . 86

Table 4. Phases of empirical design . . . . . . . . . . . . . . . . . . . . . . . . . 90 90 


\section{LIST OF FIGURES}

Figure 1. Immigrants in the U.S., number and percent 1900-2016. . . . . . . . . . . . . 3

Figure 2. Traditional language socialization framework according to Schieffelin \& Ochs (1982)

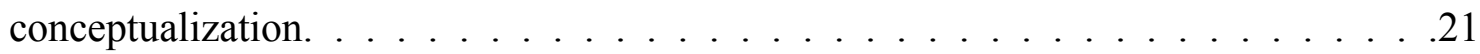

Figure 3. Language socialization in a multilingual context. . . . . . . . . . . . . . . 24

Figure 4. Conceptualization of Family Language Policy . . . . . . . . . . . . . . . . . . . 41

Figure 5. Transnational social space. . . . . . . . . . . . . . . . 66

Figure 6. The Kiisks" "system" of language learning and family language practices. . . . . .199

Figure 7. The Kiisks' Russian language space . . . . . . . . . . . . . . . . . . . 226

Figure 8. The Kiisks' Estonian language space. . . . . . . . . . . . . . . . . 226

Figure 9. The Kiisks' English language space. . . . . . . . . . . . . . . . . . . . . 227

Figure 10. The Kiisks' other languages' space. . . . . . . . . . . . . . . . . . . 227

Figure 11. Kristina's identity cloud. . . . . . . . . . . . . . . . . 241

Figure 12. Revised framework for Language Socialization in multilingual contexts . . . . . 263 


\section{LIST OF CONVERSATION EXCERPS}

Excerpt 1. "Desu, desu”. . . . . . . . . . . . . . . . . . . 1

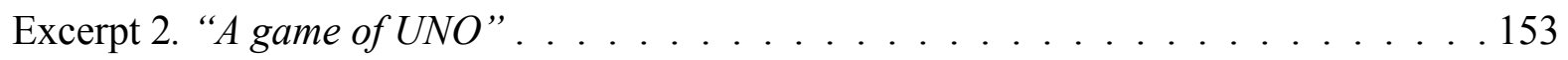

Excerpt 3. "Little flower" . . . . . . . . . . . . . . . . . . . . 155

Excerpt 4. "On Skype with baba Olya” . . . . . . . . . . . . . . . . . . . . . 156

Excerpt 5. "Color yourself" . . . . . . . . . . . . . . . . . . . . 157

Excerpt 6. "Japanese coloring book" . . . . . . . . . . . . . . . . . . . . . . 159

Excerpt 7. "Nuudlit" or"вермишель". . . . . . . . . . . . . . . . . . . 160

Excerpt 8. "ZAZ and Japanese" . . . . . . . . . . . . . . . . . . . . . . . . . . . . . . 161

Excerpt 9. "Berry party" . . . . . . . . . . . . . . . . 165

Excerpt 10. "Kitty cat" . . . . . . . . . . . . . . . . . . 171

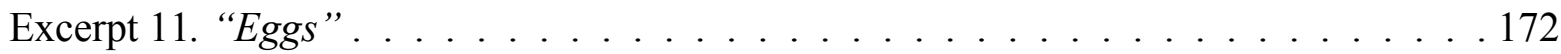

Excerpt 12. "Alexa, volume up" . . . . . . . . . . . . . . . . . . . 173

Excerpt 13. "Drumming like the heart" . . . . . . . . . . . . . . . . . . 175

Excerpt 14. "Do you like...?”. . . . . . . . . . . . . . . . . . . . . . 178

Excerpt 15. "Singing festival" . . . . . . . . . . . . . . . . . 180

Excerpt 16. "Kolobok" . . . . . . . . . . . . . . . . . . . . . 182

Excerpt 17. "What letter are you writing?” . . . . . . . . . . . . . . . . 185

Excerpt 18. "A horse, an onion, and a spruce tree" . . . . . . . . . . . . . . . . 186

Excerpt 19. "Birthday package” . . . . . . . . . . . . . . . . . . 189

Excerpt 20. "What letter is this?" . . . . . . . . . . . . . . . . . . . . . . 190

Excerpt 21. "My pen, your pen" . . . . . . . . . . . . . . . . . 192

Excerpt 22. "Big and tall" . . . . . . . . . . . . . . . . . . . . . 194 
Excerpt 23. "Iwant" . . . . . . . . . . . . . . . . . . 196

Excerpt 24. "Watch or wash" . . . . . . . . . . . . . . . . . . . . . . . . 197

Excerpt 25. "Bless you" . . . . . . . . . . . . . . . . . . . 202

Excerpt 26. "Bremen musicians" . . . . . . . . . . . . . . . . . . . . . . . 204

Excerpt 27. "Let's go" . . . . . . . . . . . . . . . . . . 210

Excerpt 28. "Look it talk, look it talks" . . . . . . . . . . . . . . . . . . . . . . . 212

Excerpt 29. "I'm a big princess" . . . . . . . . . . . . . . . . . . . . . . . 214

Excerpt 30. "Choco, don't sleep on the couch" . . . . . . . . . . . . . . . 216

Excerpt 31. "Choco you get this" . . . . . . . . . . . . . . . . . 217

Excerpt 32. "to Costco" . . . . . . . . . . . . . . . . . . . 218

Excerpt 33. "How tasty" . . . . . . . . . . . . . . . . . . . . . . . . 219

Excerpt 34. "Yes, more" . . . . . . . . . . . . . . . . 220

Excerpt 35. "Koli boli" . . . . . . . . . . . . . . . . . . . 221 
KEY TO TRANSCRIPTION CONVENTIONS

\begin{tabular}{ll}
\hline Symbol & meaning \\
\hline Initials & Identifies speakers \\
italics & Word or phrase said in Russian \\
bold & Word or phrase said in Estonian \\
$\underline{\text { word }}$ & Word or phrase in Japanese \\
bold italics & Word or phrase is emphasized \\
(gesture or sound) & non-verbal action \\
{$[[]]$} & overlapping speech \\
\hline
\end{tabular}




\section{CHAPTER 1: INTRODUCTION}

\section{Introductory Vignette}

It is late afternoon of July 27,2017 . Kristina is upstairs in the kitchen cooking porridge and her daughters, Annemarii and Keiriin, are playing around. Meelis, Kristina's husband, is not yet back home from work. Aki, a Japanese woman with whom the Kiisks share the house, comes downstairs to feed her little baby girl, Mayu, who has just turned nine months old. She puts her daughter into the baby's play-seat, saying something in Japanese, and goes to grab baby's food. Annemarii, the eldest child in the household, gets excited about the opportunity to play with Mayu; after all, what else is there to do if her little girlfriend is around in a playful mood and needs to be entertained while the adults are busy. Annemarii moves her chair closer to Mayu's little play-seat and starts pointing to different toys around, turning them and jingling them. She says,

Excerpt 1 "Desu, desu"

A: $\quad \underline{\text { Desu, desu (in Japanese) Here, here }}$

(pointing to the toys)

Then starts circling the toys around Mayu

A: $\quad$ Mayu, $\underline{\text { desu }} \quad$ Mayu, here

(showing Mayu the toys)

After some time when the baby's mother is back, Annemarii switches her attention to music

A: $\quad$ Alexa, can you play tis [trying to Alexa, can you play this say this] музыка? Alexaaa, can music? Alexaaa, can you you ginging [trying to say children music?

"children's"] music?

ALEXA radio starts playing. 
Quite an ordinary day in the Kiisk family...nothing strikingly unusual.

This vignette vividly illustrates the linguistic, cultural, and situational complexity of some contemporary households: a few languages are in contact - Japanese, English, and Russian, in this case - to serve the communicative needs of those who are involved in this quotidian routine, and there should be four, but Meelis, the Estonian-speaking member of the household, is at work. Kristina and Aki communicate in English, Kristina speaks Russian with her daughters, Aki cooks at her daughter in Japanese with her little daughter: many cultures are in contactJapanese, American, Estonian, Russian, not to mentions the hybrid ones, created in many “contact zones" (Pratt, 1991) that occur in interaction. Two families keeping individual household in a spacious house, but still, basically under the same roof, share not only space but also the richness of their languages, cultures, beliefs, and understanding of the world, through smells, sounds, objects, gestures, and even touch. Annemarii's multilingual language performance is a bright example of living in a multilingual and multicultural "borderless" context, where the main purpose of language practice is negotiation of meaning and understanding, and being understood by the interlocutor. At three years old, the little girl demonstrates her sensitivity to the context, the speaker, the language, and the purpose of communication.

\section{Human Mobility, Language, and Transnational Family ${ }^{1}$}

The situation presented in the opening vignette is not an exception. As the number of multilingual and transnational families grows, contemporary life creates a multitude of situations prompting movement of people and border-crossing.

\footnotetext{
${ }^{1}$ Here and further in this work, I use the notion "family" to signify a nuclear family, with two parents, a mother and a father, with no intention to belittle the experiences of other types of families and relationships existing between people. There has not been any reseach, to my knowledge, on heritage language socialization in single parent families, or in same-sex couples.
} 
If we make a statistical detour into the U.S context, for example, we can observe that the immigration numbers are impressive (Figure 1). The growth over the last two and half decades have almost doubled.

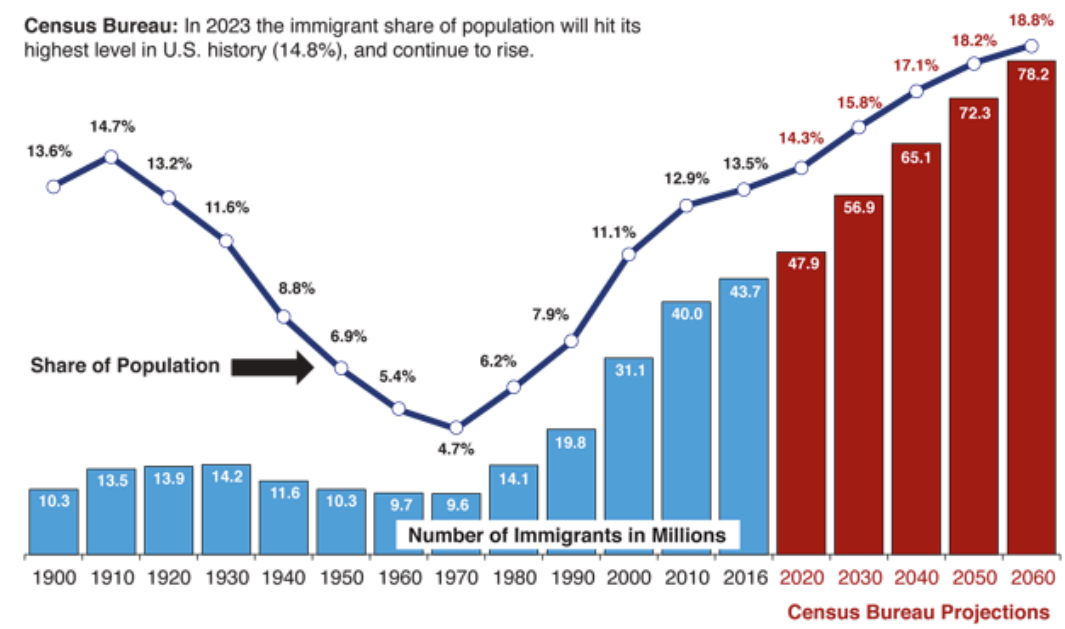

Figure 1. Immigrants in the U.S., number and percent 1900-2016. Source: Center for immigration studies, retrieved from https://cis.org/Report/US-Immigrant-Population-Hit-Record437-Million-2016

Table 1

Number and share of families speaking language other than English at home 1980-2013

\begin{tabular}{lccccc}
\hline & 1980 & 1990 & 2000 & 2010 & 2013 \\
\hline $\begin{array}{l}\text { Speaking a Language } \\
\text { Other than English } \\
\text { at Home }\end{array}$ & $23,060,040$ & $31,844,979$ & $46,951,595$ & $59,542,596$ & $61,748,740$ \\
$\begin{array}{l}\text { Share Speaking Foreign } \\
\text { Language }\end{array}$ & $11.0 \%$ & $13.8 \%$ & $17.9 \%$ & $20.6 \%$ & $20.8 \%$ \\
$\begin{array}{l}\text { Immigrant } \\
\text { Native-Born }\end{array}$ & $9,729,337$ & $15,430,434$ & $25,497,023$ & $33,621,360$ & $34,527,909$ \\
Speaks English Less than & $13,330,703$ & $16,414,545$ & $21,454,572$ & $25,921,236$ & $27,220,831$ \\
"Very Well"* & $10,181,036$ & $13,982,502$ & $21,320,407$ & $25,223,045$ & $25,125,132$ \\
& & & & & \\
\end{tabular}

Source: Center for immigration studies, retrieved from https://cis.org/One-Five-US-Residents-SpeaksForeign-Language-Home-Record-618-million 
As a result, households are becoming incresngly linguistically and culturally diverse. According to U.S. Center for Immigration studies, the number of people who speak a language other than English at home in 2013 reached 61.8 million, which is 2.2 million up since 2010 (Table 1). The data for those years imply that one in five U.S. residents speaks a languge other than Englsh at home. More current data is unavailable. But considering the projections of the Census Bureau, households will continue to be bi/multilingual, creating more contexts for bi/ multilingual first language acquisition (De Houwer, 2009; Genesee \& Nicoladis, 2007; Lanza, 2001).

Globalization, which became a significant feature of the $20^{\text {th }}$ century, is a complex phenomenon, not signifying only physical border crossing. It permeates all spheres of our human life and experience, actively shifting or even removing both physical and social borders, and unifying the world geographically, linguistically, culturally, and ideologically. As Canagarajah (2006) successfully depicts, contemporary world is a world with "porous national boundaries [in which] people, goods, and ideas flow", and such a "compression of space and time," he continues, allows "people to shuttle rapidly between communities and communicative contexts." (in de Costa 2010, p. 769). Blommaert and Rampton (2011) also underline the role of technological innovations and advancements in the diversification of the nature of mobility and new communication, and the creation of new dynamics in social and cultural life marked by complexity and constant transformations. Recent scholarship tends to shift in the theorization of those complex experiences from the static horizontal-distributional term "immigration" towards the more dynamic and multidimensional understanding "transnationalism" (Faist, 1998) highlighting interconnectednesss of people, places, and experiences between/ among home country(ies) and a new country(ies) of settlement. People who are involved in those experiences 
are "transnationals" or "transnational families" (Fogle \& King, 2013; Li, 2018; Zhu \& Li, 2016). There is also a transition from "diversity" to "superdiversity", a diversification of diversity due to changes in the migration patterns worldwide (Vertovec, 2007). It is evident that new social, technological, and geopolitical developments affect out every day practices, choices, and identities.

The mobility of people also involves the mobility of linguistic and sociolinguistic resources (Blommaert, \& Dong, 2007). Globalization and increased human mobility transform language practices and language ideologies, as the communicative contexts and needs dynamically change. As the opening vignette shows people become engaged in multilingual and translanguaging practices, "diverse multilingual and multimodal” activities (Li, 2018, n.p). It is widely recognized that language is a social practice and an important tool of human socialization which is "inextricably embedded in networks of sociocultural relation" (Ahearn, 2001, p. 110), and, whether spoken or written, it indexes both local, cultural, and vertical features of stratification, social, racial, gender, class, and also relevant identities (Blommaert \& Dong, 2007; Bucholtz \& Hall, 2010; Fuller, 2007; Gumperz, 2009). In this sense, Blommaert (2007) argues that "movement of people across space is therefore never a move across empty spaces. The spaces are always someone's space, and they are filled with norms, expectations, conceptions" (p.13) which makes language resources densely layered with multiple meanings. Therefore, people's language repertoire, “translingual” (Canagarajah, 2012), multilingual or monolingual language use and language choice in communication or in language learning - become integral complex social processes, and not just linguistic experiences.

A transnational family is a common product of globalization and a frutful site of research on language and cultural transnational processes. The family, as a unit, is engaged in a complex 
multilayered network of negotiations between being integrated into a host country community and the preservation of connections to the home-nation and maintenance of its heritage. Family is an important focus of research on transnationalism, multilingualism and translanguaging, because it constitutes a primary source of child's socialization, and sets the values, norms, and behaviors, as well as states of linguistic and cultural being and belonging. Understanding of heritage, and language and culture contact begins in the family (Super \& Harkness, 1986) and is shaped by the family capital (Coleman, 1988). "Children's language socialization occurs as part of the continuing history of conversational exchange that make up daily life" (Cook-Gumperz, 1985, p. 54). Home experience determines further children's language, cultural, social practices. Kagan (2012) keenly noted, "moving between languages and cultures happens at the threshold of their homes, not at the border between two countries." (p. 72). A child's identification with certain cultures, languages, and groups of people or the countries starts at home.

Research into transnational family language practices has revealed a diversity of experiences and decisions that a family engages in. Depending on the wider ideological discourse circulating in the society and the perception of their linguistic and culture background, the family can develop either pluralistic or assimilationist ideologies in a transnational context. Pluralistic ideologies actively maintain the heritage language within next generations. Assimilationist ideologes facilitate the complete switch to the host linguistic and cultural environment, at the expense of the heritage loss the complete switch to the host linguistic and cultural environment, at the expense of the heritage loss. The studies on language maintenance and shift inform us about these processes (e.g., Chatzidaki, \& Maligkoudi, 2013; CurdtChristiansen, 2016). Family language policies are beliefs and attitudes that a family holds and develops in the situation of migration, and language and culture contact. This involves how these 
aspects manifest in specific language practices. Family language policies are micro-level policies that are constituted within the family itself and are not formal policies such as those crafted by communities, schools, governments and similar institutions. This research has already gained momentum among researchers worldwide and in the U.S. (e.g., Curdt-Christiansen, 2009; Hua \& Wei, 2016; King \& Fogle, 2013; King, Fogle, \& Logan-Terry, 2008; Spolsky, 2004).

Discussing the negotiation of family language policies in a complex contemporary world, we cannot neglect two types of concomitant but contrastive processes raised by scholars of language: unification and diversification, happening against the backdrop of globalization. Many scholars researching language imperialism discuss the inevitable hegemony of English as a product of globalization (e.g., Macedo, Dendrinos, Gounri, 2015; Suarez, 2002; Tsuda, 2008). The research on teaching English to speakers of other languages (TESOL) is prolific. Educational language policies in many countries support early inclusion of English in their curricula. On the other hand, such a state of things brings forward the question of diversity and social justice, addressing the issues of minority languages and cultures in English-speaking countries. Researchers state that monolingualism, no matter which language is in focus, becomes “a linguistic myopia" (Edwards, 2002) which constitutes a problem nowadays (Auer \& Wei, 2007). The "diversification" is evident in the recent rise of scholarship on heritage and indigenous languages and cultures, and addresses issues of education and their preservation. These ideological processes inevitably reflect on the family language ideology and practices.

Border-crossing experiences not only put languages and cultures in contact, but also shape and create new unique experiences and identities, "the states of being and belonging" (Li \& Zhu, 2013, p. 518) which engage people in a network of decision-making about, and even sometimes questioning, their heritage and their linguistic and cultural citizenship. The post-modern 
framework is widely applied to the examination of language and identity in the contemporary world in which individual and group identities are conceptualized as multiple, hybrid, and fluid (e.g., Otsuji, \& Pennycook, 2010).

Considering the complexity of the contemporary world, studying multilingual and transnational family language socialization, as well as experiences of each of its members, and languages in contact, involves interdisciplinarity. It is crucial to acknowledge the complexity of the phenomenon and to move from the identification and classification of "practices" - social, cultural, and linguistic - to the holistic examination of "experiences", in which all those practices and spheres of human-ness are interconnected (Hua \& Wei, 2016).

Heritage language (HL) scholarship appears to succeed in its attempt to describe language experiences of transnational families, as many heritage speakers come from transnational families, and it primarily addresses the factors and nature of maintenance and loss of "the familial language". The term "heritage speaker" is problematized, to the extent of inclusivity of various characteristics. Carreira (2004) argues that a definition of HL learners has to take “identity, language, and family background” (p. 18) into consideration, Valdés (2001) focuses on the language skills and defines an HL speaker as a person raised in non-English-speaking homes, who have receptive or productive HL skills, and are to some degree bilingual. The main concern of the field has been to avoid the family language shift to the dominant language of the environment, which is found to be inevitable, for different reasons, and usually occurs within three generations or even faster for some language groups (Alba, Logan, Lutz \& Stult, 2002; Fishman, 1991). Therefore, this scholarship is more education focused, and aims to increase the language proficiency of those who identify themselves as heritage language speakers. The field has employed a range of perspectves to the study of the heritage language including linguistics 
and psycholinguistics (e.g., Bialystok, 2001; Montrul, 2010), education (e.g., Beaudrie, Ducar, \& Potowski, 2014; Carreira, \& Kagan, 2011; Valdés, 2005) anthropology (e.g., He, 2010; Hornberger, 2003) and language policy (e.g., King, \& Fogle, 2013; Spolsky, 2004). Depite such a broad coverage of the question, a few questions are still open, "What is "a heritage language"? Can we generalize among transnationals by referring to their familial languages as heritage? Can we expect all parents in transnational families to enroll their children into heritage language curriculum? In what ways and when does the language become a heritage language?" Therefore, the scholarship on heritage language is informative for studying transnational langauge experiences, but not sufficient. The contemporary world with its people shuttling across borders and with its simultaneity and the compression of time and space creates new contexts and new ideologies. Thus the phenomenon seems to generate more questions than answers. This necessitates a more diverse, more inclusive and interdisciplinary perspective on multilingual experiences.

Acknowledging the complexity of border-crossing experiences, on a variety of levels (e.g., linguistic, cultural, ideological, etc.), recognizing the importance of family on one's socialization, and its capacity to create a variety of meanings and relationships in a new linguistic and socio-cultural space should be taken up in dialogue with previous experiences. In this case study I aim to explore the ecology of languages in a multilingual transnational family. Following language socialization researchers (Kramsch, 2003; Smith-Christiansen, 2016), I employ the term "ecology" in an attempt to highlight the multifaceted nature of language, its functioning, and its relation to the speakers. This term also reflects the complexity of socio-cultural relations in which language plays an active role. 
Advancing previous work on language socialization, heritage language learning, and family language policy, the present study provides insights into the discursive and ideological processes in a multilingual transnational family, expanding our knowledge and understanding of this complex phenomenon. Unlike most language socialization and family language policy studies, centering primarily on bilingual contexts, indigenous, and immigrant communities, this study explores a multilingual household of sojourners.

This work illustrates that family language polices, including ideologies, management, practices, and family members' identity choices are connected to macro-level ideological and discursive processes occurring in socio-cultural space(s) in which the family navigates and which it actively creates. The family's daily practices center on the development of multilingual and multicultural competencies and an inclusion into a global discourse. The family understand their identities as multiple "standing points" that develop and are relevant to a particular point in time and space, beyond which is multiplicity of other developing scenarios of language choices, practices, and identifications. Moreover, this study provides empirical evidence that family is a dynamic system, which encompasses not only individuals' reaction to their broader sociocultural context, but family's active creation of spaces using the resources and their affordances (cf. Li, 2010).

\section{Statement of Purpose}

This work is an inquiry into the ways in which a multilingual family lives, understands, and builds their transnational experiences through negotiating their language practices in the context of their family and globally. I focus on a multilingual Estonian sojourning family living in the U.S., which kept Russian as one of the family languages, and had both children born in the U.S. 
The purpose of this study is multifaceted: first, it aims to explore the nature and the process of language socialization in a multilingual family in the U.S. by examining how the family negotiates their language practices in their particular transnational context. Second, it strives to investigate and bring to the fore the "superdiversity" of the Russian-speaking transnational population, which has been not fully addressed yet. Third, through deep examination of language beliefs, language choices and language behavior in a multilingual family context, this work attempts to provide insights into diverse ways of understanding language and culture contacts, and ways of being and belonging. Finally, this work seeks to explore the relationships among the three theoretical frameworks the study draws on.

First, as was discussed above, there is abundant research on language acquisition in bilingual families where the parents try to maintain their heritage language or one of the parent's native languages (e.g., Palviainen, \& Boyd, 2013; Park, \& Sarkar, 2007; Song, 2016). The present dissertation study intends to provide insight into the complexity of language socialization in a multilingual family context, i.e., language ideologies and how they translate into language choices and behaviors. Moreover, bilingual and multilingual research has been primarily conducted within developmental or psycholinguistic paradigms, focusing on the issues of proficiency in languages and language attrition, code switching, stages of acquisition, language strategies of successful bilingual development etc., and through the lens of the hegemony of the dominant language and culture. The recent rise of heritage language research has brought to light issues of private language ideology (vs. national language ideology) and identity. Literature on heritage language maintenance practices, strategies, and justfications in bilingual families has recently been prolific recently. Yet socio-cultural research on multiple language socialization is still scarce, but critical. One of the most nascent questions of contemporary multilingual research 
is the negotiation of linguistic and cultural heritage, and the role of the language in the construction of heritage and the dynamics of linguistic, cultural and ideological interactions in the family.

Second, this study also aims to bring forward the issue of "superdiversity" of the Russian-speaking population in contemporary transnational space, which is often underestimated. Considering that Russian is spoken not only in Russia, but also in former Soviet republics, which became a prolific source of Russian-speaking immigration to the U.S. after the USSR's collapse, the landscape of the Russian-speaking population in the U.S. features complexity. Such families bring more diversity and their own hierarchy of language use, as often Russian becomes just one of many family languages to be used as heritage. Moreover, the contemporary transnational population of child-bearing age from former Soviet republics was born in the USSR, or right after its collapse. The political context, in which they were growing up, brings another layer to their ethnic self-identification, the perception of their heritage and languages of the household. Thus, it is timely to distinguish and explore that population.

Third, the contemporary context generates new forms of language and culture contacts, communication and socialization (De Fina \& Perrino, 2013) that transcend space and time and create a complex multidimensional space for "ways of being and belonging" (Li \& Zhu, 2013). Considering the state of the art research on bilingualism, multilingualism, language socialization and heritage language socialization, and language ideology, it is important to continue examining the phenomenon multidimensionally and to elaborate on multilingualism and multiculturalism in the contemporary context of virtual border-crossing and "movement and flow" (De Fina \& Perrino, 2013, p. 1). 
This work is organized around three main concepts, language ideologies, practices, and space. Language ideologies are the beliefs, values, and rules about language, and language behavior constructed by the parents as a result of their interpretation of their individual experiences mediated by a broader ideological discourse in a certain dimension of life. Practices are family members' actions negotiated in every day, moment-to moment interaction. Space is the spacio-temporal context in which parents' ideological decisions shape and are shaped by their ongoing practices.

\section{Guiding Question}

In this work, I share the findings of (my) five-months' exploration of language behavior in an Estonian multilingual family of sojourners in the U.S. The study's overarching question was: What are the cultural, linguistic, ideological, and identity spaces in which the family navigates and which the family creates?

In particular, I focused on four main inquiries:

(1) What beliefs and ideologies does the family construct about their language practices?

(2) What kinds of linguistic and cultural practices of family members are embedded into those ideologies?

(3) What family language policy is established and followed by the family?

(4) What identities are constructed and negotiated through those experiences?

To answer these questions, I performed thorough ethnographic observations, interviews, and an analysis of a family's natural conversations. My observations of children's language behavior and the parents' interactions with their children allowed me to identify and scrutinize the process of language socialization in multiple languages, family members' language choices, and their language positioning. 


\section{Overview of the Dissertation}

Chapter Two provides the review of literature which situates my study conceptually and methodologically. To study such a complex phenomenon as multilingual family language socialization, I draw on three main bodies of literature - anthropological framework of language socialization, linguistic framework of family language policy and heritage language maintenance, and sociological framework of transnational social space - providing theoretical overview and analyzing the empirical findings for each of them. I identify conceptual and methodological gaps and propose a combined framework to be used as analytical base for this study.

Chapter Three is devoted to my methodological decisions and practices to construct this qualitative ethnographic data-grounded study. I describe in detail each of the multiple methodological tools I employed, including the reflections on my personal standing - my positionality - with regard to this inquiry and my relation to the participants of the study. Considering the nature of the study, I recognize the impact which the process of this ethnographic investigation. My prolonged presence in the life of the family and interaction with the children, as well as the dissemination of the data afterwards - can have on each of its participants, and therefore. Threfore, I discuss ethical issues of data collection. Finally, chapter three presents the process of data handling and data analysis, and closes with a discussion of the limitation and challenges of the analysis.

Chapter Four includes the data-driven findings of the study. They are organized according to the family language policy framework and detail the family's beliefs about languages and multilingualism, the parents' vision of their family language learning, the family's everyday language practices, including parents' strategies of teaching languages and promoting 
multilingualism in the family, and principles of language management in the family. It also presents the description of four language spaces observed in the family, unveiling their structure and ideological foundations. In this chapter I also examine the identities negotiated by the family members through their language choices, language behavior, and language polices orchestrated in the family. To support my claims, I draw on illustrative examples, i.e., excerpts from interviews and recorded naturally occurring conversations, as well as life snapshots from ethnographic observations.

In Chapter Five, I attempt to theorize the findings through the lens of their significance for understanding the language ecology in a multilingual family in the context of transnational life. I show how the study's findings illustrate the necessity of elaborating each of the three proposed frameworks and combining them into one whole to reflect the complexity of transnational family language ideologies and practices, being and belonging. I also bring forward the necessity to tease apart the notions of "heritage", "first", and "family" language, what emerged from the findings of this study. In conclusion, I provide empirical, methodological, and conceptual contributions of the study and propose directions for further research. 


\section{CHAPTER II: REVIEW OF LITERATURE}

\section{Introduction}

The purpose of this work is to explore how multilingual transnational family in the U.S. negotiates their language beliefs, practices, and identities. Familial language decisions and practices have been addressed and documented by multiple fields, so to understand language life in a multilingual transnational family, it is important to draw on knowledge from a variety of disciplines. This section provides theoretical and methodological discussions, and an empirical overview of studies on multilingualism, heritage language socialization and language use in immigrant $^{2}$ families, socio-linguo-cultural spaces, and language ideologies and identities, all created in the context of migration.

I organize the review around three main bodies of literature that I draw on to inform my study theoretically, empirically, and methodologically: language socialization (Schieffelin \& Ochs, 1982), family language policy (Spolsky, 2004) and transnational social spaces (Faist, 1998). For each of them, I provide a theoretical outline followed by the empirical findings, and the summary. I also address the ways in which each of them is theoretically limited and unable to present a full understanding of transnational family language experiences. Moreover, to explore the family's complex linguo-cultural background, I examine the cultural and ideological context of the Russian language in post-Soviet Estonia, and the landscape of Russian and Estonian language learning in the U.S.

\footnotetext{
2 Recent scholarship on heritage language maintenance and FLP exemplifies a noticable shift towards conceptualizion of "the immigrant family" as "the transnational family". Broadening the scope of reasons for and the length of immigration, this notion is more inclusive and also emphasizing the maintenance of rich connections with the home country (Hua \& Wei, 2016). Being fully aware of the differences, the patterns, and trajectories of the language socialization those entail, in this review of literature I do not specify between immigrant and sojourn families, for the reason that this distinction in the reviewed literature was not always considered.
} 
The chapter consists of five sections. In the first section I review the literature on Language Socialization (LS), discussing language socialization in multilingual settings, agents of language socialization, and the relation between language, heritage, and identity. Anthropologists have shown that language socialization plays an integral role in transmitting group values and beliefs, and helps to maintain group identity, and language socialization patterns reflect culturespecific beliefs about child-raising and language and its learning (Ochs \& Schieffelin, 2001, 2008). Sociolinguists have registered the link between socio-cultural factors for multilingual language performance, as well as the relation between language choice and identity (e.g., De Fina, 2012; Hua \& Wei, 2016; Li \& Zhu, 2013).

In the second section on family language policy (FLP), I focus on language ideology and family reasons for heritage language maintenance, family strategies directed towards heritage language maintenance practices. The review demonstrated that bilingual language development is related to parents' language input and strategies in a bilingual context (e.g., De Houwer, 2007; Lanza, 2007), as well as heritage language maintenance factors and patterns (e.g., Cho, 2000; He, 2010; Kagan, 2012). Language policy researchers demonstrated that societal language ideologies influence family language beliefs, practices and language maintenance (e.g., King \& Fogle, 2013; Kopeliovic, 2010; Spolsky, 2004).

The third section is dedicated to the examination of the sociological framework of transnational social spaces (TSS) and discusses the complexity and compound nature of contexts which transnationals encounter and in which they live. This framework distinguishes important global space in immigrants' experiences.

Section Four provides an important socio-cultural context for understanding the life of the transnational Estonian family in the U.S. Narrowing my interest to Russian-speaking 
transnational families, I reviewed the Russian-speaking environment in the U.S. and in postSoviet Estonia, where my participants come from. I found that the Russian-speaking world is generalized and over simplified and attributed to Russian cultural identity, and requires more fine-grained exploration through the lens of "superdiversity". I also reviewed the U.S. educational context for both the Russian and Estonian languages, to understand the availability of language resources for my participant family.

Section Five presents the summary of literature review, which identifies gaps in the available empirical research conducted within relevant body of literature and claim the space for the current project in the body of reviewed literature. Finally, I explain how the three frameworks work together to inform the design and the analysis of my study.

Before I proceed to the review itself, it is important to discuss some problematic issues with conceptualization of border-crossing experiences and the phenomenon of language in the context of migration resulted from the literature review, i.e., immigrant family vs. transnational family, and the conceptualization of the heritage language. In the review, I will be treating the terms immigrant family vs. transnational family interchangeably, but further, beyond the literature review, in describing and analyzing my study, I will refer to my participant family as transnationals, following Hua and Wei's (2016) conceptualization. Also, the reviewed literature problematized the use of terminology to signify the language in the context of migration. Scholars employ a variety of terms which vary in ideological connotation, as different features are in focus: the origin and "otherness" (immigrant language and culture), spatial relationships (home language and culture/ host language and culture), influential socializing agent (family language or mother tongue ${ }^{3}$ ), succession of acquisition (first or primary language), power

\footnotetext{
${ }^{3}$ The term "mother tongue" is traditionally used in the bi/ multilingual literature, and does not reflect my intention to belittle the role of fathers or other family members in the process of children's language acquisition.
} 
dynamics (minority language vs. dominant language), or broader cultural significance of the language (heritage language), or language proficiency (bilingual speakers or native quasi-native speakers). Blackledge, Creese, Baraç, Bhatt, Hamid, Wei, Lytra, Martin, Wu, and Yağcioğlu (2008) consider the term "heritage language" contested, for every language user assigns individual heritage qualities to the language. This diversity in labeling reflects the complexity of language being and functioning in the situation of migration and multilingualism, as well as the intricate network of relations between language and the broader ideological context. Reviewing the literature, I generalized these conceptualizations referring to the phenomenon under study as heritage language, but in the design and analysis of this project I carefully attended to the parents' conceptualizations of heritage, first, home, and family languages and their perceptions of those differences.

Although the majority of reviewed studies describes bilingual contexts of language socialization, I consider the findings very informative for the examination of the family language socialization in a multilingual context.

In addition to peer reviewed journals, manuscripts, and books in multilingualism, HL socialization, family language policy and language identity in immigrant contexts, for the purposes of this study, I also explored a range of recent (2010-2017) Master theses and Doctoral dissertations (not limiting my inquiry to the Russian language).

\section{Language Socialization in the Contemporary World}

This section will start with an outline of language socialization framework, moving towards examining LS in multilingual contexts. It will also review literature on agents of LS and the relation among language, heritage, and identity.

\section{Theoretical Overview}


Language socialization (LS) is a language-mediated transmission of normative beliefs and ideologies of the community through which national and group identities are maintained (Schieffelin \& Ochs, 1982) (see Figure 2). This framework emphasizes the relationship among language, cultural practices, and overall human development, and displays that social and communicative development is built on the transmission of important socio-cultural knowledge from an expert (e.g., a caregiver) to a novice (e.g., a child). An individual's behavior - both linguistic and non-linguistic - is culture-specific and the whole process of language socialization aims at continuation of specific traditions and values of the community of practice (Lave \& Wenger, 1991), its values and beliefs, and its overall longevity, being a means-end process (Ochs \& Schieffelin, 2008).

There are several important tenets of LS to consider. First, it perceives language as “fundamental medium in children's development of social and cultural knowledge and sensibilities" (Ochs \& Schieffelin, 2011, p.1). The process involves socialization into the use of the language (socialization to use proper language forms) and through the language (becoming a competent member of the community), engaging two main language functions: communication and representation. LS emphasizes that language is both a repository of socio-cultural meaning and the instrument to communicate that meaning, reflecting, as Bourdieu (1977) rightly observed, that "what speaks is not an utterance, the language, but the whole social person" (p. 653, cited in Lo-Philips, 2010). Through the lens of LS, language is viewed as an integral part of the development of the self, of the mind, and of society, that complements language socialization (He, 2011). Thus, a language learner is a language user in a natural environment where her active engagement in semiotic - not just linguistic - and interactional activity creates the affordances (or not) for language acquisition (Kramsch, 2003). 
Cultural context of the community of practice (values, beliefs, behaviors)

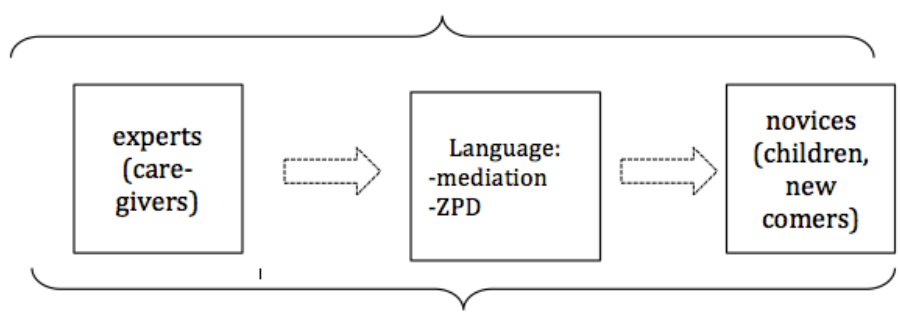

Cultural context of the community of practice (values, beliefs, behaviors)

Figure 2. Traditional language socialization framework according to Schieffelin \& Ochs' (1982) conceptualization.

Second, the LS framework assigns the roles of novice and expert to the participants in the socialization process. The novice's (or newcomer's, in a particular cultural community) learns through engagement in regular communicative situations with more expert members of the community, who initiate, support or regulate a novice's behavior in culturally appropriate ways. As a result, a novice acquires communicative competence (Gumperz, 2009) in linguistic, pragmatic and socio-cultural norms as well as the identities, ideologies and behaviors of the members of the targeted speech community and becomes a legitimate member of that community of practice.

The role of language in this process is foundational. Every level of the language whether phonological, morphological, lexical, syntactic, or pragmatic, is penetrated with socio-cultural meanings assigned by members of the speech community and reflects the needs of their life organization and contributes to its longevity. Parents socialize their children into the values and behaviors of their immediate society(ies), providing them with models of linguistic and cultural behavior. Therefore, ways of behaving, and being as well, are tied to specific socio-cultural practices individuals collaboratively construct and engage in, and become part of their inhabited 
dispositions that require people to act in certain ways and to engage in a certain symbolic exchange, what Bourdieu (2017) called "habitus". Traditionally, parents' role in socializing children into and through language into cultural behavior is crucial. Recent socialization scholarship also illustrates the important role of siblings, as "guiding lights" (Padmore, 1994, in Gregory, 2005) in socialization of the young (see also Luykx, 2005).

Third, although language socialization occurs in a variety of spaces, family is recognized as a primary community of practice, a source of primary indexicalization (Ochs \& Schieffelin, 1995) of the world. Family resources, in Coleman's (1988) terms “capitals" including financial, human, and social, reflect “the quality of children's home environment and can be transformed into their literacy development and school success" (Li, 2002, 2007, in Ren \& Hu, 2013, p. 100). Linguo-cultural capital is another layer of the family capital that permeates the three elements identified by Coleman (1988), and that is brought into relief in multilingual settings.

Language socialization framework provides an important understanding of cultural mediation of language practices and their relationship with the efficient functioning of a person in the community, and the role of a family in this process. It also provides insight into how linguistic and cultural identities of the language user are constructed.

\section{Language Socialization in Multilingual Settings}

Before discussing empirical findings on language socialization in multilingual settings, it is important to examine how language and its role in society are conceptualized in the contemporary world. Following Ruiz's (1984) analysis of language planning, Garcia (2009) theorizes about language diversity as (1) a problem, (2) right, and (3) a resource. These orientations not only influence language education policies, but also reflect on the parent's beliefs and attitudes about their family language practices. The decision to invest family 
resources into the heritage language learning or prioritize the dominant, or any other language in family practices, translate into the socializing context available to the children. Relevant to this discussion is the conceptualization of language as a social practice ${ }^{4}$ that relates to the conversation on language ideology and language choices and practices. There is evidence that family can create environment for simultaneous or consecutive (successive) multilingualism, additive or subtractive multilingualism, depending on the time of the languages' contact, and, indicating the outcome of the language contact (Garcia, 2011; Garcia \& Flores, 2012). These four conceptualizations reflect the ideological dimension of languages in contact in the immigration context.

The review of literature shows that language socialization framework has been successfully used in research in multilingual immigrant communities and families (e.g., Bayley \& Schecter, 2003 \&; Luykx, 2005; Quay, 2008) and has provided insight into the dynamics of dominant and heritage language practices in the family, and heritage language identity (He, 2006). He (2011) strongly advocates for the use of language socialization framework in heritage language research in order to highlight the socio-cultural processes that inevitably accompany heritage language learning and maintenance and their connection.

Figure 3 displays the nature of language socialization in a multilingual context. All contexts offer linguistically and culturally rich spaces for exploration of the language socialization determining the pattern(s) and the outcome(s) of language socializing practices. He (2006) states that HL learning engages a learner in multifaceted contextual dimensions with a variety of beliefs, dispositions, and bodies of knowledge, which might change across space and over time and may be divergent.

\footnotetext{
4 Ethnography of Communication promotes the study of language in use rather than as a mere linguistic code (e.g., Halliday, 1978; Hymes, 1972; Gumperz, 2009)
} 


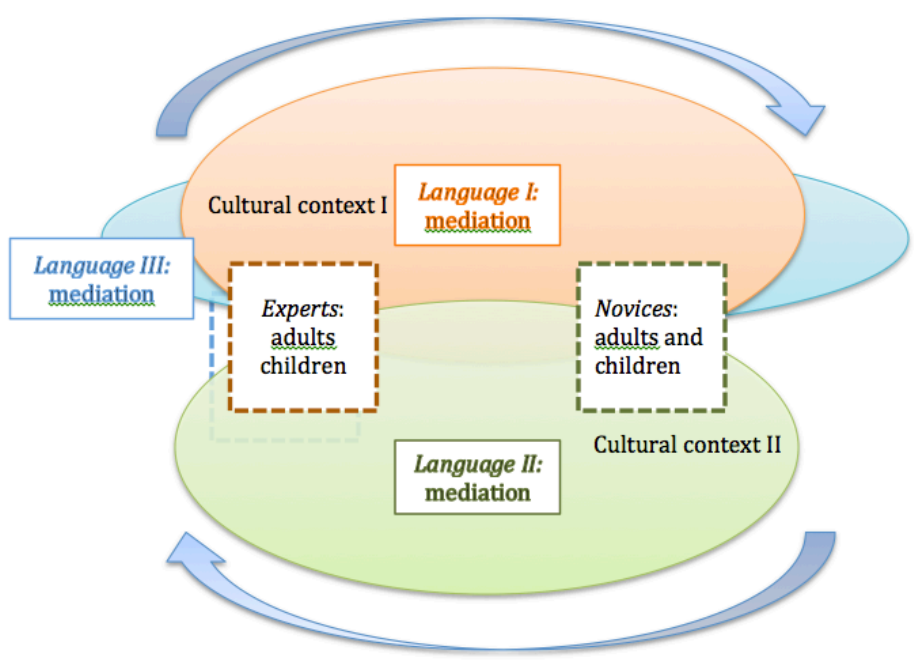

Figure 3. Language socialization in a multilingual context.

Thus, the acquisition of languages and socialization patterns in multilingual and multicultural settings is always grounded in understanding roles, relationships, identities, and events (He, 2006). Illustrative empirical evidence comes from the literature on heritage language maintenance decisions which demonstrates that values and beliefs of family members may diverge from the dominant discourse, and the statuses of the language(s) in the family and the dominant society shape language socialization patterns (Pease-Alvarez, 2003). In more detail, this issue will be addressed in the section on reasons to maintain a HL.

\section{Agents of Language Socialization}

Language socialization engages two types of agents, experts and novices. Multilingual settings offer a greater variety of language and cultural practices, elaborating language socialization processes and patterns, and engaging each agent in a more complex participation in various communities of practice. Research on language socialization in multilingual settings shows that communities of practices are situated; the roles of an expert and a novice are not constant and are distributed among parents and children according to the dominant contexts. Thus, if studies on bilingual strategies heritage language maintenance refer to older generations 
as experts - parents being primary agents of heritage language socialization - it has been documented in the literature that children tend to be more porficent in the host country language and performing the role of language brokers for their family (e.g., Orellana, 2009; Tse, 2001) and socializing younger siblings into the dominant context (Gregory, 2005; Kibler, Palacios, Simpson-Baird, Bergey, \& Yoder, 2016).

Relevant to the definition of "an expert" would be the notion of a "literacy sponsor" Literacy sponsors are "any agents, local or distant, concrete or abstract, who enable, support, teach, or model, as well as recruit, regulate, suppress, or withhold literacy - and gain advantage by it in some way" (Brandt, 1997, p. 2). "Sponsors" provide a novice with access to resources and create an environment for learning and acquiring certain skills. Describing transliteracy experiences in U.S-Mexico borderland communities, Scenters-Zapico (2013) also focuses on how sponsors operate and distinguishes between "traditional" and "electronic" literacy sponsors. The rapid advancement of technology and new ways of communication create good opportunities for heritage language maintenance connecting family members across space.

Parents appear to be the focus of HL socialization research and main experts of language socialization. Parents' language ideologies, beliefs and attitudes, shape children's language practices. Although grandparents in transnational families seem to present a direct link to the heritage culture and are a reason for HL maintenance for many parents as they are very often the ones who are left in the home country or brought along with the immigrant family (Kirsch, 2012), their role in HL socialization and their beliefs about multilingualism and HL maintenance have not ben dressed yet. Glimpses into grandparents' transnational experiences are dispersed throughout studies on family language practices. In their ethnographic study of biliteracy in Chinese families in Singapore, Ren and Hu (2013a, 2013b) observed that a grandmother in one 
of the families played a crucial role in the children's bilingual and biliteracy development and, especially, the acquisition of Chinese. The grandmother strived to maintain the children's Chinese identity and even made an effort to expose them to her native dialect. She also actively participated in the selection of school for her grandchildren. In contrast, Braun's (2012) conductd and analyzed 70 interviews with trilingual families of various nationalities: Italian, Russian, German, French, American, and Finnish, living in Germany and England. The study demonstrates that grandparents living in the same community as their grandchildren prefer to use with their grandchildren the community languages at the expense of the heritage language. Thus, grandparents' beliefs about heritage language maintenance, and children's multilingualism are diverse.

There is also empirical evidence, from ethnographic and interview data, of a child's active role in the language life of the family to the degree of influencing parental language behavior. Children's agency acts out in rebelling against parents' language policies at home. Gyegi (2015) showed that Japanese-English bilingual children resisted Japanese language policy at home, contesting, negotiating, and redefining their mother's beliefs about heritage language in general. The conversation and interview data collected from two London Japanese families with 12-year-old children illustrated the children's active negotiation of the use of English in the monolingual Japanese household. Likewise, children's negative position about the preservation of the heritage language is illustrated in De Capua and Wintergerst (2009). The children perceived their mother's attempts to develop their children's competencies in her native German in the U.S. as inhibiting their "normal" American activities, such as watching TV shows or inviting their friends over. The mother's practices even estranged the children from their parent, as they felt uncomfortable in the presence of their friends who did not understand German. 
Studying the Rwandan diaspora in Belgium, Gafaranga (2010) also found that children requested parents to switch from Kinyarwanda to French and shaped their family practices.

There is also empirical evidence that elder siblings perform as socializing experts for their younger brothers or sisters, by engaging them in syncretic literacy. Kibler and colleagues (2016) ethnographic observations of Latinx immigrant households revealed that older siblings acted as language and literacy models for the youngest, and through th use of both languages in ther repertoire enacted their expertise in both English and Spanish. Being "guiding lights", they positively influence their younger family members' performances at school. Gregory (2005) also demonstrates how an elder sibling in a family of Bangladeshi origin living in London, became a literacy mediator, initiating her younger sister into a more powerful English-speaking school discourse.

In sum, the literature shows that in multilingual contexts, the network of LS agents is complex. Parents are perceived as major socializing agents, but children can also shape language socialization patterns in the family, providing socialization contexts for younger siblings and directing the language behavior of their parents. The role of extended family, grandparents and other relatives is highlighted in socialization into the heritage language. However, most of the LS in multilingual contexts studies engage children of school age and older, providing almost no data on preschool children's language socialization patterns.

\section{Family Language Behavior}

Parents, being major socializing agents, especially during children's early stages of socialization, model language behavior for their children (e.g., one parent-one language family language policy is entirely built on this principle). De Houwer (1999) refers to the home setting as pivotal in determining children's active or passive bilingualism. In her extensive survey study 
on trilingual families in Flanders, she found that parental input patterns had influence on children's language use. If parents did not speak Dutch and both spoke different languages at home, children were more likely to be trilingual (De Houwer, 2004).

The discussion of language use in multilingual contexts brings an important question of the analysis of the language behavior of a bilingual or multilingual family. The studies on bi/ multilingualism in family contexts tend to utilize two main analytical approaches to describe "not pure" monolingual language use: traditional notion of code-switching ${ }^{5}$, focusing on the language form itself (e.g., Auer, 2013; Hua, 2008; Lanza, 2007) and currently gaining momentum. The Bakhtinian term "heteroglossia" is sometimes used to theorize about language mix and translanguaging (Blackledge, A., \& Creese, 2014) to emphasize the purpose of the language practice and meaning making process during communication (Garcia, 2009; Li, 2018; Soler \& Zabrodskaya, 2017; Song, 2016;), as opposed to code-switching, which signifies change in a language system only. A few scholars (Garcia, 2009; Li, 2011) argue that the term codeswitching in a multilingual context implies that language "competence involves distinct compartments for each language one uses" (Canagarajah, 2013, p. 1), and advocate for a more focus on the language user, the context, and the social practice in the meaning making process. Garcia (2009) explains, "translanguagings are multiple discursive practices in which bilinguals engage in order to make sense of their bilingual worlds. Translanguaging therefore goes beyond what has been termed code-switching, although it includes it, as well as other kinds of bilingual language use and bilingual contact" (p. 45). Meaning making, contextualization, pragmatic use of language, according to the speaker's communicative needs are in focus here. Li (2011) emphasizes that translanguaging embodies flexible alternations from one language to another in

${ }^{5}$ Code-switching signifies juxtoposition of two or more languages within the same speech or discourse without violation of syntactical rules (Gumpers, 1982). 
interaction, strategic combinations of different linguistic systems and features, and identity enactment through language choices in interactions with others.

Backledge and Creese's (2012) comparison of analytical approaches of code-switching and translanguaging reveals that translanguaging is conceptualized as more dynamic, flexible, creative, and transformative process of language use oriented towards the speaker and her needs, and the set purposes of communication. (Table 2).

Table 2

The comparison of analytical focus in conceptualizing code-switching and translanguaging

Code-switching Translanguaging

Language Speaker

Code $\quad$ Voice

Linguistic practice Social practice

Signification: form-function- $\quad$ Signification: meaning making relationship

Signs belonging to languages Signs used by speakers

Note: from Chisato (2015) (orginal source Blackledge and Creese, 2012)

Li (2018) states that "translanguaging is not simply going between different linguistic structures, cognitive and semiotic systems and modalities, but going beyond them", and most importantly, "the act of translanguaging creates a social space for the language user by bringing together different dimensions of their personal history, experience, and environment; their attitude, belief, and ideology; their cognitive and physical capacity, into one coordinated and meaningful performance" (Li, 2011, p. 1223). Such approach contributes to understanding of and 
theorizing about language ecology in a multilingual family, and necessitates to pay attention to the context and the purpose of family language use.

Recognizing the differences among approaches, I explored various empirical studies primarily focusing on the family member's patterns of multilingual behavior. A few studies showed a purposeful mixing of languages. For example, Lanza's $(1992,1997)$ longitudinal study of a Norwegian-English bilingual in Norway demonstrated that parents, especially the Norwegian father in that case, switched languages strategically to facilitate their daughter's language learning. She also showed that this two-year old could differentiate between languages in contextually sensitive ways. Similarly, studying language interaction during literacy events in four Korean heritage families in the U.S., Song (2016) found that the children and their family members translanguaged between English and Korean in their conversations around various types of written, oral and multimodal texts, to support biliteracy practices, and used each language as a learning resource for the other. De la Piedra and Romo (2003) also illustrated how the mother and an elder sister were jointly engaged in book reading for a 18-month-old girl, switching from Spanish to English.

Other studies focused on children's language use. For example, Vu and colleagues (2010) reported that four- and five-year-old Spanish speaking children code-switched for sociopragmatic purposes of trying to gain attention from adults and to change their social roles. Likewise, Zentella's (1997) longitudinal study of bilingual Puerto Rican children in New York found that code-switching for socio-pragmatic purposes increases with age, reflecting children's overall social maturation.

Language use norms established by the parents influence the children's languge behavior. Mealtime conversations appear to be the most explored practices for the examination of language 
practices in multilingual families in this sense. This setting is believed to be a rich source of data on linguistic and cultural patterns of child-parent interaction. A simple dinner conversation is "a fertile site for the intergenerational transmission of cultural values and identities, it fosters culturally specific ways of talking and thinking which have significance for children's lives far beyond the intimacy of family meals" (Greenhill, 2000, p. 420). For example, in her multi-year seminal study (1985-1988 and 1989-1992) of dinner talks of middle-class Jewish-American, native Israeli families and American-born Jewish families of European origin with school-age children, Blum Kulka (1997) showed that bilingual practices featuring the use of English, Hebrew and "Hebrish", a family mix of English and Hebrew, were common at Jewish-American families' dinner tables and served as the context to socialize children into the family and the dominant culture. In the same vein, Quay (2008) studied dinner conversations of a family with a trilingual (Japanese, Chinese, and English) two-year-old girl. The researcher illustrated that the child's language choices and language mixing in family dinner conversations were occurring according to the norms established in her home. Her language behavior adapted to the interlocutor. She also demonstrated awareness of each language's context and performed accordingly. For example, she uses Japanese as lingua franca to converse with her parents, as both of them know the language, in contrast to English, which is spoken by her father, and Chinese, her mother's language. Quay (2008) concludes that such linguistic behavior followed the rules of her family multilingual behavior and reflected multilingual family identity.

There is also evidence that children maneuver languages despite their parents' choices and they even shape parental language behavior and affect further language socialization patterns. Building on data from the interviews and observations of 18 families with various heritage tongues living in the Seattle metropolitan area between 1993 and 1994, Tuominen 
(1999) showed that children determined the language used at home. In her seminal study of six bilingual German-English families with children 2.5-3 years old, Döpke (1992) found that, with time, parents reduced the heritage language input, and later-born children became passive bilinguals rather than active bilinguals. Similarly, Song (2009) observed that parents in heritage families start mimicking children's linguistic patterns and cease correcting children's code switching in favor of the dominant discourse. Fogle (2012) demonstrated the child's use of interactional strategies that negotiated or resisted parental practices (for example, a Russian adoptee switched to Russian when her step-mom continued responding in English; the researcher interpreted the use of Russian as a source of conflict). Smith-Christmas (2016) in her seven-year study of Gaelic practices also found that children's every day activities and demands to read in English impeded Gaelic use in favor of English.

These patterns demonstrate context-specific dynamic realization of communicative and representational functions of languages in contact, and will be discussed in more detail in the section on "Language Interaction".

In sum, the scholarship on LS in multilingual setting display a diversity of multilingual situations and settings, the nature of language choice in LS practices, and demonstrates that translanguaging and code-switching are common practices for a multilingual home. Multilingual settings also reconceptualized the roles of expert and novice in LS. Expertise in LS is contextually assigned, so older generations with low or no proficiency in the dominant language can position themselves as experts of the heritage language and culture, and parents can consciously choose in what language they frame their children's socialization.

\section{Language, Heritage, and Identity}


Language socialization framework highlights the relation between language and identity. Language is a social practice that makes up our world experience. In his introduction to the Handbook of Language and Identity following Brimfit (1995), Preece (2016) posits, “the phenomenon of identity is related to the real-world problems in which language is a central issues" (p. 1). The issue of heritage becomes an essential point of this relationship.

Multilingualism, embedded in transnationalism, illuminates this relation very well.

Bucholtz and Hall (2010) propose five (5) principles for locating identity in the language:

(1) "The Emergence Principle": Identity emerges in interaction.

(2) "The Positionality Principle": Speakers are actively engaged in acquiring and acting out a variety of roles and stances in the process of interaction with the locally situated positions and identity categories.

(3) "The Indexicality Principle": Speakers label identities, making references overtly and covertly to particular identity roles, or describing self and others. By doing so, they also evaluate what is normative and what is not.

(4) "The Relationality Principle": Identities are always constructed in relation to other identities and include oppositions, for example, "self-other", "authentic-inauthentic".

(5) "The Partialness Principle": As they are context-bound identities are always in construction and flow, and never complete.

All five principles can be applied to the interplay of language and identity in a multilingual family context. Language choice indexes reality and allows the speaker to communicate her position, which becomes evident in interaction with speakers of the same or other languages. Preference for the dominant or heritage language in interaction with children and other members of the family signals parental position in both dominant and heritage 
societies. Language practices in multilingual contexts are context specific and permit the creation and co-existence of multiple identities. Identity flows with the change of the environment.

Overall, identity, similar to language, is a socially constructed phenomenon; it is negotiable, variable, diverse, and has many layers (Joseph, 2003). As Bucholtz and Hall's (2010 [2005]) principles state, identity is constructed upon the decision and act of belonging. Through intracommunal language practices, people understand their belonging to a particular community of practice (Phinney, 1990). Language embodies and frames our heritage, connects us to it and helps us to transmit it through generations, maintaining ethnolinguistic identity (Gile \& Johnson, 1987). Liebkind (1999) posits that language "can become the most important symbol of ethnic identity" (p. 143) even when the language is not actively used. Studies on bilingual communities, on immigrant families' heritage language maintenance reasons and practices, and on heritage language learners and speakers, show that people have an integrative attitude towards their mother tongue, perceiving its maintenance as an essential element of sustaining self through their roots.

Joseph (2003) states, “The mother tongue is itself a 'claim' about national, ethnic or religious identity (or any combination of the three) that speakers may make and hearers will certainly interpret" (p. 185). When languages and cultures are in contact, the relation among language, identity and heritage becomes more complex. The issue of subordination of ethnolinguistic groups becomes prominent, and inevitably influences one's perception of one's languages, heritage and self.

Lamarre and Dagenais (2004) illustrate that the perceived importance of language in the linguistic repertoire of speaker relates to the speaker's identity; however, the heritage language/ family language, even with low importance, is still essential for self-identification. The 
researchers conducted a case study of language practices of trilingual youths of diverse linguistic origin (e.g., Vietnamese, Panjabi, Spanish, Portuguese, Arabic, Italian) in Vancouver and Montreal. Interviewing a total of 22 high school students about their daily languages practices, their representations of multilingualism, and their linguistic repertoire, the researchers observed that each of the languages the participants spoke was perceived as linguistic capital for socialization in diverse multilingual contexts, and the degree of language importance in a particular context played a role in constructing of their identities. Interestingly, even though most participants were born outside Canada, there was a tendency to devalue their own heritage language, as they assessed their linguistic repertoire through a lens of linguistic markets in their current context. Thus, English-French bilingualism was most economically advantageous, but they did include their heritage identity in the description of self.

The migration context seems to elaborate the relation between the language, heritage, and identity. Heritage and dominant contexts, with particular norms, values, traditions and sociohistoric rules, become more salient, as people move across the space and carry with them their previous experiences. Maines (1978) in "Bodies and Selves" lucidly states that "the migration of 'selves' (or identities) usually follows different timetables than those of their corresponding 'bodies” (cited in Aronin \& O Laoire, 2004, p. 21). Supporting this vision, Horenczyk (2000) notices that:

“... Selves arrive later than bodies [...] during all phases of the intercultural migration process, newcomers must continually reorganize the delicate structure of their various sub-identities - those related to their membership in the new host society and those involving their attachment to the values of their former culture... while bodies can occupy only one place in space at a time, selves can (and often do) split and reside both 
in the new and in the old locations, the old location being gradually replaced by the minority/ immigrant culture within the majority host society" (Cited in Aronin \& O Laoire, 2004, p. 21).

This view explains the resistance of heritage identity to the changes of linguo-cultural environment, and the efforts of parents in transnational families for the preservation and transmission of the heritage language and development of heritage identity.

Other bodies of research show that there is no one-to-one correspondence between language and ethnic or national identity (Fuller, 2007). Irwin's (2009) work on Russian German re-settlers and Russian speaking Jewish refugees from the former Soviet Union in Germany illustrates that despite speaking the same language, the two groups understand ethnicity differently, as they differently position themselves in German context. The Jewish refugee group had to negotiate its identity in relation to the host country and the "other" Russian-speaking groups, and their perception of ethnicity was tied to their social and educational status rather than to language alone. They used this identity lens as a powerful tool to distingwish themselves within the Russian-speaking group in Germany. Thus, the language can have only instrumental function for the speaker.

In a bi/multilingual context, identity negotiation is exercised through particular language choices and/or through particular communicative practices, or both. The identity of the heritage language speaker is to a large measure formed through his/her speech. Dittmar, Spolsky, and Walters (1998) state that the investigation of identity may provide a better insight into language choice, since in any given interaction individuals will choose to represent themselves in the language that best enhance their social identity. 
Advocating for the role of identity in second language learning, Norton (2013) theorizes that "it is through language that the person negotiates a sense of self within and across different sites at different points in time, and it's through language that the person gains access to - or is denied access to - powerful social networks that give learners the opportunity to speak" (p. 45). This vision can be applied to the process of HL socialization. For example, Lo-Philips (2010) theorizes HL literacy learning as an embodiment of identity processes that encompass the acquisition of voice as a means of learning how to design the self and others (p. 283). A HL learner is engaged in the process of identity transformation, identity re-appropriation, identity negation and a whole score of possible identity processes that accompany language and literacy learning. (p.282). Similarly, Carreira (2004) reports that not only linguistic gains but also aims to fulfill identity needs are imperative for HL learners' motivation.

In the same vein, He (2006) proposes identity-based model of HL development. She locates HL learner identity as the centerpiece rather than the background of heritage language development. He (2006) defines identity as a process of continual emerging and becoming, a process that identifies what a person becomes and achieves through ongoing interactions with other persons. In a life narrative study of a Chinese heritage learner in the U.S. He (2006) exposes complex dynamic relationship among self, language, and heritage. Analyzing his narratives, she traces the participant's life from kindergarten to college and discovers that inheriting one's heritage language and one's heritage identity are not enough for developing heritage language skills and a complete vision of self. The participant was engaged into active transformation of his heritage language and recreated his identity over and over again in new contexts. He made several attempts to learn Chinese, and it became a FL for him at a certain point. To express the turmoil of Jason's identity, He (2006) observes, "He has learned and is still 
learning to cope with, to understand, to accept or reject, to model or modify a language and cultural behaviors of every community he has encountered throughout his life span" (p. 110). Jason's perception of self could be best described by what Aronin and O Laoire (2004) conceptualize as "multilinguality", highlighting that it extends "beyond the language and linguistic competence, and including emotion, anxiety, preferences, cognitive aspect, personality type, social ties and influences and reference groups" (p. 18). They stress that identity is fluid, and point to inevitable intrapersonal changes in the situation of language and culture contact. They state that language, skills and knowledge from various systems "overlap, fluctuate and interchange and the personality of the multilingual — the essence of multilinguality - fluctuates and changes depending on the changes in his or her life" (Aronin \& O Laoire, 2004, p. 21). Thus, each all language experiences contributes to the person's identification of self.

\section{Summary}

The language socialization framework emphasizes the following premises: (1) language is a means and goal of socialization, (2) interaction is central for language socialization, (3) language socialization is bi-directional - as it presents an exchange between a novice and an expert, and (4) and those roles are fluid. The framework also advocates for an ecological view of the process of socialization and the activity of all of its agents. Languages spoken at home, either the language of the host country or those which are the focus of the language maintenance, create a socialization base for the children, who acquire both language and culture "as bodies of knowledge, structures of understanding, conceptions of the world, collective representations" (Schieffelin and Ochs, 1982, p. 15). The review of literature shows that language socialization framework originated and still primarily focuses on language socialization in monolingual communities, or multilingual communities in situ. Although there have been attempts to apply 
the framework to multilingual contexts, their scope is limited, primarily Spanish-speaking families or Asian families and speakers have been in focus: for example, Mexican descent families in the US (Bayley \& Schecter, 1997; Pease-Alvarez, 2003), the Latinx community in New York (Zentella, 1997), Chinese bilingual families in Singapore (Ren \& Hu, 2013), and in the U.S. (He, 2006; Song 2016). The framework has also been widely applied in educational bilingual programs outside the home, also primarily with Spanish-speaking and Chinesespeaking contexts. There have been no studies on language socialization in Russian-speaking families. Moreover, migrational multilingualism has not been explored through this lens much. Another contemporary trend, recent or temporal migration (e.g., experiences of sojourners), has not been addressed either. Further, the contemporary world necessitates the consideration of diversity within transnational families (e.g., the Russian-speaking population is diverse) and the dynamics of interaction within and among different communities of practice that the family maintains or is engaged in. Additionally, although LS highlights the cultural embeddedness of language practices with the aim of cultivation of social convention and explains the relation of language, heritage, and identity, it does not illuminate the factors affecting the language choice in multilingual communities, and barely addresses the dynamics of relationship between the languages in contact.

Language socialization studies have been mostly performed in the ethnographic tradition, through interviews and the recording of naturally occurring conversations to allow rich data collection.

\section{Family Language Policy}

This section will outline the theoretical underpinnings of Spolsky's (2004) FLP framework, describe types of FLP addressed in the literature, discuss the issue of language 
ideologies, and examine the factors of HL maintenance, and multilingual language practices aiming at the maintenance of the heritage language.

\section{Theoretical Overview}

FLP is defined as "a deliberate attempt at practicing a particular language use pattern and particular literacy practices within home domains and among family members" (CurdtChristiansen, 2009, p. 352). Deriving from a public and institutional "language planning" paradigm of solving language problems at the level of state, school, workplace (King \& Fogle, 2013; King, Fogle, \& Logan-Terry, 2008), FLP has gained prominence in the context of a multilingual home and family.

FLP is realized in three interconnected elements: language beliefs or ideology (what people think about the language), language practices (what people do with the language), and language management (strategies of language use, or what people do to the language). Being exercised explicitly and overtly, FLP frames child-caretaker language interaction, playing a great role in child overall development (King, Fogle, \& Logan-Terry, 2008).

FLP scholarship distinguishes between two main forces, micro (family-internal) and macro (family external), and recognizes that the interplay between the two lies in the core of the family language beliefs and behavior. Highlighting the ecological perspective on family life and the embeddedness of a family into a broader socio-cultural discourse, Canagarajah (2008) cogently states the family is "a dynamic social unit, situated in space and time, open to sociopolitical processes/.../ the family is not a self-contained institution" (p. 170). The micro and macro processes working together determine attitudes and beliefs about languages, their position to one another and the sphere of their use, as well as individual language practices, and the way they are managed in the family. For example, Smith-Christmas (2016) illustrates how the 
bilingual Gaelic-English family's language ideology and attempts to maintain Gaelic with younger generations and their simultaneous English use with peers reflect the conflicting relationship between the family and the wider socio-cultural and historical context. The agency of the participants, the nature of location, and even the topic of conversation are essential elements of the language policies (Spolsky, 2007). Thus, the implementation of FLP has to consider the influence of a broader cultural, social and economic demands and institutional impositions.

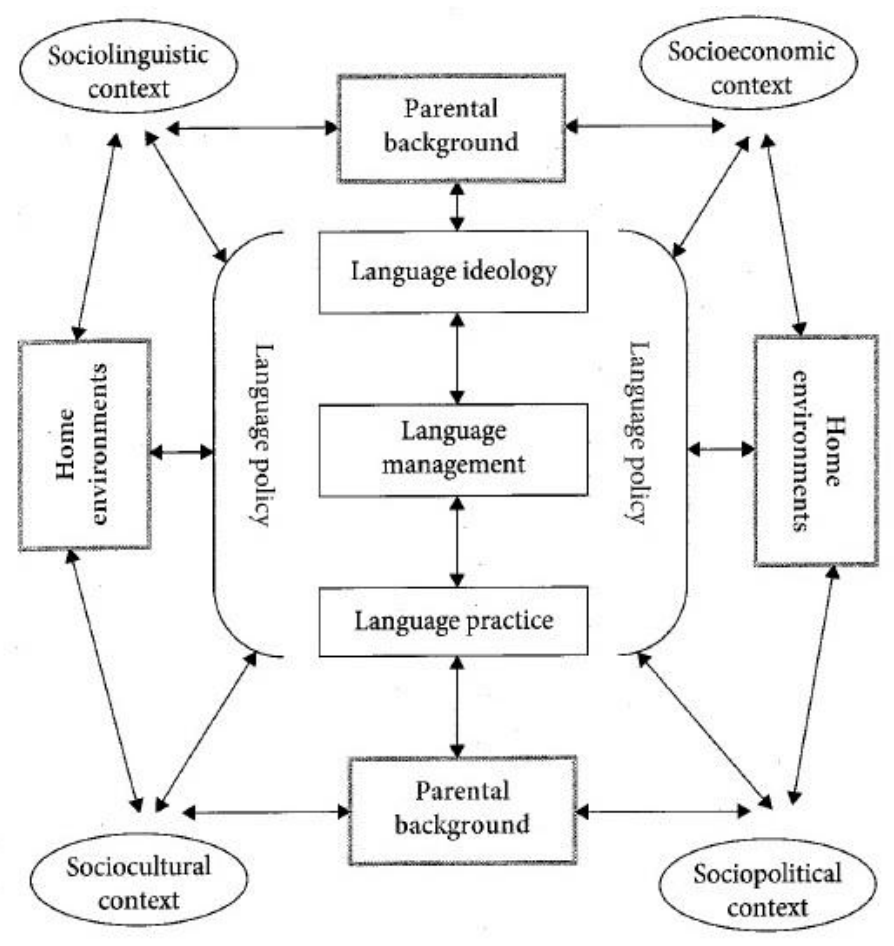

Figure 4. Conceptualization of Family Language Policy (adopted form Curdt-Christiansen, 2014).

Spolsky (2004) identifies those four contexts or conditions as follows: sociolinguistic context; socio-cultural context (the symbolic values associated with language/languages); socioeconomic context (instrumental (economic) values ascribed to a language); and socio-political 
context (national educational/ language policy; language choice as a right). Curdt-Christiansen's (2014) FLP model visualizes this dynamic (Figure 4). The dominant context and its official language policies influence family language policy through shaping parents' beliefs about language(s) and learning, and affecting their decisions about necessary home language routines. Family practices would always aim at strengthening "the family's social standing and best serve and support the family members' goals in life" (Curdt-Christiansen, 2009, p. 352). Thus, both family and societal ideology significant factor in bi/ multilingual acquisition. Thus, family practices, directed to heritage language maintenance, and those which ignite language shift and consequent loss in favor of the dominant language, are not random but a planned context-specific endeavor.

\section{Family Language Ideology}

Family language ideology encompasses family beliefs and attitudes about the language(s) and its place and role in a given community and in their life. There are individual and collective ideologies, ideologies of an immigrant and a dominant group that constantly interact with each other and determine language policies and behavior of individuals and groups. Schiffman (1996) asserts that family language ideology is the product of "values, beliefs, attitudes, prejudices, myths, religious structures, and all the other cultural "baggage" that speakers bring to their dealings with language from their culture', (in Shohamy, 2006, p. 112), mixed with the societal language ideologies in the host environment.

Among numerous works on language ideologies, multilingual parents' language choices and overall family cultural behavior, there are two main themes: parents' beliefs and ideologies about the language(s), and beliefs about learning the language(s). 
Ideologies about the language. Immigrant families develop a range of ideologies about the languages in contact, their status, use and functioning in the society. Those ideologies determine the family and children's language shift towards the dominant language of the environment or HL maintenance within further generations. Among three ideological approaches in bilingual education to language in a multilingual context: language as a resource (ethnic identity, family cohesion), language as a problem, and language as a right (Ruiz, 1984), treating language as resource or as a right lead to bilingual/ multilingual family context.

Orientation to language shift. Very often "indigenous and immigrant languages are under attack, around the world" (Hornberger, 1998, p. 439), because they are seen as liabilities or problems that need to be eradicated rather than as resources. Parents perceive HL preservation as hindering their children's success in the host society, and prioritize the host country language literacy practices in their family language policies. The concept of "ethnolinguistic vitality", the ability of the ethnic group to maintain its existence across time and space in intergroup situations "as collective entity with a distinctive identity and language" (Ehala, 2015) is important for understanding immigrant group ideologies about their linguistic and cultural behavior. There is strong empirical evidence that the perception of the mother tongue prestige (Suarez, 2002; Yamamoto, 2001) and status of the ethnic group of the immigrants (Tse, 2000) are influential factors of HL maintenance or loss ideology.

As illustrated above, language practices engage a speaker in semiotic, not just linguistic, environment and interaction (also Candlin \& Skikant Sarangi in Kramsch, 2003). Therefore, in immigration language(s) may acquire new valences or lose some of the previously possessed. Blommaert (2005) states, 
Whenever discourses travel across the globe, what is carried with them is their shape, but their value, meaning, or function do not often travel along. Value, meaning, and function are a matter of uptake; they have to be granted by others on the basis of the prevailing orders of indexicality, and increasingly also on the basis of their real or potential 'market value' as a cultural commodity.” (In De Costa, 2010, p. 72, italics original).

Therefore, the decisions on language use, heritage language maintenance or new language learning in a new context are shaped by new "value, meaning, or function" that the language acquires.

In Tse's (2001) study of Japanese language maintenance, seven out of the ten participants were trying to distance themselves from their heritage language by denying their ability to speak it and sometimes by refusing to use it outside their home. The choice of English was an attempt to fit in, and to avoid affiliation with Japanese immigration. One of the participants says:

I had to prove something, like, I was born here... I couldn't change the way I looked, so it's like, that sucks. So then, I would really try to rebel against Japanese, like, I don't want to speak Japanese at all, like in public, and even at home. I was so scared that people weren't going to like me, even if they didn't know me. (Tse, 2001, p. 693) Thus, language becomes a feature of identification and affiliation, bringing attention to "otherness". The Japanese language signifies not only affiliation to the Japanese culture, but affiliation to the "immigrant otherness". Denying the language became the solution for the exclusion problem, not only ethnic exclusion, but "otherness" immigrant exclusion.

Similar findings but from the Spanish-speaking immigrant context are reported by Suarez (2002). Parents perceived English-Spanish bilingualism as hindering economic and social opportunities in the U.S. context. The researcher demonstrates how, after keeping Spanish as a 
home language for their third-generation son, parents changed their attitudes towards the necessity of maintaining these practices when their son reached pre-school with the instruction conducted in English. The parents' decision not to maintain Spanish was based on their own painful experiences of being laughed at and struggles with humiliation and feeling different in the classroom because of their minority status. The shift from Spanish to $90 \%$ English at home was prompted by their intention to create more positive experiences for their son, socially and academically, with the home language consistent with the dominant language, English. "I would never want my son to be sitting in the classroom where he's considered an idiot. [...] He's going to make his education in English. English is his primary language” (Suarez, 2002, p. 523). A father from another family considers Spanish "a host of stereotypes and social ills" (Suarez, 2002, p. 524). It is evident that in a situation of migration the values assigned to family languages get re-calculated and re-assigned according to their new degree of functioning, very often as a problem, as perceived by the family itself. Meanings attributed to the languages by the family as a result of their negotiation of their place in the current context. During the socialization process, children in a multilingual family learn about function(s) of each language, presented in the context of socialization, inside and outside the family, as well as about the inequality of those functions and their non-replication (Aronin \& O Laoire, 2004). The shift to the dominant language appears to be a norm.

A similar finding of value-reassignment comes from research on the Russian as a heritage language in Israel context. In her longitudinal five-year study of 30 Russian-speaking immigrant families who have lived in Israel for 10-16 years, Kopeliovich (2011) reports on a rapid shift from Russian to Hebrew in the second generation of immigrants, despite the success and abundance of Russian in the public sphere. She explains the shift to Hebrew by the desire to a 
better social inclusion, so the heritage Russian was sacrificed. Similar findings from the same context were reported earlier by Olshtain \& Nissim-Namitai (2004), who examined the language life of the Circassian community in Israel. Through a questionnaire and interviews, the participants showed that Hebrew was prevalent for wider opportunities for communication and the participation in activities and institutions of the dominant society. The researchers highlighted that a bilingual/ multilingual family always faces a dilemma: to preserve the HL, enrich the linguistic repertoire and be multilingual, or to prefer social, economic, and educational mobility within society that a mastery of the dominant language can provide.

Some researchers state that in English dominant contexts, there is a strong societal push towards the "hegemony of English" (Gounari, 2006; Macedo, Dendrinos, \& Gounari, 2015; Shannon, 1995). In addition to Suarez (2002), Kirsch (2012) demonstrated how Luxembourgish mothers residing in the UK supported English in the family for reasons of integration into the dominant society. These mothers deliberately used the English "please", "thank you" and "sorry" rather than Luxembourgish equivalents of those words and phases. As discussed above, Song's (2016) study of Korean families in the U.S. also provides empirical evidence of how parent supported the development of children's skills in English.

There is no definite rule about assimilationist and pluralist ideologies. Personal experience is integral in this sense. For example, Jeon's (2008) rigorous study of the role of language ideology to maintain Korean as a $\mathrm{HL}$ at different stages of immigrants' life in the U.S. reports on a variety of diverse and opposite attitudes and beliefs circulating among senior citizens and recent immigrants with teenage children. Personal life circumstances were found to be core to those beliefs. 
Reasons to maintain a heritage language. Reasons to maintain a HL present another group of ideologies. A range of motives, reflecting parents' beliefs and attitudes towards multilingualism, maintenance of the HL and affordances of the HL, has been widely discussed in the heritage language literature. Although each family is unique and might exemplify an individual case with distinctive reasons to maintain the HL (cf. Jeon, 2008), there are a few common themes. Such themes include the parents' positive view of bilingualism and parents' own bi/multilingual experiences, the perception of the "heritage", instrumental views of heritage language and bilingualism in general, the preservation of heritage identity in the family, and the support of family cohesion. The reviewed literature also reveals that various families' reasons and motives to maintain the HL are usually intertwined, complement one another, and are embedded in the broader context.

Positive views of bilingualism and personal bilingual experiences. One of the strongest factors valorizing bilingualism in the family, as shown by the reviewed literature, is parents' own bi/multicultural competence and experiences (Kirsch, 2012; Piller, 2001) and perception of bilingualism as a gift and wealth (Palvainen \& Boyd, 2013). For example, Piller's (2001) longitudinal study of parents' posts on bilingual forums and websites, which also included selected parents' interviews revealed that parental bilinguality was a factor to support children's bilingual practicesfor example this comment from one German-English father participant: "if you are a bilingual, you are more of a world citizen and not a nationalist" (Piller, 2001, p. 71). Likewise, Kirsch (2012) shows that Luxemburgian mothers living in the UK and exposed to bi/ multilingualism themselves support Luxemburgish practices at home and have high expectations of their children's overall multilingual skills, as they hope their children will develop at least one additional language. Moin, Schwartz, and Leikin (2013) also found that Hebrew-Russian 
families in Israel positively view bilingualism and perceive it as obligatory, not an elite privilege. The reviewed studies based their conclusions on participants' self reports and interviews.

Another embodiment of the valuing of bi/ multilingual skills is the resistance to language hegemony in the host country that results in the preservation of the heritage language (Suarez, 2002). Such a conclusion is drawn from the researcher's one-year long socio-linguistic ethnographic inquiry in the life of a Hispanic community in a rural area of New York state. Her intergenerational interviews of six Spanish-speaking families with children who were enrolled and not-enrolled in an ESL class, revealed that two out of six participant families decided not to strip their children off of the opportunity to be bilingual and teach them "to embrace their heritage language and culture" (Suarez, 2002, p. 526) and to succeed in the mainstream as Hispanic. The grandmother's voice in one of those families strongly illustrates her position, she strongly believes that through bilingualism and biculturalism "her children will have both access to school and job opportunities that English proficiency promises to give them, and also the connection with and pride in their Hispanic heritage that Spanish proficiency may promise" (p. 526). In sum, parents perceive languages as resources and have positive attitudes towards next generation's multilingualism.

HL and bilingualism as incentives. Many parents exhibit instrumental motives about HL maintenance and perceive their children's bilingualism as a way to amplify their competiveness in the world. The expansion of chances for further employability (Cho, 2000; Lao, 2014; Park \& Sarkar, 2007; Palvainen \& Boyd, 2013), positive asset for career and academic opportunities (Kwon, 2017), and enhanced cognitive development (Kirsch, 2012; Palvainen \& Boyd, 2013) are cited as the main instrumental advantages of raising a child bilingually. Thus, in light of the economic metaphor, Piller (2001) found that many parents consider heritage language 
maintenance a small "investment" with high return, as the acquisition of the language happens more easily in childhood and children can achieve near native proficiency. De Capua \& Wintergerst's (2009) study illustrates in their research on German as a Heritage language that the father, who was the dominant language speaker [English], actively supported his Germanspeaking wife in her efforts to maintain German in their family, seeing this effort as investment in future linguistic and cultural advantage.

Thus, Peterson and Heywood's (2007) study in Canada, based on interviews of parents of bilingual households and of teachers in schools with diverse linguistic enrollment, demonstrates that both parents and teachers were interested in children's bilingual development, and perceived maintaining children's L1 not only as important to the maintenance of their cultural identity but also to the children's overall literacy development. Recent scholarship reveals an overall move in parental interest from the maintenance of HL to the value of bilingualism and biliteracy.

There is evidence that parents put in extra effort to create conditions and opportunities for the development of fully-fledged, oral and written, bilingualism and biliteracy. Tse (2001) reports on parents' strenuous efforts to support biliterate skills in both English and Japanese. Examining family language policies in Chinese families in Singapore, Ren and $\mathrm{Hu}$ (2013) report that parents strongly supported the development of biliteracy, providing children with literacy practices in both languages by signing them into academic and extracurricular courses both in English and Chinese. Children attended speech classes in Chinese, Tamil and English, math tutoring in English, piano, and computer. The family language management was contingent on the mother's beliefs about the children's skills. (See more on HL maintenance practices in section on "Heritage language practices") 
As was noted above, ethnolinguistic vitality, the functionality and the importance of the language in the given environment, determines the perception of the heritage language as a socio-economic advantage. Thus, Curd-Christiansen's (2014) study of Chinese immigrant families in Singapore found that parents' firm beliefs about the advantage of the development of proficiency in Chinese originates from overt socio-economic opportunities, given the role the Chinese language occupies in the global affairs. The interviewed families reveal instrumental orientation to the heritage language proficiency.

Family cohesion. Empirical studies describe two ways in which the HL creates bonding and cohesion in the family, that is parent-determined language bonding and the development of HL behavior directed toward the intergenerational connection. First, there is strong evidence that a "mother tongue" ${ }^{6}$ has more and deeper emotional value than a second language, and parents use their native tongue to socialize their culture's expectations toward emotions (Pavlenko, 2004; 2005). Therefore, in immigration a parent might favor their native tongue, and, therefore, a child's heritage language, in their child-parent communications. It serves as a reason for the HL family use and its maintenance. In Kirsch's (2012) study, Luxembourgian mothers assert that they would not consider raising their children in a language other than their "mother tongue", as this is the language of their heart. On the other hand, Pavlenko ${ }^{7}$ (2004) also illustrates that parents attach different emotive values to their mother tongue and the host country language (their L2), so L1 is not the only language of emotions for the bi/ multilingual parents. Emotionrelated language shifts, "changes in language that are associated with the verbal expression of

\footnotetext{
6 Borrowed from Pavlenko (2004).

7 The researcher analyzed an extensive sample of 1039 responses with participants representing 47 different mother tongues. The data was collected through a web questionnaire that was comprised of close and open-ended questions. Thus, parents' perception of each language in their language repertoire affects the outcomes of their family linguistic behavior and reasons to maintain the HL. Pavlenko's (2004) findings were based on bi/ multilingual parents' self reports, and it appears that ethnographic observations would shed light on the relation of emotional value of languages and its maintenance in the family.
} 
emotion, the discussion of emotion, or changes in a speaker's emotional state" (Chen, Kennedy, \& Zhou, 2012, p. 370). The shift can be related to language proficiency and lack of crosslinguistic equivalence (Chen et all, 2012), or can happen with high proficient speakers in the direction opposite to the native language. Different languages allow bilinguals enact different kinds of affect and perform different social roles, reacting to different communicative discourse situations. For example, Pavlenko (2005) report on one of her participants, who explains: "I tend to use English when I am angry, Japanese when I'm hurt or sad, both when I am happy or excited" (Pavlenko, 2005, p. 139). Koven (2006), examining a Portuguese-French bilingual's narratives, found that her "angrier, more forceful, and more aggressive in French" self, despite Portuguese being her perceived first tongue, can be accounted by the bilingual's access to the styles of affective performances in each language. More about the issue of language choice and bi/multilingual interaction will be described in more detail in the section on "Family language choice and interaction."

The second way in which HL creates bonding and cohesion in the family is through the development of HL behavior directed toward the connection with the extended family. Heritage language maintenance supports intergenerational communication (Kirsch, 2012; Kwon, 2017; Park \& Sarkar, 2007) and also keeps intact transnational bonds, which are an essential part of heritage identity. For example, Sakamoto \& Kondon-Brown (2006) analyzed the life stories of Japanese immigrant parents in Toronto, Canada, and found that family cohesion and maintenance of family intimacy were the main factors in HL maintenance, and overall family linguistic behavior. In the same vein, Kirsch (2012) observed that the maintenance of relationships with Luxemburgish relatives was one of the essential rationales for multilingual child-raising among Luxembourg-descent mothers in the UK. The mothers reported that they 
regularly traveled to Luxemburg with their children and desired to ensure healthy communication among the children and their grandparents and cousins. Kwon (2017) also reports on the value of cross border visits of Japanese and Korean immigrant families to maintain the connection with the extended families. De Fina's (2012) sociolinguistic study of meal-time conversations in a tri-generational Italian-American family also vividly illustrates how a family's heritage languages, Italian and Sicilian, function as a bonding matter for the family members across generations. Analyzing spontaneous interactions, the researcher found, that despite their low or not full Italian or Sicilian proficiency, the younger family members tried to engage in conversations with the other, more proficient, members of the family, expressing bonding, continuity of traditions and family identity.

Maintenance of ethnic identity. The preservation of the family ethnic identity through HL is brought into relief by a significant number of empirical studies as the most important family HL maintenance factor. This premise is supported by the results of the U.S. National Heritage Language Survey, which reports that the significant majority of respondents perceived the heritage language as a medium of connection to linguistic and cultural roots (Kagan, 2012). Thus, preservation of ethnic and cultural identity is an essential element of heritage language ideology in the family. There is strong evidence that heritage language proficiency positively correlates with a well-developed sense of ethnic identity and increases instances and chances of networking with the speaker's ethnic group (Cho, 2000). Cho's (2000) claims are based on surveying 114 second-generation Korean-Americans. Cho's (2000) findings are supported by De Fina's (2012) study, which illustrates how less HL proficient family members claim their "vital attachment to their Italian origin" and show their "willingness to embrace the multilinguistic identity of the family" (p. 374) through a variety of discourse strategies (e.g., speech 
accommodation, brokering [spontaneous or elicited], metalinguistic reflection). Similarly, Park and Sarkar's (2007) questionnaire and interview study of Korean immigrant families in Montreal, Canada reports that all the participants were very positive toward their children's heritage language maintenance. Moreover, the parents believed that their children's high level of proficiency in the Korean language would help their children keep their cultural identity as Koreans.

Participation in the ethnic community network within the host country is perceived by many parents as advantageous, as a way to develop and exercise ethnic affiliation (Lao, 2004; Wei, 1994). It has been empirically observed that many parents refer to the support of the heritage ethnic community abroad. This support may range from communication in the native language and information exchange, to signing children into heritage language speaking kindergartens, primary schools or extracurricular activities, to expanding access to resources in the host country and actual material help (e.g., Moore, 2012; Ren \& Hu, 2013).

With regard to the Russian-speaking families, Kasatkina (2010) finds three main reasons of family heritage language maintenance and biliteracy support in their children. They are: (1) the importance of knowing the country of origin and its culture; (2) parents' desire to raise children differently from the parents' perception of American children; and (3) fostering "Russianness" in children's ethnic identity.

The reviewed studies showed that parents' reasons to preserve and support heritage language development range from instrumental values of bilingualism to more innate perception of the heritage language as an essential element of ethnic identity, embodying their being and belonging. However, most of the studies describe a bilingual situation, and still little is known about the dynamics of reasons to maintain and develop home languages in a multilingual setting. 
Despite the abundance of empirical evidence on HL maintenance reasons and perceptions from Spanish, Korean, or Chinese-speaking households, Russian-speaking families have not been sufficiently studied in depth. Interestingly, the decision to bring up a child bilingually might go beyond the values of the heritage language or bilingualism itself, and be simply an attribute of good parenting (King \& Fogle, 2006), as the competence in one or two more languages can bring all the same economic and cognitive assets and provide access to a broader socio-cultural network of opportunities.

Ideologies about language learning. De Houwer (1999) states that parental beliefs about the way children acquire the language and what activities should be provided for the children influence family language ecology. There is still a paucity of knowledge about the ideologies families exercise about the process of multiple language learning. Parent-oriented literature on children's bilingualism argues for the benefits of simultaneous bilingual language acquisition, frequently referring to Cummins’s Interdependence hypothesis (e.g., King \& Mackey, 2007). However, there is evidence that some parents view simultaneous exposure to multiple languages as harmful resulting in delay and problems in child development. For example, Li (2012) reports that parents stopped teaching a child his heritage Chinese in favor of developing his English skills, because they "have no choice, right now his English is not good enough, if we add Chinese to him, it's not good for his English". Chatzidaki and Maligkoudi’s (2013) study of Albanian immigrant families in Greece demonstrated that despite positive attitudes towards their language and heritage language maintenance, families did not actively engage in HL maintenance practices because the parents believed that simultaneous learning of two languages may impede the development of the majority language. 
Case studies of families that attempt to preserve a heritage language for their children demonstrate parents' awareness of the sufficiency of heritage language input and the parent's active role in successful in heritage language maintenance. Many families interested in HL maintenance believe that the one parent-one language policy (OPOL) and home language vs. community language paradigms (Piller, 2001) are able to provide rich input and practice in each language supporting, children's multilingual development. For example, Korean-Canadian immigrant families in Park and Sarkar's (2007) study, exhibit a high degree of Korean language use in interaction with their children, with parents being proficient in English and French. In their interviews, parents revealed that, despite realizing that their children lack the Korean language competence to hold a conversation with their parents solely in Korean, they are persistent in the use of Korean to keep at least children's receptive skills as strong as possible. To expand and strengthen the exposure to Korean, the parents also try to create a rich literacy environment for their children, providing books, videos, a variety of educational materials for Korean language development, as well as organized literacy practices, teaching children how to read, count, write in Korean. Three out of the nine interviewed families used educational Korean grammar and vocabulary books to provide systematic learning of the language. The parents also engaged their children in transnational interactions with their distant relatives via the Internet or phone in order to practice their Korean.

In sum, family language ideologies are shaped by diverse factors and conditions, which can be linguistic and non-linguistic. Among these are: (1) the differential power among cultural and linguistic groups in the host country, (2) the national language policy, (3) the status of the minority language(s) in the hosting society, (4) stigmatization of the minority language and culture, and (5) the presence of HL(s) in the educational system (e.g., the availability of HL 
classes or schools in the host country and the area). Language shift towards the host language can occur as an attempt to alleviate stigmatization about the family heritage, or to gain access to different forms of capital (social, symbolic, human). The decision to maintain their heritage identity or construct a new one reflects transnationals' active engagement in multilayered ideological interplay. Thus, family language ideologies reflect both individual and societal ideology about the ecology of language at home and in the society, and the relationship between those views, and do not always translate into practices.

\section{Family Language Practices and Management}

Family language practices and management are the observable behaviors and choices people engage with the language(s) (e.g., various literacy practices and events and diverse opportunities for language(s) use created in the family context, etc.) that provide a linguistic context for anyone learning language (Spolsky, 2007). Those activities are intrinsically linked to ideologies about languages. Language management mediates language ideologies and language practices. It encompasses family regulation on who speaks what language and when and with whom and where, how members of the family react to language mixing, what efforts are taken to promote the study of HL or host language in the family. Spolsky (2007) states that management is executed by an authoritative person who has a power to modify the group's beliefs, and the empirical studies often present parents in this authoritative role. Nicoladis and Genesee (1998) propose a Parental Discourse Hypothesis that emphasizes the role of parents' linguistic behavior, attitudes and beliefs in children's degree of bilingualism. De Houwer (1999) employs the term "impact belief" to signify "the belief that parents can exercise some sort of control over their children's linguistic functioning" (p.83). An ongoing language socialization scholarship also 
provides evidence for children's agency in molding family language practices (see “Agents of language socialization").

Heritage language maintenance practices. Family HL practices aim at HL maintenance. A family can provide resources itself or utilize communal resources for HL maintenance. Park (2007) posits that in the U.S. context, with still relatively low support of the minority languages, “input and scaffolding of heritage language among immigrant populations might rely heavily on familial network" (Cited in Park, Tsai, Liu, Lau, 2012, p. 2).

Input and its variety. As mentioned before, Piller (2001) identifies four major language strategies that define family language practices in a bilingual setting: (1) one person-one language (OPOL), (2) home language vs. community language, (3) code-switching and language mixing, and (4) consecutive introduction of the two languages. Analyzing a big pool of data collected from bilingual/ trilingual families with children of 6-10 years old living in Flanders, Belgium (1,899 families), De Houwer (2007) found that when both parents used the minority language at home and only one spoke the majority language the chances for children to be bilingual increased. Although engaging a large sample, the researcher's main conclusions were based strictly on the parents' answers to a one-page questionnaire and, evidently, could not represent the full picture of children's degree of trilingualism in those families.

There is evidence that successful development of bilingualism requires quality of input, not just quantity (Döpke, 1992). Döpke found that parent-children diverse interaction in and about the minority language helps support its understanding and value, and its ultimate development. Qualitative findings are supported quantitatively by Park and colleagues (2012) who obtained data from 68 Chinese immigrant parents and their children residing with their families in LA, who demonstrated that parental amount and quality of heritage language use 
correlated with children's language proficiency more than general parental attitudes toward cultural maintenance. The data includes interviews of parents, children's proficiency test, and a parental cultural values questionnaire.

Case studies of families who attempt to preserve heritage language for their children demonstrate parents' awareness of the sufficiency of heritage language input and their attempts to provide it through different means. Kwon (2017) provides the following list of regular family strategies in her Korean and Japanese transnational family participants: (1) transnational media to teach culture, (2) frequent visits to home countries, and (3) rich exposure to print and literacy resources in Korean and Japanese. De Capua and Wintergerst's (2009) case study illustrates determination of a German mother to preserve the language of her heritage via employing an only German policy and surrounding her children with German print and other media. Some parents may also seek for an available community support. Sunday schools, kindergartens and churches are some of the sites (Kagan, 2012; Moore, 2012; Park \& Sarkar, 2007). Transnational practices that involve connections to the host country, are a very common routine among families in immigration (Kagan, 2012). Kirsch (2012) shows that trips to Luxemburg, the mother's home country, are an essential practice in the family that provides an abundance of language practices for children and connection with the relatives.

The research shows that the mother's role in family language management is unprecedented. The mother helps locate and define the family subculture (Kenner, 2005). Luo and Wiseman (2000) report that the mother's attitudes toward the HL correlate with HL maintenance. Kondo (1998) demonstrates the mother's role in preservation of Japanese of six second-generation college students in Hawaii. The mother not only speaks the language to the children, but also searches for opportunities for them to interact in Japanese outside of the home 
(e.g., sending children to be educated in Japan, joining local Japanese religious and secular organizations). Although fathers support heritage language maintenance, they might not be interested in the management of heritage language practices. For example, Barron-Hauwaert (2004) reports that half of fathers participating in research answered, "Nothing!" to the openended question, “what do you know about OPOL?" The research on the father's role in multilingual language socialization is still scarce. I located only one study focusing on the father's role in HL learning, that is Li's (2012) ethnographic observation of how a father engaged in role play in Mandarin with his four-year-old daughter to support the maintenance of heritage language in an English dominant Australian context. Beyond this study, the father's role and agency in heritage family socialization has not been recorded, to my knowledge.

Structure of input. Providing heritage language input for their children, parents choose a different manner of presenting it. In some families, heritage language practices embody a schoollike character, and are forced upon children by their parents or grandparents. Language socialization patterns in a Persian-Kurdish family in Sweden studied by Kheirkhah \& Cekaite (2015) resembled formal language instruction rather than a relaxed home heritage language interaction. Smagulova (2017) also reports that Kazakh language practices in Kazakh-Russian speaking families in the language revival context in Kazakhstan were limited to pedagogic practices and reminded school talk. Likewise, Pease-Alvarez (2003) describes adult-centered views of learning and teaching in Mexican-descent immigrant families in California, where children are assigning extra homework, and engaged in recitation activities. In contrast, Luxemburgish mothers supported a natural and pressure free way of acquisition, as they experienced themselves in the multilingual Luxemburg. They strove to create an environment of "an enjoyable encounter with the languages, to develop an ear for languages in general not just to 
the mother's native language" (p.9). Thus, the mothers did not overtly focus on developing literacy skills in any of the languages they taught their children (Kirsch, 2012). Similarly, Huss (1991) found that parental permissive reaction to the minority language (Finish) mixing with dominant (Swedish) created a comfortable feeling about the minority language in Finish heritage families in Sweden.

Beliefs vs. practices. Interestingly, a few researchers report on lack of correlation between parents' beliefs and actual family practices (Lao, 2004); others found disparity between parents' answers on surveys and observed language practice at home (Goodz, 1994). Parents may have difficulties in following through with their intentions to use the heritage language with their children on a daily basis. Studying Cambodian families in Philadelphia, Hardman (2013) reports that even though the mothers regretted their children lack of heritage language competency, no measures were taken in response to this regret.

Many bilingual families familiarize themselves with the principles of bilingual child upbringing by reading books (Barron-Hauwaert, 2004), so many of the family practices might reflect scientific principles of bilingual child upbringing. Conversely, King and Fogle (2013) report that parents' beliefs and actions coincide with media and the populist mood, and are far from scientific research findings on successful bilingual development.

Practices dynamics. The reviewed literature provides evidence that family language practices are not static and may change over time. There is a range of reasons framing this change: family language preference change adjusting to the context (Luykx, 2005), a family's novel immigration experience (Grosjean, 2010), or a change in parents' beliefs about children's language acquisition (Ren \& Hu, 2013). Palvainen and Boyd (2013) illustrate that the birth of children can also introduce new language dynamics into the family. In their study of language 
strategies in Finnish-Swedish families, they revealed that parents became less strict about OPOL strategy with the birth of a second child, as they found it exhausting, or made explicit changes in their interaction order if they wanted to boost one language. In her Gaelic family study, SmithChristmas (2016) observed that orientation to Gaelic-centered family language policies also weakened across time. The researcher attributed this change to the fluctuation of values in the family and in a broader socio-economic context.

Most of the reviewed studies describe bilingual households, describing multilingual family linguistic life, it is important to consider all types of languages in which communication occurs, and all practices engaging those languages, as well as the position each of the languages occupy in the broader circulating ideology at a given context and time (Hornberger, 2003).

Language(s) interactions. It is important to explore language practices in transnational families at the socio-linguistic level of languages' contact. Scholars acknowledge that young bilinguals, provided that parents use more than one language in the family, begin developing their languages a little before the age of two, following a normal first language development timeframe (Döpke, 1992). Language choice and language interaction between an adult and a child in a bi/multilingual family may have diverse patterns. As was discussed earlier (see "Family language behavior" in "Language Socialization") translanguaging (Garcia, 2009) is common for a transnational household, even if parents claim OPOL or community language vs. home language policies. As exemplified by numerous example, language choice in a bilingual family is associated with a variety of pragmatic functions (Blum Kulka, 1997; Quay, 2008). As a result of an OPOL (one parent - one language) policy established at home, children exercise language boundaries of each language (Baker, 2000), manifesting associations between the language and particular people, contexts, and activities and the crossing of those boundaries 
make children cautious and cause the child to react (Palvainen \& Boyd, 2013). Further, I will describe findings on parents' language use and children's language use.

Parents' language use. As native language was found to mark an affective stance of the speaker (Pavlenko, 2007), parents may use their native language extensively communicating with their children. Zentella (1997) observed that the mother's choice of Spanish in a Puerto Rican community in New York signaled anger and was used to reprimand her children. In their study of Mexican-decent families in California and Texas, Schecter and Bayley (1997) noticed that Spanish was preferred for endearment, with English being an overall daily routine. Kirsch (2012) also reports through referring to Luxemburgish (their native language) as a language of their emotions, mothers explained their reason to maintain heritage language in their family in the UK. In this light, interlocutors' code-mixing serves as a communication strategy to get attention, to discipline or to emphasize a point (Smith-Christmas, 2016). The analysis of naturally occurring conversations in a Scottish family, which tried to maintain endangered Gaelic, Smith-Christmas (2016) found that Gaelic was assigned the status of authority, power, adulthood, and was used equally by children and adults in this sense.

Parents' language interaction strategies are an integral part of implementation of family language polices. Lanza $(1992,1997)$ suggests five types of language interaction strategies, employed by parents as responses to children's language choice and to use in a bilingual context. These parental discourse strategies are placed on the continuum from the most monolingual to bilingual. They are minimal grasp (parents' requests to clarify the utterance in another language, monolingual context is negotiated with the child), expressed guess (parent reformulates child's utterance in a form yes/ no question), adult repetition (a parent repeats child's utterance in a 
different language, not in the form of the question), move on (parent continues the conversation signaling comprehension), code switching. Code switching is the most bilingual strategy.

Children language use. Bilingual children are context sensitive, and learn to navigate through a multiplicity of contexts and situations at early age (Lanza, 1992). For about nine months Deuchar and Quay (2000) analyzed the language use of the daughter of one of the researcher's, who was 1.7 at the beginning of study. They found that the child maneuvered the contexts, exhibited the use of English in an English context, and Spanish in the Spanish context. In addition, the child's matching of the Spanish language with the context was stronger than English. The researchers suggested that the use of Spanish by both parents at home accounted for the child's stronger awareness of the Spanish context.

There is evidence that children are sensitive not only to the context but also to the strategies parents utilize in multilingual interaction. Mishima (1999) examined language switching in a Japanese-English family and found that children mixed less with the dominantlanguage father and more with the minority-language mother, because the mother was accepting of children's behavior. Similar findings are reported by Lanza (1992). She examining the nature of language interaction between two two-year-olds Norwegian-English bilinguals and their parents, found that the children's linguistic behavior was related to the parental response strategies. Both children exhibited preference for Norwegian in their utterances, but one of them, Thomas, was code switching more frequently than the other, Siri. The researcher observed that Thomas's mother would be lenient to her son's mixing languages, whereas Siri's mother was more inclined to monolingual policies, and corrected her daughter's utterances or requested repetitions in one language. Siri also mixed more with her father who was neutral to his daughter code switching. This study exemplifies children's ability to skillfully evaluate the discourse 
situation and act pragmatically. The interaction patterns range from conscious request to unconscious accommodation (Curd-Christiansen, 2013; Palviainen \& Boyd, 2013). Interaction patterns shed light on the live enactment of FLP, and can serve as a valuable resource to family language ideologies.

The only set of studies on Russian language interaction in family-naturally-occurring conversations was conducted by Fogle (2012) and Fogle and King (2013). The work engaged Russian-speaking adoptees in American families and was devoted to children's agency in family language policies. For example, Fogle and King (2013) demonstrated the child's use of Russian in interactional strategies that negotiated or resisted parental practices.

\section{Summary}

The FLP framework aims at describing and explaining the dynamics of language use in the family, which is framed into a broader ideological context of the host culture: it directly connects societal ideologies to what a family does with the languages and how. In comparison to the language socialization framework, which focuses on the longevity of the community of practice, FLP strongly emphasizes the act of the analysis and planning in the language behavior of experts, in order to get cultural, symbolic, and other profit. This analysis and planning are embeddied in family beliefs. Family language ideologies encompass family beliefs about home and host languages, and about the vitality of home language(s) in the host country, as well as family attitudes towards home language maintenance, shift or loss, and the process of language learning. Family language ideology also includes attitudes towards bilingualism (or multilingualism), and attitudes towards specific bilingual praxis (e.g., codeswitching), attitudes toward specific interactional strategies. 
The review of literature shows that there is a range of family reasons to maintain their heritage language or contribute to its loss, as well a range of language practices and language interaction patterns; all of them are dynamic and contingent to the changes in socio-cultural, socio-political, socio-economic environment. Mothers play a prominent role in determining family language policies. Parents' reactions to children's language are very illustrative of language ideologies. There is also evidence that what is "preached" by parents in the form of beliefs, is not always carried out into practices.

Similar to language socialization scholarship, the work on FLP in Russian-speaking homes is not well developed. Most of the studies have been done in bilingual contexts, and multilingual contexts are still underexplored.

\section{Transnational Spaces}

This section presents an overview of the theory on transnational social spaces, and the conceptualization of transnational space in multilingual research. It also explores the Russianspeaking context in the U.S. and Estonia and briefly describes educational context for Russian and Estonian in the U.S.

\section{Theoretical Overview}

Globalization, increase in people's mobility, widespread use of technology and new technological advancements have created a complex pattern of interaction among local and global, heritage and dominant spaces. The dynamics of interaction include not only the question of language, culture and identity loss or, conversely, cultural syncretism, but also the development of new practices and orientations, "a transcultural mélange or bricolage" (Faist, 1998, p. 234) of experiences. "Transnational social spaces" include a triadic relationship between the host country, home (sending state) country (sometimes perceived as external home), the 
global context, and the immigrant group, which works on the principles of reciprocity and solidarity (Faist, 1998) (see Figure 5).

Transnational social spaces are "combinations of social and symbolic ties, positions in networks and organizations, and networks of organizations that can be found in at least two geographically and internationally distinct places" (Faist, 1998, p. 216). They engage a wide range of people who do not necessarily experience migration or are connected to transnationals, transnational families, and communities. The term underlines the complexity of an immigration phenomenon and complements two traditionally discussed polar trajectories available to the new comers at border crossing - assimilation and ethnic pluralism. Assimilation is characterized by a full blending into the dominant culture, while ethnic pluralism exhibits a contrary behavior, i.e., formation of ethnic enclaves and niches within but isolated from host culture. Conceptualizing immigrant experiences as transnational, not dichotomous (pertinent only to heritage vs. host language and culture), helps better understand the nuances of immigrants' linguo-cultural decisions and practices.

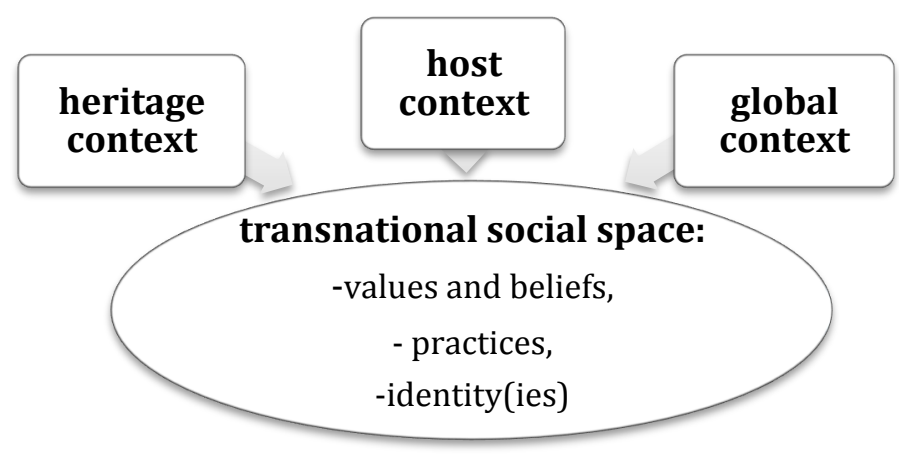

Figure 5. Transnational social space.

Additionally, transnational conceptualization of immigrant experiences addresses “dual or multiple identifications" of immigrants. Vertovec (1999) posits "there are depictions of individuals' awareness of decentered attachments, of being simultaneously 'home away from 
home,' 'here and there"” (p. 450). Physical border crossing does not impede "imaginary coherence" sustaining links to the identities one holds in the home country. On the other hand, movement and multilocality produces a multiplicity of histories, "communities and selves" (ibid. p. 451). It is worth comparing this theorization of transnational experiences to Maines (1978) and Horenczyk (2000) theorization of self in the process of migration (in Aronin \& O Laoire, 2004).

\section{"Transnationalism" in Family Language Socialization}

Contemporary research on immigration, diaspora studies, globalization, multilingualism, multilingual practices, and identities, has widely adopted the "trans"-approach, highlighting the conceptual and analytical complexity of present day experiences.

There is a current trend in family language policy research to utilize the notions of transnational and translanguaging as analytic frameworks. Connecting linguistic research on family language policies to the new waves in scholarship in diaspora studies in sociology (e.g., Faist, 1998), Zhu and Li (2016) propose reconceptualizing "migrant" and "immigrant" families as "transnational", considering "the interconnectivity across and beyond national boundaries an important dimension of their experience (p. 656). They also differentiate between transnational and multilingual families in their research, separating the nature of their experiences and backgrounds, and stating that "transnational families are bilingual or multilingual; certainly not every individual member of these families is bilingual or multilingual." (Zhu \& Li, 2016, p. 656). They claim, such an approach allows studying bi/multililnguals' experiences holistically, multidimensionally, and contextually. Soler and Zabrodskaya (2017), developing this line, also refer to their Estonian-Spanish speaking families as "product of current globalized world of transnational mobility" (p. 551), emphasizing the couples' experiences of living in a third country, outside Estonia and Latin America. They examine families' translanguaging practices 
which construct "new spaces" of being and language use.

Language is a significant element of a transnational social space. Earlier discussion illustrates that language constitutes an integral part of the symbolic, social, and economic capital. Different languages provide, or, on the contrary, deprive or hinder different access to the forms of capital, reflecting the distribution of authority, power and other resources in the social spaces. Language, both heritage language(s) and the language(s) of the host country, is an inherent resource for creating, supporting, and indicating social and symbolic ties in transnational social spaces, and therefore an integral element of a transnational's identity. Theorizing about translanguaging, Li (2018) asserts that this term captures “multilingual language users' fluid and dynamic practices" (n.p.). He also develops the discussion into proposing the notions of “translanguaging space”, a space for translanguaging practices "where language users break down the ideologically laden dichotomies between the macro and the micro, the societal and the individual, and the social and the psychological through interaction" and "translanguaging instinct", which is defined as "the salience of mediated interaction in everyday life in the $21 \mathrm{st}$ century, the multisensory and multimodal process of language learning and language use" (Li, 2018, n.p.). Faist (1998) states that social and symbolic resources "mobilize other forms of capital, especially among those short of economic capital" (p. 219). Thus, the decision on language choices, language maintenance, and use reflects the language user/ speaker' positioning in the social space.

There is empirical evidence from HL maintenance research that families engage in transnational practices through traveling or via contemporary means of communication, which contribute to this life "beyond national borders" (Li \& Zhu, 2013, p. 517), helping to maintain meaningful ties with the home country and/ or creating and developing new networks with 
people and communities of similar immigrant experiences in the host country (e.g., Kirsch, 2012;

Song 2016). These ties widen the scope of possibilities in economic, political and cultural domains (Faist, 1998).

Darvin and Norton (2014) distinguish transnational identity of migrant language learners, highlighting their complex linguo-cultural backgrounds, and simultaneous participation in different spaces in order "to reorganize a sense of who they are and how they relate to the world" (p. 57). To my knowledge, this is the only resource employing the term transnational identity in language related research.

The home country can already present a transnational space before the immigration; the linguistic and cultural landscape of former Soviet republics within the Soviet Union is very illustrative in this sense. If those republics could be called multicultural during the Soviet Union's prime (as they had a right to keep their national language, along with the dominant Russian), after gaining sovereignty in 1991, they faced a transition from the dominant Russian culture to the rise of national languages and cultures as the uniting core of national awareness and identity. It was not only linguistic and cultural transition, but also an ideological transition that created a new environment for cultural, social, and economic capital. Upon immigrating to a different state, immigrants from former Soviet republics expand and complicate their transnational social spaces. As heritage language research presents evidence that a considerable part of those immigrants in the U.S. treat Russian as a part of their linguistic and cultural background; the exploration of the nature of transnational social spaces in such contexts sheds light on the dynamics of social, economic and human capital in the contemporary world. Such contexts are worth attention. 


\section{Socio-cultural Context of the Study}

As the participant family is a transnational Estonian family which exercises Russian and Estonian language practices re imbedded into the English-speaking environment, I will provide information on the Russian and Estonian speaking context in the U.S, the ideologies of the Russian post-Soviet speaking space in Estonia, and Russian and Estonian educational context in the U.S.

\section{The Russian-Speaking Context in the U.S.}

According to a former Russian State Duma speaker's report, about 160 million people in total consider Russian as their first language, while more than 270 million use it as a regular means of communication (Naryshkin, 2012 in Ryazanova-Clarke, 2014). Since the dissolution of the USSR, the Russian-speaking diaspora worldwide is estimated at about ten million people, with three million people living in the US and Canada (Elias \& Shorer-Zeltser, 2006). According to the U.S. Census data issued in 2013, there were 905,843 citizens identifying themselves as Russians in the US, compared to 2000 about .3\% of the US population, about 706.000 people, spoke Russian in the household ${ }^{8}$. The Russian language is on the list of ten most popular languages spoken in American homes.

According to the US Census in 2000, Russian speakers are a well-educated population with about $51 \%$ having an equivalent of a Bachelor's diploma and about $92 \%$ at least a high school diploma. About $75 \%$ of Russian speakers over the age of five report speaking English "well" or "very well". Russian speakers, independent of ethnicity or language tend, to have jobs requiring a higher level of qualification when compared to overall US population (Kagan \& Dillon, 2010).

\footnotetext{
${ }^{8}$ http://factfinder2.census.gov
} 
It is worth highlighting that the Russian-speaking population in the U.S. is "superdiverse". The U.S. experienced several waves of Russian speaking immigration, most of which occurred at the end of the $19^{\text {th }}$ beginning of the $20^{\text {th }}$ century, in the 1940 s after World War II, and after the dissolution of the Soviet Union, at the end of the 1980s into the beginning of the 1990s.

Additionally, Russian-speaking immigrants are ethnically diverse, and represent immigrants from former Soviet republics for many of whom the Russian language may constitute one of the languages in their linguistic repertoire or heritage, and who may exercise a certain ideological perspective about the Russian language, reflecting certain historical experiences. The collapse of the Soviet Union and regained political, linguistic, and cultural independency of former Soviet republics diversified the demographics of Russian speaking immigrants, and in the new post-Soviet environment, not only did people get on the move, but also "borders moved across people” (Brubaker, 1996 in Ryazanova-Clarke, 2014, p. 2), creating additional socio-cultural and ideological contexts. Many ethnic Russians, or those who identify themselves as such, stayed within the borders of a newly formed country.

With the acquisition of independence, former Soviet republics' national language policies focused on the revival of the national heritage to strengthen the autonomy of the independent country. Ryazanova-Clarke (2014) writes that the newly independent states "took resolute steps towards de-russification of public domains and the rebalancing of the language regimes towards favouring the 'titular' languages [...] The result was that the previously dominant and de-facto official Russian language was rapidly losing in symbolic value while its speakers were relegated to the position of "imperial minority"' (p.7). Estonia and Latvia appeared to be the most radical states, in which, despite the high percentage of Russian speakers (30\% of the Latvian population 
and $26 \%$ of the Estonian), Russian was resolutely declared a foreign language (Iatsenko 2008 in Ryazanova-Clarke, 2014, p. 7).

However, 70 years of the Soviet regime ensured the Russification of the many aspects of the republics' lives. Many former Soviet republics are historically bi/multilingual, with the population speaking the national language and Russian. Although there is a decline in the preservation of the Russian as the heritage language in those republics, for many families in immigration, Russian is still preserved as a symbol of and link to the heritage.

Contemporary advancements in communication technologies support the connections between home and host countries through creation of "virtual diaspora" (Elias \& Shorer-Zeltser, 2006). Social network groups, web-sites and blogs create a Russian-language "virtual nation" of post-Soviets "who found on the Web a space for sharing mutual experiences and an efficient means of connecting them with their co-ethnics who have settled in other countries, as well as with their relatives and friends in their home countries" (p.2). Elias and Shorer-Zeltser (2006) also report that the Russian-language websites originating in the host country were most popular among the participants, whereas the frequency of visiting the websites in the host language was the lowest one: $46 \%$ of the respondents visited the Russian-language websites originating in the host country several times a week, compared to $40 \%$ who visited the host language websites in the same time frame. Similarly, $20 \%$ of the respondents never visited the host language websites, compared to only $11 \%$ who never visited the Russian-language websites. Moreover, $71 \%$ of the respondents recognized the importance of maintaining connections with Russian-speaking immigrants in other countries; half the respondents, who did not have Russian-speaking friends abroad, expressed a willingness to create such friendships in the future. Thus, the process of 
immigration and the nature of the immigrants' linguistic and cultural experiences complicate the phenomenon of heritage and the role of language in its construction.

\section{The Russian Language in the Estonian context}

To understand the impetus, motivations and nature of Russian language maintenance in a transnational Estonian family in the U.S., it is important to explore the Russian-speaking context in contemporary Estonia as a complex phenomenon.

The majority of the Russian population settled in Estonia in the post-war 1940s, after the annexation of the Baltic countries by the Soviet Union. Estonia had a sizable Russian-speaking population during Soviet times. In 1991, after the breakup of the Soviet Union, about 35\% of the population had Russian as their first language, and $34 \%$ of this number were ethnically Russian (Pavlenko, 2006). Today $25 \%$ of population identifies themselves as ethnic Russians, as of June $2016^{9}$, and $31.7 \%$ of Estonian population in Census 2000 was represented by Russian speakers.

During Soviet times, Russian was compulsory in Estonian-medium schools, and in communication in general. Although Estonian was also taught in schools, the Russian population appeared not to prioritize acquiring it. Vihalemm's (1999) survey showed that even after the change of the regime and the language policy, the Estonian language competence of the Russianspeaking population did not show any drastic change. These findings are based on self-reported data which were collected longitudinally from 1989 till 1997. The north-east of the country was predominantly Russian speaking, and functional bilingualism was the norm for the majority of Estonians in other areas.

With regard to educational opportunities for the Russian-speaking population, today Russian-speaking children have three educational options: (1) Attending a Russian-speaking school, with a shift to Estonian in high school, (2) Attending an Estonian-speaking school, and

\footnotetext{
${ }^{9}$ Statistics Estonia, http://www.stat.ee/34278
} 
(3) A public school immersion program, introduced in the early $2000 \mathrm{~s},-$ a bilingual school with both Russian and Estonian as languages of instruction (Kemppainen, Hilton, \& Rannut, 2015). Thus, in public education, both Russian and Estonian are still official languages. Kemppainen and colleagues (2015) report that Russian-language schools support the preservation of the Russian language in Estonia and strongly contribute to the maintenance of ethnic identification among the Russian population. Most importantly, their survey research also showed that the ethnic identification of children is strictly bipolar, without tendency towards multilingualism (Kemppainen, Hilton, \& Rannut, 2015). They either identify as Estonians or Russians.

Reflecting the repercussions of the historical narrative, and "existential angst" about the loss of the national language and culture (Feldman, 2005, p. 682), the position of Russian speakers has been conflicted and contested (Ehala \& Zabrodskaya, 2014). In the Estoniannationalizing consciousness, Russians, who moved to Baltic countries after 1940, are still not perceived as minorities but colonizers, and are identified as "the internal Other against whom Estonianness has been construed" (Petersoo, 2007, p. 124). Therefore, after Estonia acquired independence in 1991, language became one of the ways to articulate Estonian-nationalizing consciousness and exclude "Russianness."

Estonian language became a strong tool of national revival on the one hand, and of “othering Russianness" on the other. Since 1991, Estonian has been proclaimed the only official language of the country (in comparison to post-Soviet language policies in other former Soviet republics), and Russian became a foreign language. Responding to ethnic diversity, the Estonian government adopted Estonian language and culture as the core of national consciousness and aimed at the integration of non-Estonians into Estonian society and values (e.g., the Estonian State Integration Programme 1997, the Estonian State Integration programmes 2000-2007). 
Feldman (2005) asserts that political exclusiveness of the Estonian language in post-Soviet policies played an integral uniting "security" role which revived and strengthened Estonia as a nation. "National language" is not a strictly linguistic category but an ideological object used in the construction and reconstruction of national identity (Bakhtin 1981; Woolard 1998). Moreover, the Baltic republics spent the least amount of time as part of the Soviet Union, and managed to preserve "a high level of national consciousness and loyalty" (Pavlenko, 2006, p. 89), which supported the unification and de-Russification processeses. However, overtime the national policies in Estonia have become more inclusive of minorities (e.g., Brosig, 2008).

The governmental language policies negatively affected the socio-economic status of the Russian population, decreasing educational and employment opportunities. Obtaining Estonian citizenship became another vulnerable issue, and a substantial percentage of Russian-speakers, with poor or no command of Estonian, was left stateless when the country gained independence in 1991. Residents who were not Estonian citizens before World War II - many of them ethnic Russians - or their descendants, have to go through a strict naturalization process, including a language test and a residency period. In 2015, Estonia had 6.3\% stateless persons, most of them of Russian heritage.

An extensive sociological survey of the Russian-speaking population conducted by Lauristin and colleagues (2011) illustrated that the knowledge of Estonian is integral to successful integration into Estonian society, as is the willingness to adapt. Additionally, about half the respondents showed little or no integration at all, and are characterized by pessimism, poor command of Estonian, an undefined citizenship or Russian citizenship, and economic insecurity. Five main integration patterns emerge in this study:

1) Successfully integrated. 
2) Russian-speaking patriots of Estonia.

3) Critically-minded Estonian-speaking.

4) Little integrated.

5) Unintegrated passive.

Thus, the study shows that over the past two decades of Estonia's independence, the Russian-speaking population has become more heterogeneous than in the ' 90 s. It illustrates that proficiency in the Estonian language has become a fundamental factor in community inclusion and economic and social well-being for the majority of former Russians. The strength of the language factor is not surprising, because the language is a primary means of communication, ultimately leading to other possibilities.

Similar claims are made by Ehala and Zabrodskaya (2014). In their mixed-method study, the researchers explored ethnic and linguistic affiliation and identity construction of Russianspeakers and found that participants formed a heterogeneous community with diverse values and attitudes towards the country, languages, and themselves. Ethnolinguistic vitality depended on social networks, linguistic environment, education and professional success. Orientation towards Russian is stronger in bigger cities, and among low income Russian speakers with minimum education. The younger generation with Russian heritage is more proficient in Estonian and more likely to successfully integrate into the Estonian society. Conversely, the level of Russian among Estonians is decreasing. Laitin (1998) reported that parents sometimes "go out of their way to help eliminate Russian from their children's repertoires” (p. 130, in Pavlenko, 2006, p. 90), by sending children to Estonian schools and encouraging them study other languages, primarily English, as it was gaining momentum in 1990s. 
Thus, in a language contact situation, the functions assigned to the languages change and shift, responding to the contextual changes. To explore whether and how each of the two maintaining their roles in the society, in order to be a means of communication or a symbol of group membership, Vihalemm (1999) conducted a comparative survey (1989-1997) of the attitudes towards the Estonian and Russian languages. He found that with time the instrumental motivation to learn Estonian became stronger, and Russian started acquiring a stronger symbolic function.

In sum, the Russian-speaking community is quite diverse with respect to their histories, beliefs, and attitudes towards heritage language preservation and learning, and willingness to cope and adapt to the dominant environment. The status of the Russian language is very vulnerable in Estonia. However, the dynamics of Russian in Estonia creates a number of inquiries. Too few studies explore attitudes and beliefs of population of Russian heritage towards the Russian language and its maintenance, and the Russian identity in Estonia. A number of questions arise: Is tere a place of Russian in an Estonin family? And what is it? What is the impetus of maintaining Russian in an Estonian family in immigration? What attributes are assigned towards the Russian language, and what are the values of the Russian heritage? Such questions are intertwined with exploring family language policies.

\section{U.S. Educational Context for Russian and Estonian}

Community support is an invaluable factor of successful HL maintenance and a great contribution to the family efforts. It is important to explore how Russian and Estonian are represented in the US context, in particular in the Washington, DC, area, where the participant family resides. 
In terms of the availability of educational resources targeting the maintenance of the heritage language, Russian is more represented than Estonian in the U.S. in general, for the Russian-speaking immigration has a longer history and has higher numbers.

Russian Life web resource registers 288 schools that teach Russian in the US ${ }^{10}$. An online search also provided information on 19 Russian speaking kindergartens and educational centers in the area of Washington, DC, Maryland, and Virginia ${ }^{11}$.

According to the 2000 US Census 25,034 Americans claimed Estonian descent ${ }^{12}$. Information on Estonian speaking school across the US is unavailable, but a search discovered information on six Estonian schools in Baltimore (MD), Andover (CT), Lakewood (NJ), Middle Island (NY), and New York City ${ }^{13}$.

\section{Putting Frameworks Together}

Language socialization and family language policies have many convergent points. Both view language as an integral part of person's socializing experience. Language is perceived as a "doing" phenomenon and "a product of social action not just a tool to be used" (Pennycook, 2010, p. 2). Broadening the notion of practices, both frameworks emphasize the role of the context and perceive it as an essential part of the language practice. They acknowledge and highlight the representational function of the language and language practices.

While LS explicates the connection between language and the development of the sense of being and belonging, through the acquisition of both language and culture "as bodies of knowledge, structures of understanding, conceptions of the world, collective representations"

\footnotetext{
${ }^{10}$ https://www.russianlife.com/contact/become-a-sponsor/schools-list/

${ }^{11}$ http://www.allrussiandc.com/kids.html

$12 \mathrm{http}$ ://immigrationtous.net/99-estonian-immigration.html

13 http://www.saturday-schools.org/estonian, http://www.vabaeestisona.com/index.php/news-in-english/6303national-language-day-celebrated-by estonian-youth-around-the-world.html
} 
(Schieffelin and Ochs, 1982, p. 15), FLP sheds light on why and how certain languages and practices are selected, prioritized over others, hierarchically organized, or can harmoniously function together, and embedded into a broader ideological context. Theorization of transnational social space explicates and brings to the fore the complexity of the context for LS and FLP, when the socializing context is multifaceted, multilayered, concurrently developing in one and many physical and temporal spaces, when both heritage and host dimensions (at different degrees) interact with the global space, expanding opportunities for negotiation of place and space in border-crossing situations.

On the other hand, although originating from language socialization research, the fastdeveloping area of family language policies seems to forget the essential premises of language socialization in favor of the focus on power dynamics informing the language practices. Yet both bodies of scholarship primarily describe family language environment through the lens of the battle of the opposites: heritage and host language, first and second language, and minority and dominant language, theorizing transnationals' behavior with a touch of idealization of the HL maintenance and sympathy for its loss. The majority of studies appeared to overlook the existence of the newly emerged linguistic, cultural, ideological "Is" (Pratt, 1991) in the situation of migration. In these zones, "cultures meet, clash and grapple with each other, often in contexts of highly asymmetrical relations of power, such as colonialism, slavery, or their aftermaths as they lived out in many parts of the world today" (p.34). Globalization has created transnational experiences, which feature new forms of contacts, novel socialization, and communication processes, ideologies about languages and linguistic behavior, and can shape immigrant families' spaces. These experiences may be presented by a continuum between heritage and host poles. 
Such changes also have great impact on the processes of negotiation and construction of the identity of each member of the language socialization process in an immigration context.

For the purposes of this study I propose to combine the three frameworks into one analytical approach to examine the language ecology and negotiation of language practices in a transnational multilingual Estonian family in the U.S.

\section{Summary of Literature Review}

The literature review helped explore major theoretical and methodological orientations of the family language socialization, heritage language maintenance, language ideology, and the relationship between language and identity. It also helped examine the ideological and applied position of the Russian-language in the Estonian and the U.S. context.

First, the main principles of language socialization were defined, and their particular realizations in the contemporary multilingual context were examined and described. The framework of language socialization explained the link between language, culture, heritage, and identity, and presented different agents of socialization and their role in the language socialization process. Second, Family language policy framework brought forward a power dimension to understanding of the linguistic behavior of family members. It demonstrated that family language decisions are the product of interaction of immigrant family ideologies with the broader socio-economic, socio-political, socio-cultural context in which that family resides. Empirical findings showed that parents' beliefs and ideologies do not always translate into the actions they identify being important. Many practices are stigmatized. Additionally, FLP were found to be dynamic in nature and changed across time and space, reflecting the ideological underpinnings of the macro context. The concept of transnational social spaces exposes the formation of a hybrid space upon the contact between/ among languages and cultures. There are 
not a pure heritage country or host country contexts in which a family in immigration lives, but a transnational space which is formed as a result of interaction among heritage, host, and global contexts, elaborating transnationals' language experiences, and identities. The section on Russian-speaking landscape in post-Soviet Estonia and Russian- and Estonian-speaking landscape in the U.S. portrayed that language ideology is a socio-historical and socio-cultural product. The review also revealed that there were more Russian than Estonian resources available to the transnational families in the U.S.

The review of literature allowed me to reveal limitations in this research area up to date. Language socialization in Russian-speaking transnational families has not been examined much, despite several waves of migration from the Russian-speaking region over the last century. Moreover, the "superdiversity" of the Russian-speaking population, so crucial to consider within the current socio-cultural and historic context, has been hardly addressed, and practices of families have been overgeneralized through survey and questionnaires. There is also limited knowledge of the father's role in language socialization. Additionally, heritage language socialization literature has been focusing mostly on bilingual families, and considering the complexity of human transnational experiences, multilingualism has become a common experience of transnational families. More research in ethnographic tradition will remarkably contribute policymakers, communities, teachers and teacher educators in their understanding of the complexities and intricacies of contemporary human experiences. Educators should become more thoughtful about learners' backgrounds and experiences when they come into their classrooms. 


\section{CHAPTER III: METHODOLOGY}

This work aims to comprehensively explore the ecology of language and language practices in a multilingual transnational family in the U.S. I focus on an Estonian Russianspeaking transnational family to investigate how the family navigates and constructs ideological, linguistic, cultural, and identity spaces. This section provides a detailed description of the methodology of this study and the analysis procedure. First, I will clarify the research design and justify the choice of the data collection tools and analysis methods, and will comment on ethical and theoretical issues of data collection. Then, I will describe the participants of the proposed study. I will also allocate special part if this section to unveiling my positionality, as I perceive it an integral part of the chosen ethnographic methodology and the whole research process. I will conclude this chapter with the data analysis procedure and the limitations and challenges of the data analysis process.

\section{Research Design}

The focus of this research project was a multilingual transnational family in the U.S. The family was a full family with two daughters (three years old, and one year and three months old), which was engaged in multilingual practices with major languages Estonian, Russian, and English. The project employed a qualitative case study in a tradition of linguistic ethnography.

First, seeking answers to the research questions of: "Why does the family fully engage in multilingual practices?" and "How does the family do it?", the case study method helped capture the nuances of rich human practices at large. This method also allowed me to deeply understand complex human experiences embedded in the family and observe the life from inside. According to Yin (2003), "The case study method allows investigators to retain the holistic and meaningful 
characteristics of real-life events" (p. 2). For the purposes of this work the case study design was an optimal decision.

Second, inherently existential and constructivist, qualitative research is "a specific, complex, functioning thing... an object rather than a process" (Stake 1995, p. 2), that encompasses multiple realities of all its actors simultaneously living in diverse contexts, “temporal and spatial, historical, political, economic, cultural, social, and personal" (Stake, 1995, p. 43). Therefore, qualitative case study allowed me to approach the phenomenon holistically (Schwand, 1994 in Stake 1995 p. 43) and helped obtain “a thick description”, "an experiential understanding", "multiple realities" and voices of participants and their relation to the contexts, and even gain contradictory views of what was happening (Stake, 1995, p. 43). In addition, Kulick and Schieffelin (2004) highlight three important criteria of any study of language socialization: (1) The design should be ethnographic; (2) The perspective should be longitudinal; and (3) The study should demonstrate specific linguistic and cultural practices over time and across contexts (Weldeyesus, 2009, p. 350). The ethnographic method served the purpose "to observe interesting, significant events in order to produce a detailed written record of them" (Emerson, Fretz, \& Shaw 2011, p. 4). The data collection spanned five months (May 2017September 2017). A variety of linguistic and cultural practices was captured through a variety of data-gathering methods: ethnographic observations, informal interviews, recordings of naturally occurring utterances, and linguo-cultural ego-maps accompanied by talk-alouds. All this allowed me to achieve an understanding of family stories with their rich multiple realities, those DNA of family life (Stone, Gomez, Hotzoglou, \& Lipnitsky, 2005, p. 385).

Third, focusing on family language practices to explore family language ideologies, the study followed Linguistic ethnography key assumptions (Copland \& Creese, 2015). 
1) Language and social reality are mutually constituitive, therefore, the language is studied in context;

2) The contexts of communication and meaning making processes should be ethnographically investigated, therefore the examination of language in context encompasses both emic and etic approaches;

3) The language is analyzed holistically and in its entirety, attending to the form, use, and ideology. Such an approach requires meticulous examination of the interactional data (NOCs) in order to understand how social and historical structures and positionings are enacted, re-created or contested in everyday talk.

\section{Participants}

The study intends to explore the life of a multilingual transnational family living in the U.S. and having Russian as one of the heritage languages. The participants of the case study are members of a young full (a husband and a wife) Estonian family with two children which immigrated to the U.S. about 6 years ago in pursuit of educational opportunities. Grandparents are also considered. Their children were born in the US, and both parents are fluent in English. The family keeps Russian as one of their family languages. The mother is of Russian descent and considers the Russian language an essential part of her heritage. The father has advanced low proficiency in Russian on the ACTFL (American Asscation of Teachers of Foreign Languages) proficiency scale. Two grandparents participated in the study. Following Zhu and Li (2016), I call participants "transnationals" considering the interconnectivity across and beyond national boundaries an important dimension of their experience (p. 2).

\section{Data Collection Tools}


For the purpose of this work, I designed and utilized five data collection tools: (1) ethnographic observations, (2) naturally occurring conversations (NOCs), (3) interviews, (4) language ego-maps, (5) a weekly trip journal. I also consider my positionality as a data collection and data analysis tool, for my personal experience penetrated the whole process of the research, data gathering, data analysis, and its interpretation. A researcher herself acts as a valuable "data gathering tool, with skills in listening, observing and understanding” (Stake, 1995, p. 21). Stake (1995) claims that "a considerable portion of all the data is impressionistic" (p. 49). Therefore, there was no particular time when my data gathering in qualitative research began. I recognize that my current observations of the participants were affected by what I had learned about the family unconsciously since our first encounter in August 2012 (see the section on positionality). Moreover, the data collection and data analysis was an iterative process, which was a strength as it allows for theory development which is grounded in empirical evidence (Hartley, 2004). Table 3 displays the data collection timeline detailing the data collection procedure.

Ethnographic Observations. I began with ethnographic observations (Emerson et al., 2011) of daily family routines, widely adopted in language socialization research (e.g., Bayley \& Schecter, 2003; Schieffelin, \& Ochs, 1982), and continued my observations throughout the study. The observation helped me encompass a detailed description of each member's language practices, literacy objects (with the record of their languages) and participants' interactions with them. Such a "microscope" approach (Derry, 2010, p. 6) allowed me "to collect dense, close-toreality information about ongoing human activity in complex learning environments" (p. 9), and provided maximum accuracy of the case for the analysis. I create a gallery of the images of the family place, very often with the help of the family (See Appendix J for illustrations). 
Table 3

Data collection timeline

\begin{tabular}{|c|c|c|c|c|c|c|}
\hline Time & Observations & $\begin{array}{l}\text { Recording of } \\
\text { naturally } \\
\text { occurring } \\
\text { conversations } \\
\text { (NOC) }\end{array}$ & $\begin{array}{l}\text { Trip } \\
\text { journal }\end{array}$ & Interview & $\begin{array}{l}\text { Language } \\
\text { ego-map }\end{array}$ & $\begin{array}{l}\text { Grandparents' } \\
\text { essay }\end{array}$ \\
\hline May 2017 & $\begin{array}{l}\text { daily } \\
\text { observations, } \\
\text { two stays } \\
\text { with the } \\
\text { family (four } \\
\text { (4) days and } \\
\text { two (2) days) }\end{array}$ & daily & & $\begin{array}{l}\text { Occasional } \\
\text { interview- } \\
\text { conversations } \\
\text { with the elder } \\
\text { child, } \\
\text { occasional } \\
\text { conversations } \\
\text { with parents } \\
\text { about their } \\
\text { language } \\
\text { background }\end{array}$ & & \\
\hline $\begin{array}{l}\text { May- } \\
\text { July2017 }\end{array}$ & & $\begin{array}{l}\text { Weekly, at } \\
\text { least two ( } 2) \\
\text { hours of } \\
\text { recording per } \\
\text { week }\end{array}$ & $\begin{array}{l}\text { Mother's } \\
\text { trip } \\
\text { journal }\end{array}$ & & & $\begin{array}{l}\text { two (2) } \\
\text { grandmothers } \\
\text { of both side of } \\
\text { the family }\end{array}$ \\
\hline $\begin{array}{l}\text { July- } \\
\text { September } \\
2017\end{array}$ & $\begin{array}{l}\text { A five (5) } \\
\text { day stay with } \\
\text { the family }\end{array}$ & $\begin{array}{l}\text { Daily during } \\
\text { the stay with } \\
\text { the family, } \\
\text { and weekly }\end{array}$ & & $\begin{array}{l}\text { Interview } \\
\text { with the } \\
\text { parents } \\
\text { (mother and } \\
\text { father) }\end{array}$ & & \\
\hline $\begin{array}{l}\text { September } \\
2017\end{array}$ & $\begin{array}{l}\text { A three (3) } \\
\text { day stay with } \\
\text { the family }\end{array}$ & & & $\begin{array}{l}\text { Follow up } \\
\text { interview } \\
\text { with parents, } \\
\text { clarifications }\end{array}$ & $\begin{array}{l}\text { Mother } \\
\text { and } \\
\text { Father- } \\
\text { think } \\
\text { aloud } \\
\text { interview }\end{array}$ & \\
\hline
\end{tabular}

Naturally occurring conversations (NOCs). To gain rich and authentic data on human interaction, I collected spontaneous naturally occurring conversations via audio recordings (Atkinson, \& Heritage, 1984), accompanied by ethnographic observations. Naturally occurring utterances are a valuable source of language behavior. The method is also widely adopted by linguistic studies in sociocultural tradition (Dopke, 1992; Lanza, 2009). The efficiency of using 
recorded data is also emphasized by ten Have (1990). Underlining its indefinite richness in empirical detail, ten Have states that it could "never be produced by the imagination of anybody" (ten Have, p. 2), and therefore serves as a pillar of truthfulness to observations. To support his thought, he refers to Heritage and Atkinson (1984):

(T)he use of recorded data serves as a control on the limitations and fallibilities of intuition and recollection; it exposes the observer to a wide range of interactional materials and circumstances and also provides some guarantee that analytic conclusions will not arise as artifacts of intuitive idiosyncrasy, selective attention or recollection or experimental design. (cited in ten Have, 1990, p. 2)

Therefore, in my case taped records were valuable during data analysis, as they facilitated repeated and more scrupulous examination of the interactional event.

The recordings were collected during every of my on-site visits in which I focused on recording any interactions happening among parents and children, children between each other, or children interacting with other adults. During my absence, the parents performed approximately two hours of recordings of meal times, book reading, or game time three times per week, by means of the audio recorder and other literacy events to their choice. During the analysis, I also examined which events were considered meaningful by the parents. The recordings carried valuable information about the parents' input and interaction style. NOCs is a valuable source of language behavior, and widely adopted by linguistic studies in sociocultural tradition (Döpke, 1992; Lanza, 2009).

I also had to consider that my presence was a part of their routine, and some conversations could be provoked by me. 
Interviews. The main goal of research is not limited to the topic of study but learning what is important to those being studied (Rubin, 2005), rich ethnographic description should also include the perspectives of members of a social group, their "beliefs and values that underlie and organize their activities and utterances" (Ochs \& Schieffelin, 1995, p. 477). The elder participants' reflection on and interpretations of their decisions and activities were elicited through open-ended interviews. Qualitative interviewing helped grasp “experiences and reconstruct events in which you [the researcher] did not participate" (Rubin, 2005, p. 3). The interview filled in the gaps in what was not caught during the observation and in the audio recordings, and also served as a catalyst for the observational focus.

I interviewed the parents, the Russian-speaking grandmother (via Skype), and the elder child (the interview was embedded in my every day interactions with her). I conducted two sets of interviews with the parents (see Appendix B for the prompt questions). They were performed after the ethnographic observations with the aim of the first to collect family biographic data, such as parents' language background, languages spoken in the immediate and extended family, the story and context of immigration, and transnational practices in the family, and the second focused on parents and grandparents' ideologies (beliefs and attitudes). During the ideological interview, parents were asked about: (1) their attitudes to and beliefs about multilingualism, (2) heritage language maintenance, (3) language practices and interactions in the family, and (4) their perceived language and ethnic identities and perceived identities of their children, and (5) spaces they navigate in. Member checks were performed through conversations and via emails and focused on the clarification of the observed data and the interview responses, invited the participants (mostly the adults, and occasionally the elder child) to comment on their language 
behavior in particular situations, and also aimed to gain additional information the participants wanted to share.

Rubin (2005) states that an interview is a conversation in which the researcher and the participant act as conversational partners and both shape the direction of the interview. Although there was a protocol for each type of the interview, the process of data collection provided space for some necessary flexibility and spontaneity. Ethnographic observations also informed and elaborated on the themes and questions of the interview.

I interviewed the elder child in the form of a game and focused on where the child realized her engagement in multilingual practices, distinguished among interlocutors and whether she developed and possessed metalinguistic knowledge (see Appendix F for the prompt questions for the child). Instead of the interview, for the lack of an opportunity, the grandparents were asked to answer the questions in writing (see Appendix D for the promp essay questions for the grandmothers). I also had a chance to converse with the Russian-speaking grandmother for 40 minutes via Skype and meet her briefly in person when she was visiting her daughter's family in October, 2017 (see Appendix E for the prompt questions).

Ego-maps. Ego-maps (Richter, 2012) were administered at the very end of the data collection period and helped glean the parents' conscious account of how they defined themselves and where they stood in their connections to places, objects, languages, and people. Imagined and presented visually by the participants, the data allowed me to understand the adult participants' perception of heritage and their identities. First, the participants (parents) were asked to divide a circle into sectors representing languages they speak and identify themselves with. Then, they were invited to write what connected them to that language and how (what domains of life are related with a particular language center: intellectual, emotional, professional, 
social life, etc.). The participants' comments during the ego-map task were recorded and constitute a talk aloud data (see Appendix G for the protocol for the language ego-maps).

A weekly trip-journal. Both parents were asked to keep during the trip journal, when the family was on two months' vacation in Estonia, with the project's purpose to gain parent's account of changes in children's and personal behavior, traversing the socio-cultural-linguistic space. I generated question prompts which the parents were expected to use to register their observations of their and their children's language behavior during their travelling (see Appendix $\mathrm{C}$ for the guding questions for the parents). Only the mother provided such a journal, the father opted to withdraw from this data collection.

Table 4

Phases of empirical design and the scope offocus of the data collection tools

\begin{tabular}{llcccccc}
\hline Phase & Method & Language & $\begin{array}{l}\text { Discursive } \\
\text { context }\end{array}$ & People & Time & Space & Ideologies \\
\hline 1.1 & Observations & $\mathrm{X}$ & $\mathrm{X}$ & $\mathrm{X}$ & $\mathrm{X}$ & $\mathrm{X}$ & \\
1.2 & $\begin{array}{l}\text { Naturally } \\
\text { occurring } \\
\text { utterances }\end{array}$ & $\mathrm{X}$ & $\mathrm{X}$ & $\mathrm{X}$ & $\mathrm{X}$ & $\mathrm{X}$ & \\
2 & $\begin{array}{l}\text { Biographical } \\
\text { and } \\
\text { ideological }\end{array}$ & $\mathrm{X}$ & $\mathrm{X}$ & $\mathrm{X}$ & $\mathrm{X}$ & $\mathrm{X}$ & $\mathrm{X}$ \\
$\begin{array}{l}\text { Interviews } \\
3\end{array}$ & $\begin{array}{l}\text { Language ego- } \\
\text { maps }\end{array}$ & $\mathrm{X}$ & $\mathrm{X}$ & $\mathrm{X}$ & $\mathrm{X}$ & $\mathrm{X}$ & $\mathrm{X}$ \\
4 & $\begin{array}{l}\text { Clarification } \\
\text { interviews }\end{array}$ & $\mathrm{X}$ & $\mathrm{X}$ & $\mathrm{X}$ & $\mathrm{X}$ & $\mathrm{X}$ & $\mathrm{X}$ \\
\hline
\end{tabular}

The complex and holistic approach of this research project, combining emic and etic methods, to describe even more complex and diverse family experiences, is reflected in the 
variety of data collection tool and the ability of each of the tool to gaze at various variables and is presented in Table 4 . The table also shows the sequence of data collection stages.

\section{Positionality}

"Research represents a shared space, shaped by both researcher and participants" (England, 1994, in Bourke, 2014, p. 1). The researcher's positionality provides a filter for the whole study and its results and constitutes a special space of consideration in the project proposal. I have to recognize that my socio-cultural experience influences my research process and the interpretation of the data, and I am entering the project with prior assumptions, biases, and even misconceptions.

I position myself as a transnational individual and a researcher, who has been living abroad for the last nine years, but who has been engaged in multicultural understanding and experiences from many years earlier, who has numerous bi/ multilingual friends and who is acquainted with many immigrant families, and who has just created a multilingual/ multicultural family herself. I speak Russian as my native language, and English; and throughout my life I also have made attempts to study Spanish, Italian, and French for different reasons, primarily for communicative purposes and for the appreciation and understanding of the heritage of people I have encountered in my life journey.

I am a Russian born in the Soviet Union, and possess vibrant memories of the Soviet times, Perestroika and the chaotic transition of the 1990s. I remember my place in the Soviet state and the place of my family in it scattered around former Soviet republics. I rmember the holiday cards from my grandfather's sisters featuring funny Russian with unknown foreign letters and wrong non-Russian spelling of familiar words, as I perceived it at that time (later, I would learn it was Belorussian and Ukrainian), packages from Riga, where my uncle lived 
(which had that succulent western foreign flavor), and my mother's long and meticulously written letters to relatives, all taught me that there were different places with not quite Russian languages and cultures, and that Soviet republics were not all the same. Then December of 1991 thundered and split the country into 15 independent states, reviving the development of the national languages and cultures as part of the national self-determination. News about the Russian population and the status of the Russian language in former Soviet republics flooded the media. I could hardly hide my indignation and pity for the Russian speaking population and the right to the heritage they were deprived of. Then I studied world languages and cultures, then came to the U.S., and plunged into a more diverse multiculturalism, and then I met my participants.

The participants were the first people from Estonia I had met in my life. The Estonian government fought very hard for the Estonification of the country, granting citizenship to nonEstonians only upon the successful completion of a very hard Estonian language test. It was exciting to meet an Estonian who had been teaching Russian at a secondary school in Estonia and whose mother was Russian. Our first encounter could mark the first day of my field work for the coming project. The research process had started long before the first research question was generated. Thus, the whole process of research is engrained in my reflection on my previous numerous encounters with the family, on my knowledge about the family history, on parents' ideologies, aspirations, life goals and vision of parenting, on being the participant's friend and a colleague of theirs in the World Languages Department, and the smilarities of language and professional backgrounds.

The participants' qualities are also worth acknowledging as reasons for including them in this research. The participants' socio-cultural consciousness might have built certain assumption 
about my persona and my ethnic and linguistic background and could affect their home linguistic and cultural behavior, as well as the information they wanted to share with me during interviews. The family also might have influenced the research with the way they perceived themselves and the way they presented themselves. They had total freedom to share with me what they considered important, relevant, and illustrative of their experiences. "Identities come into play via our perceptions, not only of others, but of the ways in which we expect others will perceive us" (Bourke, 2014, p. 1). The research recognizes the participants' active work in the construction of their identities during the interviews and treats it as an illustrative example of how fluid and dynamic identity is. On the one hand, the participants might have felt comfortable sharing with me their life stories, on the other hand, knowing me personally, they might have decided to consciously omit certain episodes of their live.

Thus, I position myself as both an insider and an outsider of the participants' experiences and their context. I am insider for the shared professional and some socio-cultural experience. They can share more and behave naturally as they feel safe and comfortable in my presence and interacting with me. As an outsider, the fact that I am Russian, who has never lived the life of anyone from a satellite Soviet republic, can obscure some of their linguistic, cultural and ideological experiences. Our language identities might clash in contact. Therefore, I have to be careful about this influence.

My subjectivity intermingles and intertwines with the participants' contexts and experiences, and affects the design of my project, and will influence both my interpretation of the data and the reporting of research findings. Acknowledging the role of all research actors, the researcher and the participants, in the execution of the project, I gain a deeper and better understanding of the problem. "There's no enunciation without positionality. You have to 
position yourself somewhere in order to say anything at all” (Hall, 1990, p.18). Therefore, for this project, I position myself as Russian, as a transnational citizen, as a friend of my participants, as a researcher of language experiences of transnational families, and as a Russian language educator, who is passionate about observing Russian language acquisition patterns and contexts.

At every step of research, I tried to be conscious of the complex connections and underlying meanings that lie between me, my goal for the project, my research in general, my participants, the research site, and even the results I was anticipating.

\section{Ethical and Theoretical Issues of Data Collection}

Conducting this research, I tried to address all ethical and theoretical issues. Before the data collection I applied for the IRB clearance and all the participants signed consent forms confirming their approval to have their conversations recorded, that they understood what the recording were used for and that they have a right to request to turn of the recording device at any point and to delete any part of their conversation of their discretion. (See Appendix A for the IRB approval letter). Throughout the study the participants did not exercised any intention to cease the recording or the interview, or requested any deletion of any excerpts. However, I sometimes turned off the device on my discretion if the conversations touched upon sensitive family issues. When the family was recording independently, they were in control of the moments caught by the recording. The parents also gave me their consent to keep their real names in the data handing and data dissemination in print, therefore I kept their identifications. Keeping the family member's real names also allowed me to be more personal in describing the findings of the data and the discussion. The names of other participants, not family members, 
were changed. Although those participants did not request that I delete any other identifications of their personas, and they also did not object to my wish to keep those in my text.

It is important to mention that one of the theoretical issues of data collection was Observer's paradox (Labov, 1972a, 1972b; Smith-Christmas, 2016). The question of "how much the awareness of being observed or recorded influenced family natural behavior?" accompanied the whole process of data collection, especially in relation to the corpus of natural spontaneous speech and observational data.

The already established trustworthy relationship with the family, their willingness to participate in the study, and multiple prior entries into the family household before the data collection helped me evaluate family behavior and select the instances which reflected the family normal routines and actual language practices. I was also able to establish the crucial relationship of trust and comfort - so important for observations, interviews, and the recordings of naturally occurring conversations - with the family members, particularly with the children prior the data collection. The elder members of the family were familiar with my scholarly interest in languages, bilingual language practices, and Russian language pedagogy, and were open to discuss and share their insights on their family language use and their overall beliefs and attitudes towards multilingualism, multiculturalism, language policies statewide and family wise. The children saw their parents' friend in me, and it helped to have relaxed conversations with them in a playful manner.

The aim of the study was to gain insight into natural life flow of the family, to capture a truly representative language behavior. However, on several occasions I observed that the parents tried to shift into providing me with the behavior they assumed I wanted to see and to observe. Also at certain points the family members exhibited their awareness of being recorded, 
as on several occasions, the mother inserted almost simultaneous translations of speech acts from Estonian into Russian or English while being recorded.

\section{Data Analysis}

This section presents my data analysis process, including the components and stages of the analysis, my decision-making, ethical considerations, challenges and limitations of data collection and data analysis methods used.

As I stated above the data collection and analysis were an iterative process (Hartley, 2004). I began data analysis immediately during the data collection and continued after the transcriptions of the naturally occurring conversations from Estonian to English. Each data piece was analyzed separately and underwent comparison and contrast in order to "to discover variation, portray shades of meaning, and examine complexity” (Rubin, 2005, p. 202). There were two main processes of data analysis: (1) data preparation and organizing of data, and (2) data coding.

\section{Data Preparation and Organization of Data}

Data preparation. This project engages a variety of data analysis tools. The data collected from each of them underwent careful handling and analysis.

Observational notes. While visiting the family in their U.S. home I fully participated in their family life and observed how it unfolds. I cooked and ate with the family, helped with the household chores, played with the children in the house and at the playground, babysat the children, accompanied them to their story times trips in the library, participated in various family events, such as after dinner walks or cartoon watching, and went to museums and different outings with the family. I tried to live life how the family lived it in order to glean ways of family daily lives, trying to gain insights into how the family language spaces are understood, 
constructed and leveraged, and how each language is lived through. My observations generated observational notes that I was recording in my researcher's journal either during the process of observation or at the end of the day. Simultaneously, I was writing analytical notes, recording my reflections on the observed and experienced. After the NOCs data was transcribed, I chronologically matched them with the observational notes. While rereading field notes, I extended field notes with theoretic, methodological and personal notes.

Naturally occurring conversations (NOCs). The recordings of audio data of NOCs generated 44 hours of audio data of pre, during and after Estonia trip family's conversations. I listened to each of the recordings in its entirety to understand the context and selected episodes with significant multilingual or monolingual literacy practices. The criteria for significance were the instances of the participants' translanguaging behavior, distinctive literacy events in either of the family languages, parents' interaction with each other and with the children, and children initiated interactions. The field notes also helped pre-select significant events. Some of the recordings would not elicit any significant conversation to transcribe but would provide a valuable context for understanding the interaction between the family members and their language behavior. I transcribed the conversations verbatim, preserving all the grammatical forms and pronunciations used by the children. I did not represent the accents, unless it was meaningful for distinguishing between the utterances in different languages.

Interviews. I interviewed each parent, and the Russian-speaking grandmother, individually and audio-recorded the conversations. Later each conversation was transcribed verbatim. 
Language ego-maps. I recorded the conversation during the ego-map task, and collected the parents' individual drawings (see Appendix H for the examples of the parents language egomaps). The interviews and talk-alouds of ego maps were transcribed verbatim.

Weekly trip journal. I created a shared document space on Google docs where parents could individually share with me their trip-journals. I had access to all the updates.

Grandparents' essays. Grandparents written responses were collected via email. I sought for help from and Etonian-English bilingual to assist me with the translation of the essay of the Estonian-speaking grandmother ${ }^{14}$.

Transcription. The selected transcribed NOCs data, underwent translation and transcription from Estonian to English and Russian to English (at the end of the data collection). During the data collection, I was also periodically asking either Meelis or Kristina to translate some Estonian words and phrases for me. I referred to Kristina's help to transcribe and translate indicated parts of Estonian episodes of the NOCs, utterances of herself and of others. The rationale for asking the participants: She was featured on every recording she transcribed, as there was no confidentiality issue involved, and the mother could understand her children's speech better than anyone else. Sometimes Kristina provided me with a gist of the piece and would do a detailed transcription and translation of the pieces I was interested in. Occasionally I asked Annemarii to help me with the translation of the audio material I was listening to, and she developed some interest in my activity. Such extra data collection during data analysis helped me gain a valuable perspective of the child on her individual speech behavior. Using a child as a language broker, I tested child's awareness of practices in different languages and most

${ }^{14}$ Eveline, Estonian-speaking grandmother, knows Russian, but preferred to answer her essay questions in Estonian 
importantly the reaction to the use of different languages. While I was preparing NOCs, going through observation notes, reading interviews and go-maps, I also was taking researcher's notes.

Member checking. The process of data preparation and analysis (at its different stages, from initial to the final stage) elicited a few questions that required the clarification of factual information or the participants' check of my interpretation of the information they had provided in the interviews (formal and informal) and my notes of ethnographic observations. As Kristina's role in the family's multilingualism and overall family language ideology and practices became evident through the data, I looked for more insights into this dynamic in Kristina's bilingual childhood. To do so, I initiated a short 30 minutes skype interview with Olga, Kristina's mother, when she was in the U.S. visiting her daughter and grandchildren in October. I also had a chance to meet Olga in person, during their trip to Morgantown. This additional information from Olga's perspective on Kristina's language behavior, their family context when Kristina was growing up, and Olga's positioning on her own language identity, her being a parent of bilingual children and a grandparent of multilingual grandchildren. I also communicated with Meelis and Kristina via email during the data preparation and data analysis, every time the data posed more questions. Kristina was very engaged in helping me to collect more data about her family and now and then was emailing me her observations about her daughters and pictures of their activities, or would pose questions herself.

Data organization. After transcription, the ethnographic data and NOCs were organized chronologically and merged into pre-trip, during the trip, and post-trip sets, as the family summer trip to Estonia appeared to be a central event of the data collection period. Such organization helped create rich context for NOCs and the overall picture of the organic flow of events for the analysis. 
Next, I color coded conversation in Estonian, Russian, English and instances of translanguaging either by adults or by children, or in the interaction between the adults and the children. I transferred all NOCs data into excel format organized in three relevant files (pre, during and post trip), and identified the time of the conversation, the participants, the language(s) in use, and the type of activity.

\section{Coding}

General approach to coding. According to the principles of the ethnographic case study and making the case speak for itself, I followed Grounded Theory (Glaser \& Strauss, 1967) which allowed me systematic scrutiny of data to identify important grounded themes and let the data exude participants' own voices (emic approach) and lead me in the understanding of their familial multilingual phenomenon. Such an approach helped me "discover theories in data" (Emerson et al, 2001). However, I do recognize the influence of my academic and professional training and my analysis and synthesis of the theories for the literature review on the data analysis process, my construction of understanding and theorizing from the data. All the data were manually coded. I referred to the NVivo qualitative software after I completed all the coding manually to cross compare different data sets.

The analysis was cyclical. Although I recognize that I began applying analytical lens on the data simultaneously to the process of data collection and recording thoughts in my researcher's journal, and continued to do so into the data transcription, I formally distinguished three coding phases: pre-coding, coding, and categorization. Each of the data sets underwent these three phases individually and as a whole.

Pre-coding. Pre-coding included the first read-through of the transcribed and chronologically organized data which also involved circling and highlighting of words, phrases 
and passages without naming. Those were worthy "codable moments" (Saldana, 2015, p. 20).

Pre-coding began during my first encounter with the data, or after its transcription.

Coding. I performed coding in two cycles. The first cycle involved a thorough read through of the data sets in groups: interviews, ego maps, naturally observing conversations, ethnographic notes, and coding for emergent themes. Performing the analysis of the interview data, ego maps, and journal data I applied in vivo coding to give voice to the participant, to name the realia, emotions, and to evaluate their beliefs, positions, life events and life choices.

During the analysis of the conversational data (NOCs) great attention was paid to the context. As linguistic and cultural meanings are highly context-dependent, "researcher-controlled selection, presentation and re-contextualisation of verbal data are critical determinants of its information content... Data are only analysable to the extent that we have made them a part of our meaning-world" (Lemke, 2011, p. 2). Lemke (2011) further states that "language is always used as part of a complex cultural activity. Verbal data make sense only in relation to this activity context and to other social events and texts with which we normally connect them, their intertexts" (p. 4). Therefore, the conversational data were reduced and contextualized according to the needs of the research project - in particular, to grasp each language's space, function, use and ideology in family life. The NOCs underwent an ethnographically informed discourse analysis (King, 2013) (e.g., patterns of language choice, semantic thematic analysis). I also matched the data against Lanza's (2009) interaction strategies categories (minimal grasp, expressed guess, adult repetition, move on, code switching). The NOCs' analysis also focused on: (1) how the parents use the language(s) at home and in their interaction with the child (reaction to children's linguistic behavior), and (2) how the children use the language(s) at home and in their interaction with parents (reaction to parents' linguistic behavior). I tracked the 
parents' and children's language choices and patterns of language use throughout the recordings naturally occurring conversations (NOCs), examining language use consistency, the instance of translanguaging, and trying to identify the factors of language behavior, such as the context, interlocutors, the content and purpose of the talks.

The second cycle of coding involved several read-throughs of the data sets with the aim to compare emergent themes between the data sets within the participant and of the same data sets across participants. For example, if in the interview Meelis, the father of the family, mentioned that a special language system was exercised in their family, I tried to compare his conceptualization of their "system" with Kristina's view of the family language use in her interview and further searched for the evidence of the "system" behavior in NOCs and ethnographic notes. A reverse direction also occurred, when, for example, I during my observation I noticed that Kristina was intensively initiating literacy activities directed to engaging her children in reading and writing. In her interview, she proudly revealed that she herself learned to read at an early age, and perceived early reading practices as a necessary activity not only for language development but children's overall organic development. Then I went back to the NOCs data to search for the contexts and strategies Kristina used to initiate and maintain reading and writing practices of her children.

Categorization. During the third phase of analysis I performed categorization of the emergent themes. (see Appendix I for emergent themes). All the data fell into 10 big categories:

(1) Family multilingual background (context and childhood practices).

(2) Beliefs about languages.

(3) Beliefs about language learning. 
(4) Dynamic character of multilingual ideologies and practices (changing in space and time).

(5) Parents' individual language practices.

(6) Parents' teaching (parents' practices directed to children's language learning).

(7) Children language practices.

(8) Languaging identity.

(9) Language management.

(10) Language dimensions.

It is difficult to draw demarcating lines between those categories as life experiences are complex and human practices are interwoven into a web of diverse meanings. These categories provide pathways to addressing the project's guiding question "What are the cultural, linguistic, and ideological spaces in which the family navigates?"

Such an iterative approach to data analysis allowed me to fully engage with the data, and develop data reorganization and re-coding, shaping the focus of the analysis as not only the new data but as new visions of the data were coming into the analysis. Code recycling did not prevent the generation of new codes. Multiple read-throughs provided space for new codes to appeare. The generation of analytic memos, "sites of conversations with ourselves about our data" (Saldana, 2015) accompanied all stages of engagement with the data. Multiple re-readings of the data and constant comparison and contrast between the data sets, participants, contexts helped reach "heuristic fluidity... to prioritize insightful qualitative analytic discovery over mechanistic validation" (Saldana, p. 9, 2015) in coding. 
The overall analysis of the data proceeded from reflectivity to reflexivity - from observation, description, introspection, to making connections between what has been observed in the present case and my knowledge of other cases (Zhu \& Li, 2016).

Whilst reflectivity emphasizes critical evaluation and analysis of the available evidence, reflexivity promotes the incorporation of the subjective, that is, the analyst' s own position, experience and knowledge accumulated and synthesised through previous research in similar as well as different situations, in exploring the understanding or rationale related to questions of what, why, how and by whom. (Zhu \& Li, 2016, p. 3-4). The actual fieldwork process involved four core elements of ethnography LLTT, that is, looking, listening, talking and thinking. As it is a transnational family ethnography project, special attention was paid to spatial and temporal connectedness and "relational thinking" (Enfield, 2013 in Zhu \& Li, 2016), including contacts with extended relations living in other parts of the world, as well as the variety of the family's contexts - temporal and spatial, historical, political, economic, cultural, social, and personal.

Theorization. Relying on analytical memos and the findings of the analysis I was able to theorize about the ecology of family multilingual life: how the family conceptualized languages, and multilingualism, how linguo-cutural spaces are ideologically and practically created, developed, and crossed by family members, and how those spaces function in a broader environment.

\section{Limitations and Challenges of Data Collection and Data Analysis}

\section{Myself}

I felt that my presence affected the language behavior of my participants, despite my attempts to keep an impartial posture. I was a source of the Russian language for the girls, and 
for Kristina, and actively participated, and was expected to educate. Moreover, it affected the features of the conversational data collected: a lot of interactions observed were in Russian. I performed multiples role simultaneously and alternated among them: a language educator, a researcher into heritage language socialization and family language policies, a family friend, a babysitter, an adult, and simply a bilingual person in their environment. Such multiple positions, on the one hand allowed me to experience the participants' life from various angles and lessen the effect of the Observer's Paradox (Labov, 1972a) but, on the other hand, it might have affected my analytical assumptions.

\section{Limits of time and my absence}

Time was one of the limitations on many levels. The project of this nature required a more longitudinal data collection, as the children grow fast and quickly pass through the stages of overall physchological, physical, and also language development, and language socialization. These rapid changes in children's performance constitute a very valuable material for analysis, and the findings of the research could have benefited from a longer observation period. During the analysis it was unclear, sometimes, if a certain linguistic performance was the children's behavior ignited by the parents' activity or a simple developmental change, as the children were maturing.

Another limitation was a lack of possibility of spending time with the family and taking ethnographic notes during the trip and the family stay in Estonia. This circumstance reduced the amount of contextual information available during the analysis, and I had to rely entirely on the family recorded NOCs and Kristina's journal.

\section{Lack of competency in Estonian}


Although, thanks to my academic training in linguistics and professional experience with languages, I could distinguish Estonian language patterns from other languages, my lack of knowledge of Estonian was a challenge in understanding the dynamics of family interaction in Estonian, between the father and the children, between the parents, and during the trip to Estonia. I could not derive the patterns of switching between Estonian, English, and Russian when such cases occurred. As a result, I might have naturally been more attuned and meticulous about English-Russian episodes rather than Estonian. The process of selecting the Estonian episodes for transcription and translation was a tedious task when I had to rely on my intuition, and ethnographic observations. 


\section{CHAPTER 4: FINDINGS}

In this section I will report on the findings of the analysis of the study starting with the family members' profiles and developing the narrative into the data-driven examination and the family's language socialization, instantiated in their every day language behaviour, language decisions, and their reflection on their linguo-cultural background, language choices and practices. Then, I will move towards illustrating the Kiisk's family language policies, starting with the findings on parents' beliefs about languages and language learning, and proceeding towards comparing macro and micro level beliefs. Further, I will detail parents and children's individual language practices and derive the principles of family language policies. I will conclude this chapter describing the process how the family negotiate their identities through language choices and practices.

\section{Family Profiles}

\section{The Kiisks}

They moved to the U.S. in 2011 to pursue educational and sport opportunities. Being both engaged in shooting since teenage years - Meelis works with a rifle and Kristina does pneumatic pistol shooting-they had visited quite a few European championships and considered the United States the place where they could boost their opportunities both in gaining a degree and enriching their experience in international shooting scenario. To some extent the choice of the destination was determined by Kristina's familiarity with the U.S. due to her BA years in an American university on the East coast.

They both were born and grew up in Paide, a small town about 57 miles to the south from Tallin, the geographical heart of Estonia. About 8,000 people reside there: $92 \%$ Estonians, and 4 $\%$ Russians. 
By the time they were boarding the plane to Washington DC, Kristina had already earned a MA in Translation from a university in the UK and was working full time teaching foreign languages (English, French, and Russian) in secondary school, and Meelis just finished high school and hauld his sails up for the wind of new opportunities. The young family followed the admission letter which provided Meelis with a generous athletic scholarship and BA tuition waiver. Kristina got accepted into a MA in French program and received a graduate teaching assistant position at the same university. While living in Morgantown, they acquired a lot of international friends and were exposed to diverse cultural experiences through the shooting team and world languages community. Sometimes they also had to share their lodging to cut the expenses. They co-habitated with an American graduate student one year, and a French student another year. They also had their friend from Estonia staying for three months with them and helping them to take care of their first child, and then Meelis's mother stayed for almost a month. They had their first child when Kristina was completing her MA studies and they stayed at the University for two more years, and had their second daughter.

Presently, they live in a cozy small town in Northern Virginia. The town vividly lacks cultural diversity. Most of the residents are Americans (Caucasian). Meelis is working for an IT company and Kristina is a stay at home mom. They are sharing the house with their friends, a Japanese-American couple. The Kiisks live in the well-equipped two-room basement in a twostoried town house, and the two families always interact during meal preparation time, breakfasts and dinners. They have game nights together, pumpkin carving or help each other to watch the children. Recently, Kristina started babysitting their child for half a day, while the parents are at work. Major interaction happens during the weekend, when everybody is at home, and the rolling laughter or sobbing of the little ones permeate the house from the basement to the top 
floor and out. One of the house residents is a dog, who appears to play a special role in language socialization of the household and multilingual development of the children. The Kiisks visit Estonia, their home country, every year, for different periods of time. The longest stay was three months and the shortest two weeks. They are very active and spend their weekends out, either visiting museums, or picking vegetables in the farms of their friends, or going to concerts.

A big Estonian flag covering a substantial part of the wall above their couch in the living room is the first thing that a visitor's eye may catch. Those blue, black, and white confident stripes seem to bring them closer to home. They brought it when they first came here in 2011; since than it has had substantial presence in their household. Over the years many more posters and wall crafts have been welcomed by the walls of their household that moved from Morgantown to Purcellville. They are in English, Japanese, or French, and were gifted by family friends on the birth of the children.

The fridge is spotted with the magnet-cards of the family, each commemorating a new year being together. Here and there, one also finds colorful letters, from both the Latin and Cyrillic alphabets, coexisting peacefully together, and vividly exemplifying the harmonious multilingual "system". The letter-magnets are always there on the fridge, by the table, within the reach of the children's hand - grab them and create. Slightly torn edges show they have been in good use.

For many months Annemarii, the elder daughter, had a whole room for herself. The room was also a storage for all their toys, children books in different languages (I could see there Russian, Estonian, English, French books) and games. After the family came from a trip to Estonia, they moved the two girls together, keeping the room as an alcove of children space and babies joy. It increased the children's interactions and created new dynamics between the sisters. 
The number of English-script literacy objects is ample. Notes, print outs with schedules, and interesting family things, calendars, post card are in English. Recently, the family acquired a toy house and the English script is evident. There are also two posters with the names of the girls in Japanese on the wall. (see Appendix $\mathrm{J}$ for illustrations). Overall, it is a very literacy friendly and multilingualism-provoking environment.

Meelis is bilingual; he started learning English at school, what would be characterized by additive bilingualism, and Kristina is simultaneous bilingual in Estonian and Russian, and additive multilingual in English, and French. Their children are simultaneous multilinguals, as they are naturally acquiring Estonian, Russian, and English.

\section{Children: Annemarii and Keiriin}

Annemarii and Keiriin are the daughters of Meelis and Kristina, two little girls who are the genuine reason and a driving force for this inquiry. I have known these girls since they were born, and even before. Observing their parent's preparations for their births, name choosing (both names are Estonian), and stocking up the shelves with children's literature in Estonian and Russian, I could capture their future language environment at home. There were also confident talks about "one parent - one language" system the parents wanted to practice with the children. When I began my observations in the family, Annemarii was turning three years, and Keiriin was only 14 months. They were not only in different stages of their language development then, but also had been experiencing different environments which were accompanying that development. Despite both being born in Morgantown, while their parents were at the university, still studying or working and the maintained language policy in the family, each of the children experienced their own individual linguistic and cultural composition. 
Annemarii. Annemarii is a lovely girl who loves reading. She is always dancing, always singing, and always eager to braid my hair. Here she comes in her blue princess dress or a princess cape, made from small blankets. She does this on her tiptoes, gracefully.

During the project, she speaks Estonian and Russian fluently, and also is very communicative in English. She definitely understands more than she can say. During the span of my research, she greatly developed and improved her competency in English, communicating more with the English-speaking members of the household, English-speaking gadgets and the dog. Also after the trip to Estonia, her parents started expressing more interest in providing their children with an English input in the form of various videos and songs.

When Annemarii was born, there happened to be a lot of Estonian in her first year (she would receive a richer Estonian input than her younger sister). When Annemarii was only one month old, the Kiisks spent two weeks in Estonia in summer, followed by a family friend coming from Estonia on a visit for three months. This friend was helping Kristina to care for the child, and later Meelis's mother stayed with them for a month performing her grandma's duty. Annemarii has also been in Estonia four times on the trips of various lengths, the longest was three months when she was 12 months old and the shortest - two weeks. Thus, there was a substantial amount of Estonian around Annemarii during her first months.

During her second year, Annemarii was intensively exposed to French from a French graduate student, Jasmine, who shared an apartment with the family, and even occasionally babysat Annemarii. That woman still has some fond attachment to Annemarii, because she saw her "awakening" (her own words). Being fluent in French, Kristina and the young French woman held conversations in French. There were books and games in French. They also welcomed friends from Germany, Slovenia, and Poland, people who were either Meelis's colleagues from 
the rifle team or Kristina's colleagues from the World languages department. The language of communication would be English, but Kristina would encourage everyone who stepped over their threshold share a piece of their language culture with the children.

When in September 2016, the family relocated to Northern Virginia, they enveloped themselves into a new linguistic and cultural environment. Japanese became a new language in their household, as they moved in with a Japanese-American family. Japanese culture is pervading the house now, Asian food is abundant, and communication with the children in Japanese is encouraged by the girls' parents. The week they moved, in Kristina and the Japanese lady, Aki, bet when Annemarii would speak a Japanese phrase independently and functionally, Kristina would treat Aki to lunch. And Annemarii did, at the end of that very first week.

Thus, in Northern Virginia, both girls spent more time with their mother during the weekdays. In Spring 2017, around Annemari's third birthday, she started attending a Russian kindergarten once a week. Meelis drops her off on his way to work at 8:30 am and picks her up at the end of the day a 5:30 pm. The choice of the kindergarten was a meticulous adventure, as it reflected Kristina and Meelis's values of good childcare, in particular, for the children have to have a versatile schedule with literacy and physical activities, some art classes and the facilities to have a good afternoon nap, and, of course, homemade healthy meals. The kindergarten is run by a Russian immigrant family, and "reminds of our old good kindergartens where children dance and sing to the real piano", says Kristina, and learn rhymes for every action they do and every object they see, Kristina and Meelis mutually agreed. In the Fall, they increased the number of days in the kindergarten to two days a week, Wednesdays and Fridays. Annemarii made some friends in the kindergarten and actively attends their birthday parties. 
Although the kindergarten is in Russian, there is a class of English in their curriculum. Kristina thinks the kindergarten experience might be the catalyst of Annemarii's increased instances of "how is it in English" inquiries in the fall 2017. This interest might be attributed to her psychological maturing and linguistic development. The English input around her is abundant: the library story times, her parents switching to English when they speak with each other or with others, there are household devices that "speak" English, and the dog, Choco, whom she perceives as English speaking.

The observation caught the age when Annemarii was very productive with her languages and imagination. She often invents her own language, and sings in it, or even tries to push this communication on her parents. Kristina calls it "Annemarii" language.

Keiriin. Keiriin is the youngest of the two children. "Madame Nyet" (a mix of Russian and French, in English: "Miss No") and "professor" are her two nicknames reflecting her relevant behavior. She is more quiet, and more of an observer. This research found her at the age of one year and three months, when she was trying to speak at a word level, some of which were more comprehensible for her mom and dad. In May, Kristina and Meelis commented that Keiriin was more competent, and therefore productive, in Russian. Meelis started working full time after she was born, so Keiriin has been staying with her mother and sister for the whole day, using Russian as a major language of communication. There has been quantitatively more Russian around Keiriin than Annemarii was exposed to at the same age, as Keiriin has also been receiving input from observing the language use between her mother and her elder sister. Annemarii's kindergarten days provided Kristina with more quality time for Keiriin, as she feels that her younger daughter was lacking the attention Annemarii was getting when being Keiriin's age. When Keiriin was three months of age, the Kiisks spent three months in Estonia. Age wise, 
Annemarii's experience with her Estonian babysitter could have similar language conditions as Keririin's three months in Estonia.

Keiriin's exposure to French differed from Annemarii's. Although she was exposed to French during her first three months (as the French young woman was living with the Kiisks), it was expectedly limited, as attention was drawn to the elder child, Annemarii, who was more manageable and "fun" (Jasmine's words).

During the observations, from May to September, Keiriin exponentially improved in her speaking, due to developmental progress at this age. In the May observations and recordings she was almost silent or echoing the adults and her elder sister. In September, she behaved more vocally; she initiated games and other activities.

Being quiet and not verbally active at her age, Keiriin is not a passive participant of the family language experience: she is an active interlocutor for her sister's socio-cultural plays, she initiates certain language use when mother or father exercise their language policies. She is an active recipient of the rich language and cultural input that is enveloping around her.

Language development: comparing Annemarii and Keiriin. In terms of the children's language development, both girls have been bilingual from the moment they started responding to the language stimulus and producing their own first words. Kristina shared that Keiriin would speak more than Annemarii at her age. She repeats more, produces longer words, and more full words, not onomatopoeic substitutes for words.

Parents state their daughters' first words were mostly in Russian. Annemarii said «пуп» (belly button) and «папа» (father). But Russian was not her only language, as by the time she was 20 months old Kristina said Annemarii's list would count to 50 words, and she had vocabulary in three different languages, Russian, Estonian, and English. By 21 months, her 
vocabulary exponentially exploded. Although Kristina stopped keeping track of Annemarii's vocabulary, but said that by the age of two Annemarii "was.. really good." In contrast, Keiriin started speaking later, but she appeared to have been more adept to picking up the languages. I observed her repeating words clearly and with enthusiasm, absorbing the language like a sponge. Kristina provided the following illustrative example, «Annemarii would do «au-au» for the dog, and she wouldn't use a word «sobaka» (Russian for «dog»), although she had much more complex vocabulary under her belt. But she thought «sobaka» was «au-au», she expressed it this way from the very beginning, and it took her awhile to get to the word. So it took Annemarii some time to transtion to full word level. But Keiriin goes more into the linguistic side than just a sound, and distinctly says full words, for example, «sobaka».

Another difference is the language the children used for regular communication. As a result of her early linguistic context (described above), Annemarii spoke more words in Estonian than Russian. Kristina evaluates that "Annemarii was a little more, ... not fluent, ... she would have more vocabulary in Estonian than in Russian, but she understood everything perfectly for her development for her age". Evaluating Keiriin's knowledge of Estonian, Kristina stressed that "Keiriin has to struggle a little more with Estonian, understanding wise, but she is doing ok, she is not falling behind."

More translanguaging is evident in Keiriin's case. Being more fluent in Russian, she uses Estonian words in some circumstances to respond to her mother. Kristina suggested that Keiriin chooses easier words in terms of pronunciation, which are shorter and more concise in Estonian. For example, "aitah" (Estonian for "thank you"), "kõik" (Estonian for "that's all”) equally understanding their meaning in Russian. When she is asked to say thank you in Russian "Skazhi spasibo" (Russian for "say thank you") - Keiriin says "aitah", (thank you) in Estonian. 


\section{Kristina}

Kristina is the mother of the family and definitely the core of the family's language behavior and policies, as the observation showed. Her beliefs about raising children in a multilingual environment and multilingually are very strong, primarily due to her own naturally bilingual childhood, her educational and professional experiences revolving around languages and learning languages, and most importantly, her perseverance, as Olga, Kristina's mother repeatedly mentioned.

Kristina identifies herself as Russian culturally (“русская”), but not a Russian citizen (“россиянка"), an Estonian citizen but not Estonian. She clearly differentiates between cultural ethnicity and citizenship, and observes how conveniently the Russian language distinguishes between the two concepts, although Estonian has just one (“Эстонка" vs. “Эстонка"). She comments on how it makes sense in Russian to distinguish between the two.

When I think about Kristina, I picture her mixing up her essential oils or searching for recipes for the crockpot or reading to her daughters or hastily dressing up and finishing combing her hair while pushing a stroller out to the porch executing the mission to make it on time for the story time in the Purcellville library, every Tuesday at 10 AM. It is 9:50 AM and the girls are still hesitant to choose which shoes and hats to choose for going out. Ready, set, go!

Now, Kristina is a stay at home mom, and does casual tutoring or babysitting jobs. She also does translations from French to English, and from English to Estonian, providing a rewarding opportunity to use her translation degree. Fluently speaking Estonian, Russian, English, and French, and having attempted studying other languages formally, she enthusiastically welcomes languages and cultures into her life, through people she encounters 
and interacts with, through traveling and exuding that overall openness to world diversity in everything she does.

Kristina grew up in a bilingual, or even trilingual family. Her mother, Olga, is Russian. Her father was also born in Russia but into a German-Estonian-Finnish family. His mother was a Volga German by ethnicity (those Germans who settled along the Volga river during Peter the Great's and Ekaterina II's times), and shared the destiny of many who were exiled to Siberia during 1930s-40s. The Volga Germans lived autonomously for many centuries, preserving their language and culture, and Kristina's grandmother started learning and using Russian more consistently only after moving to Siberia. Her grandmother never acquired native-like fluency in Russian, with all the complexity of the language and eloquence that formal education gives, and started forgetting her German. After she married to an Estonian-Finnish man, Kristina's grandfather, Russian became the common home language, and the children (Kristina's father and his brothers) went to a Russian school. Being educated in Russian the children also self-taught themselves how to read and write in Estonian. Kristina remembers that her father was literate in both languages, and would go to the library to read in both Russian and Estonian, although spoke the latter with an accent and made minor mistakes.

Kristina spent a lot of time at her grandparents' home. Occasionally, her German grandma spoke to her in German, and her grandfather taught her how to read and write. Olga, Kristina's mother, remembered that there were a lot of books in that house, both in Estonian and Russian. Kristina learned to read very early, at around two years and eight months. It was her grandfather's achievement.

Thus, Kristina's language portrait is very complex. Being exposed to various linguistic and cultural self-expressions within the family she also was experiencing bilinguality beyond 
home, for life in Estonia always flew by in two languages, Russian and Estonian. She also witnessed the transition of Estonia from the Soviet republic to an independent state, and the rise of Estonian as a more prominent national language. However, she never stopped speaking Russian at home, even being fluent in Estonian.

Although Kristina was using Estonian and Russian "almost interchangeably”, she has developed distinct relationship with those languages. This relationship reflects the degree of proficiency in the language and the necessity of the language for communication in the urgent context. She considers Russian her prevailing most spoken home language, "which is more spoken than anything", and which she understands "120\%", and Estonian as her first language.

Despite being able to read in Russian at the age of three, reading lavishly, speaking Russian at home and having regular trips to her Russian grandmother in Russia, being enrolled into a Russian course at the secondary school as part of her foreign language curriculum - more against her will and to her prolonged regret - and yet successfully performing in Russian language competitions and contests, and taking a graduate course on translating into Russian for her MA, she feels uncomfortable expressing her thoughts, emotions and feelings via this language. She affirms she has never actually read in Russian, or has not read enough to be fluent and feel comfortable, "I have a trouble reading fast. First it takes me slow, because of a different alphabet, but I can read and write. Just don't ask me to write an academic paper in Russian, because I never really learned in Russian, in an academic environment." Kristina says that over the years, after she immersed herself into transnational life, her Russian deteriorated even more, as she lacks practice and is far away from her mother and her "русскоязычная коммуна» («Russian speaking community») of cousins. Her cousins are more Russian speaking, as they experienced formal education in Russian in Estonia. Today, she does not read in Russian 
anything beyond children books, and does not watch Russian TV which was an integral part of their household routine in her childhood.

Moreover, she clearly recognizes and distinguishes deficiency in the quality of Russian in grammar, the depth and the width of vocabulary, overal literacy - she was exposed to when growing up. Her better Russian speaking and Russian educated cousins performed more eloquently compared to the language she was exposed to from her mom with technical education, her father and multilingual grandparents. Kristina repeatedly emphasizes the signficance of formal instruction in the language for language development and growth. Therefore, she assocites herself mostly with Estonian: "My first language is Estonian, because I can read and write, and majority of my friends were Estonian." She also emphasizes that out of all her cousins she and her brother and sister (who are twins) are the most Estonian-speaking, as they were more exposed to pure and correct Estonian languge growing up.

Despite her "non-sufficient and decaying" Russian and a challenging struggle to find words in Russian, Kristina resolutely invests her time and effort into maintaining a Russian-only language policy with her daughters now, for the linguistic benefit of this adventure. In her trip journals she shared, "Russian is a choice language for me since I really want them to benefit from me being multilingual and being able to teach them multiple languages." Kristina initiated sending Annemarii to the Russian kindergarten, and actively participated in the search of one. Meelis also experienced the outgrowth of Kristina's love for languages and her perseverance. On Meelis's graduation from high school, she gave him a Russian book to practice his Russian, but he did not show any enthusiasm in putting more effort into interacting with Russian beyond his communication with Kristina's family. She encouraged Meelis to take a semester of Russian in college, planning and executing the idea of having Russian as one of the family languages. "Go 
and learn, I'm giving my children this language resource [Russian]', responded Kristina to Meelis when he expressed concern that his children would speak a language he did not understand. When in my circle, she nudged him a lot into speaking Russian. Remembering their dating years, she shared,

“Teaching Meelis Russian I even said, "We are gonna read a page of a Russian book every day". But not conversationally. I tried to push him a little more that he would learn Russian and practice Russian. With my mom I would like him to speak Russian more, but he was never really enthusiastic about it. So, I dropped it.” (Interview with Kristina, July 28, 2017).

She never speaks with her children in Estonian for communication purposes, but allows herself to correct their Estonian, and helps them find the right equivalents in Estonian to facilitate their communication with their father. However, Kristina shared that it is "strange, controversial, and feels foreign" to use Estonian with her children while "looking into their eyes" after having communicated with them in Russian since the moment they were born. She confesses that the words come out easier in English rather than Estonian. In one of our last conversations, she confessed that she could not wait till the children would grow a bit older and they could move back to Estonia and she would speak English to her children.

A mouthful of other languages left meaningful footprints in Kristina's linguistic and cultural life. Her studies of French began in the secondary school, continued into a semester of a study abroad in France during her BA, and culminated in receiving a MA in French. She also devoted four semesters to Spanish, and took a semester of German, to "validate her German roots". Kristina reads in different languages, prefers English though, as they live in an Englishspeaking country. She has many international friends, enjoys watching French films and listening 
to French music. Calling herself a language fan, she says she cannot leave it to the natural occurrence of things and let it vanish. Kristina is determined she will teach and encourage her daughters to learn other languages as well.

\section{Meelis}

Meelis is the father of the family, and the "pure Estonian input" for the little girls, as Kristina referred to him in her interview. He adores his two little daughters, and regrets that due to his work he does not spend enough quality time with them and cannot participate in their daily routines, observing all the changes occurring exponentially at this age. He works in the IT area, and has to commute about an hour and half to and from work. He works five days a week, usually comes home by dinner time, and tries to devote his evenings to his family, playing with the children in the playground, or drawing, or reading, or squatting uncomfortably but always with a big fatherly smile, in a carton house. The house was invented, designed and erected by his alert engineering vision and skills, from two huge carton delivery boxes. He made a roof, and cut out doors and windows frames. Annemarii and Keiriin love their carton shelter. How many Russian fairy tales have been acted out within those walls and around, how many songs have been sung there, how many cries over the toys the girls did not want to share with each other, how many parents" "Annemariis" and "Keiriins" have gotten swallowed by the house, without any answer. When the children go to sleep, Meelis devotes some time to his rifle shooting practice or does some project work on the computer for his job.

He speaks to his daughters only in Estonian, sings children songs in English for them and with them, and watches Disney animations in English with them. He does not correct Annemarii if she mispronounces words or makes grammatical mistakes. As Keiriin speaks more Russian, he 
does not retreat to Russian, but responds to Keiriin in Estonian, providing her with the language she is expected to communicate in with her daddy.

Being "pure Estonian input", Meelis speaks to his daughters in Estonian, as a part of the family language policy. He was born in the Soviet Republic of Estonia, but experienced official Soviet citizenry for only seven months, as the Soviet Union disintegrated soon after. He remembers himself growing up speaking only Estonian, although his parents, who are both Estonian, had been growing up with two languages, Estonian and Russian, as Russian was a titular language in the Soviet Estonian state. Meelis says, after two decades of not using Russian, and not having a necessity to use Russian his parents' command of the language decayed. Although having a conversation in Russian for them is difficult, they still understand it. Meelis's family does not have any Russian roots, and his exposure to the Russian-speaking population and community was always limited while he was growing up. Interestingly, he married a Russianspeaking woman, and now Russian is an integral part of his household.

About himself, Meelis jokes that he is fluent in 2.5 languages, Estonian, English, and the half goes to Russian. He began studying English in the third grade, and in the sixth grade he had to get enrolled into a second foreign language, which was Russian. He studied both languages untill the end of high school, fulfilling the requirement of the Estonian secondary school curriculum. He considers himself a multilingual person, due to his language and cultural experiences, and is very motivated to provide his children with language learning opportunities, as a resource to better understanding of people and cultures. He states:

The more languages the better because it opens up so many opportunities. I would really appreciate if I spoke three languages fluently... or even more languages. ... Like I, right now, I feel it right now, I would have more opportunities, ... and even when traveling and 
getting to know people, their culture better if I'm traveling, just knowing a language is a big issue, ... when you go travel somewhere and you don't speak a local language it will a lot more difficult. (Interview with Meelis, July 27, 2017).

Meelis says he knows basic vocabulary and common words in Russian and understands “enough of the words so I piece it together from there". He knows enough Russian to get by, but “definitely don't know enough Russian to have a free conversation with a Russian speaking person in Russian." He pushes the responsibility on the schooling experiences with is Russian classes in Estonia, when he would get good grades without effort as the teachers expectations were low and the whole process was not organized well. Another explanation of not taking Russian too seriously is being young and not thoughtful about the benefits of knowing another language. He adds, “I didn’t push myself enough to study harder to actually study Russian more than what was required by my teacher."

During my stay with the family, Meelis would insert a phrase or two in Russian into the conversation with me. He understands what the girls say in Russian and translate it into Estonian, but himself never initiates Russian despite Kristina's vehement push for the use of Russian when the Russian-speakers are around. Meelis took a semester of Intermediate Russian in college. The effort aimed at reaching three goals: (1) the curriculum language requirement at his university, (2) his wife's push towards refreshing his knowledge of Russian, as they were expecting their first child at that time, and were already planning their family language policy, and (3) the fact that he himself did not want his children to speak a language he does not understand. Meelis supports his wife's effort to expose the children to Russian from early on, he "completely liked that knowing more languages from early on makes it so natural for them" and believes in the benefits of development in a multilingual environment. He is happy to take their elder daughter 
to Russian day care twice a week, as he confessed he enjoyed spending more time with her driving her.

It happened that English found more response and urgency in his personal and professional life. Similar to Russian, his access to English was limited, but "it was kind of more natural to study... you are young to use, I had a lot of more input from like surroundings in terms of watching cartoons”. He grew up “looking things up in English, on the Internet I was.. I didn't look up any stuff in Russian, I did in English, starting with movies and TV shows that were in English. I think that's why I was more exposed to English.” Moreover, his school environment was more supportive of English: "the teachers were more strict, and I studied grammar properly, writing properly and everything a lot better." This support might have been happening at the background of a common trend in post-Soviet countries to welcome overpowering English into the state's borders, to establish independency and orientation towards the progressive West. The English language was a resource leading to many educational, economic, and ideological opportunities.

Now Meelis considers English the major language of his personal and professional growth. They have been living in the U.S. for the past six years. They both hold BAs from U.S. universities. He accepts the effects of a domineering English-language environment. Despite establishing Estonian as a family language, the majority of domains he participates in are English speaking. He speaks English at work, and does most of his reading in English, as the concepts he is interested in are available mostly in English rather than Estonian. He listens to music in English, and resolves his basic household needs with the help of English. The space for Estonian is also preserved, but is mostly expressed in writing. He says, 
If I'm at work, everything is in English. But if I do stuff for myself it's mostly Estonian, like if I want to type something up in the computer in the document. Write something by hand, ... it's mostly Estonian. And reading, it kind of depends, if it's an English book, I'll read it in English, but if it's an Estonian book and it has never been translated in any other languages I'd read it in Estonian. So it's kind of mix and match. (Interview with Meelis, July 27, 2017).

It's also "mix and match" between him and his wife, English and Estonian operate together.

His language ego is not limited to the two and half languages he speaks, and is extended to German and Japanese; he is fascinated by German culture, their way of life and the job opportunities it harbors for him, and wishes that he could speak German. He took a summer course of German 100, but it did not extend far. There were teammates from Germany on his rifle team at WVU, and he has traveled to Germany often. Japan is another dream place, because it is connected to the dream of the Olympic Games and the proximity of Japanese culture at this period of their life. Japanese is richly present at home linguistically and culturally, and organically interweaves into the life of every member of their family.

Meelis identifies himself as multilingual Estonian, and assumes that culturally they all will "always be Estonian", despite where they go and where they live. Although he admits that his daughters' linguistic identity will depend on the linguistic context of their schooling. The children can hear him speaking in English, rarely to almost never in Russian, and never in other languages, because he, regretfully for himself, does not speak more.

\section{Baba Olya, Olga, Kristina's mother}

Olga - Kristina's mother - or baba Olya, as I will continue to identify her further, was born, grew up and received her technical vocational education in Bryansk region, the Russian 
part the USSR. She perceived her childhood language and culture as "a mix of Russian, Ukrainian, and Belorussian”, as the region is a borderland of its sort. By now baba Olya has lived in Estonia for more years than in Russia, as she left for Estonia in her early 20s due to job deployment, so common in the Soviet 1980s. She got married and had three children, Kristina and twins, Kristina's younger brother and sister. However, she often visited her home town and took her children with her. Kristina had fond memories of her mom and herself taking a longdistance train from Moscow to her mother's native town to visit her Russian grandparents. All of baba Olya's children are married by now and have children of their own. Her second daughter and her family live in Estonia, Kristina's brother moved to Finland with his family for job opportunities, and Kristina with her family live in the U.S. now. Her sons-in-law are both Estonian.

Olga considers herself ethnic Russian, speaking Russian as her native language. She says that now she knows and speaks two languages, Russian and Estonian. She does not speak English. In our conversation Olga mentioned that she reads and writes both in Russian and Estonian at home. Her Russian reading mostly includes newspapers, magazines, and fiction, and Estonian is taking the space of official papers and newspapers. She learned Estonian gradually with her children and "with the dictionary". Kristina says that her mother does not have a good command of Estonian as she never learned it properly for the lack of necessity, "teaching everyone Russian wherever she has worked”. When Olga moved to Estonia in the 1980s, Russian was a titular language, the lingua franca across the Soviet state. However, during the last decade she had learned more Estonian than she ever has in her life. But, she still might be feeling cautious about her accent and uses Estonian rarely. In contrast to becoming more functional in Estonian, Kristina says that her mother has started forgetting Russian, "the eloquence and the 
fluency of her Russian is diminishing", as she has not been developing it. One of the factors, as Kristina assumes, might be a weak language foundation built on the rural background and technical education of the whole family. Her father was working on the train, and her mom worked in a chemist lab. Kristina asserts that "there were no profound intellectuals in the family, ... my uncle (Olga's brother) was working in the hospital, nobody was writing poems.... And I think it reflects on the [quality of] Russian language she [Olga] uses" (Kristina, personal communication, May, 2017).

Olga's multilingual space is filled up with a complex network of multicultural friendships. Her best friend is a Russian speaking woman from Ukraine, others are Estonians or other Russian speaking from former Soviet republics, who have lived in Estonia for many years and to represent a colorful mix of cultures destined to be united by one language, Russian, still throbbing in Russian speaking communities within Estonian borders.

Olga does not see all of her grandchildren often, as they are scattered around the world, far and close. Observing her children growing up bilingually, in Russian and Estonian, she seemingly supports her grandchildren knowing many languages. In our last conversation over skype, she said she s very proud of her multilingual daughter, Kristina, and all her achievements in successfully teaching her children many languages. She shares, "it helps their overall development, communication and their world outlook", and says she uses both Estonian and Russian communicating with them depending on the situation, "If their dad speaks to them in Estonian, I support that. But I do use mostly Russian." The recordings revealed that she mostly speaks Russian to her children and nephews, but slightly adjusts her language when speaking with her sons-in-law, Meelis and Maadis, as they are Estonians. She inserts a few words in Estonian here and there. 
She was working as a chef on the cruise ship when the research started, and in the summer got the news that she had to leave the job because of the staff cut. She visited the U.S. in the Fall 2017, staying with her daughter and her grandchildren for two weeks.

\section{Eveline/ Eve, Meelis's mother}

I had a chance to meet Eve once, when she was visiting her son's family in the U.S. when Annemraii was nine months old. She stayed for about a month and babysat her when Kristina was working. Eve speaks three languages, Estonia, Russian, and a bit of English. Although she was born in the Soviet Union with the Russian as a titular language, she considers Estonian her mother tongue, and says that Estonian has always been the language of her communication there. She studied Russian in school and can read and write at an intermediate level. She studied English in school and when she was visiting her son's family in the U.S., she was able to communicate. She reads different types of media in Estonian and speaks Estonian all the time. On occasion, she communicates with about ten people in the Russian language.

She has a total of three grandchildren and wants all of them to speak Estonian, especially those who live in a different cultural and language context and experience a lack of Estonian language input. She aligns the knowledge of the language with the national identity, by saying "every nation has their own language", and desires for her grandchildren abroad to be Estonian and absorb Estonian culture through the language. Eve also supports multilingualism and is fascinated that Annemarii is already able to communicate in several languages.

In the next section I will demonstrate how family members' profiles are instantiated and negotiated in their every day practices and their reflections on those experiences. 


\section{Family Language Policies}

To describe the ecology of the Kiisk's multilingual life, I followed the Spolsky's Family language policy (FLP) framework structure, and organized the findings according to the family language ideologies, management, and practices. An individual section will be devoted to the discussion of identities negotiated in and through multilingual practices and ideologies Such organizational approach allowed me to explore family's language socialization processes and their contexts, identify socializing agents and examine their behaviour through connecting the themes discovered during the data analysis with the guiding questions of the study. It helped me derive and describe linguistic, cultural, ideological, identity spaces in the multilingual transnational family in the U.S.

\section{Family Ideologies}

Ideologies in family language policy constitute the beliefs and values about languages, their functioning, and their learning that govern family member's language behavior and decisions about language learning practices. The data showed, shaped by parents' attitudes towards their languages and multilingualism, their own language learning experiences, and their evaluation of affordances of multilingual practices, the family beliefs reflected both microlevel (individual, familial, local) and macrolevel (societal, global) ideological underpinnings. Guided by their beliefs, the Kiisks adopted and have been developing, what they identified themselves as OPOL (one parent-one language) policy. Their family language policy was constructed upon and shaped by their views about languages and about language learning. Moreover, this policy was found to be directed more towards developing multilingual competencies, instead of heritage language maintenance. Through their beliefs and practices, the Kiisks conceptualized multilingualism as a resource and assigned distinctive resource values to each language in their 
family repertoire. Further, I will discuss the findings of the beliefs the family holds about language, and how it is acquired.

Beliefs about the language. The findings on beliefs include parents' understanding of what language is, how it functions at the individual and societal level, and how language status is exercised, and what affordances each language can provide according to that status. The data showed that parents' beliefs about the language translated into and shaped their beliefs about multilingualism, the value of knowing and learning multiple languages, and the process of multiple language acquisition. The study revealed that the Kiisks conceptualized the language in various ways: as a tool, as a resource, and as a social construct.

Language as a tool: "it's opening up the borders". The data showed instrumental view of language was one of the strongest beliefs about language exercised by both parents. The family perceived language as a tool of communication of information and expression of emotions, the key to understanding culture, and building connections with people and cultures. The family's multilingual orientation to "the more the better" was evident in their language profiles, and family language pedagogies, and illustrated the "language as a tool" premise well. For example, on several occasions Kristina suggested that the choice of Russian as one of the family languages was driven primarily by linguistic "otherness" from Estonian and English, and the "heritage" affiliation to the Russian-speaking world, through her Russian roots came second. The parents' stance on language as a tool illustrated in their language ego-maps and interviews. Mapping his languages and their functions, Meelis emphasized that having a variety of languages in one's repertoire contributes to a better communication with different people in various contexts and more efficient knowledge acquisition. In the interview, Meelis defined 
language as an essential tool for human functioning, constructing, sharing, and gaining the knowledge in order to get things done quicker and more efficiently. He shared:

There are so many ways to communicate with people but I think language is something that enables communicating with other people in some straightforward and easily understandable way. When we are younger, when we are young kids we point at things, and most times we understand what is meant, but there are times when we don't understand and I think language is kind of the same thing. If you speak the same language with someone it's very easy to understand, and exactly express your opinions and your ideas and what you have to say and exchange information, so if you don't speak the language you go into more primitive ways to using your body language, pointing at things, so I think there are so many different forms to language, but I think language is a way to communicate and interact with people around us (Interview with Meelis, July 27, 2017).

Comparing not knowing the language to being a child, who is deficiently interacting with the world through gestures and sounds untill she learns to speak, Meelis emphasized the power of the traditional human language to establish connections with people and the world around them. Recognizing a variety of language forms, he highlighted their instrumentality in building the diverse world knowledge and opportunities to which he could get access through mastering those linguistic forms. Meelis shared that he "would really appreciate if I [he] spoke three languages fluently [referring to Russian as his half language]. Or even more languages. Like I, right now, I feel it right now, I would have more opportunities." Thus, by supporting and helping his daughters in their language learning, he was equipping them with a powerful, effective tool of communication with the world, its people, its systems, its rules, etc. Therefore, according to the 
family language ideology, a person can only benefit from possessing multiple language tools which allow them to broaden the scope of successful functioning in diverse communicative contexts.

Kristina also viewed the language as a tool for better cross-cultural communication, as “it's opening up borders, not physical borders but again, this cross-culturalism. If you speak the language you can understand the culture better." Similarly, to her husband, she stated that more language tools created better leeways for connecting to more people, places, and cultures and eventually broadened access to opportunities.

An instrumental approach to language was also evident in Kristina's assigning different functions to languages in her repertoire to convey different shades of information or express her emotions. During her interview and our informal conversations, she often emphasized her dependence on all the languages she speaks, because her rich linguistic repertoire represented her and served her well only in its entirety. She shared:

There's certain languages that pinpoint different things better than others and since I'm familiar with all those languages to utilize it, I feel in those languages and I feel "ok, this is more appropriate exactly what I wanna say". And you cannot really translate it or find an equivalent in different languages (Interview with Kristina, July 28, 2018).

Kristina claimed that she functionally used all the languages she was competent in, and even was able to justify the mixing of languages, such as the use of Estonglish with her husband, and, the use of irregular for the family rule language, such as English with her children.

It is worth commenting on Kristina's occasional switch to English communicating with her daughters to illustrate her instrumental orientation to language. For her it was not a break of her Russian-only rule, with the purpose of exposing her daughters to English, but a purposeful 
instrumental use of English to express the exact meaning she wanted to convey and to signal the warning about undesired actions of her children in a more impactful way, as English would break the natural flow of Russian. She explained that she switched languages when she naturally feels the need. Kristina shared,

“Or English, I sometimes use English for emphasis, to make it fun. It’s different. In Russian I don't know how to say it "it is not negotiable". ... I could not come up with this, when I needed to say it to my kids, I could not come up with it "this is not negotiable”. I could not think of it in Russian, so I started using it in English and that's why I say it. And they know". (Interview with Kristina, July 28, 2017, the emphasis is mine)

I could observe that the children knew very well those disciplinary moments in English, as well as the moments of high praise. "High five!" would fill the room and be happily followed by children starching up their arms high. Thus, The Kiisks use languages as tools to convey and negotiate meanings.

An orientation to language as a tool was also evident in the ways parents coordinated language learning. The parents eagerly supported and invested a lot of their time, effort, and resources into creating opportunities for their children to acquire and master at least three language tools: two home ones, Russian and Estonian, and English, the language of the environment. Russian and Estonian are tools for intergenerational and intragenerational communication and understanding their Estonian and Russian heritage culture, and English is the linguistic key to the global world.

Both parents spoke English fluently and in their interviews and language ego maps emphasized significant role the knowledge of English played in their current educational and 
professional opportunities. They tried to make the most of the chance to raise their children in the English-speaking country with conducive conditions for natural English language acquisition. According to the Kiisks philosophy, multiple language tools increase the ability to communicate with a variety of people and cultures, and broaden the scope of opportunities to get access to an array of resources - for example, economic, cultural, emotional - and contribute to the betterment of life. This instrumental view of language explains parents' initiative and support of their children interaction with other languages, such as Japanese and French. Kristina supported this thought by saying that she chooses to willingly "expose them to that, to give them idea about multiculturalism, linguistic variety in the world."

Thinking about the language as a tool of and for communication, Meelis expressed the lack of preference for imposing any prevalent language on children:

If in that situation they would speak all three languages fluently, I don't really see a reason why, I would like a certain language to be their main language. If I can communicate with them, if Kristina can communicate with them and they can communicate with the environment, that would be perfect (Interview Meelis, July 27, 2017).

He stressed that the need for communication dictated language choice, and as long as the language tool served its purpose, it was "perfect".

Kristina shared her husband's view giving no preference to one of the family languages and aiming to provide her daughters with the linguistic tools and the opportunity to practice their use, “no preference, I don’t care. It depends where life is gonna take them. I just want to give them a good starting point. They will take it wherever they need to take it, so I wouldn't be upset if they were more fluent in Russian than Estonian, I wouldn't not at all, not at all. I'm just giving 
them what I can. And they will make of it what they want and what they can." Orientation to acquiring linguistic tools without any attachment to heritage is evident in Kristina's words. It is clear that she valued the construction of a solid foundation in the language and feels her parental responsibility for providing her children with "a good starting point" for further linguistic independent development.

Moreover, the parents demonstrated their interest in the development of both procedural and declarative knowledge in languages: they want their children not just to perform a speaking activity but also be able to comment on the linguistic form and explain why. The development of metalinguistic knowledge appeared to be an essential feature and part of language acquisition in the Kiisks family (more in Practices).

\section{Language as a resource: "I have this resource, and I want to pass it on to my}

children”. With the pluralistic language philosophy, the Kiisks treated language as resource, a storage of socio-cultural, intellectual, socio-economic, symbolic capital (Bourdieu, 2017), expanding the scope of their personal and family resources with each language in their repertoire. Emphasizing the importance of all languages that had come into her life through her family heritage, her academic experiences, and traveling, Kristina treated every language in her repertoire as a resource that she relied on in her daily activities connecting to various cultures, different people, and getting access to other resources (e.g., economic, symbolic, etc.). By doing so, she negotiates her own being, because "even the fact that I recognize this language that I didn't before, or if there are few words there, I learned, and it feels good."

The study found that for the family Estonian was the resource of their linguistic, cultural, historical, and citizenship background, and identity; Russian served as a heritage and identity resource for Kristina; and English was the resource of the parents' educational and professional 
experiences, economic prosperity, providing access to the global world, its resources and opportunities. Thus, the family commodified linguistic competences and believed they would benefit from access to multiple resources and enrich their lives culturally, intellectually, and financially.

Moreover, the parents perceived multilingualism as a resource facilitating their children's cognitive development. Further, in the section on family language practices I will discuss how the parents and Annemarii drew on Annemarii's languages as resources for teaching her other languages, for developing socialization skills, and understanding the world around.

Thus, understanding and valuing the affordances of multilingual competence the parents invested their time and resources into their children's multilingualism, even occasionally questioning their sufficient language proficiency. Kristina was eager to pass on her Russian language knowledge to her children even stating on multiple occasions that she was not fully fluent in it, and strived to provide her daughters with an access to one more linguistic and cultural resource, contributing to their multilingualism and multiculturalism. She shared:

I feel I have enough background and skill left to pass it on, so they will be able to have it as one of the languages, so once they learn how to read, once they learn to switch between their two languages, once they assimilate Russian as their own, they can go from there (Interview Kristina, July 28, 2017).

Three important ideas are evident here: Kristina perceives multilingualism as a norm, emphasizes parental responsibility for children's language knowledge and multilingualism, and claims the importance of the acquisition of the foundational language knowledge and basic metacognitive skills. The orientation to language as a resource explains the interest in multilingual family practices and multilingual parenting. 


\section{Language as a social construct: “one language may be more prominent than another".}

Language is not a neutral tool and resource, it is a social phenomenon which participates in the world's structural inequalities (Blommaert, 2005). Having rich and broad multilingual experiences, the Kiisks recognized socio-cultural potential of diverse linguistic tools and resources; actively supporting multilingualism they assigned different values to each language in their linguistic repertoire. Not building a solid hierarchy but recognizing the place and affordances of each language in particular socio-cultural, economic, and political context, they confidently explained their language preferences and practices, and acknowledged the possible and inevitable shifts and changes in linguistic behavior over time and space.

The family's linguistic choice is pragmatic. The three family languages - Estonian, Russian, and English - differ in their linguistic and socio-cultural nature, and vary in economic and political potential. Developing the command in these languages from early childhood would allow the children to cover a broad scope of world resources and be a linguistically, culturally, economically well-off individual. Kristina methodically explains the choice of the three languages, "but now that we are here I just took it practically, pragmatically. Meelis is here to speak Estonian, they hear English when they get out of the house or with us communicating to other people. And who's there to teach them Russian?" Thus, the parents leveraged children's language acquisition to guarantee their inclusion in diverse socio-linguistic and socio-cultural contexts, such as, communication with their grandparents, their cousins in Estonia, their peers in the U.S. as well as participation in a broader multilingual discourse.

The data showed that despite their seemingly equal inclusion into the family language practices, family languages were granted different statuses. Estonian is the language of their citizenry. The family is planning to return to Estonia, as both parents were born and grew up 
there, and consider Estonian the language of their cultural identity. Estonian is also symbolic with regard to its high status in post post-Soviet Estonia as opposed to Russian.

The meaning of the Russian language for the family is twofold: on the one hand, Russian was an essential part of the family's heritage, through Kristina's mother, and connected them to their Russian-speaking relatives. But on the other hand, it evoked bitter moods about the Russian-speaking Soviet past. In her trip journal, Kristna shared, that conversing in Russian with her daughters in public places in Estonia, she tended to rush to explain that Russian was just one of many languages her children and she were speaking, and demonstrated her native command of Estonian, and not to be associated with Russians in Estonia

On several occasions Kristina referred to herself as Russian (in the sense of Russiancultured). Although currently Russian was the prevalent language of the Annemarii and Keiriin, as they spent more time with their Russian-speaking mother, and Annemarii attends full-day Russian daycare twice a week, the status of Russian as expressed in language ego-maps is a bit lower than that of Estonian and English. Kristina referred to her own Russian classes at school and later at the university as "six years a waste of time", and preferred English and later French. Kristina acknowledged that despite her Russian roots her interest in developing and maintaining Russian with her children did not harbor in the maintenance of the Russian linguistic and cultural identity and developing a connection to the Russian heritage, but devised from a very rational decision about the affordances of possessing a good command of Russian in the contemporary society.

Meelis, growing up in independent Estonia, also prioritized his learning of English over Russian. He highlighted the "natural" aspects of learning English due to the availability of 
resources and his high motivation, yet in his Russian classes at school he "didn't push himself more than was required by the teacher". Comparing his learning of the two languages he shared:

I had a lot of more input from my surroundings in terms of watching cartoons, I mean my family since like we had, most of my relatives we have, we don't have any Russian roots in my family so I didn't have any exposure to Russian. Regardless I didn’t have any exposure to English either, but I think as the fact as I grew up as I was looking things up in English, on the Internet I was... I didn't look up any stuff in Russian, I did in English, starting with movies and TV shows that were in English. I think that's why I was more exposed to English (Interview with Meelis, July 27, 2017).

The political dynamic behind language practices is made clear here: one growing up in 90s in a new independent Estonia would witness more of the orientation to the West and the Englishspeaking world. Globalization eventually penetrated old Soviet borders and entered Estonian homes through music, TV, and numerous popular colorful goods, making the youth more enthusiastic about English rather than still a compulsory Russian course in school.

The current ideology about the Russian language in contemporary Estonia, almost three decades after replacing the hammer and sickle by white, black and blue, is embodied in people's reactions to Kristina's use of Russian with her children that she witnessed this past summer. In her trip journal Kristina shared how frequently she would be addressed with a puzzling question, "WHY are you speaking Russian to them???" [capitalization is authentic], to which she would return her "baffled answer" of "... and why not? Why on earth would someone object to knowing several languages?" Further, in her journal she tried to analyze such negative perceptions of the Russian language juxtaposing it to English, "But I guess some cultural and historical issues come into play with Estonians being more opposed to Russian than other languages. I bet if I was 
speaking English, they would all be impressed out of their minds and not even have a second thought as to why I'm doing it“ (Kristina's trip journal, final thoughts). Acknowledging the power of historical memory and contemporary ideological orientations in shaping the perception of languages and, therefore, affecting language practices, Kristina foregrounded the inherent symbolic capital of languages, reflecting contextual ideological underpinnings, and also brought multilingualism to the fore of necessary social practices in the contemporary world.

On the whole, both parents evidently recognized the advantage of acquiring and possessing English language competency. Now raising their children in an English-speaking country, the parents, with native-like proficiency in English themselves, highly value the acquisition of English by their daughters. They exposed children to English language input through children's books and media, and supported children's performances in English, but only if it was pure and without language mixing. They enjoyed observing and mentally patted themselves on the back even, at Annemarii's achievement in mastering English when she was improving in her conversing with the family's English-speaking friends, or asking ALEXA (the radio) to play her favorite song, or ordering Choco not to jump on the couch. Both parents shared their plans to continue greater support of English when they return to Estonia, "or at least make time for a more consistent exposure to English. Because they cannot get it in Estonia as much as they can get here." (Interview with Meelis, July 27, 2017). Thus, the parents were eager to invest their resources, time, and efforts into empowering their children with English language capital.

The data also showed that parents' language ideologies, perceiving language as a tool, as a resource, and a social construct, and assigning status to a particular family language, are sensitive to changes over time and across space. The shift seems unavoidable as language development itself implies a process and inevitable developmental change; and the parents 
recognized possible fluctuations in their family's needs, capacities, and opportunities in different temporal and spetial paradigms. Kristina strongly foregrounded this thought during her language ego-map interview:

I think it's very important to mention that it [idedologes and language practices] does change with time, every period of time it shifts, yesterday, let's not say yesterday, today, this year it's like that, last year on the same day, 18 month ago on the same day, it was already different, you know one language was more prominent than other, maybe a year from now, we are in Estonia it's gonna shift again, maybe I'm gonna value, not value, bring English to the surface lot more, and make it of a bigger importance because we are away from it and want to keep it in my life, and in my daughters' lives (Kristina, egomap, September 3, 2017).

Perceiving life and their family language practices and ideologies as in a constant flux and change, Kristina still demonstrated her agency in evaluating the situation and moving her family's language practice sails in the direction she "wants" in the ways she believed were the most optimal.

Beliefs about language learning: "children are confused anyways". The data showed that family beliefs about language learning derived from the parents' beliefs about the nature of language and its acquisition, and their own language learning experiences. Natural language acquisition, early exposure to the language, rich and diverse input, and parental support were among the optimal factors to guarantee successful language acquisition and its further development.

Although Meelis's childhood was constructed monolingually around the Estonian language in the family, he was exposed to Russian language and culture through the community, 
his schoolmates, members of the shooting club, and other Russian speakers who kept calling Estonia their home after the dissolution of the Soviet Union. His interview and language egomap revealed that he was not a stranger to bilingualism, interacting with people who had good command of several languages, and definitely perceived the benefits of multilingual practices. Moreover, Meelis studied two foreign languages formally in school (Russian and English), fulfilling the requirement of the Estonian secondary school curriculum.

Kristina's own bilingual childhood with harmonious socialization into Russian and Estonian also shaped her vision about bilingualism as a natural practice. Referring to her own experience, she emphasized the importance of the early exposure to languages for successful language acquisition, as "kids pick up languages so fast". Moreover, by her own example she disproved a common vision of bilingual child language deficiency, despite their neighbors' comments, "I just know my neighbor was worried when they sent me to an Estonian school, because she was like, "How's she gonna cope? Because she does not speak Estonian very well". Kristina is proud of herself, not only because she became fluent in both languages, Estonian and Russian, but because she also participated in language competitions in both while in school, and learned a variety of other languages throughout her life.

Being a good example to herself Kristina implemented her orientation to multilingualism and language learning to her parenting, raising her children multilingually and creating a conducive natural environment for multiple language practices. Kristina strongly believed that language learning contributes to her children's overall cognitive and intellectual growth, "If nothing else, it's a great development boost. I mean if they never use any of the languages they speak. It's still helping their brain development." 
Observing her children's successful acquisition of family languages, Kristina shared her "fascination to witness their language development and how it all came to life despite multiple challenges",

It's funny and interesting, and some parents are hesitant because "it throws them off, they struggle at first” but I don't care because, ... “oh they start speaking later, and they are confused more", ...but they are kids, they are confused anyways. But the rewards afterwards, I didn't even think about them being confused or anything when they speak. I was ready for this. And when Annemarii started speaking at the age of one and Keiriin slightly later and the doctor was like "wow” (Intervew with Kristina, July 28, 2017)

She accepted the hardship of parental decision to venture on the multilingual quest with their children, but highlighted the positive outcome of this initiative, illustrating it by the success of her own children.

Similarly, Meelis emphasized the role of language input and extended the benefits of his daughters' early exposure to languages to their future language learning success:

Think possibly English is the easiest to kinda learn at school, and I think having that kind of input from home would make learning the language more, ... easier for the children, because they do not to necessarily learn it, it comes naturally to them, since they already spoke it in their young age (Interview with Meelis, July 27, 2017)

The Kiisk's language profile and transnational life was favorable for the children's multilingual development: there are two family languages, Russian and Estonian, and the rich input for the third language comes from the environment, or from parents' efforts. The parents were both very proficient in all three languages, and can guide and support their children in attaining multilingual proficiency naturally from an early age. 
Beliefs about children's linguistic and cultural citizenship. Perceiving the language as a tool and a resource, and consciously assigning various social practices to languages in their repertoire, the Kiisks held a strong belief about their multilingual and multicultural practices, identities, and citizenship in transnational spaces. They did not consider themselves immigrants in the U.S, as this country was not a terminal point of their living and settlement. Their constant visits to Estonia made their U.S. experience not more than another transit point in their transnational life. Kristina did not consider and treat their family languages, Russian and Estonian, as heritage languages that they were trying to maintain or preserve, but as the acquisition of necessary linguistic resources and means of communication that could provide the children with opportunities to connect to more people and more places, and develop a broader network of resources. In parents' perspective the variety of languages and cultures, the children were exposed to from early age, merged into one whole, making them global citizens.

Kristina felt her dependence on all languages she spoke, maneuvering according to the situation, context, her interlocutors, and the messages she intended to convey. Exercising her values in her parenting she raised her children multilingually into citizens of the world.

Culture-wise, they are both, they are everything. They are picking up a lot of American culture. They are multicultural, they are citizens of the world. But if you ask me to pinpoint, they have an Estonian passport, they have an Estonian nationality, they have an American passport, they have an American nationality. But what they really are, difficult to say (Intervew with Kristina, July 28, 2017).

In sum, considering the context, in which the Kiisks are embedded and create through their practices, it is worth and more relevant to talk about, not just language, but multilingualism as a tool, multilingualism as a resource, and multilingualism as a social practice. Such orientation 
towards languages stands out in the still powerful monolingual discourse, or juxtaposition of heritage and host country language. Languages allow them to obtain an additional socioeconomic and socio-cultural status that they flexibly use. Comparing to immigrant families that often assimilate to the dominant culture in order to get access to the resources, the Kiisks made multilingualism their resource, and promoted it.

Comparing macrolevel and microlevel beliefs. The analysis of the data demonstrated that the family's language ideologies can be examined through macrolevel and microlevel lens. The parents constructed and followed the following macrolevel (adapted from society and global space beliefs) beliefs: being multilingual is prestigious current necessity, which provides pathways to connect to the world; English language competence is a global communication necessity; the language status of Russian in Estonia is determined by socio-historical context and reflects the repercussions of the Soviet times; the current linguo-cultural context (e.g., the presence of Japanese in the household) influences family language practices and ignite the parents' desire to provide the children with one more language input.

At the microlevel (personal, family) the following beliefs are salient: parents exercise their personal language learning experiences, (e.g., growing up bilingual for Kristina, and growing up in a newly formed Independent state with orientation to the West for Meelis); US education orients towards the value of English; Kristina's BA and MA degrees in languages influenced her approach to her language parenting and language learning by her children; the family's lifestyle (e.g., international traveling for competitions, education and work) shapes its communicative needs and influence the beliefs about language and multilingualism.

Of course, by categorizing beliefs into macro-and micro, I do not assume that these two levels are exclusive. Human experiences are complex and macro and micro forces work together. 
For example, the perception of Russian in the family as heritage through Kristina's side of the family, and the status of Russian in Estonia collide. It is important for Kristina to teach her children Russian, as it is an integral part of her identity. In our last interview Olga, Kristina's mom, shared that Kristina occasionally says "but mom we are Russians". Kristina cannot cut her ties with the Russian culture, even not living in Russia, as she absorbed cultural Russianness through her mom and the language growing up in Estonia. Interestingly, then Olga shook her head and said, "she thinks that she is, but she is not, she was born in Estonia, grew up in Estonia, she is Estonian" (Olga, Skype interview, October 2017). And when macro level conceptualization comes in play, Kristina sounds bitter sometimes in her evaluations of the years of the Estonian republic under the Soviet Union: "when Estonian were Russia's slaves". It is evident that too much history is encompassed in Russian language discourse in Estonia, even after almost three decades after the dissolution of the Soviet Union. At the moments like this Kristina started conceptualizing Russian and the value of knowing it as an extra tool and resource, like many other languages.

Values of being multilingual. To sum up, the following values appear to form the core of the Kiisks' family ideologies about languages, language learning, and their individual language practices.

Instrumental value. It is the most prominent value as illustrated by the parents' orientation to language, their family multilingualism, and language learning in general. "The more the better" orientation and the focus on the acquisition of the foundational proficiency in three languages at early age via readily accessible language input attest the family promoted the belief that multilingualism is a necessity of successful functioning in the contemporary world. A variety of language tools in one's repertoire provides access to a broader scope of cultural and 
economic resources, connects people and fosters better understanding among people and cultures. Placing the acquisition of Russian more towards instrumental rather than heritage value side of scale, the Kiisks envisioned multilingualism as a tool.

Developmental value. The family invested into multingualism by exercising their beliefs that learning languages at an early age contributes to social, cognitive, and emotional development. Referring to her own bilingual childhood, Kristina spoke highly about her linguistic achievements, and constantly compared her daughters to other children of their age highlighted their outstanding linguistic performance despite their doctors warning about possible delays in speech development.

Familial value. It embodies language as "a tool" orientation, and is assigned to Russian and Estonian for they connect the children with the relatives in Estonia. Interestingly, the understanding of "familial" differs from "heritage" in the Kiisk's family: "heritage" encompasses the perception of inherent connection across distance developed over time of separation; "familial" is perceived as an important feeling of being and staying connected despite the distance in the current time of separation.

Cultural citizenship value. It signifies the appropriation of the cultural citizenship through the acquisition of language. Cultural citizenship differs from national citizenship and encompasses an understanding of the culture through knowing and using the languages. Thus, Kristina understands Russian culture, but she is not Russian by nationality. The Kiisks wanted their children to possess multicultural citizenship through their multilingual competencies.

\section{Family Language Practices}

Language practice is one of the major components of language policies, "the habitual pattern of selecting among the varieties that make up its linguistic repertoire" (Spolsky, 2004, p. 
5), which provides the linguistic and cultural context for language acquisition. In a family context, language practice is an observable behavior implemented by the parents to facilitate children's language practices or the parents' reaction to the children's language use, children's agency. Thus, observable children's language behavior is the result of the parents' imposed practices and the children's own agency in the language acquisition process. Therefore, family language practices may be presented in the parents' discourses and the children' discourses. The parents' discourses include parents' and parent-motivated contexts and children's behavior in every day interactions and activities at home. The children's discourses illustrate children's independent language practices and those in which their agency is exercised.

The data showed that in the Kiisk's family, the parents mold and facilitate their children's multilingual language behavior in a variety of ways that include at home and beyond home contexts and practices, including communication in the virtual spaces. The children, in their turn, were also observed to test their grounds with the language(s) to which they are exposed in the process of language socialization and language acquisition, exercising their agency, and contributing to the dynamics of the family language behavior. Family language practices will be presented in two sections: first, parents' discourses, which include parents' individual language behavior, and language behavior directed towards the children, and second, children's discourses, which include children interaction with the languages (e.g., creating with the language, children's metalinguistic comments), socio-cultural plays, and children interaction with each other children.

During the period of observation, I elicited the major portion of language examples from Annemarii, the elder sibling (three years old - three years and four months old); Keiriin (14-19 months old) being at the holophrastic stage (one-word stage) of language acquisition appeared 
rarely in the verbal interaction with her sister. However, it is important to state that being not an active verbal participant of language practices, she was an active recipient of parents' verbal behavior, therefore in the examples below I will use "the children" when I generalize parents' child-directed behavior, and in examples I will uses the data coming from Annemarii.

Parents' discourses: parents teaching. The data demonstrated that the parents created spaces and rules for each language and language practices to realize their family language beliefs. Those spaces and rules aimed at ensuring sufficient input and practices in major family languages, Russian, Estonian, and English, as the language of the environment, as well as others French, and Japanese. Family language spaces were comprised of language and cultural resources of various media, opportunities for interaction with and in the language, and literacy practices initiated by the parents. Additionally, language spaces were also created by naturallyoccurring parents' language behavior during interpersonal communication between each other and with other adults. Directed to the children or not, parents' language behavior was an essential part of the environment in which the children were developing linguistically. First, I will comment on parents' personal language practices, and then will proceed to analyzing their activities directed to shaping and modifying their children's behavior.

Creating language spaces. Parents create language spaces in different ways: by natural translanguaging and by intentional separating language domains for children.

Parents translanguaging. Being multilingual and living transnationally, Meelis and Kristina were engaged in active multilingual practices, which served either isolated language domains, such as communication with the extended family in Estonia in Estonian or Russian, work interaction in English, or translanguaging practices in their interaction with each other and with their children. Interestingly, both of them allotted almost equal importance to Estonian and 
English in their language ego-maps, and were more functionally versatile in their lives in comparison to Russian. Russian was primarily connected to the communication with their children and Kristina's side of the family, and Russian-speaking friends.

Kristina and Meelis were aware of translanguaging and could explain the purposes of language mixing. Both of them shared in the interview - and the observational data confirm it that they used Estonglish with each other in oral and written communication, and it was their natural language behavior. Kristina said, "when we write to each other, Meelis and I, it's very much in English. It's not very much in Estonian as you think between two Estonians, because it's easier to convey what has happened here in English in English." The choice depends on the topic they were conversing about, on the language economy and language suitability, reflecting which language would provide a better equivalent to render the thought, on the emotion that needed to be expressed.

The parents were engaged in purposeful translanguaging while interacting with their children. Meelis said he tended to use a sandwich of Estonian-Russian-Estonian to communicate with Keiriin and to teach her Estonian as she showed more proficiency in Russian. Kristina utilized English to draw children's attention, "for emphasis, to make it fun" because "it's different. In Russian I don't know how to say it "it is not negotiable". ...I could not come up with this, when I needed to say it to my kids, I could not come up with it "this is not negotiable". I could not think of it in Russian, so I started using it in English and that's why I say it. And they know". She was conscious about translanguaging and used it strategically.

Parents also translanguage for instructional language learning purposes. However, the children did not demonstrate this language mix in their linguistic behavior. 
Separating language domains for children. According to their language and language learning beliefs, mixing of languages was not supported and Russian was spoken by and with the mother, and other Russian-speaking extended family members, family friends and acquaintances lack, and Estonian was spoken by and with the father, Estonian-speaking extended family members, family friends and acquaintances. To maintain this policy, parents' language use was supplemented by resources of different media, such as music, and reading.

To enrich language input in Russian and Estonian in the English-speaking country, the parents made a selection of Russian and Estonian children's music, and play it in turns. Kristina shared that "on Monday we play Russian songs, on Tuesday -Estonian, on Wednesday Russian, Thursday - classical music, Friday - Estonian, and on Saturday - classical again”. The parents took turns in putting the children to bed, and read them children books in different languages, respectfully. Kristina was observed to pair the pre-bed cartoon with the story they had read with the girls during the day to strengthen the language input and make the girls remember the story. Kristina's i-pod with music would wake up with the children, and accompanied them in their morning routine. I also noticed that children went to bed with the Russian music on.

English was the language of the environment and the essential medium for many literacy events, such as library story times, concerts, playground activities with the neighbors. English music, available through Alexa-radio, always accompanied family's dinners upstairs. Annemarii learned a lot from this music English input, what was evident in her language behavior. She knew popular children's songs and allowed herself to correct her mom when the latter tried to invent her own song using the same melody. Annemarii often made requests to sing or play certain songs from the children's radio station. Once in the mood of singing "heads and 
shoulders knees and toes" she asked her dad to turn on the radio, and starts jumping with her him to the music, singing along.

After the trip to Estonia, Annemarii linguistically matured and developed an interest in English, which was greatly supported by the parents. Even before the trip the children's songs in English were available to the children and the family were occasionally screening excerpts of Disney animations for the good night cartoon times. After the summer trip, the number of screening times and the length of each screening increased. The increase of input reflected on Annemarii's language behavior as she could be heard more often humming tunes from Disney cartoons, wrapped in her little fleece blanket or a shawl stepping carefully on her tippy toes like a real princess, "I'm a princess, a pretty pretty princess".

Apart from these English-songs interjections, the parents were strict about their language use with the children. Drawing, reading, playing hide-and-seek with the father occurred in Estonian, and Russian was brought in by mother's participation. A linguistically complex and versatile example of an UNO session is illustrative in this sense: it demonstrates how Annemarii was very confidently using two language mediums maneuvering between her father and her mother discourses (Excerpt 2).

It is May 13, after breakfast time. In the background, I can hear classical music, which is interrupted by a commercial. It's an American radio station. Keiriin is enjoying her midday nap, and Annemarii, being an older sister, is enjoying a game of UNO with her parents before her midday nap. Kristina is shuffling a deck of UNO and fixing the UNO box that Annemarii has torn apart when opening it. While her father is giving out the cards, Annemarii sees that there are cards of different colors, and asks her mom about those colors. Meelis gives the cards to the players and Kristina engages Annemarii into counting the number of the cards with her father. 
Meelis counts in Estonian and Annemarii counts with him in Estonian. It seems that she can count in Estonian, at least till eight or nine. Then they start playing. The language space encompsses a mix of Estonian and Russian, Russian is prevailing as Kristina is leading the conversation, and she is also an initiator of the Estonian language use by Annemarii.

Excerpt 2 “A game of UNO” (May 13, 2018)

\begin{tabular}{|c|c|c|}
\hline $\mathrm{K}:$ & $\begin{array}{l}\text { Аннемарии, теперь посмотри, у тебя } \\
\text { есть или восемь или такая красная. .. } \\
\text { Есть у тебя или красная или такая } \\
\text { восемь? }\end{array}$ & $\begin{array}{l}\text { Annemarii, look, do you } \\
\text { have ether an eight or a red } \\
\text { card, .. do you have either } \\
\text { red or number eight? }\end{array}$ \\
\hline $\begin{array}{l}\text { A: } \\
\text { (addressing } \\
\text { her father) }\end{array}$ & $\begin{array}{l}\text { Kas sa tahad roheline [gm] või } \\
\text { punane[gm]? }\end{array}$ & $\begin{array}{l}\text { Do you want green or red? } \\
\text { [wrong declension] }\end{array}$ \\
\hline M: & Kõike tahan, mõlemat tahan. & I want it all. I want both \\
\hline $\mathrm{K}:$ & Поверни картыл, ... nana, почитай... & $\begin{array}{l}\text { Flip your cards, ... daddy, } \\
\text { read... }\end{array}$ \\
\hline M: & U...N...O.... uno. & U...N...O...uno. \\
\hline A: & UNO... тут тоже жёлтая. & UNO, there is also yellow. \\
\hline M: & Peaaegu, Annemarii. & Almost, Annemarii. \\
\hline $\mathrm{K}:$ & Молодеи!! & Good job! \\
\hline
\end{tabular}

M and A: $\quad$ Üks, kaks, kolm, neli, viis, kuus, seitse.

One, two, three, four, five, six, seven.

M: $\quad$ oot oota, emme kord. Peale emmet on Wait wait, mommy's turn. Annemarii kord. After mommy it's Annemarii turn.

M: Annemarii kaks kaarti peab juurde võtma.

Annemarii has to take 2 cards.

And the game went on, in both languages Estonian and Russian. Kristina did not switch to 
Estonian, and Meelis, understanding what Kristina says in Russian, responds only in Estonian.

Two language inputs, Russian and Estonian, were intertwined and easily available to Annemarii, and she confidently maneuvered between the languages addressing each of her interlocutors in the appropriate language. It seemed that the fact that the parents were competent in both Russian and Estonian helped them harmonize the flow of activity. The communication was natural despite each parent speaking only the assigned language.

The parents used different types of instruction to help the children with learning languages, preventing language mix among the languages (mode correcting, language bordering), expanding their vocabulary and accuracy in the language (indexing, semantic linking, brokering, narrating, correcting), and monolingual multilingualism (controlling proficiency, reading and writing). Translanguaging was found to play an essential role in these languages' learning strategies.

Preventing language mix. To prevent the mix of languages the parents referred to language mode correcting and language bordering strategies.

Language mode correcting. Despite translanguaging with each other and utilizing translanguaging as a teaching strategy, Kristina and Meelis tried to prevent language mixing, especially if it was mixing into English, the most comfortable language of the situation, and corrected their children's utterances into context-dependent mono-lingual modes.

The following excerpt illustrates Kristina's reaction to Annemarii’s language mix. (Excerpt 3). One day Nastya, Kristina's Russian-speaking friend, a mother of three, invited them to spend an afternoon in the park. What a joyful time they had, running and rolling on the grass, playing a ball, jumping, singing, retelling their favorite Russian tales. Although Nastya wanted to maintain Russian with her children, she occasionally switched to English, and Nastya's daughter 
Kira, who was a couple of month older than Annemarii, would initiate or switch to English in her conversation. Thus, Kira became one more source of the English language for Annemarii and peer-based input. After joyfully playing tag with Kira, Annemarii ran up to her mom and showing her a flower told her mom she wanted to take another flower.

Excerpt 3 “Little flower” (May 17, 2017)
A:
I'll take another flower, flower.
K: Ц Цветочек, Аннемари.
Little flower (in Russian), Annemarii.

There might be a few explanations for Annemarri's choice of English for the word "flower": first, she was prompted by recent conversation with Kira who had used English for this word or Annemarii forgot the word in her "mother's language" and used the one he had heard from Kira. Kristina chose to correct Annemarii's language use, addressing tis criticism directly to her, not extending this comment to Kira's language use. In this short but confident request to use Russian, the Russin speaking mother delivered a clear message about the accetable language code in the interaction with her. Kristina still used a diminutive, a distinctive characteristic of Russian motherese, so common in the speech of heritage speakers of Russian.

Kristina's rule about diferentiation of languages is also evident in the episode involving baba Olya, Annemarii's grandma. (Excerpt 4). Closing one of their regular skype conversation with baba Olya Annemarii said "bye-bye“, and Kristina openly dissaproved Annemarii's language choice exercising her family language policy more directly. 
Excerpt 4 "On Skype with baba Olya" (May 21, 2017)
A: (to her grandma) Bye, bye.
Bye bye.
$\mathrm{K}:$
не надо bye bye.
We don't need bye bye.
Keriin: (repeats
Bye, bye.
Bye bye.
after Annemarii)
A:
пока, пока.
Bye bye (in Russian).

Kristina wanted Annemarii to say the Russian formular for good bye. Keiriin repeating an English phrase after her sister, or her mother, most likely even not knowing the meaning demonstrated how much the environment could become instantaneous and spontaneous input for the children's language acquisition.

Linguistic bordering of languages. Language bordering means that languages are assigned to different people, when the focus is on language in one's personal repertoire; to objects that can be operated in particular languages, such as books, films, toys, etc.; or to particular linguistic elements, such as words, that children are used, when the focus is on the differences in naming objects in different languages. Linguistic bordering of languages is a very common practice in the multilingual family which values proficiency in the family languages. The observation showed that parents did not allow themselves to language mix when conversing with their children or when children were speaking with the parents; however, parents' translanguaging happened in those situations, but was always marked. Children could perform in multiple languages but parents always try to develop their awareness of the languages in which their multilingual off-springs used to formulate the utterance if it went in discord with the family language policy. Linguistic bordering happens during literacy practices, when Kristina describes 
some books or other textual materials as Russian, Estonian or French, or Japanese and are connected with particular people who are able to read or play with those sources.

The following short episode vividly illustrates how Kristina linguistically labeled activities and objects (Excerpt 5). We are in Annemarri's room surrounded by books and toys. Annemarii grabs books and wants to read. Kristina draws her daughter's attention to a book explaining to her that the book was Estonian. While Annemarii is turning the pages of the Estonian book, Kristina approvingly looks at her daughter and emphasizes that Annemarii can read it with her father. Although Kristina could read in Estonian, and she demonstrated her understanding of Estonian by reading and translating the title of the book, she followed the family language policy differentiating languages between the two parents. She detached herself from the Estonian discourse when activities were involved.

Excerpt 5 “Color yourself” (May 8, 2017)

\begin{tabular}{|c|c|c|}
\hline $\mathrm{K}:$ & $\begin{array}{l}\text { Тьи видела, что здесь ещуе } \\
\text { можно красить? Это } \\
\text { эстонская книга. Что здесь } \\
\text { написано? - «крась сама». }\end{array}$ & $\begin{array}{l}\text { Did you see that you can color here? } \\
\text { This is an Estonian book, what is } \\
\text { written here? "Color yourself". }\end{array}$ \\
\hline \multicolumn{3}{|c|}{$\begin{array}{l}\text { Kristina reads the name of the book in Estonian and translates it for Annemarii into } \\
\text { Russian. }\end{array}$} \\
\hline $\mathrm{K}:$ & $\begin{array}{l}\text { Потом, когда с папой будешь } \\
\text { читать эту книжку, можешь } \\
\text { покрасить эту страничку. }\end{array}$ & $\begin{array}{l}\text { Later, when you and daddy are } \\
\text { reading this book you can color this } \\
\text { page. }\end{array}$ \\
\hline
\end{tabular}

Kristina's attempt to engage her daughter into interaction with the book is very methodical and worth discussion. First, by initiating an action with “ты видела?” (Did уоu see?), the mother draws attention to the book, prompting Annemarii to take it. Then she labeled the 
book as Estonian, and provided another action question, “Что здесь написано?” (What is written here?). Then, when Annemarii's attention was entirely focused on the letters, Kristina made a gesture that she was reading and provided information for Annemarii. Then she strengthened her daughter's association of the Estonian language with her father's discourse, and promised a fun activity to do. By doing so, Kristina purposefully and methodically developed her daughter's awareness of languages, language speakers, and reading. As it was arranged from the beginning of their parenthood, and even earlier, the father is the source of the Estonian input and the main vehicle of Estonian language development, and in this episode with the book, Kristina followed this family language rule.

Another example comes from Annemarii’s interaction with a Japanese activity book, a gift from their Japanese friend, which was a combination of a coloring book, questions, and games. During one of their frequent coloring sessions with their mother, Annemarii was using the book to color her favorite Disney princesses (Excerpt 6). She saw some script on the page and tried to read those images, which apparently resembled her letters. Annemarii tried to pronounce them like the letters of the Russian alphabet she was familiar with. While "reading" she followed the same pattern of a reading session she would engage with her mother: first, they read letter by letter and then the whole word. Hearing her daughter trying to read Japanese characters, Kristina interfered and explained to Annemarii's that the coloring book was Japanese, and the way Annemarii tried to read it was not the language that was represented in the book. The mother attributed the text to the person, saying that it was Aunt Aki's language and she was the one who could read it later to Annemarii. By saying that Kristina differentiated between language expressions and strengthened her daughter's associations between the language and the speaker. 
Excerpt 6 "Japanese coloring book" (July 28, 2017)

\begin{tabular}{|c|c|c|}
\hline $\mathrm{K}:$ & Это японский язык. & This is Japanese. \\
\hline A: & Какой? & What language? \\
\hline $\mathrm{K}:$ & $\begin{array}{l}\text { К: японский. тёти Аки } \\
\text { язык. }\end{array}$ & $\begin{array}{l}\text { Japanese. The language of } \\
\text { aunty Aki. }\end{array}$ \\
\hline $\begin{array}{l}\text { A: (continues } \\
\text { reading) }\end{array}$ & д. & "D". \\
\hline $\mathrm{K}:$ & $\begin{array}{l}\text { К: тётя Аки должна } \\
\text { почитать тебе. }\end{array}$ & aunty Aki should read for you. \\
\hline Keiriin: & Aki. & Aki. \\
\hline $\mathrm{K}:$ & Да, Аки. & yes, Aki. \\
\hline A: & ке мо бе. & ke mo be. \\
\hline
\end{tabular}

As the observation showed, Annemarii continued reading "in Japanese", not listening to her mother and applying the Russin phonetical pattern to the Japanese text. This scene demonstrated that Annemarii internalized the concepts of "a letter" and "reading" well: she was able to distinguishe the script from images, and could dissect symbols. I am not sure if after her mother mentioned Aki, Annemarii tried to imitate the way she perceived Aki sounded, or if she was saying the first letters that came to her mind.

Language bordering between the two family languages, Russian and English, also happened. The following episode richly exemplified the state of language affaires beween the two. It demonstrated implementation of family language policy through language bordering, and illustrated the process of development of two linguistic forms for one concept in a multilingual setting (semantic linking). The Kiisks' meal times were always multilingual occasions, with at least three languages in work, Russian, Estonian, and English. This time they served Asian thick 
noodles for lunch. Annemarii was taking one by one, and slowly biting it. She showed her parents how she bit a noodle in half. (Excerpt 7).

Except 7 "Nuudlit” or ”вермишель“"(May 14, 2017)

A: (shows Ивот так. And like this.
her mom
half of her
noodle)

K: $\quad$ Tbl ртом порвала вермишель? You tore the noodle with your teeth?

A: Да...нет... это не вербишель No, it's not, ... It's not noodle

K: $\quad$ Это вермишель. This is noodle.

A: Hem, эmo nuudlit. No, it's nudlit.

K: $\quad$ А по-эстонски nuudlit, a по- In Estonian nudlit, but in

русски вермишель, да. Russian, noodle [vermishel'].

A: $\quad$ Эmo nuudlit. $\quad$ This is nudlit.

K: $\quad$ Но маме тыл скажешь but you'd say noodle to your “вермишель”, а папе ты mom, and to your dad nudlit, скажешь "nuudlit” бабушке granny Eve you'd say noodle, Оле тыл скажешь “вермишель”, and to grandma Olya nudlit. And а бабушке Эве ты скажешь... $\quad$ to grandma Eve, you'll say...

A: Nuudlit. $\quad$ Nudlit.

By insisting that she is eating "nuudlit" (English: noodles) but not "вермишель" (English: noodles), she revealed that the Russian equivalent for noodles was new to her, or at least not common for her language repertoire. At first Kristina emploed language labeling to show Annemarii the difference between the words, and explained that "nuudlit" was an Estonian 
word, but “вермишель” is a Rusian word. After seeing that Annemarii insisted on providing only an Estonian equivalent for noodles, Kristina elaborated her explanation in referring to people who were associated with particular languages. By doing so Kristina emphasized linguistic boundaries existing between the languages, and among people, and implemented their family language rule striving for the proficiency in both languages.

As a result of Kristina's scaffolding of her daughter's understanding of language bordering, Annemarii developed an evident awareness of a variety of languages, and made good progress in differentiating among the speakers of different languages. If encountering difficulty in identifying and naming the language, and responding to her interlocutor, she would tend to invent her own language to construct a response or refer to English to name the language, not always being able to name a variety of languages yet. At the beginning of the observation she could confidently name Russian and Estonian, and occasionally English. By the end of my five months' observation she showed the ability to distinguish between and name English and French.

The following activity on identifying languages and their speakers occurred in August, upon return from the trip to Estonia. It was initiated and shaped by Kristina's questions and carried features of a lesson on matching languages and speakers. The mother and the girls were playing upstairs with the radio on. ZAZ, a French musician, was filling up the room. Then, the following conversation took place. (Excerpt 8)

Excerpt 8 "ZAZ and Japanese" (August 3, 2017)

$\begin{array}{lll}\text { K: } & \begin{array}{l}\text { Что ты маме сказала? Кто } \\ \text { так говорит? Кто так } \\ \text { говорит? }\end{array} & \begin{array}{l}\text { What did you tell your mom? Who } \\ \text { speaks like that? Who speaks like } \\ \text { that? }\end{array} \\ \text { A: } & \text { Ммм, Жасмин. } & \text { Mmm, Jasmine. }\end{array}$




$\begin{array}{lll}\text { К: } & \text { тётя Жасмин так говорит? } & \text { Aunty Jasmine speaks like that? } \\ \text { A: } & \text { Дааа. } & \text { Yees. } \\ \text { K: } & \text { Как кто? } & \text { Like who? } \\ \text { А: } & \text { По, по-франиузски. } & \text { In, in French. } \\ \text { K: } & \begin{array}{l}\text { По-франиузски? А кто так ешёё } \\ \text { говорит? Кто это поёт? Как }\end{array} & \text { In French? And who else speaks } \\ & \text { её зовут? }\end{array}$
A: $\quad 3 a 3$.
Zaz.

K: $\quad$ Заз! Тоже по-франиузски

Zaz! Also in French

A: $\quad$ Мама тоже по-франиузски.

Mommy also in French.

$\mathrm{K}: \quad$ Мама тоже умеет по-

Mommy also can speak French. франиузски.

A:

A Hamama?

And Natasha?

$\mathrm{K}: \quad$ А Наташа немножко умеет Natasha can speak in French a little по-франиузски. Наташа порусски говорит. Жасмин говорит по-франиузски. Тётя Наташа говорит по-русски, а как папа говорит? bit. Natasha speaks Russian. Jasmine speaks French. Aunty Natasha speaks Russian. And your daddy, what language does he speak?
A: $\quad$ Моя папа говорит по ... говорит...
My/f daddy speaks, speaks...
K: По-эстонски!
In Estonian!
A: По-эстонски.
In Estonian.
K: $\quad$ А как дядя Том говорит?
And uncle Tom, what does he speak?
A: $\quad$ По-английски.
In English. 
K: $\quad$ Мхм, а тётя Аки? And aunty Aki?

A: $\quad$ тоже по-английски. Also in English.

К: Она умеет по-английски, а еще Ahe can speak English, and what как она говорит? /2sec/ Origato, else does she speak? ..."Origato, sayonara, oyasumi, oishi, что sayonara, oyasumi, oishi" what is это? Какой это язык? it? What language is it?

A: $\quad$ По-английски. In English.

K: $\quad$ Это японский. It's Japanese.

A: Японский. Japanese.

$\mathrm{K}: \quad$ Это японский язык, да, это $\quad$ This is the Japanese language, yes, японский язык. the Japanese language.

Kristina picked up on Annemarii's curious inquiry about French, and skillfully developed it into a teaching moment about other languages. She asked her daughter questions linking the aural language image with the speaker, moving from one person to another: family friends, father, and household members. Annemarii successfully identified the language of their French friend, who also visited them in Estonia, so the recency and the quantity of input in French available while in Estonia might have played a role. She identified English, but needed some help with her father's language and Japanese. When Annemarii repeated the name of the language after her mother, Kristina strengthened the connection, repeating the name of the language twice.

In sum, the mother promoted the language bordering as a strategy to raise and dvelope Annemarii's (and in general her children's) multilingual awareness, drawing their attention to the phonetic structure of the languages and to the variety of speakers. By doing so, she engaged her 
daughters in multilingual practices, showing how harmonius and at the same time linguistically diverse the world is.

Language teaching routine. The parents' activities directed to teaching languages expanding their children's vocabulary and accuracy in the language - included indexing or labeling, semantic linking, brokering, narrating, and correcting.

Indexing or labeling. Indexing means pointing things around and naming them in a respectful language or providing names for the objects and actions upon the children's requests. The strategy is very applicable with the little children starting with pre-linguistic through multiple word sentences stages of language development especially in multilingual families (Walker, Bigelow, Harjusola-Webb, Small, \& Kirk, 2004). In his interview, Meelis called indexing ("pointing to things" in his words) one of his regular and common activities with his children, and believed that it was one of the successful activities to facilitate language learning. He explained his technique as follows, "when Keiriin starts babbling, and it's not at all comprehensible, I catch the moment to point to objects and name them, even tough what she really meant was a different thing. But I engage her into naming things and she learns". The observational data revealed many occasions when the parents try to provide rich language input for their children.

A very good example of this strategy is "a berry lesson" that Kristina delivered during their summer trip to Estonia (Excerpt 9). This "lesson" engaged three generations, two languages and one goal to support bilingual communication of the children, Russian and Estonian. The whole episode reminded of a good structured lesson on teaching the girls the names of berries in Russian, smoothly transitioning into a lesson in Estonian, when the company of berry eaters increased in number and language diversity. All elements of a foreign language didactics were at 
large - presentation, practice, application, and assessment - and Kristina's skills as language educator shone at their best.

Excerpt 9 "Berry party" (June 20, in Estonia, 2017)

\begin{tabular}{|c|c|c|}
\hline A: & Это что зовут? & What is it named? \\
\hline $\mathrm{K}:$ & $\begin{array}{l}\text { Как зовут, ... это как } \\
\text { называется? }\end{array}$ & $\begin{array}{l}\text { What is it named... What is } \\
\text { it called? }\end{array}$ \\
\hline A: & Это как называется? & What is it called? \\
\hline $\mathrm{K}:$ & $\begin{array}{l}\text { Вабушка Оля сказала, что это } \\
\text { мурель, но это по-эстонски, я не } \\
\text { знаю, как по-русски, черешня это } \\
\text { что-то другое...клубника. }\end{array}$ & $\begin{array}{l}\text { Grandma Olya said it was } \\
\text { called murel, but it's in } \\
\text { Estonian, I don't know the } \\
\text { Russian word for it, cherry is } \\
\text { something else... } \\
\text { strawberry. }\end{array}$ \\
\hline $\begin{array}{l}\text { A: counting } \\
\text { berries }\end{array}$ & Один, два, четыре, пять, иесть. & One, two, four, five, six. \\
\hline $\begin{array}{l}\text { K: (Kristina } \\
\text { corrects } \\
\text { Annemarii } \\
\text { as she skips } \\
\text { number } \\
\text { three) }\end{array}$ & $\begin{array}{l}\text { Один, два, ТРИ, четыре, пять, } \\
\text { шесть. }\end{array}$ & $\begin{array}{l}\text { One, two, THREE, four, } \\
\text { five, six. }\end{array}$ \\
\hline \multicolumn{3}{|c|}{$\begin{array}{l}\text { Presentation- Kristina starts with naming the berries- presentation. Annemarii is } \\
\text { an engaged student as she structures the presentational part by asking "what is it?" }\end{array}$} \\
\hline A: & А что это? & And what is this? \\
\hline $\mathrm{K}:$ & Черника. & Blueberry. \\
\hline A: & A что это? & And what is this? \\
\hline $\mathrm{K}:$ & Малина. & Raspberry. \\
\hline A: & А что это? & And what is this? \\
\hline
\end{tabular}


K: (thinking) Ну скажем, черешня, эта мурель, вишня такая.

A:

$\mathrm{K}$ :

A:

Клубника, вишня... можно ещё?... Ох, Я укусила язычок.

“До свадьбы заживёт!”

$\mathrm{K}$ : (kisses

Annemarri

onto her

forehead)

/.../
Let's say it's a cherry, this is murel, ... a type of cherry.

And this?

This is strawberry.

Strawberry, cherry, ... Can I have more? ... Oh, I've bitten my tongue

It will heal by your wedding day (a Russian saying), don't worry!

Practice-Annmearii is practicing and producing, by naming the berries, not necessarily naming them correctly just naming them all at once

A:

K:

A:

Черника у тебя есть.

А малину... и вот эта.. Муреля

Assessment - Kristina is asking to name the berries

K: $\quad$ Мхм, вкусно? Какие у нас ягодки?

A:

Чёрные.

K: $\quad$ Как называются?

A:

Красные.
Mommy, can I have more blueberry, raspberry, strawberry and this one murel, ... More blueberry/ sg... can I have strawberry and blueberry? You have blueberry.

And raspberry, ... and this one/f ...murel

$\mathrm{Mmm}$, its so delicious. What berries do we have here?

Black.

How are they called?

Red. 


\begin{tabular}{|c|c|c|}
\hline $\mathrm{K}$ : & Какие у нас ягоды? & $\begin{array}{l}\text { What kind of berries do we } \\
\text { have? }\end{array}$ \\
\hline A: & Малина, черника & Raspberry, blueberry \\
\hline $\mathrm{K}:$ & Это что за ягода? & And this one what is it? \\
\hline A: & $\begin{array}{l}\text { Клубника... мама можно малина, } \\
\text { черника, и вот эту клубнику? }\end{array}$ & $\begin{array}{l}\text { Strawberry, ... Mommy can } \\
\text { I have raspberry, blueberry } \\
\text { and this one strawberry? }\end{array}$ \\
\hline /... & & \\
\hline A: & Вот эту тоже? & And this one too? \\
\hline $\mathrm{K}:$ & ..., малину тоже? &.., and raspberry too? \\
\hline
\end{tabular}

Grandma Eve comes home, says "Ciao" to everyone, and joins this berry eating session. At first Eve takes a role of a student. They start contemplating about what murel might be in Russian. Annemarii asked for a raspberry
A:
Мама, можно малину?
Mommy can I have
$\mathrm{J}:$
Kust sa tead need malinad? raspberry?
K: $\quad$ Mis mõttes? Miks ta siis ei tea?
Ta teab kõiki marju. Küsi. Ta teab kôki marju. Küsi.
How do you know those are raspberries [a Russian word, but with Estonian plural ending]? What do you mean? She knows all berries. Ask.

$\mathrm{J}$ :

A mis see on?

And what's this?
A:
Um...

Eve: $\quad$ Ütle vene keeles.

Say it in Russian.

$\mathrm{K}$ :

Как по-русски?

In Russian?

A:

Клубника.

Strawberry. 


\begin{tabular}{|c|c|c|}
\hline $\begin{array}{l}\text { Eve: } \\
\text { (repeats) }\end{array}$ & Клубника. & Strawberry. \\
\hline $\mathrm{K}:$ & $A$ это? & And this one? \\
\hline A: & Малина. & Raspberry. \\
\hline K: & Малина. & Strawberry. \\
\hline $\begin{array}{l}\text { Eve: } \\
/ \ldots /\end{array}$ & A, малина. & Ah, strawberry. \\
\hline $\begin{array}{l}\text { K: (to Eve, } \\
\text { whispers } \\
\text { away from } \\
\text { Annemarii.): }\end{array}$ & $\begin{array}{l}\text { K küsi ta käest, mis marjad need } \\
\text { on. }\end{array}$ & $\begin{array}{l}\text { Ask her what those berries } \\
\text { are. }\end{array}$ \\
\hline $\mathrm{E}:$ & $\begin{array}{l}\text { Mis marjad need on? Mis mari } \\
\text { see on? Vanama ei tea, mis see } \\
\text { on? }\end{array}$ & $\begin{array}{l}\text { What are those berries? } \\
\text { What's that berry? Gramma } \\
\text { doesn't know, what's that? }\end{array}$ \\
\hline A: & Murel. & Sweet cherry. \\
\hline $\mathrm{E}:$ & Murel? On täitsa. A mis need on? & $\begin{array}{l}\text { Sweet cherry. That it is. And } \\
\text { what are those? }\end{array}$ \\
\hline A: & Maasikad. & Strawberries. \\
\hline Eve: & Maasikad. & Strawberries. \\
\hline $\mathrm{J}:$ & Mis see on? & And what's that? \\
\hline A: & Maasikad. & Strawberries. \\
\hline Eve: & Ei see on... a mis see on? & No that's...what's that? \\
\hline A: & Ka maasikas. & Strawberry too. \\
\hline Eve: & Ei see ei ole maasikas. Mustikas. & $\begin{array}{l}\text { Not that's not a strawberry, } \\
\text { that's a blueberry. }\end{array}$ \\
\hline \multicolumn{3}{|l|}{ /.../ } \\
\hline A: & $\begin{array}{l}\text { Можно вот ту? Потом ту? } \\
\text { Потом два, четыре, пять, }\end{array}$ & $\begin{array}{l}\text { Can have that one? Then this } \\
\text { one, two, four, five, six... }\end{array}$ \\
\hline
\end{tabular}


шесть.

\begin{tabular}{|c|c|c|}
\hline $\begin{array}{l}\mathrm{J} \text { : (pointing } \\
\text { to different } \\
\text { objects) }\end{array}$ & Pipar, sool, sibul, õunamahl. & $\begin{array}{l}\text { Pepper. Salt. Onion. Apple } \\
\text { juice. }\end{array}$ \\
\hline $\begin{array}{l}\text { A: } \\
\text { (addressing } \\
\text { her mom) }\end{array}$ & $\begin{array}{l}\text { Можно вот эту? Вот эту, } \\
\text { вот... эту, много! }\end{array}$ & $\begin{array}{l}\text { Can I have this one? This } \\
\text { one, this...this one... a lot! }\end{array}$ \\
\hline
\end{tabular}

The adults continue speaking in Estonian.

A: Mама, можно эту? Mommy, can I have this one?

K: $\quad$ Что ты хочешь? What do you want?

Annemarii starts talking to Jan in Estonian

This excerpt vividly illustrated the children's routine home language learning context of simultaneous multilingualism, Annemarri’s growing proficiency in two languages (Russian and Estonian), her ability to differentiate between languages and speakers, and the process of languages' learning orchestrated by her mother. During "the berry lesson" Kristina approached her children's multilingualism methodically, requesting full answers, asking content question, and always trying to get a verbal answer from her children rather than pointing to things. Covering the whole instructional sequence, presentation, practice, application and assessment, she aimed at the internalization of the new vocabulary both in Russian and Estonian. She made Eve repeat with Annemarii all the "lesson" words in Russian first, before practicing them in Estonian. Switching between languages and interlocutors, Kristina did not mix the languages, and framed her questions and answers to Annemarii only in Russian. Through making her 
daughter provide the names of the berries in Russian and then in Estonian, Kristina also displayed her pride of her multilingual mothering in front of her mother-in-law.

Semantic linking. The purpose of semantic linking was to expand children's vocabulary in two and more languages. The parents provided translation of a word or a phrase in different languages, and, therefore, facilitated children's matching linguistic resources available to them in order to strengthen the links between two or even three language systems and enrich children's multilingual repertoire.

In one of informal interviews Kristina emphasized her strategy of increasing the difficulty of input, by, first, providing the children with a simple word and then with a more complex word or a phrase. Moreover, observations revealed that she constantly made an attempt to double in Russian everything what Meelis was saying in Estonian in order to immerse her daughters into diverse and rich linguistic context. Kristina shared raising up the girls multilingually she became both very conscious and conscientious about her own linguistic behavior, and responding to her children's developmental changes she felt she needs to expand her daughters' vocabulary and provide sufficient context and communicative situations for languages' development with a greater rigor, "that's not something I decided, it's something, I started doing, ... I also start putting things in context, I notice the reason, why I do [say] certain thing and use certain language". It was evident that Kristina willingly applied her language pedagogy training and beliefs into her daughter's language development.

The NOCs data illustrated ample instances in using semantic linking strategy by Kristina engaging English and Russian (Excerpt 10). Once Annemarii and I were reading books in her room and I grabbed a book that featured animals on the cover. 
Pointing to a kitten I asked:

Excerpt 10 "Kitty cat" (May 8, 2017)

\begin{tabular}{|c|c|c|}
\hline Я: & Это кто? & Who is it? \\
\hline $\mathrm{K}:$ & $\begin{array}{l}\text { Это имена. (explaining the } \\
\text { text of the cover). }\end{array}$ & These are the names. \\
\hline A: & Kitty cat. & Kitty cat. \\
\hline $\mathrm{K}:$ & Kitty cat, Kitty cat. & Kitty cat, Kitty cat. \\
\hline A: & Kitty cat. Это она зовут. & She they call Kitty Cat. \\
\hline $\mathrm{K}:$ & Kitty cat. & Kitty cat. \\
\hline A: & Который киса. & The one/m who is a kitty cat. \\
\hline $\mathrm{K}:$ & $\begin{array}{l}\text { Киса, по-английски kitty } \\
\text { cat. }\end{array}$ & Kisa in English is a Kitty cat. \\
\hline A: & Kitty cat. & Kitty cat. \\
\hline $\mathrm{K}:$ & Kitty cat. & Kitty cat. \\
\hline
\end{tabular}

The parent's control of language learning is evident in this episode. Although Kristina did not participate in the book reading and was walking around doing her household chores, she heard our conversation and tried to get actively engaged in it. She repeated after Annemarii the Kitty cat's name, and then took a lead to translate for Annemarii that "киса" stood for Kitty cat in English. Annemarii repeated words after her mom in English, and Kristina closed the scene. Thus, providing the translation for a word or drawing her children's attention to equivalents in 
different languages, and also deliberately identifying the languages themselves, Kristina reinforced semantic links, aiming at expanding her daughters' vocabulary in both languages.

The following short scene presents an example of semantic linking between Estonian and English, surprisingly excluding Russian, despite Kristina’s participation in the conversation (Excerpt 11). It occurred during ocasna happy family meal time with smiling faces around, as "food is motivating", Kristina said. Annemarii was eating corn and speaking with her father in Estonian commenting on her food, while Kristina was feeding Keirin. Suddenly, Annemarii saw her dad peeling eggs.

Excerpt 11 "Eggs" (August 5, 2017)

\begin{tabular}{lll}
$\begin{array}{l}\text { A: (very } \\
\text { excitedly) }\end{array}$ & $\begin{array}{l}\text { Maiz, ... smothit, smothit, } \\
\text { aaaa, eggs, eggs, eggs, eggs. }\end{array}$ & Corn... \\
M: & Ta munad??? & Egg??? \\
A: & Ja. & Yes. \\
K: & $\begin{array}{l}\text { Tь сказала, eggs? По- } \\
\text { английски? }\end{array}$ & You said eggs? in English? \\
A: & Eggs, eggs...munad. & Eggs, eggs .... Eggs. \\
M: & Munad, ja. & Eggs, yes. \\
Keiriin: & Muna (trying to say “munad") & Egg... \\
\hline
\end{tabular}

Annemarii's reaction to eggs was an utterance in English. She exultantly burst into asking for eggs. Meelis stayed loyal to their family language policy and provided an Estonian equivalent for “eggs", making connection between English and Estonian, and successfully prompting Annemarii to switch to "father's language". Kristina, in her turn, reacted to Annemarii's "egg 
rapture" in Russian, but still employing an English equivalent for "eggs" and indicating the language used, “по английски?” (English: “in English”) for semantic linking and language bordering. In the next move, Annemarii constructed her utterance in English and Estonian. And Meelis again insisted on the Estonian equivalent for "eggs". It is worth drawing attention to the communicatively actively passive member of the family, Keiriin. Slowly maturing linguistically according to her age she was gaining voice and agency as I heard her trying to repeat "munad" (English: "eggs") after her father and Annemarii. It was one of few episodes when Keiriin was linguistically active in Estonian, conversing mostly in Russian. Thus, this episode portrays how the multilingual environment was created by both parents and children for the children's language development.

The following episode is also characteristic for the everyday language dynamics of the Kiisks (Excerpt 12). Kristina translanguaged, when she was communicating with the Englishspeaking gadget; tried to implement strict OPOL policy, responding entirely in Russian, while constructing the meaning in collaboration with her daughter about a children's song sung in English on the radio. She applied semantic linking strategy, encouraging the use of English in this situation, as the communication happened. Annemarii and her mother were in the kitchen with Alexa radio on, as always, tuned into the children's music station. When a new song started, Annemarii initiated the following conversation:

Excerpt 12 “Alexa, volume up” (May 9, 2017)

$\begin{array}{lll}\text { A: } & \text { Что это за песня? } & \text { What song is it? } \\ \text { K: } & \text { Я не знаю, первый раз сльишу, } & \text { I don't know, ... It's the first } \\ & \text {... про снеговика поют. } & \begin{array}{l}\text { time I hear it... they are singing } \\ \text { about a snowman. }\end{array}\end{array}$


A: Snow. Snow.

K: $\quad$ Да, про снег поют, .. про снег, $\quad$ Yes, they are singing about про снеговика. $\quad$ snow, ... about snow and a snowman.

Alexa, volume down. Alexa, volume down.

A: $\quad$ Что? что? What? What?

K: Alexa! volume down. $\quad$ Alexa! Volume down.

They continue their conversation about grandma Eve's house. About what they are going to do there and whom they are going to see and meet. After a while

A: $\quad$ Alexa, volume up! Alexa, volume up!

$\mathrm{K}:$

Оо, она поняла тебя.

A:

K: $\quad$ Ты ей сказала «погромче», $\quad$ е она поняла тебя.
Alexa, volume up! Alexa, volume up!

[The radio starts playing louder].

Oh, it understood you.

Yes, it understood me.

You told her "louder" and she understood you, clapping her hands.

Annemarii asked her mother about the song they were listening to. Even though the song was in English, Kristina responded in Russian saying that the song was about a snowman. Annemarii continued listening carefully and extracted from the song the word "snow". Kristina confirmed that Annemarii was right, and further commented that the song was about snow, snowmen, maintaining Russian. However, in her next step trying to put the volume down Kristina 
commanded the voice-sensitive gadget to put the volume down. After a while, Annemarii returned to communication with the radio, ordering the radio to go back up n English. Annemari's use of English is encouraged by her mother, as the communicative task putting the volume up happened. Kristina exultantly explained/translated Annemarii what she had ordered to the radio and that that her request was successful. By doing so, Kristina supported her daughters cmmunicative English use, stying loyal to their family language policy and keeping Russian in the comunication between the child and the mother.

Parent brokering. As was illustrated by previous examples, the multilingual parents facilitated children's language acquisition being a depository of linguistic resources available at the children's needs. This is not an occurrence of translanguaging, but rather a purposeful translation practice, in which the parents were involved to assist the child's successful language performance in the other not their language, by providing a necessary language equivalent, to support language acquisition in that language. I called this practice "parent brokering".

To illustrate parent brokering I chose Annemarii's third birthday celebration in the Discovery museum. We spent a wonderful day there full of hands-on activities, learning how the human body and the heart works and what bees do every day, counting apples in the bucket and observing water running in tubes. Upon returning home Kristina wanted Annemarii to practice more Estonian and to tell her father about her adventures in the museum. Annemarii chose to talk about the drum that would show the beat of the heart upon the touch (Excerpt 13).

Excerpt 13 "Drumming like the heart" (May 11, 2017)

$\begin{array}{lll}\mathrm{K}: & \text { Tы расскажешь папе, что мы в } & \text { Will you tell daddy what we were } \\ & \text { музее делали?... Расскажи } & \text { doing in the museum? Tell your } \\ \text { nanе. } & \text { daddy. }\end{array}$


M:

$\mathrm{K}:$

A:

M:

A:

$\mathrm{M}$ :

Annemarii is mumbling.

$\mathrm{K}$ :

A:

$\mathrm{K}$ :

A:

M:

A:

$\mathrm{K}$ :

A:

M:

A:

$\mathrm{K}$ :

A: (makes

the noise

with her
Mis sa räägid?

Расскажи nane.

Ma tahtis[gm], eh, eee...

Mida sa tahad?

EI ma räägin!

A sa räägid. No räägi.
What are you going to tell me?

Tell your daddy.

I wanted [you form instead of I, but she used past tense correctly]

What do you want?

NO I'm speaking!

Oh you're speaking. Ok tell me.
Tы спроси у мамы слово, если ты не знаешь, мама поможет.

Я делала на барабане, тук.

Trumm.

Trumm.

Sa mängisid trummi?

Mkm.

Что барабан делал? Скажи nane...

$\Pi y м-n y м-n y м$.

Lõid trummi?

Ei

Барабан делал тук-тук.

Барабан делал тук-тук.
Ask your mom if you don't know the word, mommy will help you.

I was doing with the drum tuk tuk.

Drum.

Drum.

You played the drum?

No.

What was the drum doing? Tell daddy.

Pum pum pum.

You beat the drum?

No.

The drum was doing tuk tuk.

The drum was doing tuk tuk. 
hands)

$\mathrm{K}$ :

A:

$\mathrm{K}$ :

M:

$\mathrm{K}$ :

A:

M:

A: (continues drumming on the table)
Trumm.

Trumm tegi...

Как сердие, да?

Trumm tegi pum pum pum

Как сердияе.

See oli как сердиче.

Nagu süda?

Mhm, nagu süda nagu süda.
Drum.

The drum did.

Like the heart, right?

The drum did pum pum pum.

Like the heart.

It was...like a heart.

Like a heart?

Yes, like a heart, like a heart.

When Annemarii experiences difficulties in expressing herself in Estonian, Kristina offered to help her and employed parent's brokering strategy. She does not provide her daughter with the whole phrase in Estonian, but gave only one word, "drum”, pushing Annemarii into constructing the utterance in Estonian independently. Then, observing Annemarii struggling Kristina decided to help her shape the narration by asking questions. Meelis also provided the translation from Russian into Estonian scaffolding Annemarii's narration and helping her finish story. The parents' collaboration alleviated Annemarii difficulties and supported her performance in a more challenging for her Estonian structure, executing meaningful, purposeful communication with her dad.

The following scene demonstrates how by means of translation Kristina facilitated Annemarii's communication in English with their English-speaking family friend, Hailey 
(Excerpt 14). The whole party, Kristina, Annemarii and Hailey, were in the kitchen preparing early lunch, and the Haily was playfully interrogating Annemarii what she liked eating. Annemarii heard her mother using English with Haily and set herself on evidently an Englishspeaking mode responding to Haily's inquiries with her confident English “yes”. Interestingly, although Kristina was translating Hailey's questions into Russian the girl did not switch to Russian, as she understood, that Hailey was not speaking Russian, and continued interacting with her through her mother's translation. In the middle of their conversation Annemarii initiated a request in English reacting to the conversation about toasted bread. Kristina also employed semantic linking during this conversation, connecting "beets" to the Russian equivalent “свекла”. It's worth noting, that responding whether she liked beets or not, Annemarii provided an answer twice, for Hailey, and for her mother in relative languages, in English and Russian. She demonstrated her ability to differentiate between the speakers and communicative tasks.

Excerpt 14 “Do you like...?” (May 22, 2017)

$\begin{array}{lll}\text { H: } & \text { Do you like pickles? } & \text { Do you like pickles? } \\ \text { K: } & \text { Солёные огуривь нравятся? } & \text { Do you like pickles? } \\ \text { A: } & \text { Yes. } & \text { Yes. } \\ \text { H: } & \text { Do you like raisins? } & \text { Do you like raisins? } \\ \text { K: } & \text { Изюм } & \text { Raisins. } \\ \text { A: } & \text { Yes. } & \text { Yes. } \\ \text { K: } & \text { It's really difficult to find } & \text { It's really difficult to find } \\ & \text { something she does not like } & \text { something she does not like. } \\ \text { H: } & \text { I'm gonna try. Do you like } & \text { I'm gonna try. Do you like }\end{array}$


nuts? nuts?

$\begin{array}{lll}\text { K: } & \text { Opexu. } & \text { Nuts. } \\ \text { A: } & \text { Yes. } & \text { Yes. }\end{array}$

K: (to Do you like your bread lightly

Hedi) toasted, well toasted?

Do you like your bread lightly toasted, well toasted?
A:
And me.
And me.
H:
And you?
And you?
$\mathrm{K}$ :
Yes, you too.
Yes, you too.
$\mathrm{H}$ :
Do you like liverwurst?
Do you like liverwurst?
$\mathrm{K}:($ to
Тебе печёнка нравится?... А Annemarii) мы не кушали печенку,
Do you like liver?... Ah we haven't tried liver yet, so... sо...тебе нравится лук? A тебе нравится сырой лук, острый немножко ... DDo you like onions? Do you like raw onions, a bit spicy.

She doesn't like raw onions. She doesn't like raw onions.

(to Heidi)

$\mathrm{H}$ :

Do you like brussel sprouts?

Do you like brussel sprouts?

$\mathrm{K}:$ (to

Брюссельская капуста

Annemarii)

нравится?

/.../

$\mathrm{H}$ :

Do you like beets?

Do you like beets?

A:

Yes.

Yes.

$\mathrm{K}$ :

Нравится свёкла? Beets.

Do you like beets? Beets

A:

Да.

$\mathrm{H}$ :

Beets? Yes?... do you like
Yes.

Beets? Yes?... Do you like 


$$
\text { turnips? }
$$

$$
\text { A: }
$$$$
\text { Yes }
$$

$\mathrm{K}$ :

Yes
Cooked, raw is not that we eat a lot of them, we don't really eat them raw. turnips?

Yes.

Cooked, raw is not that we eat a lot of them, we don't really eat them raw.

Teaching narrating. Narrating is an integral activity in language development, as it allows the child to use the language beyond a word level and orient a child toward abstracting from the present real events. Re-telling of daily events in Estonian and Russian, and fairy tale storytelling in Russian were among the common activities initiated and facilitated by adults in the family. For example, if Kristina spent time with the children out, upon returning home, she always created a situation engaging Annemarii in retelling the events of the day to her father in Estonian. Very often a parent brokering strategy was used when Kristina facilitated Annemarii's narration by providing some Estonian words for her. (See Narration).

The following examples are illustrative. Being on a summer in Estonia, Kristina, Eve, and the girls visited their relatives in Tallinn and spent the whole day at the music festival. Upon the return home, Kristina asked Annemarii to recall what they had been doing throughout the day. From the example below I saw how Kristina facilitated Annemarii's narration by providing questions asking for details or providing more details in her question to help her daughter construct a more logical sequence of utterances (Excerpt 15).

Excerpt 15 "Singing festival" (July 4, Estonia, 2017)

$\begin{array}{ll}\text { A: } & \text { Я поехала гости на Эдику и } \quad \text { I went visit Edik and Artie. } \\ & \text { Арти. }\end{array}$


K: $\quad$ Мы ездили к Эдику и Арти? А что мы там делали?

A: $\quad$ мы танцевали, платье одели и пошли спать.

K: $\quad$ мй были на певческом празднике?

A: $\quad$ Мы были на певческом на празднике. Очень-очень красиво, вот эта который косичка, эта мы в магазине купили ... красиво косичка, который эта волосы.

K: $\quad$ Бабушка Эве купила тебе игрушечку, а там была такая косичка красивая?

A: $\quad$ Да, и потому что она на голову... чтобь очень красиво было.

$\mathrm{K}: \quad$ Мхм, как Эльза, да?

А: $\quad$ Как Эльза, да.
We went to Edik and Artie?

What did we do there?

We danced, put on a dress and went to bed.

We were at the singing festival?

We were at the singing at the festival. Very-very beautiful, this one (fem.).. which (masc.) is a braid (fem.), this (fem.), we bought in a store, beautfully braid, which (masc.) this (fem.) hair.

Grandma Eve bought you a toy, and there was a beautiful braid there?

Yes, and because it's on the head to be beautiful.

Mmm, like Elza, yes?

Like Elza, yes.

When Kristina asked Annemarii “мы были на певческом празднике?” (English: "We were at the singing festival?'), Annemarii repeated the question, and it helped her construct a sentence and then react to it, developing her narration. In the following move Kristina inquired about grandma Eve buying a toy where they found a braid, whch was a linking detail that Annemarii had missed in her previous utterance. Kristina's questions scaffolded Annemarii's narrating practices in the past not only on the linguistic level, but also on the developemental level. 
I observed that Kristina read to her children a lot, and the number of children poems, songs, stories and tales that Annemarii knew by heart in Russian was abundant for her age. Russian tales, such as Kolobok and Teremok were her favorite and found output when she was playing alone or with other Russian-speaking children, or even with her mother who always initiated these narrating activities.

For example, once while in Estonia Annemarii burst into singing a Kolobok song, and Kristina willingly joined in and initiated the acting out together of the whole Kolobok drama story. Kristina took the lead in the story but encouraged Annemarii to sing for different animals or Kolobok (Excerpt 16). She asked Annemarii about different characters in Kolobok story, and they took turns to play it out. Kristina put on a role of a wolf, a fox, and even Kolobok, helping Annemarii to retell the story, and engaging her into singing her favorite Kolobok's song.

Excerpt 16 "Kolobok” (June 20, in Estonia, 2017)

К: Колобок, колобок, я тебя съем. А что еще волк говорит? "Какую такую песню?"

A: Нет, ты “какую такую песню?”

$\mathrm{K}: \quad$ a, я говорю? хорошо, “какую такую песню”. Ну давай пой!

Kristina and Annemari are singing the song.

K: $\quad$ А дальше кто?

A:

К: $\quad$ Смедведем споём?
Kolobok, kolobok, I'm gonna eat you... and what else does the wolf say? "What kind of song?"

No, you say "what kind of song?"

Oh, it's my line? Alright "what kind of song?" You, sing!

And who's next?

Bear and a fox.

Let's sing with the bear? 
Kristina and Annemari are singing the song.

К: “И от тебя медведь я тоже убегу”, а потом кого он встретил?

A: Лиса.

Annemari starts singing the song, and Kristina chimes in and finishes the song
К: И от тебя лиса я тоже уйду.

A: $\quad$ Еще колобок, еще колобок мама.

К: «Какая хорошая песня, сядь ко мне на мордочку и спой еще раз», а что колобок сказал?

A: $\quad$ Ага, яколобок.

$\mathrm{K}: \quad$ Xaм, ypa!

A: Помнишь как лиса у бабушки Оли петух съела?

K: Да, у бабушки Оли петуха и курицу съела, вот такая вот лиса!
"And I will run from you too, bear", and then, who did h meet?

Fox fox.

And I will run from you too,

More Kolobok, more Kolobok, mommy.

"What a nice song! Sit on my nose and sing it for me again", and what did Kolobok say?

I'm Kolobok...

Hurray!

Do you remember how a fox ate baba Olya's rooster?

Yes, it ate both, a rooster and a hen, what a fox!

Kolobok narration went beyond the scope of the story into the real life, when Annemarii recalled how a fox had eaten a rooster at grandma Olya's place. Through NOCs and observations it was evident that Kristina believed that narrative practices helped children logically perceive and construct the reality, therefore she strongly emphsized such activities in her children's language practices. 
Traditional literacy practices. Through parents' reflections on their own multilingual practices and my observations of family language parenting activities, it is evident that the parents defined literacy around reading and writing practices. Kristina very proudly shared the fact that she herself had begun reading at the age of three (Kristina's mother Olga said being five years old Kristina was reading Jules Verne's “Twenty Thousand Leagues Under the Sea), and emphasized that children's vocabulary growth, elaboration of grammatical knowledge, and overall language development was attained through reading and writing. Therefore, in their house I saw Russian and Latin (Estonian) magnet letters on the fridge, which were used very often for some of the corners of the hand-made paper letters were torn. There were numerous literacy objects in the form of signs (e.g., postcards, posters, and notes), the majority of which were in English, but also Japanese and Estonian. Russian script was mostly available through children books. I did not see any posters or cards with the Russian script on the walls.

The observation revealed a greater number of overt and covert Russian reading and writing practices in comparison to Estonian. Kristina explained that the children would go to Estonian school when the family moved to Estonia, and they would be exposed to more language and literacy practices there. She believed that due to the similarity between Estonian English script, as both are based on the Latin alphabet, she found it more beneficial to focus on teaching her children reading and writing in a more difficult Russian script.

I observed that whenever Annemarii took a pen and began drawing something, Kristina attempted to catch a moment to turn the drawing activity into a letter-writing task. Letter recognition and word reading was also a common practice at the end of bed-time reading. Choosing two or three words in the book or on its cover, Kristina engaged Annemarii to name 
letters and then read the whole word. The mother would expand a letter-naming task to listing words starting with that letter. For example, “K” как “кошка" (Eng: "K” like in "cat").

The following episode illustrates this dynamic very well. Kristina and the girls were coming back home from the playground, all happily tired from running, swaying, and sliding down the hill. Annemarii saw a chalk in the grass, grabbed it and ran to the chalkboard they had in the yard. Kristina caught the moment to engage Annemarii into a literacy event (Excerpt 17).

Excerpt 17 "What letter are you writing?" (May 8, 2017)

\begin{tabular}{|c|c|c|}
\hline $\mathrm{K}:$ & $\begin{array}{l}\text { Ты писать будешь? буквы будешь } \\
\text { писать? /.../ какую букву ты } \\
\text { пишешь? }\end{array}$ & $\begin{array}{l}\text { Are you going to write? Are } \\
\text { you going to write letters? } \\
\text { Which letter are you writing? }\end{array}$ \\
\hline A: & Один. & One. \\
\hline $\mathrm{K}$ : & $\begin{array}{l}\text { Это ичифра, ицифра один, а буква? } \\
\text { Букву какую? }\end{array}$ & $\begin{array}{l}\text { This is a number, number one, } \\
\text { and a letter? What letter? }\end{array}$ \\
\hline A: & Ц. & TS. \\
\hline $\mathrm{K}$ : & Ц, пиши букву Ц...написала? & $\begin{array}{l}\text { TS, write letter TS.. Have you } \\
\text { written it? }\end{array}$ \\
\hline A: & Да. & Yes. \\
\hline $\mathrm{K}:$ & А теперь какую букву пишешь? & $\begin{array}{l}\text { And now, what letter are you } \\
\text { writing? }\end{array}$ \\
\hline A: & Я напишу «Э». & I am going to write "E”. \\
\hline K: & «Э», пищи букву «Э» & $\mathrm{E}$, write letter $\mathrm{E}$. \\
\hline A: & Hem. & No. \\
\hline K: & $\begin{array}{l}\text { Tыл хочешь «нет» написать? Как } \\
\text { мы сегодня на холодильнике } \\
\text { написали? Давай пиши «нет». }\end{array}$ & $\begin{array}{l}\text { Do you want to write "no" } \\
\text { How did we write it today on } \\
\text { the fridge? Go ahead and wrte }\end{array}$ \\
\hline
\end{tabular}




\begin{tabular}{|c|c|c|}
\hline & & "no". \\
\hline $\begin{array}{l}\text { K: } \\
\text { Kristina } \\
\text { leads her } \\
\text { to it, } \\
\text { spelling } \\
\text { out letters }\end{array}$ & /.../ а как мы «да» пишем? «д» «а». & $\begin{array}{l}\text { And how do we spell "da"? D } \\
\text { and A. }\end{array}$ \\
\hline A: & $« A »$. & "A". \\
\hline $\mathrm{K}:$ & Две буквы «д» и «а». & Two letters "d" and "a". \\
\hline
\end{tabular}

In this episode Kristina engaged Annemarii into writing, overtly talking her into it, as she used the verb "write"” eight times. At first, Annemarii confused numbers and letters, saying she wanted to write number "one", but Kristina, pointing to this mistake, persistently led her daughter into writing letters and words. The mother also prompted her daughter's choice of letters suggesting words to write.

Another reading activity demonstrates Kristina's pattern of reading instruction. At first, she asked Annemarii to recognize letters she was pointing to (Excerpt 18). The mother was assisting her daughter in recalling the names of the letter. Then Kristina provided a word that starts with that letter, inviting Annemarii to produce more words. The words, then, were used in a broader discourse to ensure the contextual use of the word. Kristina personified the situation trying to evoke Annemarii's experiences when using the word. Finally, they together read the whole word. Following this pattern, Annemarii was instructed how to read, as well as was engaged in situations to enrich her vocabulary and had structured speaking practice in Russian.

Excerpt 18 "A horse, an onion, and a spruce tree" (May 12, 2017) 
$\mathrm{K}$ :

A:

$\mathrm{K}$ :

A:

$\mathrm{K}$ :

A:

$\mathrm{K}$ :

A:

$\mathrm{K}$ : (whispering)

A:

$\mathrm{K}$ :

A:

$\mathrm{K}$ :

A:

$\mathrm{K}$ :

A:

$\mathrm{K}$ :

A:
Давай буквы почитаем. Что это за буква? Какая эта буква? Ё ...

$\ddot{\mathrm{E}}$.

Как ёлка, да?

Как ёлка.

Как ёлка?

Да.

А эта?

Как? Как? (

Лош...

Лошадь.

Да, как лошадь!

Как лук.

Как лук, правильно! Тебе нравится лук?

Нет, он острый.

Немножечко острый, ну так да, он крепкий вкус... а это что, это какая буква?

«К», как каша.

Как каша, ты любишь кашу по утрам кушать?

Да.
Let's read the letters. What letter is this? What letter is this? Yo...

Yo.

Like spruce tree.

Like spruce tree.

Like spruce tree.

Yes.

And this one?

What? What?

Hor..

Horse.

Yes, like a horse!

Like an onion.

Right, like an inion! Do you

like onions?

No, it's hot.

Yes, a bit hot, /.../ taste... And what is this letter?

"K", like porridge.

Like porridge, do you like eating porridge in the mornings?

Yes. 
$\mathrm{K}$

A:

$\mathrm{K}$ :

A:

K: (smiling happily, as her child is making such progress),

A:

K:

A:

K:

A: (reads the word)

K:
Даааа... а это что за буква?

«A».

Как?

Абрикос.

Абрикос он тебе нравится?

Абрикос кончилась.

Наверно, кончился абрикос, ты завтра попроси у мамы, может мама найдет еще /.../ Значит вот эта была буква «ё», «Л», «К»».

К-К-К-К. «А», ... что тут написано?

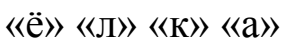

Ёлка.

Ёлка! Правильно, правильно! ... а что вот это за буква?...
Yeees...And what is this letter?

"A".

Like what?

Apricot.

Apricot, do you like it?

Apricot finished/ $\mathrm{f}$.

maybe, we ran out of apricots, ask mommy tomorrow, maybe she will find more /.../ so this letter was “ё”, “л”, “к”.

К-К-К-К.

$\mathrm{A}$, what is written here? (reading the letters)

Spruce tree.

Spruce tree, right!... And what is this letter?

Continue reading words.

Meelis also participated in literacy practices but more rarely. He was "responsible" (in Kristina's words) for the Latin script. Thus, he showed Annemarii how to read the name of UNO game on the deck of UNO cards. At first he named every letter, and then read the whole word. On another 
occasion, the father and the daughter were reading the recipient's name on the package that was delivered for Annemarii's birthday (Excerpt 19). The parents addressed it to Annemarii on purpose, so when the package arrived, Kristina told Annemarii to go read for whom the package was brought.

Excerpt 19 "Birthday Package" (May 15, 2017).

\begin{tabular}{|c|c|c|}
\hline K: & Иди, посмотри, прочитай с & Go, have a look, read with your \\
\hline & nапой. Для кого эта & daddy. Who is this package for? \\
\hline
\end{tabular}

Meelis puts the package on the lower table. He uses the same strategy, pointing to each letter, he reads letter by letter and then the whole word.

M: $\quad \mathbf{A}, \mathbf{N}, \mathbf{N}, \mathbf{E}, \mathbf{M}, \mathbf{A}, \mathbf{R}, \mathbf{R}, \mathbf{I}, \quad \mathrm{A}, \mathrm{N}, \mathrm{N}, \mathrm{E}, \mathrm{M}, \mathrm{A}, \mathrm{R}, \mathrm{R}, \mathrm{I}$, ANNEMARII, Annemarii. ANNEMARII, Annemarii.

A: Annemarii. Annemarii. (smiling)

I can assume that Annemarii has had many occasions to read her name in Russian like this as well. Her idea of reading was shaped by these practices. First, she would read letters, one by one and then proceded to the whole word. I had a chance to observe Annemrii'd independent literacy event one morning in May, at early stage of data collection. A day before, Kristina and 
Annemarii were painting Russian letters, and on the morning of my observation Annemarii brought the A4 paper covered in beautiful colorful letters. She held out the piece of paper and began her reading routine (Excerpt 20).

Excerpt 20 "What letter is this?" (May 16, 2017)

A: Мыкрасили буковки. We painted some letters.

She starts reading the letters but not the way they are written.

А: $\quad$ О, Ю Аннемарии, П, Ш, Н, У, Щ, Аннемарии, Т, В, О, три, 3, $H$, твердый знак, Аннемарии, Семь, Г, а потом вот этот, $И, O$, вот это что за буква? Х, Ю, Аннемарии, Вот это что за буква? О, П, Р, как тигр, вот это что за буква? Цапля, это тоже забуквы, остались тут ещуе забуквы, твердый знак, мягкий знак, Аннемарии, А, C, Э, Аннемарии, И такая, $O, . . A, O, H$, Э, Аннемарии, И, А, 3, И, Аннемарии, Ещее? Вот эту. О, Ю, И, Т, вот эта что за буква, Ю как ...? юла, юбка.
O, U, Annemarii, P, SH, N, U, SCH, Annemarii, T, V, O, three, Z, N, hard sign, Annemarii, Seven, G, and then this one, I, O, what letter is this? X, U, Annemarii, What letter is this? O, P, R, like a tiger, what letter is this? Heron, an these re also letters, some letters are left here, hard sign, soft sign, Annemarii, A, $\mathrm{S}, \mathrm{E}$, Annemarii, and this one $\mathrm{O}, \ldots \mathrm{A}, \mathrm{O}$, N, E, Annemarii, I, A, Z, I, Annemarii, More? This one, O, U, I, T, and what letter is this? U, like a ...? Top, skirt...

Я: А тетя Жасмин знает эти буквы?

And does aunty Jasmine know these letters?

A: Нет, это мама знает, эти буквы. No, mommy knows, these letters.

Я: A nana знает? And does your daddy know? 

A: Да.
Yes.

This practice differed from her story time activity, as the latter did not involve reading, but narrating. While reading, she followed the pattern her parents had taught her to do. They named letters and then gave a full word out, they also named other words starting with the letter just read. Annemarii might be imagining that there was her name written several times across the paper, and similar to reading her name on the birthday package she was reading her list of colorful letters, showing it out to me, as if she was teaching. Annemarii did not always name the letters she was pointing to right, but she revealed a good competence in knowing the names of Russian letters. She also demonstrates the knowledge of numbers in Russian, as she confused the image of some letters with the similar looking digits, $\Gamma(\mathrm{G})$ and 7, $3(\mathrm{Z})$ and 3 . In her repetitive request, "What letter is this?", I could hear her mother's voice and didactics. Also, by confidently stating that her parents knew those letters, Annemarii associated reading events with the activities she would usually do with her parents, therefore aunty Jasmine could not know these letters, s se was not engaged in reading with Annemarii. It is to the lesser degree that she demonstrates her awareness of the linguistic ways of expression, she will begin more consciously and confidently differentiate between languages a couple of months later after this episode.

Focus on language proficiency: monolingual multilingualism. The data demonstrated that parents were interested in keeping good proficiency of each of the languages in their family repertoire. They actively worked on it by correcting children's grammatical performance and developing their traditional literacy skills, reading and writing.

Correcting. Parents consciously amended mistakes and errors in children's use of grammar, lexicon or phonology in everyday communication. Interestingly, despite Russian only 
policy, the mother of the family took the lead on correcting her children's performance in all home languages, Russian, Estonian, and English. Meelis kept an impartial attitude to the children's language mistakes and preferred recasts to direct corrections, exercising his belief of the natural language development Kristina demonstrated the use of various strategies to support the development of the grammatically correct language or the pronunciation. With Russian, Kristina was observed to choose recasts over direct correction, but moving to direct correction if recasts did not elicit any result.

Once returning from the playground Annemarii saw a piece of chalk in the yard and began drawing on the chalk board. Kristina did not miss an opportunity to direct her daughter into letter writing. While drawing on the chalk board Annemarii also found a pen and the following conversation took place (Excerpt 21).

Excerpt 21 "My pen, your pen" (May 8, late afternoon, 2017)

\begin{tabular}{|c|c|c|}
\hline A: & $« A »$. & "A". \\
\hline $\mathrm{K}:$ & Две буквил «Д», «А». & Two letters "D" and "A". \\
\hline A: & $\begin{array}{l}\text { А какую букву? Хорошо...Это мой } \\
\text { ручка. }\end{array}$ & $\begin{array}{l}\text { And what letter? Alright... } \\
\text { This is } \mathrm{my} / \mathrm{m} \text { pen. }\end{array}$ \\
\hline $\mathrm{K}:$ & Это моя ручка? & This is my/f pen? \\
\hline A: & $\begin{array}{l}\text { Да, нет, это мой .... нет, это } \\
\text { мой. }\end{array}$ & $\begin{array}{l}\text { Yes, no, this is } \mathrm{my} / \mathrm{m} \text {...no, } \\
\mathrm{my} / \mathrm{m} \text {. }\end{array}$ \\
\hline $\mathrm{K}:$ & Твоя ручка? & You/f pen? \\
\hline A: & Да. & Yes. \\
\hline $\mathrm{K}:$ & Твоя ручка? ...ия это ручка? & $\begin{array}{l}\text { Your/f pen?... whose/f pen } \\
\text { is it? }\end{array}$ \\
\hline
\end{tabular}


A: Аннемарии

K:

A: $\quad$ Mö̈.

K: Моя.

A: Моя.

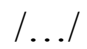

A: Это плавать, это большой.

K: $\quad$ Ты большая? Ты уже плавать умеешь?

A: $\quad$ Да /.../ и это моя ручка.

К: $\quad$ Это твоя ручка, хорошо, бери ручку домой, бери домой.
Annemarii's

Yours / f? whose/f pen is it?

My/n.

My/fem.

My/fem.
This is to swim, and this is $\mathrm{big} / \mathrm{m}$

You are big and you can swim?

Yes, and this is my/f pen.

This is your/f pen, good, take the pen and bring it home.

This conversation demonstrated Annemarii's struggle with the gender agreement of pronouns, and illustrated how Kristina didactically corrected and taught her daughter this grammatical rule. It started with Annemarii wanting to say that the pen she had found was hers. She used masculine adjective "my" with a feminine noun "pen". Kristina corrected her daughter by asking if the pen was hers, trying to emphasize the use of the grammatically proper pronoun. Having understood that her mom wanted to say that the pen was hers [Kristina's], Annemarii insisted that on the possession of the pen, and repeated it twice, using the wrong (masculine) form again. Kristina decided to take a different path, and trying to establish the common ground of the pen's belonging, she confirmed that the pen belonged to Annemarii, saying "yours" in the correct 
feminine form. Annemarii happily agreed. Kristina wanting her daughter to use the right form employed question stimulus. Her inquiry about the possession of the pen did not elicit a satisfying response, as Annemarii referred to herself using a proper name. Using an element of ordering Kristina asked to say whose pen it is. Annemarii responded using a pronoun in a neuter form. Kristina provided the right form, expecting her daughter to repeat, and she did. A couple of turns after, Annemarii switched topics and described herself as "big”. Adjectives also require noun agreement, and Annemarii fell into the same grammatically incorrect pattern again, using an adjective in the masculine form referring to herself. Employing recast Kristina used a question to provide Annemarii with the right form. Although Annemarii confirmed using just a conjunction, "yes", and returned to her pen again, Kristina did not develop this lesson to the same depth of instruction s the previous one, but confirmed that the pen belonged to Annemarii. She did that using the structure of the noun with a pronoun, wrapping up the "lesson" with more grammatically correct inputs, reinforcing the use of the structure.

The correction of the gender agreement of adjectives appeared in another example. Kristina chose direct correction and recasts again to show Annemarii the difference between feminine and masculine endings of adjectives. In this episode Annemarii and her mother are describing people (Excerpt 22).

Excerpt 22 "Big and Tall” (May 20, 2017)
A:
Аннемарии большой девочка.
Annemarii is a big/ $\mathrm{m}$ girl.
$\mathrm{K}$ :
БольиАЯ девочка.
Big/f girl.
A:
Большая. Мама, а Наташа, тоже большая.
Big/f. Mommy is Natasha big/f too? 


$\begin{array}{lll}\mathrm{K}: & \begin{array}{l}\text { Наташа, тоже большая и } \\ \text { высокая. }\end{array} & \text { Natasha big/f and tall/f. } \\ \mathrm{A}: & \text { Папа высокая? } & \text { Daddy is tall/f? } \\ \mathrm{K}: & \text { Папа высокий? } & \text { Is daddy tall } / \mathrm{m} ? \\ \mathrm{~A}: & \text { Мхмх. } & \text { Mhm, confirmation. } \\ \mathrm{K}: \text { (smiling) } & \text { Да, не маленький. } & \text { Yes, not short } / \mathrm{m} .\end{array}$

Similarly to the previous example with possessive pronouns, at first, Annemarii uses the masculine form of the adjective with a feminine noun. Kristina amended this use providing the correct form and even annunciating the ending of the adjective. In her next turn Annemarii repeated the right form of the adjective and extended it to another situation, describing a different person. Kristina responded in the full sentence reinforcing the use of the form. As a response Annemarii asked if her daddy was tall, using the new word provided by Kristina in the previous turn exactly in the same feminine form. Kristina made a recast with a question, showing the right use of the adjective. Annemarii mumbled in confirmation, and in her response Kristina provided a new adjective to enrich the language input. Both examples were taken from the pre-trip corpus. The post-trip observational data showed a significant improvement in the gender agreement of nouns and adjectives, and conjugations.

Despite maintaining OPOL policy, Kristina also took a lead on correcting her daughter's Estonian grammar and pronunciation, crossing her husband's language domain. She did not do recasts, but turned more commenting on the incorrect structure or pronunciation and providing the correct one. In one of the recordings of NOCs made by the family, Annemarii was talking with her father (in Estonian), asking him about something, and got corrected by her mother. Kristina heard Annemarii's faulty use of a grammatical structure and intervened in their Estonian 
talk explaining why it was wrong. After her daughter repeated the right structure, the mother praised her in Russian (Excerpt 23).

Excerpt 23 "I want" (May 20, 2017)

\begin{tabular}{|c|c|c|}
\hline $\mathrm{K}:$ & Ma taha. & I want [correct in Estonian]. \\
\hline A: & Motoha. & I want [wrong in Estonian]. \\
\hline $\mathrm{K}:$ & $\begin{array}{l}\text { Если ты скажечь "та A taha", } \\
\text { это ты скажешь, "я не хочу", } \\
\text { ma taha - "я хочy" }\end{array}$ & $\begin{array}{l}\text { If you say "ma-A-tah, you say } \\
\text { "I don't want, M-taha, - I } \\
\text { want. }\end{array}$ \\
\hline A: & Ma taha. & [saying it right]. \\
\hline $\mathrm{K}:$ & Вот так вот. & Right you are. \\
\hline
\end{tabular}

Interestingly, Kristina uses Estonian only to correct the wrongly used Estonian structure, wrapping her correction into the Russian utterance to sustain the communication with her daughter around the language policies established in the family.

Although English was not one of the family language policy languages, it was the language of the environment and means of communication with other household members, family friends, and many visitors. Kristina and Meelis strongly supported their daughters' English learning. In the episode that follows Kristina took a role of an English teacher instructing Annemarii on the difference in the pronunciation of two words, "watch" and "wash", which Annemarii confused conversing with their family friend Haily.

It was dinner time, the end of Haily's visit. The family was altogether, with the father back from work and the mother finishing meal preparations (Excerpt 24). Haily is American, her native angauge is Engish, and she teaches French; the adult conversations were hold mostly in 
English, and Kristina and Meelis would occasionally switch to Estoniglsh. Annemarii was more confident communicating with Haily in English at the end of the day, and was very well differentiating among speakers and maneuvering among three languages. Before the dinner Annemarii wanted to wash her hands, Haily decided to assist her and some miscommunication happened around "washing" and "watching".

Excerpt 24 "Watch or wash" (May 22, dinner time, 2017)
A: (to her Я не помыла ничего руки. mom)
I haven't washed nothing my hands (wrong grammar).
$\mathrm{K}$ :
Tы не помыла руки? Давай бери стул. (to Haily) She is upset that she didn't wash her hands. You haven't washed you hands yet? Take a chair.
H: $\quad$ I'm upset too, that she didn't (laughing) wash her hands.
I'm upset too, that she didn't wash her hands.
$\mathrm{M}$
I told her that she needs to wash
I told her that she needs to wash her hands before every time she eats. Maybe that's why. her hands before every time she eats. Maybe that's why.
H: $\quad$ We can all wash our hands. We can all wash our hands.
A: $\quad$ You watsch (meaning wash). $\quad$ You watsch (meaning wash).
H: $\quad$ Oh yes, I do. I'm gonna watch Oh yes, I do. I'm gonna watch you, watch you (Haily heard you, watch you. Annemarii saying "watch").
A: $\quad$ No, I gonna watsch (meaning wash).
No, I gonna watsch (meaning wash).
K: $\quad$ Annemarii, "watch", "wash”, Annemarii, "watch", "wash", "watch", "wash", "watch", "watch", "wash", "watch", 
“wash”, два разных слова. "wash" - two different word.

H: I gonna watch you. I gonna watch you.

A: $\quad$ Yes. $\quad$ Yes.

K: Now she got it! Now she got it!

Annemarii's first "wash" was addressed to Heily, asking to wash her hands. Heidi misheard it and took it as an invitation to watch Annemarii washing her hands. In her next move Annemarii still thinking about washing their hands perceived Heily's statement as intention to wash Annemarii's hands, and rejected Heily's suggestion. Kristina understood the issue of miscommunication and intervened into the conversation to repair it by explaining Annemarii the difference in pronunciation between "wash" and "watch". The scene ended with successful communication between Heidi and Annemarii in English, and clean hands. In this episode, Kristina used the same strategy to maintain within the framework of their family language policy, as in the previous episode, she wrapped the correction of English pronunciation into the Russian utterance addressed to Annemarii.

The examples of correcting the children's language demonstrated very well how Kristina skillfully leveraged her proficiency in Russian, Estonian, and English. Being responsible for the acquisition of Russian in the family, she willingly employed all her resources to help her children practice the father's language and the language of the environment.

Summary of Parents' Teaching. The examination of parents' discourses encompassing activities directed to the children's language learning and development of proficiency in Estonian, Russian, and English, revealed the parents' vision of language as "doing something else" and successful language learning. Emphasizing parents' fundamental role in the children's 
language acquisition, Kristina and Meelis believe that languages are learned through systematic, rich language input and structured scaffolding of literacy activities and language practices. Referring to their approach as "system" the parents strive to create an environment which provides rich input and also actively engages their daughters in a variety of activities with the language and in the language. The children read, write, draw, recite stories, narrate, and communicate with the members of their household. Children enter and participate in various social discourses through languages available to them. Figure 6 visually summarizes the Kiisks' "system" of language learning and family language practices. The parents believed that languages are acquired naturally through rich input and engagement into regular socializing routine in language, and one language facilitates the acquisition of any other (cf. Cummins "Interdependency Hypothesis). The role of an adult is crucial for creating an optimal languagestimulating environment. The parents focused on monolingual multingulism, as they were supporting the developing of multilingual competencies but trying to prevent language mix.

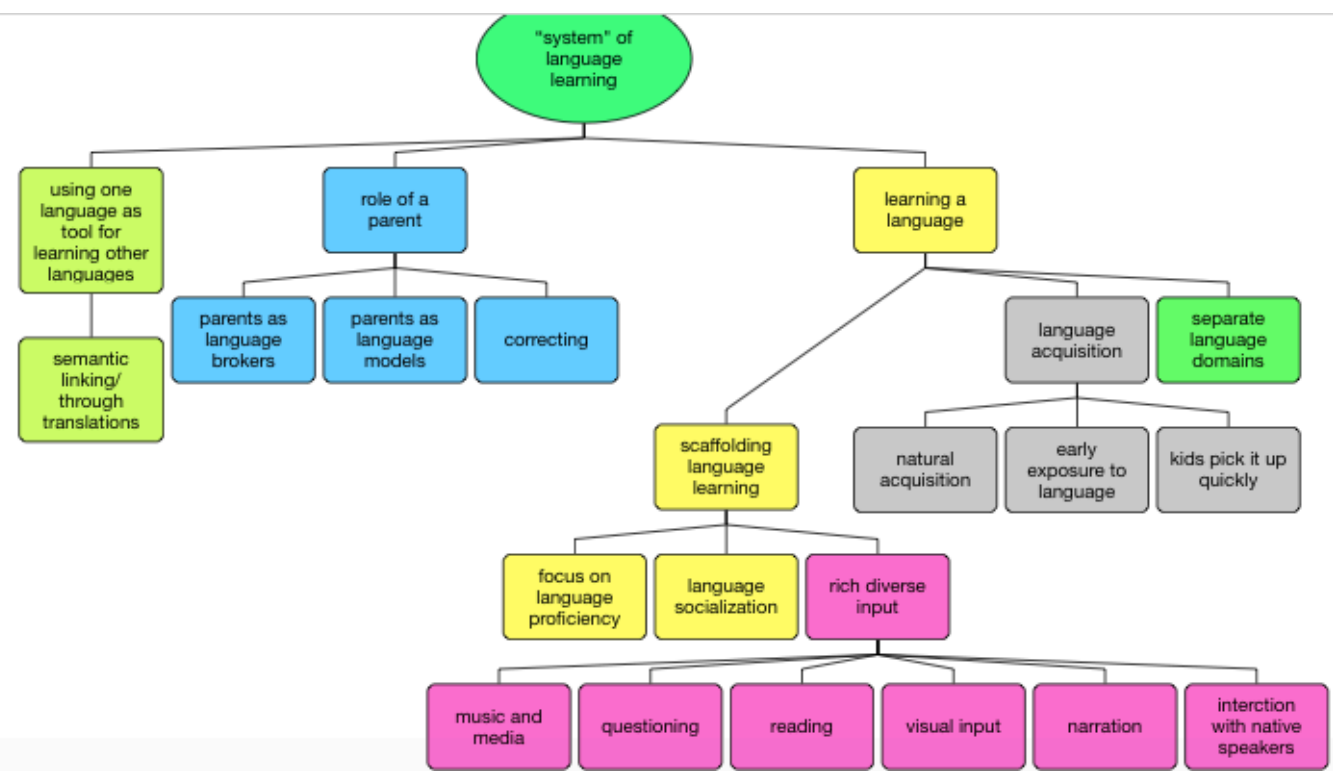

Figure 6. The Kiisk's language learning "system" 
Children's discourses: children learning. Although the previous section focused on parents' language behavior and their practices oriented to the development of multilingual competence of their children, the examples used also illustrated children's input into initiating, maintaining, and overall orchestrating those practices. In this section I will focus on children's language behavior that embodied the consequence of parents' teaching and/or the expression of children's agency. I will discuss children's language awareness, socio-cultural play, the use of English, and practices illustrating creating with languages.

Language awareness. The section on parents' discourses demonstrated the parents', primarily mother's, effort to develop awareness of diverse language patterns and differentiate between interlocutors, according to the language pattern. The development of a sense of multiple language use happened simultaneously with the development of awareness what the language was, and what one could do with it. Ethnographic observations and NOCs at the beginning of data collection when Annemarii just turned three years old, revealed that she was a confident conversant in Russian and Estonian, an did not mix language codes. She switched between languages according to the interlocutor, having a solidified understanding that her mother and father spoke different languages with her and read different books to her, and therefore she had to address each of them differently. Moreover, she distinguished her parent's languages from other languages she also had exposure to, English, French, and Japanese. Although she could not label those languages, she clearly understood that the way Aki, Tom and their French friend Jasmine spoke differed from the sound patterns she heard from her parents, and grandparents.

In her trip journal Kristina described the day when her cousin, "an interesting fella" and high-spirited man, often behaves goofy, and multilingual", and his family came to visit, and an interesting situation occurred out of that meeting. "He always creates a very interesting linguistic 
dynamic because he switches between Russian and Estonian a lot, and also throws in some (broken) English”, Kristina wrote, “Annemarii can’t quite figure out how she should interact with him, so she quietly watches him a lot, but eventually she goes with the flow and mostly manages to speak in the language she's addressed in. But she does tend to be quieter in situations like this, especially at first“ (Kristina’s trip journal, second week in Estonia). This situation vividly illustrated Annemarii's "figuring out" of the language pattern in order to choose the right language code to communicate.

When Annemarii struggled responding to the linguistic input different from her family languages, she would get engaged in her imaginative language, that did not sound like Russian, Estonian or English. I observed such behavior, when their family French-speaking friend, Jasmine was visiting for a one day in May. When a visitor did not speak any of the family languages the adult communication usually happened in English. That day Annemarii was very happy to see Jasmine, she remembered her well, and had always asked about her visit. Jasmine brought a plush toy for the girls, and after playing for a while Annemarii ran to the kitchen and noticeably wanted to attract Jasmine's attention engaging her into play. Jasmine turned to Annemarii and started talking to her in French. Annemarii happily jumping with the toy around Jasmine, stopped, thought for a moment and responded in her imaginative language. Jasmine continued the talk describing the toy and making more questions in French. Annemarii responded in the same imaginative manner and danced herself away and joined her little sister in the living room. This observation illustrates Annemarii's process of evaluation of the linguistic message she received from the environment. Did Annemarii think Jasmine was inventing a language, so she just repeated what she had heard? Or was she trying to solve the challenging language puzzle by inventing the language for her response, and taking control of this 
communicative task? The fact that Annemarii retreated to the leaving room, stopping the conversation in the language she could not communicate, might demonstrate her awareness of language as a means of communication and differences that exist between languages. She could not continue speaking with the French-speaking friend, and left.

Interestingly, during their summer trip to Estonia, when Jasmine was visiting for a week, Annemarii and Jasmine were communicating mostly in English. The choice of the language medium might have resulted from the fact that she heard Jasmine communicating in English with people in Estonia, as it was the only language she could communicate with the context around. It leads to the next point, modeling the world around.

One early morning in May when everybody was sleeping, Annemarii and I had conversation about languages. Visiting the family in May I very often spent mornings playing with Annemarii, she would braid my hair, do a story time for me, or showed off how high she could jump. Once playing in the morning I suddenly sneezed. Annemarii looked at me and started laughing. The following conversation followed (Excerpt 25):

Excerpt 25 "Bless you" (May 9, morning, 2017)

$\begin{array}{lll}\text { A: } & \text { Ть чихнула. } & \text { You sneezed. } \\ \text { Я: } & \text { Что нужно сказать? } & \text { What should you say? } \\ \text { A: } & \text { Будь здорова. } & \text { Bless you. } \\ \text { Я: } & \text { Спасибо! } & \text { Thank you! }\end{array}$

Then Annemarii sneezes, and I, taking control of the research situation, decide to respond to her in Estonian.
Я:
Tervi seks!
Bless you! 
She looks at me being puzzled. She knows I regularly speak her mom's language, I speak English, but where is dad's language coming from? The silence continues and trying to help her I suggest:

Я: $\quad$ Эmo nana так говориm? Is it what your daddy says?

A: $\quad$ Да, а мама говорит $\quad$ Yes, and mommy says "bless «буд здорова». уоч".

Я: $\quad$ Да, я тётя Аки как $\quad$ And what does aunty Aki говорит? say?

A: Bless you! Bless you!

Я: $\quad$ А дядя Том? And uncle Tom?

A: Bless you! Bless you!

Я: $\quad$ А Чоко? Чоко говорит? And Choco? Does Choco speak?

A: (smiling) Heeem. Nooooo.

Я: $\quad$ А бабушки как говорят? And what do you grannies Бабушки? say? Grannies?)

A: (pauses, Tervi keks! Bless you! and thinks a little bit)

This short conversation illustrated Annemarii's awareness of differences between her father's and her mother's languages, the existence and presence of another language in conversation, beyond their family languages, and revealed her perception of language as a human capacity. She confirmed that she used her father's phrase, and was able to explain what her mother would say in similar situation. She was aware that her grandmother would answer in Estonian (She might 
be thinking about her Estonian grandmother). Aki and Tom spoke English at home, and were not a part of her parents' languages discourse. Although Annemarii was observed speaking with Choco in English, in this conversation she showed her awareness that Choco was an animal and could not speak human language, so could not react to sneezing.

Later that morning I was fortunate to observe another illustrative episode of Annemarii's ability to differentiate among her language resources. Busy in her morning routine, she started humming a song in Russian (Excerpt 26). I recognized the song as a music theme from a very famous Soviet cartoon "The Bremen Musicians". It is important to highlight, that the songs from Russian cartoons were essential language input that Kristina played regularly for the children. When Annemarii began singing I joined her, and we sang together.

Excerpt 26 "Bremen musicians" (May 9, 2017)

\begin{tabular}{|c|c|c|}
\hline Я: & $\begin{array}{l}\text { Annemarii, what's your } \\
\text { favorite song? }\end{array}$ & $\begin{array}{l}\text { Annemarii, what's your } \\
\text { favorite song? }\end{array}$ \\
\hline A: & Yes. & Yes. \\
\hline Я: & This one? & This one? \\
\hline $\begin{array}{l}\text { A: } \\
\text { (humming) }\end{array}$ & Я слушаю [agency]. & I'm listening. \\
\hline Я: & $\begin{array}{l}\text { А на каком языке они } \\
\text { поют, на русском или } \\
\text { эстонском? }\end{array}$ & $\begin{array}{l}\text { In what language do they } \\
\text { sing, Russian or Estonian? }\end{array}$ \\
\hline $\begin{array}{l}\text { A: } \\
\text { (continues } \\
\text { singing) }\end{array}$ & ой ля-ля, ой ля-ля. & La-la-la. \\
\hline Я: & $\begin{array}{l}\text { А какой это язык? } \\
\text { Русский или эстонский? }\end{array}$ & $\begin{array}{l}\text { What language is it? Russian } \\
\text { or Estonian? }\end{array}$ \\
\hline
\end{tabular}



A: Рукий.
Rusin [incorrect
pronunciation in Russian].
Я:
Русский?
Russian?
A:
Да, ой ля-ля ой ля-ля эха.
Yes, la-la-la.
Я: $\quad$ A nana поёт тебе эту
Does daddy sing you this песню? song?
A:
A нет.
No.
Я:
Он не знает?
He doesn't know it?
A:
Hem.
No.
Я:
А почему он не знает?
And why doesn't he know?
A:
Он не знает.
He doesn't know.
Я:
Но он не поёт, а кто
Who sings you this song, поёт тебе эту песню? mommy or daddy?
... мама или nana?
A:
мама.
Mommy.
Я:
А бабушки?
And grannies?
A:
Тоже.
Also.
Я:
Тоже? Какая бабушка noёm?
A:
Бременские музыканты. Bremen musicians.
Я:
A Аки знает?
And does Aki know it?
A:
Hет, не знает.
No, she doesn't.
Я:
А почему не знает?
Why doesn't she know it? 

A: $\quad$ Да, потому что Аки, $\quad$ Yes, because Aki knows in (sighs) по-русски знает.
Russian.
Я:
Она знает по-русски?
She knows Russian?
A:
Да, наверху.
Yes, upstairs.
Я:
Да, или по-японски? /.../
Yes, or in Japanese? What на каком языке Аки а, language does she speak? In тётя Аки говорит? По- Russian or Japanese. русски или по-японски?
A:
По-японски.
In Japanese .
(starts speaking in her gibberish language)
Я:
Ага, а дядя Том?
Mhm, and uncle Tom?
A:
Тоже (gibbersh).
Too.

Annemarii knew that it was her mother's song, and differentiated between people who could and could not understand it and sing it. When she explained why Aki did not sing this song I caught Annemarii labeling the languages for the first time. She explained that, Aki did not sing the songs because she did not know Russian. Although Annemarii confused the names of the languages while naming them, she clearly referred to the differences in the means of communication that Aki and Tom use. She demonstrated the same pattern, as with Jasmine's use of French earlier, switching to gibberish when she tried to imitate the language she did not know. Annemarii was not consistently exposed to French, Japanese, or English through her parents, and could not reproduce it, resorting to gibberish to maintain the conversation. 
Annemarie demonstrated phonetic awareness of languages in her environment. On several occasions she confidently corrected my pronunciation of her and her sister's names. Once I called Keiriin to play with us, and Annemarii looked at me and strictly said, "Нет, не правильно, нужно говорить Кэйриин” (Eng: No, it’s wrong, you should say Keiriin). She pronounced her sister's name with a distinct American English accent, aspirating her /k/, rolling her $/ \mathrm{r}$ /, and making the vowel /e/ more open. I made the second and third attempts to pronounce Keiriin's name, and again, and again Annmarii found some fault in my pronunciation.

Due to her age and language developmental stage, Keiriin did not show any features of differntating between interlocutors. Her dominating language of production was Russian, she was able to comprehend her father's utterances, and prefered a few words in Estonian over Russian. By the end of my research, as she grew older, and linguistically matured, she improved in her language performance, and started differentiating between Estonian and Russian more.

Annemarii's socio-dramatic play. Socio-dramatic play is an integral part of children's socialization and language development (Lillard, Lerner, Hopkins, Dore, Smith, \& Palmquist, 2013; Piaget 1962; Vygotsky 1967). Annemarii was regularly observed playing "family" with her dolls or with her sister, re-playing the episodes from her library trips, calling on a toy phone to her dad in the U.S, while they were still in Estonia. Linguistically her plays followed a predictable pattern of borrowing the features of the real situation she had participated or observed before. Her library story times were in English, her talks on the phone with her father were in Estonian.

At Annemarii's age, caught by the observation, re-playing social situations of parenting appeared to be an integral part of her social development and language socialization. Having a little sister, she had observed and participated in her up-bringing. Despite the language policy of 
having two home languages Estonian and Russian, Russian and English vividly occupied a more prominent position in Annemarii's "mothering" games. She always referred to a child as "a baby" (in English). Annemarii had evidently poorer exposure to "baby-talk" Estonian, for the time she spent with her father and her Estonian grandma was limited. One explanations of Annemarri's preference of English in her "parenting games" could be her mom occasionally using a baby talk with her in English and her other adult household members conversing with Annemarii in English. Moreover, another resource could be Kristina's casual baby-sitting jobs, where she always took her own children with her. The girls love playing with other children. Observing her mom baby-sitting English speaking children, Annemarii translated this pattern into her behavior with children or dolls. I heard her using English when imitating a telephone call to her baby-sitting English speaking friends. I observed Annemarii speaking English with her Estonian-speaking doll, Annalisa. Interestingly, although she understood what phrases Annalisa was saying in Estonian, I once observed her talking with her mom about Annalisa. She asked her mom to help her translate what Annalisa was saying in Estonian.

The following episode illustrates the dynamics of using English with an Estonian speaking doll very well. It was early afternoon of May 20. The Russian children's music was filling up the background. Kristina and Meelis were busy packing for the summer Estonia trip that would occur in a couple of days. They spoke Estonian. Keiriin and Annmarii were playing around, sometimes offering help to their parents by bringing them things to pack. Annemarii was playing with her Annalisa, an Estonian doll, evidently framing her conversational plays in English. I heard her saying “are you ok, that's ok, no?” Even when Annemarii was murmuring something, it was evident that intonation patterns, sounds, and random words of this imaginative 
language followed the English language pattern. Then she turned to her mom and momentarily switched to Russian.

Sometimes Keiriin also participated in those socio-cultural plays, and as she could not respond much, she mostly performed the role of the recipient of Annemarii's socializing experiments. Kristina shared that according to her observation the girls spoke Russian and English with each other, but not Estonian. On several occasions, I observed Annemarii coming up to Keiriin saying "Keiriin are you ok, you are ok". Kristina said that Annemarii often used the phrases "are you ok? it's ok, it's ok" referring to Keiriin or her toys. Having heard it from her parents communicating with other children, or from others addressing her, she practiced those phrases as important socializing formulae to enter the adult world. Annemarii used the language and linguistic tools of the situation she had been previously exposed to. She understood languages existence through language functions, the communicative task she wanted to accomplish.

Annemarii's socio-dramatic plays created a rich resource for her younger sister's socialization and language development. She also modeled ways of using different languages in different situations, for different communicative and self-expression purposes. In the following conversation Annemarii skillfully maneuvers between Russian, which she uses for communicating with Keiriin, to English when she wants to sing a song from her favorite Frozen animation (Excerpt 27). The girls are playing hide-and-seek, Annemarii is leading the game, directing her sister's actions. She also demonstrates metalinguistic analysis of Keiriin's utterances. The way her little sister pronounces her name amuses her, and, at first, she laughs, offering a gibberish word, but then supports Keiriin, providing the right pronunciation of her name, "yes, Annemarii". This move is a clearly stated act of realizing and performing her social 
role of an adult. By using Russian, she might be trying a role of their mother. The episode closes with Annemarii singing in English. She again invites her sister to participate, and by doing so she sets an example of language behavior.

Excerpt 27 "Let's go" (July 27, 2017)

\begin{tabular}{lll}
\hline Keiriin: & Амана, Амана, Амана. & Amana, Amana, \\
& [Keiriin calls her sister] & \\
A: & Идём Кейриин! & Let's go Keiriin!
\end{tabular}

(Keiriin shyly enters the room, as if playing hide and seek)
A:
Bom mbl где!
Here you are!

Keiriin: Амана. Amana

A: Би ло ба. [gibberish]

Keiriin: Амана. Amana.
A: Да, Аннемерии, ...Кейриин, Yes, Annemrii, ... Keiriin, идём делай мне привет, let's go, tell me "hello", Кейриин. Keiriin.

Keiriin: Пивет. [childish pronunciation Hello. with mispronounced $/ \mathrm{r} /$ ]
A
Идём Кейриин, идём Кейриин, Кейриин, идём, идём... let's go
Keiriin: Пивет. Hello.

(Keiriin re-enters the room and leaves again) 
A: Peekaboo. Peekaboo.

[Annemarii starts talking to herself, it looks like she is singing a song]

A

"I can fly, ... I'm, I can be a ...” [singng], Keriin, come see

Кейриин идём посмотри, что what I'm doing.

я делаю.

[singing]

[Annemarii starts dancing and

singing again]

«you will be.. ha, la, la, kipola,

la, la, like, you can

remember...»

Annemarii starts singing definitely in English while they re choosing which shoes to wear for the walk outside.

Thus, in her socio-dramatic plays Annemarii demonstrated the awareness of the interlocutor's language in her imagined situation, or was reproducing the linguistic situations she had encountered before.

Use of English. Previous section illustrated Annemarii's occasional use of English in socio-dramatic play. In this section, I will focus on the situations when she used English for her own communication and exhibited more interest toward knowing English equivalents for the words she knew in Estonian and Russian.

In May, I did not observe Annemarii's actively participations in conversations in English, apart from re-playing social interaction phrases modeled after the adults, library story telling, and singing songs along with Alexa radio and music themes from her favorite Disney cartoons.

Her bursts of library story times, replayed at home, illustrated this dynamic. Every Tuesday at 10 am Kristina took the girls to the local library. Annemarii, familiar with the routine 
would look forward to another reading adventure very week. The library reading sessions included singing, listening to music, playing the instruments, and would usually finish with a story read by the librarian, when she was holding out book showing pictures to the children, turning pages one by one, and sometimes pausing to ask children questions about the story or the pictures. The girls enjoyed their library outings.

Annemarii's home story times followed similar pattern and were always framed in English. She would take a book, hold it out showing to the audience and pointing to the pictures, carefully turning the pages and telling her story. She vividly tried to annunciate some of the words in her narration, pausing, making an eye contact with the audience, doing the comprehension check, like the librarian did. Along the way, not having rich vocabulary in English, she would create her own words, and mix up English with her imaginative language. During one of her story time I could distinguish the following words: «kitty cat”, "what's up”, “a princess", "the dog". Then she would switch to Russian and say "eщё», and then back to English again, «ok», and continued in her imaginative language. She used «ok» several times throughout the story to link the parts of her imaginative story. The following example illustrated this dynamics (Excerpt 28).

Excerpt 28 "Look it talk, look it talks" (May, 8 2017)

A: What do you do today? What do you do today? /.../

A: $\quad$ Look it talk, look it talks (?) look it talks. Look it talk, and then bla-bla-bla, baby, 


$$
\begin{aligned}
& \text { princess (!), and the } / . . . / \text { princess with } \\
& \text { dress ... kitty cat princess. } \\
& \text { /.../ }
\end{aligned}
$$

A: Вот этот, ещуе не прочитали. We haven’t read it yet. Then she switched to Russian again, addressing her comment to me, then English took over in her "bla-bla-bla".

This translanguaging between English and Russian demonstrated her ability and intention to assign different functions to the languages: Russian was used for communication with me and English for retelling the story. She knew that she had to communicate with me similarly she did with her mother, but the rule for the story was to be told the way she hears in the library, in English. Telling me a story in English, she assumed that I understoond it, but not because I knew English, but because that was the linguistic form how the story existed and needed to be told. She expected me to understand it. Although, this project did not focus on cognitive side of language acquisition, it is worth noticing Annemarii's use of the verb "talk" in $3^{\text {rd }}$ person singular: she switched from "talk" to "talks", and then back to "talk". The conjugation was not well internalized yet, but her language performance demonstrated the development of the structure.

The following episode corroborated the previous findings demonstrating Annemarii's understanding of languages and their functions. Once playing with Annemarii, I tried to make an experiment and switched to English trying to test and control her language choice, I was testing Annemarii's awareness of language functions and interlocutors. She showed already familiar to me pattern of language choice based on the function of the utterance nd the interlocutor. The 
epsode began with Annemarii deciding on which book to read. She chose the Estonian book with coloring pages, the one her mom was talking about the day before. She remembered that it was an Estonian book, and her father could read it to her (Excerpt 29).

Excerpt 29 "I'm a big princess" (May, 9 2017).

\begin{tabular}{|c|c|c|}
\hline A: & Вот эту давай почитаем. & Let's read this one. \\
\hline Я: & $\begin{array}{l}\text { Давай /.../ это какая русская } \\
\text { или эстонская? }\end{array}$ & Is it a Russian or Estonian book? \\
\hline
\end{tabular}

А: $\quad$ Эстонская. Тут Анне будет красить.

Я: $\quad$ Да, Аннемарии будет красить.

A: Kuca.

Я: Кису будешь, кошку?

A: $\quad$ Kitty cat. Kucy зовуm Kitty cat /.../ смотри ...that book. /.../

A: Anna is a princess, and Natasha a princess.

Я: $\quad$ I'm a princess.

A: Yes.

Я: $\quad$ I'm a kitty cat.

A: No, you are no kitty cat.

Я: $\quad$ I'm a kitty cat, meow, meow.

A: $\quad$ You are not kitty cat, no.
An Estonian one, Anne will be coloring here.

Yes, Annemarii will be coloring here.

Kitty cat.

You will color kitty cat, a cat?

Kitty cat. The cat's name is kitty cat /.../ look... that book.

Anna is a princess, and Natasha a princess.

I'm a princess.

Yes.

I'm a kitty cat.

No, you are no kitty cat.

I'm a kitty cat, miau, miau.

You are not kitty cat, no. 
Я: $\quad$ And who are you?

A: $\quad$ Princess, I'm a princess, princess, pretty pretty princess. I'm a pretty princess.

Я: $\quad$ I'm a pretty princess too.

A: $\quad \mathrm{Ok}$, you are princess ... mbl большой приниесса.

Я: Я большая принщесса?

A: Да.

Я: $\quad$ Большая.

A: $\quad$ я тоже большой, смотри как я могу.
And who are you?

Princess, I'm a princess, princess, pretty pretty princess. I'm a pretty princess.

I'm a pretty princess too.

OK, you are princess ...you re a $\mathrm{big} / \mathrm{m}$ princess.

Am I a big princess?

Yes.

Big.

I am big/m too, look how high I can jump.

Annemarii starts showing me how high she can jump.

Mixing languages in one utterance, she showed a gradual and very confident shift from Russian to English. She understood the meaning in both languages and for her the language switch was natural maneuvering between different communicative purposes. She continued in English, opening up her story time. Annemarii’s move to Russian in order to describe me as “большой принцесса" (Eng: big/ m princess) might be interpreted as her transition from the story telling to holding a conversation with me, and Russian was a more familiar and comfortable mode to perform the task ssdering the interlocutor's language profile. When I supported her move and replied in Russian, she eagerly followed me. This scene also revealed Annemarii's agency in leading the conversation and choosing the language mode. The choice of languages at her repertoire helped her mark her communicative intentions. 
Over the summer Annemarii vividly progressed in language development in general. Upon return from Estonia she became more interested in English. The parents continued their support of this interest in English use, yet, not allowing the language mix. She expressed her interest in how to say certain phrases and words in English. It might be connected to her interest in Disney films that they had begun watching regularly in English over summer, and the parents' language focus shift from Estonian and Russian only to English, as they made a decision to return to Estonia after spending one more year in the U.S. As they went to various concerts and performances she became more aware of the dominant language, English, she heard around. She gradually started extending a network of her English communicative partners, one of which became Choco, their household dog.

The following two episodes illustrate Annemarii's communcation with Choco. Kristina and the girls were getting ready to leave for a walk (Excerpt 30 and 31). They picked up the shoes and go upstairs. Annemarii rushed upstairs to hold the door for Keiriin and her mom. She saw Choco sleeping on the coach in the living room and said,

Excerpt 30 "Choco, don't sleep on the couch" (July 27, 2017)

A: $\quad$ Choco, don't sleep on that bed, couch!

K: $\quad$ why not? Почему ему нельзя на диване спать.

Why not? Why cannot he sleep on the couch?

A: потому что он на кровати cnum.

Because he is sleeping on the couch.

K: $\quad$ нет, он может на диване No, he is allowed to sleep on тоже. the couch too. 
Both episodes showed Annemarii switching from Russian to English, and and back when she changed her communictive partners. She maintained English mode with Choco, reproaching him for sitting on the coach or urging him to hurry up, and Russian in her explanations to her mother. Kristina also tried to maintain Russian with Annemarii, however slipping once. Her use of «why not» in English could be explained by her own personal rection to the situation rather than a purposefu switch to English. On many occasions Kristina shared that English came more natural to her than Russian, with the latter being sometimes a real "struggle" to express herself in. This repair of the language slip of tongue demonstrated the mother's persistance in maintaining OPOL rules in th family.

Excerpt 31 "Choco, you get this" (August 3, 2018)

A: $\quad$ вот она, ябуду с ней, ... я буду с ней гулять, ...мама, а где... Чоко нюхает. ...она нюхает.

K: $\quad$ Чоко знает, что мы пойдем гулять.

A: Мама. я пойду с ней гулять.

K: ..с ним. Чоко мальчик.

A:

$\mathrm{K}$ :

A:

$\mathrm{K}$ :

Holding out the leash

A: $\quad$ Choco you get this, ... $я б у д у с$ ней гулять. А Кейриин как?
Here she is, I'm going for a walk with her... Choco is sniffing, she is sniffing.

Choco knows we re going to take him out.

Mommy, I'm going to take her out.

Him, Choco is a boy

Yes.

So, we say "with him".

And I'm a girl.

Yes, so we say "with her”.

Choco you get this... I'm going to take her out. And what about Keiriin? 
K: $\quad$ Кейриин с нами, пешком. Keiriin will g with us on

Kristina puts the leash on and open the door.
A: $\quad$ Go Choco! Go!
Go Choco! Go!
K Go Choco!
Go Choco!

They leave for a walk.

Among other instances of the English language use, in September I observed how Annemarii initiated the conversation in English and communicatively constructed the whole interaction with other English-speaking members of the household. Tom and Aki, were getting ready to go to Costco. Annemarii and her family had just finished their breakfast and Annemarii was playing in the living room (Excerpt 32). When she saw Tom grabbing the bags, curiosity made her accompany them to the door, and Annemarii asked:

Excerpt 32 "to Costco" (July, 28, 2017)

$\begin{array}{ll}\text { A: } & \text { Where you go? } \\ \text { T: } & \text { To Costco. } \\ \text { A: } & \text { We are going there too. } \\ \text { T: } & \text { Oh, you are going there too? } \\ \text { A: } & \text { Yes. }\end{array}$

It was the first complex logical conversation with the question, response, additional information, and confirmation I had a chance to observe during the data collection. It illustrated Annemarii 's growing competence in English, along with developing her language skills in Russian and Estonian. Her active vocabulary in English was smaller than those in her parents' languages, but it was developing fast. She independently evaluated the communicative situation, and the linguistic codes, and initiated and held a conversation in English. 
Creating with the languages. Although being more proficient in Russian (due to availability of literacy resources, structured instruction, and number of literacy practices and events in Russian initiated by the mother), Annemarii demonstrated language creativity in all family languages and English, actively or passively. The episodes of her creating in multiple languages indirectly demonstrated her multilingual communicative competence, as language performance data can "provide inderect evidence about children's underlying linguistic competence" (Genesie, Boivin \& Nicoladis, 1995, p. 19).

The following examples derived from NOCs and observations shed light on Annemari's creative language use. It was Mother's day in the family (May 14). The family gathered in the dining room enjoying their lunch. This time it was noodles time. Meelis also wanted to give some boiled egg to the girls, but Annemarii made a face showing she did not want to eat them. Because Keiriin loved them, Kristina began peeling the egg and giving it to Keiriin, and Annemarii could not miss a commentary (Excerpt 33).

Excerpt 33 "How tasty” (May 14, 2017)

\begin{tabular}{lll}
\hline $\mathrm{K}:$ & Нямка какая! & How nom-nom! \\
$\mathrm{A}:$ & Нямка не какая! & How not nom-nom! \\
$\mathrm{K}:$ & Какая вкуснятинка! & How tasty! \\
$\mathrm{A}:$ & Какая не вкуснятинка! & How not tasty! \\
\hline
\end{tabular}

In this episode Annemarii demonstrated her grammatical competence in constructing negative sentenses in Russian: the negative particle "He" (Eng: "not") precedes the word the meaning of which is negated. This scene showed that she confidently used and placed negations 
in her utterances. However, the sentences she constructed in this scene, although being grammatically correct, were not stylistically appropriate. She took the structure her mother provided and inserted the negation. She laughed as she definitely found it funny to contradict her mother in such a playful manner. During the whole data corpus, this scene was the only instance of Annemarii's creative use of the negation. Doing it twice in the consequtive sentences, she demonstrated her intentionality of a grammatical game tht she found amusing.

Another example comes from Annemarii's creative use of English during the after-trip ethnographic observations. Almost identical situation happened during another meal time, but the reverse communication task was in focus, when Annemarii changed a negative construction into an affirmative one. When Keiriin became full having her dinner, she began playing with food. She babbled "no mo, no mo", something resembling "no more". Her father picked up on Keiriin's words asking for clarification (Excerpt 34).

Excerpt 34 "Yes, more" (August 5, 2017)

M: $\quad$ No more? No more?

Annemarii hears that and repeats:

A: $\quad$ No more.

Meelis continues his conversation with his wife. But Annemarii picks up on this play and reacts

A: $\quad$ Yes more! Yes, more, yes, more, yes, more, no

(turning it more, no more, yes more, yes, more. into a song) 
In this scene Annemarii turned negative statement into affirmative adding an element of a play, as she made a song out of the phrases. Such a comment evoked mother's pleased smile, wo was proud of her child's creative use of the language. Annemarii demonstrated comfort and confidence with the English language, as with Russian before, the language creativity came naturally to her and into her multilingual world.

Another example of Annemarii's language creativity comes from Estonian. In this case she engaged her father in a word game, in which her gibberish bore distinctive features of Estonian. It was one of those relaxing May afternoons, when the father and the children were chilling in the living room. Annemarii put her princess dress on and began singing some tunes form her favorite animation "Frozen". Keiriin was making herself busy running around. There was always something to grab, to drop or to throw for her. Trying to engage Annemarii in some game, Meelis pointed to a picture of a mermaid in the book. Annemarii responded to her father in Estonian but then switched to Estonian gibberish (Excerpt 35). She was persistent in pushing her own language, and did not repeat after her father despite his persistence. The child's agency in language practices is evident here; Annemarii was not only creating her imaginative language, but was shaping the conversation with her father, taking the lead.

Excerpt 35 "Koli boli” (May, 19 2017)

\section{M:}

A:

M:
Annemarii. Kus Keiriin on? Annemrii where is Keriin?

Here.
Siin.

A leidsin.

Kei tantsib.

Tule tee issile kalli.
Oh, I found her.

Kei is dancing. Come give daddy a 

Annemarii.
hug, Annemarii.

A: Mkm. No

M: Kes see on? Who is this?

(pointing

to the

book)

A:

Uidid.

(gibberish)

M:

Merineitsi.

Mermaid

A:

Merukuidid.

(gibberish)

M:

Meri...neitsi.

Meri koli.

Mer...maid.

A:

M:

Meri...neitsi.

(gibberish)

Meri...neitsi.

A:

Koli bolik.

(gibberish)

M:

Kes see on?

Who's this?

A:

(gibberish)

(gibberish)

M:

Kes see on?

Who's this?

A:

(gibberish)

(gibberish)

M:

A kes mina olen?

And who am I?

A:

(gibberish)

(gibberish)

As Meelis heard Annemarii saying a wrong word for the "mermaid" in Estonian, he, at first, attempted to correct and direct his daughter's utterances. The word that she offered to her father consisted half of what he wanted her to say and half of her imaginative element. $\mathrm{He}$ insisted on her repeating the word, pronouncing it syllable by syllable, until he realized that she 
was turning it into a game. His persistence was not coming out as fruitful, and he switched to the question strategy. After gaining no proper intelligible response to his question "Who am I?" he gave up in this word battle. There was an evident pattern in Annemarii's utterances, she created in a language, picking up on her father's word, modifying it in her own way, and picking up again. Her answers showed development, and not a random babbling.

Enjoying this language puzzle, Annemarii confidently used the resources that were available to her, all three languages, Russian, Estonian, and English, which was not a language of her family language policy, but the language of her environment and one of the languages of her household. Through creating with languages she did not only test her language skills but also exercised her agency. The last, Estonian piece is particularly illustrative of it.

Commenting on the parents' role in Annemarii's language creativity, it was observed that with Russian and English, they supported their child and were even pleased that she exhibited relatively high level of language development for being multilingual, as she demonstrated "an intuition", "some feeling for the language." Regarding Estonian, the father chose to correct the child and even employed various methods to do so, striving for better comprehension. With her mother Annemarii's language creativity throve: Kristina was very supportive of those language games.

The exmination of the socio-dramatic play, the use of the English language, and language creativity exibited by Annemarii improved my understanding of the development of children's multilingual competences in the family. The children are sensitive to the lingustic context and the communicative need, and use appropriate resources to respond and participate in communication. In sum, the children's language use occurs as an integral component of the language socialization. The children absorb and model language behavior of social situations in 
which they actively participate. Social situations are framed by particular language codes, and by modeling them the children learn how the world functions.

\section{Defining the Kiisk's Family Language Policy}

\section{The Kiisk’ Family Language Policy}

Exercising their beliefs about language, multilingualism, and language learning the Kiisks developed their own "system” of multilingual parenting, exercising “impact belief” (De Houwer, 1999). This system allowed the parents to be always purposeful and on task with their language decisions and use, and already elicited positive and proud results: their daughters comfortably and confidently conversed in Russian and Estonian in the family and with their friends, and also were successfully acquiring and confidently communicating in English. The approach chosen by the family for their multilingual parenting structurally resembled OPOL (one parent-one language) strategy (Piller, 2001), widely used in bilingual families. OPOL is "axiomatic in recommendations for bilingual parents and bilingual parents themselves regard it as 'the best' strategy" (Piller, 2001, p. 65). The Kiisks displayed relevant consistency with the chosen "system" directed towards children's language use, but, yet, occasionally - especially after the family decided to return to Estonia - the parents were observed to create spaces for children's acquisition of the language of the dominant environment, English. The parents also practiced occasional translanguaging between each other, maneuvering between Estonian and English, and very rarely inserting Russian words and phrases. Therefore, the family OPOL was not pure.

To describe the Kiisk's language "system" in more detail, first, I will examine language spaces created in the family, then I will present the parents' decision making behind the construction of their family language practices, and finally I will develop the principles of the 
Kiisk's OPOL and family language policy.

\section{Language Spaces}

I identified four language spaces in the Kiisk's "system" as of the data collection period (May 2017-September 2017): Russian, Estonian, English, and other languages, and explored each of them across the following parameters: agents of the socializing space (who?), place (where?), time (when?), the process of socialization (how?), the reason to create the space (why?), the ideology of the space and the concerns the parents have about the space. The spaces intertwined or overlapped in one or several points, primarily in agents of socialization, places of language use and the process of language exposure and learning. It signifies that the environment of children's language socialization is very complex, one agent was a source of multiple language inputs, and one place created the environment for practicing multiple languages. In terms of the process "how the language is acquired and taught", interaction with print and audio materials, and face-to-face and virtual conversational practices were the most common.

The family's language network is rich; this diversity signifies the family's broad social connections constructed by their life style and transnational experiences. Each language in this network performs a particular meaningful social function connecting Kristina and Meelis to their relatives, shooting and university friends, their household social circle. At different periods of life, as Kristina highlighted, a certain language would gain more importance and others would wait at the background. Overall, all language spaces in which the family navigated and which it created, formed a meaningful discourse of the Kiisk's socio-cultural life, and their "selves". 


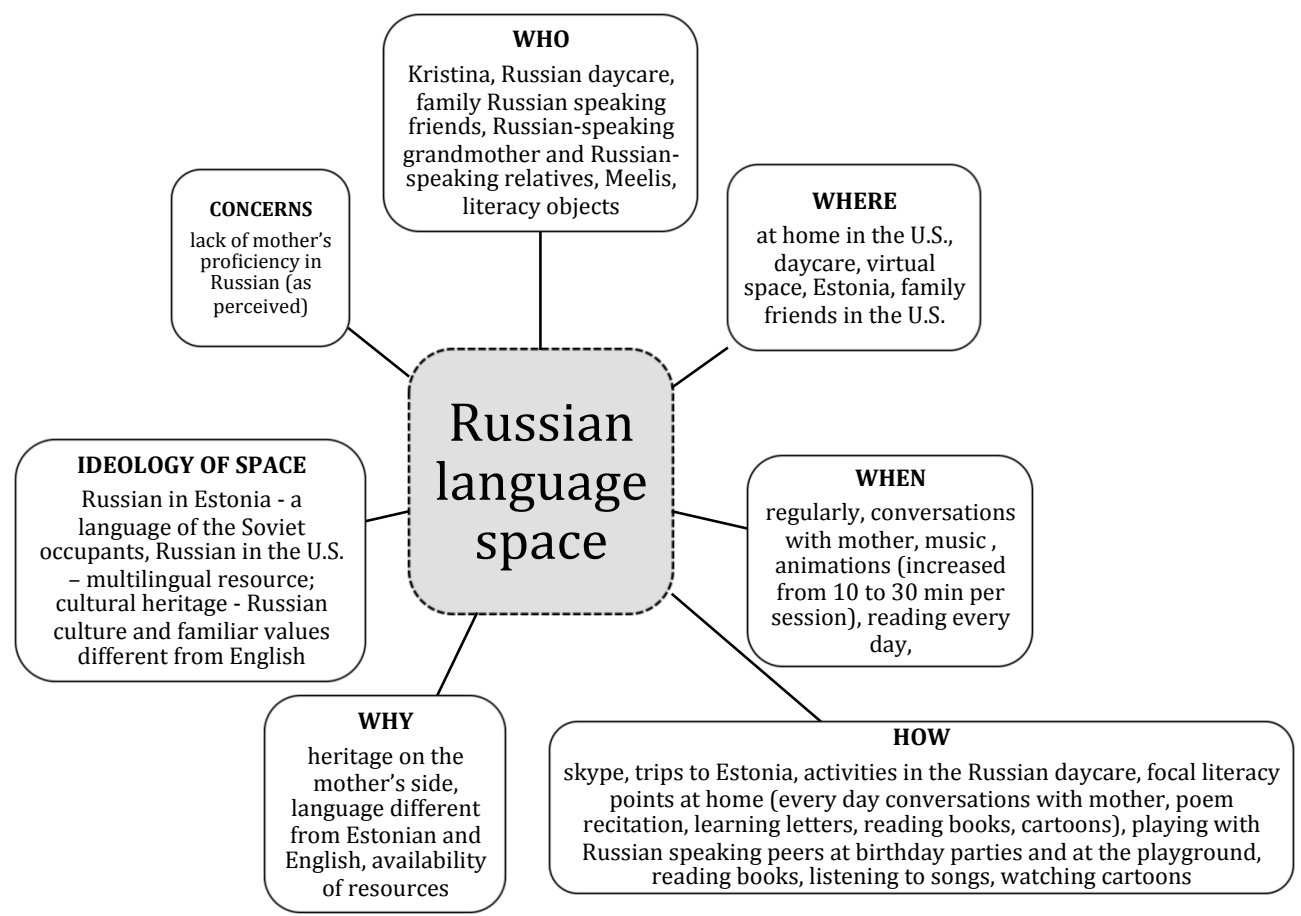

Figure 7. The Kiisks' Russian language space

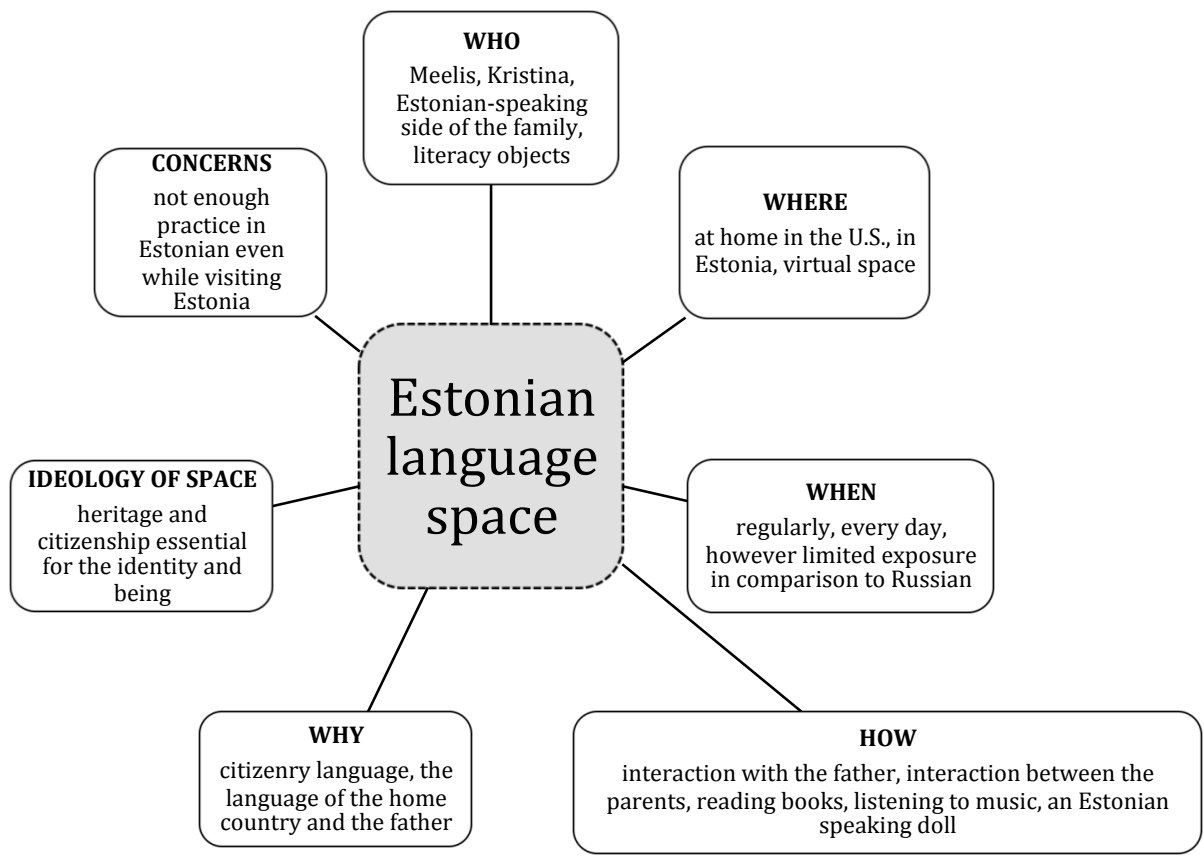

Figure 8. The Kiisks' Estonian language space 


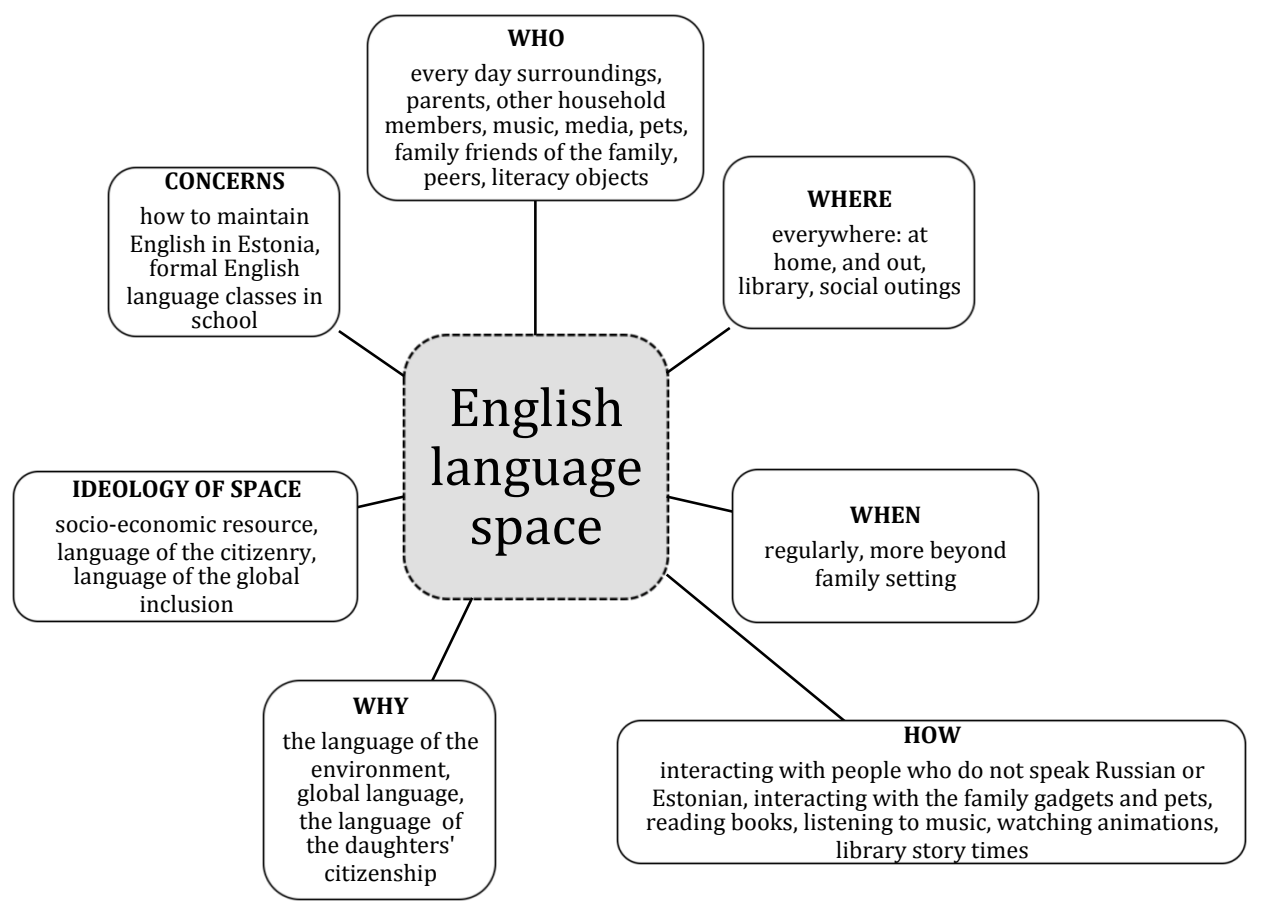

Figure 9. The Kiisks' English language space

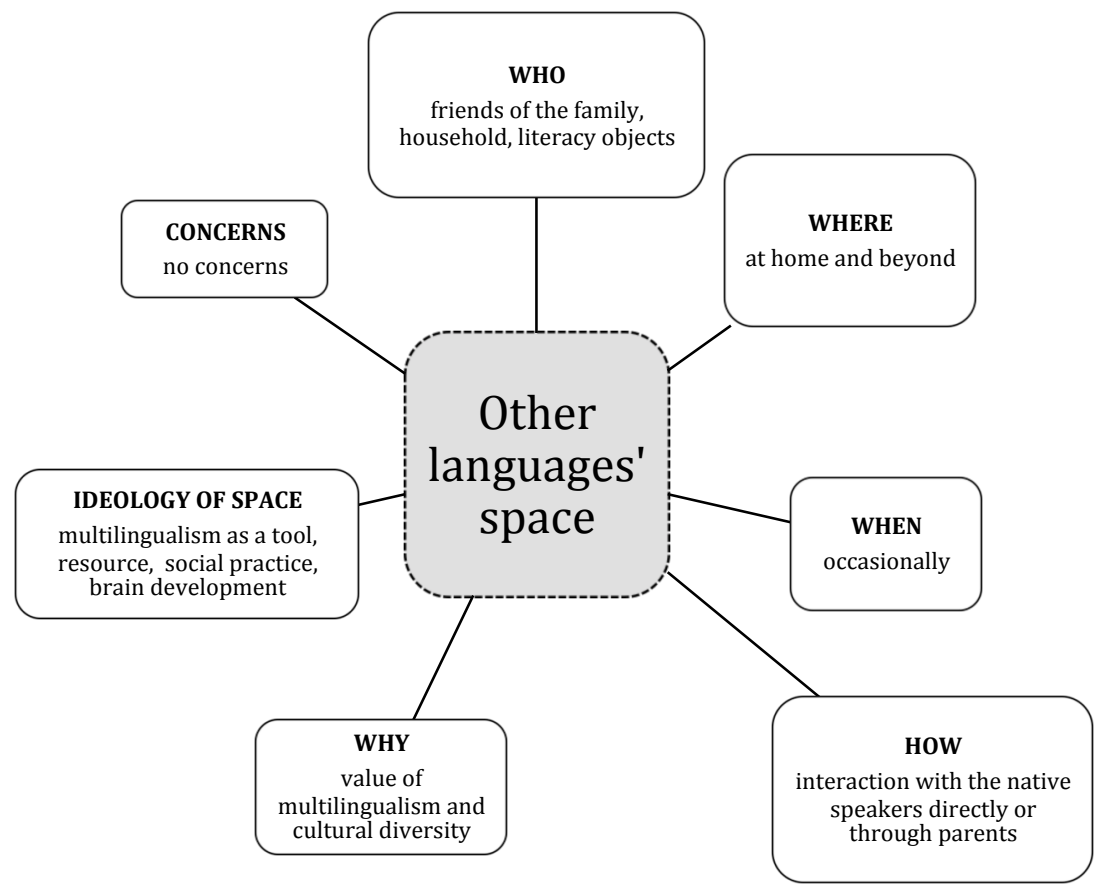

Figure 10. The Kiisks' other languages' space (French, Japanese, German, Spanish, etc.) 


\section{Constructing Family Language Policy}

In their interviews, the Kiisks shared that they began considering OPOL even before their first daughter was born, as for both of them having a command in at least two languages was a live necessity and a norm. Thus, their family language policy was "a planned affair" (Grosjean, 1982). Being brought up bilingually Kristina did not experience OPOL and until she went to school, she was growing mixing up languages, her Estonian speaking father and grandfather used Russian and Estonian interchangeably with her and the whole interaction was not systematic. Moreover, the context she was growing up was bilingual beyond the family space: in the time of the Soviet Union, literacy materials were accessible in both languages, Russian and Estonian, and Russian served as "lingua franca" in the multiethnic and multicultural Soviet republic and later early post-Soviet space. Schooling was available in both Estonian and Russian, and Russian was an "unofficially" mandatory foreign language in the curriculum. Experiencing this natural language exposure and acquisition, Kristina might have constructed the value and affordances of natural multilinguistic development.

Kristina, being active bilingual since childhood and a grown multilingual, did not have any doubt about her children possessing multiple language competences and did not hesitate to create conducive environment for their multilingual development, if not from the conditions of the environment, but as a result of her own efforts teaching her children a variety of languages that she knew. In her interview Kristina shared, "I knew it would be something else, not Estonian or English that I would speak to my kids". Further she highlighted that even though Meelis and she did not have discrepancies about language policies in the family, as they shared the views on multilingualism and language learning, Meelis still felt uncomfortable to have his children speaking the language he was not fully competent in, Russian in their case. Having a religious 
belief in multilingualism, Kristina insisted on Russian language practices in the family and shifted responsibility to Meelis to improve his command of Russian. She shared:

And I was like "you know that I'm gonna teach them Russian and you know that I would be speaking some, so it's your responsibility to learn some. I will not not speak Russian to them because you don't speak it. But there was a discussion one time but he never opposed it. From what I know he is very open, and I think he is very excited about the fact that they speak so many languages. It's a good thing. So, it was a very mutual decision. He was totally fine with me speaking Russian and them picking up English. (Kristina, interview, July 28, 2017)

Estonian and Russian OPOL policy in the English-speaking context contributed to the parents' plan to raise their children as balanced multilinguals. The Kiisk's system was welldefined, well-organized, and well-orchestrated responding to and leveraging the demands and affordances of the particular socio-cultural and economic contexts of their life. As Kristina pointed "there is everything categorized and there is a reason behind everything... I can explain all of my decisions. It's not just what comes “oh, grandma will teach you Russian /.../ I have to be more systematic about it and I'm very glad and proud that we are." (Kristina, interview, August, 2017). The loyalty to the system derived from family's ideologies about language(s) and language learning, reflected their own language experiences, interpreted through the lens of the contemporary worlds, and aimed at creation of a multilingual family.

\section{The Kiisk's Family Language Policy Principles}

I can derive a range of rules and principles that the family followed to support the 'ideal' implementation of their family language policy. 
The first rule is to expose children simultaneously to three languages. The parents utilized two different languages when they interacted with their children, and the third language was the language of the environment. In the U.S. context, the family languages were Estonian and Russian, and English was the language of the environment, and according to the family's plans upon their return to Estonia, Russian and English will be home languages and Estonian will be the language of the environment.

Second, the family employed systemic approach to their language polices being very consistent about language use. Both Meelis and Kristina on different occasions referred to their family language choices as a "system". Kristina covertly criticized her younger sister for language mixing and parental language laziness in her family, "her daughter does not speak, and it's worse than my kids". During their Estonia trip in summer 2017, Kristina's language choice and behavior did not change, and she kept her Russian duty with her children, letting others communicate with the children in different languages.

Third, parents were responsible to educate children multilingually and as multilinguals. On multiple occasions Kristina and Meelis highlighted their enthusiastic investment into their children multilingualism, and the parental duty that lied behind this; and as was illustrated above, they regretted that some parents underestimated the importance of multilingualism and multilingual development of their children and choosing the path of least resistance opt for the most convenient language, the dominant language of the environment. Kristina and Meelis were proud of their efforts to have "the system" and to expose their children to a variety of language experiences, and inquired "if not us, who?"

Forth, the parents were raising their children as "balanced" bilinguals (cf. Piller, 2001). Following OPOL the parents value the development of proficiency in each language, not 
supporting language mix. If it happened it was imbedded into a learning task aimed at raising children's language awareness. Kristina often took the role of the teacher and corrected her children's Russian, Estonian and English (see more in practices). Creating the solid foundation in the language was perceived as the key to the future multilingual success.

Fifth, the parents believed in simultaneous language acquisition and natural language attainment from an early age (cf. Piller, 2001). Language acquisition accompanied language socialization and was an integral part of it. The parents taught children to communicate with the world rather than to know the languages. They encourage language switch in their children if it was communicatively oriented.

Six, "nativeness" and "authenticity" in the language were strongly valued but not to the exclusion of a good command of the language, which was considered enough for implementing OPOL. Thus, authenticity rule which is one of major characteristics of OPOL (cf. Park, 2008; Piller, 2001; Chisato, 2015) was not strictly followed. Meelis spoke his native language with the girls; but Kristina, bilingual from the childhood, chose Russian, the language she was least proficient in, in her own opinion. She believed she could give the children legitimate foundation by her hard work looking up the words in the dictionary or referring to native speakers for help. She occasionally wrote to me asking for a translation a certain animal, a fruit, or an action into Russian, or asking for a grammaticality of a phrase. If parents had a good command of the language they strongly believed they could teach it to their children. Parents were not excluding themselves from a group of native speakers, and did not pose themselves as "non-native" of English when they talked about their decision to start speaking with their daughters in English after they return to Estonia. Instead, the parents focused on multilingualism, "I think the initial idea that I would switch to English with them, to make sure that they have enough exposure to 
English, as all the environment will be Estonian. And will make sure that they are still fluent in English, since we already started those three languages.” (Meelis's interview, July 27, 2017). Moreover, by highlighting that he wanted to ensure the girl's fluency in English even living in officially a non-English speaking country, Meelis pointed to global nature, importance, and prestige of good English language skills.

Seventh, the Kiisk's OPOL was predominantly mother-driven, the pattern similar to previous OPOL studies (e.g., DeCapua \& Wintergerst, 2009; De Houwer, 1999; Piller, 2007). The data demonstrated that Kristina initiated, guarded, and even directed the family language policy with her beliefs and practices. The distribution of roles in the family was a significant factor in this dynamics. Kristina took a role of the main childcarer while Meelis was responsible for the economic stability of the family. The mother spent more time with the children feeling responsibility for orchestrating the agenda and the process of language socialization. She developed and followed "schedules and plans." As was illustrated in practices above, Kristina's parenting curriculum was impressive, "while in the States during the year one of my specific goals is language learning, socializing and mental development (our systematic visits to the library, for example) as well as a bigger concentration on indoor play (crafts, books), then here [Estonia] it's a lot more centered on being outdoors, wild and free." (Kristina's trip journal, JuneJuly, 2017). This reflection revealed her analytical approach to overall human development and socialization. She thoughtfully identified various resources and invested them into her children and her family's future.

\section{Negotiating Identity through Family Language Policy}

The data vividly illustrated how family members negotiated their identities through their language choices, translanguaging in every day interactions, and simply positioning self in 
diverse linguistic, cultural, and ideological spaces. The parents' interviews revealed how they negotiated their identities through discussing their family language backgrounds and language learning choices throughout their childhoods and in their current family language policies, through their perspectives for their language future. Their ego-maps elicited how they position themselves functionally through each of the languages in their language repertoire now. Ethnographic observations and NOCs allowed me to glean identities being performed in every day language life. The trip journal displayed identity work through retrospective account of the language situations, and language interactions in the family prompted by the trip. In what follows next, I will discuss the identities negotiated by the parents for themselves and for their children, and identities negotiated by the elder child, Annemarii, through language practices.

\section{Parents' Identities}

Through their language beliefs and language behavior Kristina and Meelis positioned themselves as multilingual individuals and parents of multilingual children. Both parents supported multilingual practices of their children, and in their conversations praised themselves for the ability to manage successfully their family language "system". The success was evident in their children's good commands of Estonian and Russian, and emerging English. Further, I will focus on describing identities negotiated by Kristina, the mother of the family, as she appeared to be the "engine" of the family language system, and was also a very prominent figure in all the data that I collected. By focusing on the mother, I do not belittle the role of the father in the family dynamics and overall children's language socialization process.

\section{A language learner, a mother, a language educator, ... and what not. Defining} identity as "not necessarily the roots" but necessary "certain standing points", Kristina grounded herself in various ways in relation to her linguistic and cultural heritage, languages of her 
competence, and her language practices at home and across time and space. In her interview and language ego-map she identified language, cultural, heritage, and citizenship identities, as well as recognized certain local and global positioning of self, highlighting diverse contexts for those "standing points". Kristina also defined herself in relation to her role in the family. All of those "selves" were revealed as not exclusive but tightly intertwined, and, as I argue, present a transnational identity. Further, I will elaborate on Kristina’s language, cultural, heritage identities, and her identity as a multilingual intellectual and a parent-educator of multilingual children.

Linguistic identity. Kristina's language self was very complex. In her interview Kristina directly stated that she is "a language person" who was "defined through all the languages that I've studied and interacted with in my life" either through formal instruction or informal interactions through friends and shooting teammates. Successful intellectual multilingual was the most prominent identity that Kristina constructs. Being bilingual from her childhood, she frequently described herself as an eager language learner. She highlighted her fluent command of Estonian and Russian, when she was in the kindergarten, and her ability to read at early age. She also proudly shared that being in secondary school she starred in Russian language Olympiads, and won an award to participate in the festival "Northern Star" in Saint Petersburg with a group of other winners. Interestingly, on many occasions Kritina also highlighted the lack of proficiency in Russian, as if detaching herself from it (cf. Tse, 2001; and see Cultural identity).

Overall, Kristina clearly attributed her overall development to language learning experiences. She also excelled in mastering other languages in secondary school and beyond. In school English brought her to the U.S. to work on her BA. In college, she completed her independent studies in French course a level higher than she was expected to according to her 
curriculum. She also enrolled in courses of German and Spanish during her demanding graduate studies. She also did her best in using Japanese with her Japanese speaking household member. Languages seemed to penetrate all her activities and being. Overall, she positioned herself as a multilingual persona across geographical spaces, either in the U.S, or Estonia, or any country she traveled and lived in.

She embraced all the languages that entered her life but evidently put them in some personal hierarchy. Having Russian, Estonian, and English as major languages in her life, Kristina spoke Russian fluently and called it an important part of her heritage; but on several occasions she shared, and as the observations and NOCs revealed, her languages of selfexpression were Estonian and English. These two languages served her needs in speaking, writing, talking, and asking about various emotions, expressing praise or indignation. Kristina referred to Estonian as her first language and was categorical about her insufficient proficiency in Russian, as she had not read or written "enough in Russian beyond the scope of her family communication in her childhood and now interacting with her children”. Taking Russian as an L2 in secondary and high school, she referred to those classes as "a waste of time". Despite speaking Russian from birth, as her mother's confirmed, and learning to read in Russian before Estonian, Kristina labeled the former as her family language, giving the first language rank to Estonian. Estonian and English evidently played a greater role in her maturing as a person. Interestingly, in sharing her life experiences, Kristina employed the linguistic feature, the Russian language, as one of the characteristics uniting post-Soviet citizens, "our people, well, Russians, you can easily distinguish them abroad" (Kristina, personal communication, May 2017). The language identity became an essential part of one's being, especially against the bi/ 
multilingual background. Thus, linguistically she perceived herself as multilingual, a product of many linguistic experiences in her life across time end space.

Cultural and heritage identities. Kristina's cultural identity appeared to be more complex than the language one. Over the course of research while discussing her linguistic and cultural background, she referred to Russian as an integral part of her heritage, "it's part of my culture, part of my background, not Russia, but Russian, historically, ...not Russia as a country but Russian (language) background and culture". (Kristina, personal conversation, May, 2017). The choice of the Russian kindergarten for Annemarii was determined by "familiar cultural values" the Russian daycare could offer for their family. However, in her conversations about her family background Kristina stronger emphasizes her European heritage, "my grandma was German, grandfather has Finnish roots”, “my father is Estonian born in Siberia”. Although Kristina said she valued her Russian roots, to which she linked through her mother, she appeared to actively detach herself from her Russian heritage, emphasizing her European being and belonging. It could have been more of an association with the "Soviet Russianness" that she was trying to shake off of her Estonian shoulders.

Overall, she positioned herself as a cultural mix, Russian-culturally and Estonian by birth. The following episode was very illustrative in this sense. On a long drive to the Discovery Museum for Annemarii’s birthday Kristina began reminiscing about a day in April 2007 that caused a rift in post-Soviet relationship between Estonia and Russia. That day witnessed arrests, vandalism, and looting in downtown Tallinn, the Estonian capital, over the authorities' decision to move the statue of the Bronze soldier - a tribute to the Red Army soldiers who died fighting Nazi Germany during World War II - from downtown to the cemetery in the outskirts of the capital. Kristina was studying in the UK when those turmoil days shook her country, but recalled 
discussing this event with her Russian-speaking uncle. She told me, "belonging to two languages, and two cultures, I try not to take sides, and can be very rough with my judgments of both sides. I take the best of my identity of being bicultural, bilingual". Positioning herself as bilingual, she felt above the "nationalistic conflict" between Russians and Estonians: her dual language experiences allowed her to cognize the roots of the opinions, views, and tensions of both camps better.

On the other hand, Kristina repudiates to be associated with a Russian, and speaking the Russian language could signify her belonging to the Russian community in Estonia. "I don't want to speak Russian in Estonia as much as in the U.S., when I speak Russian in Estonia I want to let others know that I'm trilingual, and I do speak Estonian and English fluently as well'. People can speak the language but not culturally identify with the community of practice. Such a stance exemplifies the symbolic capital of Russian to be the remnant of the Soviet past. Kristina says "many people still bear a grudge against Russian associating it with the Soviet regime" (personal conversation, September 2017). Former Soviet republic's orientation to democratic West, as opposed to "suffocating communism" is reflected in the language choice of the new free generation of Estonians. When growing up Meelis was more exposed and drawn to English texts and resources, and as a result mastered it better despite having Russian speaking in-laws and his wife efforts to increase his overall proficiency in Russian.

Kristina's mom shared her observations of contemporary reconceptualization of the status and the value of the Russian language in contemporary Estonia, post "post '90s". She said, she felt that the tension towards Russian, and consequently, Russian-speaking population, reduced in comparison to the 1990s, "I can state that now the Russian language is not suppressed, and has not disappeared, ... it was different five years ago, now they again appreciate and learn the 
language" (Olga, skype conversation, October, 2017). However, Kristina still experienced the symbolic repercussions of the 90s, escaping heritage labeling, historical past, relationships between Soviet Russia and Estonia, when she positioned herself in the community of practice with which she identified the most, Estonian. Claiming her entry into the Russian culture through her heritage, she strove for and signified not her belonging to it, but the ability to understand it better. For her, Russian culturally became one of tools enabling her to belong to a group of intellectual multilinguals, global citizens.

Parent-educator. Kristina also positioned herself as a successful parent educator expressing herself through her children. As she directly highlighted many times and it was already illustrated on many occasion before, she was especially proud of their family to be an example of multilingual household in the U.S. Following OPOL policy she spoke Russian to her children outdoors and other public places, and did not miss an opportunity to elaborate in her small talks with others that her daughters also understood and spoke Estonian and English. In her trip journal Kristina recorded that when her relatives tried to switch to Russian speaking with her children, she had to explain that the girls were multilingual and could hold conversations. She enjoyed observing Annemarii successfully conversing with the English-speaking household members, friends or shop assistants, or giving commands to ALEXA radio (which programmed to react to English) to play her favorite Disney or children's song. It made her feel proud as a parent.

Frequently, as noticed throughout the data, Kristina referred to herself as a teacher, and highlighted the crucial parental role and utmost responsibility in passing on the knowledge, one of which was the knowledge of languages, to their children. She illustrated her pedagogical orientations in her every day behavior, by providing very well directed scaffolding in learning 
languages, which encompassed rich input, modified speech, initiation of traditional literacy events, and corrections. She taught her daughters languages across the borders. In her trip journal Kristina shared, "I notice that I facilitate between Estonian and Russian quite a bit. I guess I do it to maximize learning and/or understanding. A teacher in me wants to expose Rii (and Kei) to several languages for the same concept." (Kristina, trip journal, Week 6). In her interview she referred to her moments of language correction as "the teacher in me." (Kristina, interview, August, 2017). Switching off her teaching mode after almost 7 years of pedagogical practices was very challenging for Kristina.

Being a good parent of multilingual children, Kristina posed as a parent who not only valued multilingualism and actively engaged her daughters, and her husband as well, into multilingual behavior at home, but also invested time and efforts into it, and sought for various language development resources beyond her household walls. Her initiative to send Annemarii to the Russian kindergarten, regular outings to museums, concerts, and theater performances with their children are illustrative examples.

Kristina's successful multilingual parent identity was fully embodied in their wellestablished family language "system", "which "requires a lot of effort and patience, but I can see that it's working" (Kristina, interview, August 2017). She compared her children's language development achievements - the onset of speaking, the number of words each of her daughters speaks in both home languages, the differentiation between languages - to her sister's daughter's language attainment, and was critical of her sister switching between Estonian and Russian, that "her daughter does not understand which language to start speaking" (Kristina, trip journal, week 3). She even went further and while at home, as it became evident through NOCs, attempted to promote her multilingual parenting "system" in her sister and cousins' families. She initiated 
conversations in Russian with other children of the family, demonstrating a strong belief in the support of Russian, as an extra resource for intellectual and cognitive development, and a tool that the children should be exposed to and be given a chance to acquire if they had an opportunity. She positioned herself as a good parent and a good model to all bi/ multilingual parents or at least mothers of children growing in bi/ multilingual environments.

Citizenship identity. In her contemplations of her language, cultural and heritage self, and her children's identity, Kristina distinguished citizenship identity as a part of self-positioning of a transnational and or/ multilingual person. Firmly identifying herself as Estonian, rather than Russian - because she was born and grew up in Estonia, and her family lived there - she extended her vision onto her children's identity. In the following excerpt from her interview she illustrated how multiple identities - language identity, cultural, and citizenship identities - could co-exist. Kristina shared:

Right now I'm still geared towards they are Estonian, because this is where we are going to live, but I also very much appreciate the Russian roots, and their knowledge...it's funny because Keiriin speaks more Russian and Annemarii speaks Estonian with a slight accent and it's very funny for Estonians to pick up her accent. But I still would identify her more with Estonian than Russian, country-wise /.../ But ask me what they are, I don't really know. There is a little bit of everything, but mostly Estonian, if I have to pick one, I'd say Estonian. Just because we are from there. Because language-wise no, they are not. They speak less Estonian than Russian, but my family is there, even my mom, who is from Russia, is there. Our home is there, I was there, I went to school there, our friends are there. I associate myself most with that culture. (Kristina, interview, July 28, 2017) 
Referring to her children and her mother in this discussion of identifications and "standing points", Kristina highlighted the multiplicity and synchronicity of "being and belonging". In her view, identifications occurred in multiple dimensions simultaneously: her mother was Russian who had lived in Estonia more than half of her life, her children spoke better Russian than Estonian being born in an English-speaking country and holding both Estonian and American passports, but they were Estonian, in her vision. Citizenship identity is distnguished from national and ethnic identities, and became an integral part of self, as it engaged the person into a variety of language and cultural socialization activities, through the necessity to function in that particular context.

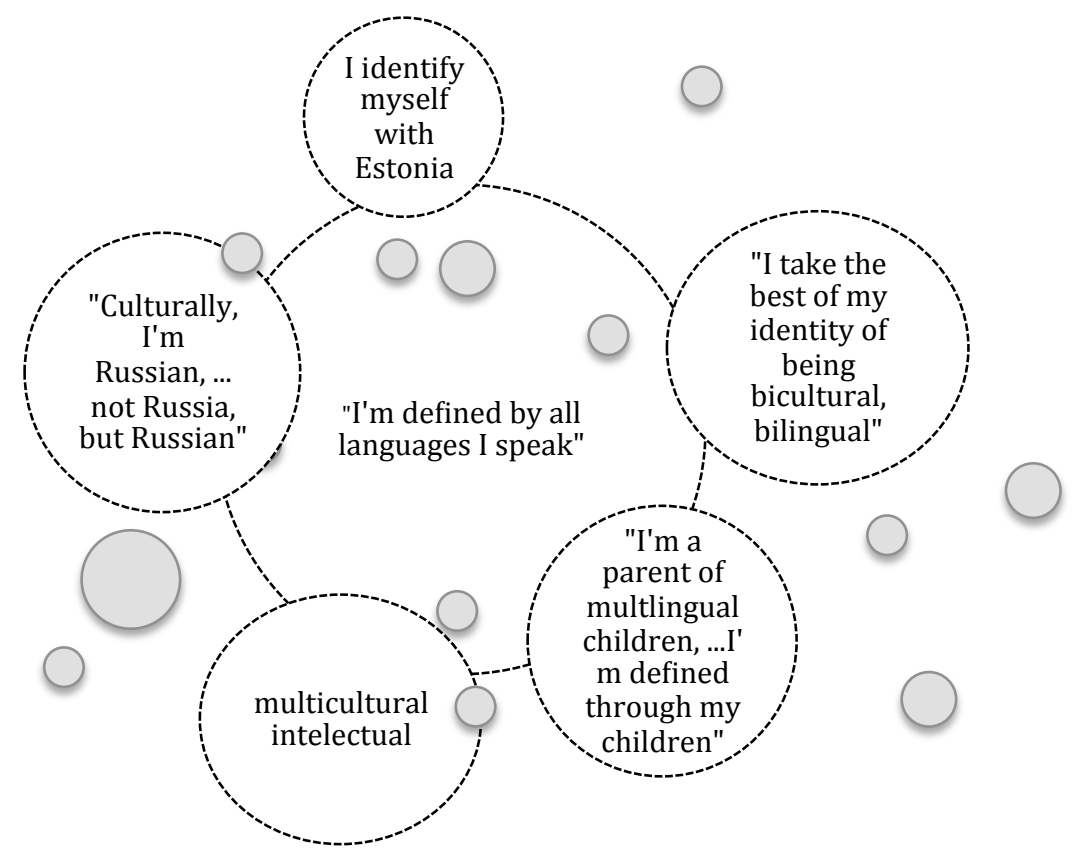

Figure 11. Kristina's identity cloud

Thus, the data illustrated that Kristina's multilingual identity elaborated into three essential parts: language identity (am I defined by what languages I speak?), cultural identity (what is my culture?) and country/ citizenship identity (am I defined by where I was born and 
grew up?). All of these, I argue, can merge into a transnational identity, which encompasses more than the sum of its all parts, e.g., multiple language identities, multiple cultural identities, and multiple citizenship identities. This identity may be localized and reveal context-dependent positioning of "Who I am in this place and how I function, linguistically and culturally, in this particular context, what is relevant for me?" or globalized "I'm multilingual, multicultural citizen of the world". Kristina's negotiation of identity is illustrative in this sense: for instance, the same linguistic identity, Russian, may be negotiated differently in the U.S. in the Estonian context, and during her trips to Russia in her childhood. The positioning is never the same in different contexts, even if it engages the same participants and the same resources.

\section{Constructing Children Identity}

Perceiving self primarily as multilingual intellectual Estonians, I observed that Kristina and Meelis cultivated children's core identity, in the same vein. The parents identified their children as Estonians, and wanted them to perceive themselves as Estonians. On a bigger scale they recognized linguistic and cultural diversity, and transnationality of their children. By creating and engaging their children in multilingual behavior, raising awareness of individual languages that their children encountered and spoke, Kristina was orchestrating the development of the sense of linguistic diversity and her children's ability to understand and communicate with a variety of people in a variety of contexts.

Little Estonians. As illustrated in the previous section Kristina confidently identified her children as Estonians, "there is a little bit of everything, but mostly Estonian, if I have to pick one, I'd say Estonian”, she said. Distinguishing between his children's language and cultural identity, Meelis posited, "culturally, we all will always be Estonian". 
Children's Estonian identity, as shown by observations, was constructed through material and communicative sources. The years of my personal interaction with the Kiisks, I observed, that an Estonian flag always had a reserved place on the wall wherever they lived, the car's number plate with the colors of the Estonian flag (which they regretfully had to replace upon moving to Virginia, according to the state regulations). Estonian space for children encompassed regular skyping and traveling to Estonia, their home country, religiously watching Eurovision (a popular European song contest that takes place every May) and cheering for Estonian participants, parents referring to themselves as Estonians in casual conversations with their friends, serving Estonian meals (calling some Soviet dishes Estonian, although they are common for all Soviet culture space), and in general referring to Estonia as home. Thus, being linguistically diverse, Annemarii and Keiriin were nurtured as Estonians in their hearts, because t was the home for their parents, the family originated there, and was planning to return there soon.

Transnational citizens. Both Meelis and Kristina in their interviews recognized transnational, linguistically and culturally diverse experiences of their children. In their account of the children's identity "localization" of identity (see Kristina's identity) in the form of the "first school language" becomes evident. Meelis stated he did not want to force an identity for Annemarii and Keiriin, as he thought "it will be largely shaped by what language they first go to school. I think we'll try to make it so that they would speak at least three languages fluently." (Meelis, interview, August 2017). Kristina expressed similar vision, as she could not underestimate the importance of her bilingual and bicultural childhood experience.

Kristina's reflection on her own heritage and identification of self raised an important issue of the role of birth and childhood place on the development of the sense of identification, 
despite the linguistic and cultural roots. She compared her children's context to her life story of growing bilingual with an immigrant parent. Kristina's mom, Olga, perceived Russia as her homeland and naturally raised her children with the sense of being Russian, with the cultural values of being Russian. However, growing up in Estonia, Olga's children acquired the sense of being Estonian. Having experienced this, Kristina expressed awareness about the possibility of her children identifying themselves as Americans, if they were to stay in the U.S. for longer. Kristina said that she could not oppose to such development, as it would be a natural course of events, "I don't know what we are, ... depends on the place we are going to live". Thus, selfidentification, in Kristina’s terms, was place-dependent.

\section{Children Constructing Identity}

Drawing on Annemarii's language behavior, in this section I will describe and theorize how children negotiated their identities despite their age and insufficient language competence. Annemarii signified "self" through the choice of language in socio-dramatic plays, creating with languages in her repertoire, and correcting an interlocutor's pronunciation.

Illustrative examples of Annemari's socio-dramatic play and her linguistic creations were detailed in the section on children's family language practices. Her language choice during the socio-dramatic play signified her intention to embody a person who spoke that language: either an adult soothing the child, when she was calmly repeating "it's ok, it's ok" talking to her doll or Keiriin, or a librarian educating the children through her story times. The instances of Annemarii's creativity with the language embodied her language independence. In the episode with the "mermaid", she did not only reject to follow her father's corrections of her pronunciation but engaged him into a game offering him one gibberish version of the word after 
another. She succeeded and the game with her father lasted for a several turns, till he understood the trick.

Annemarii acted out as a competent English speaker. On two occasions in August, 2018 she corrected my pronunciation of her and Keiriin's names in English directing me to American pronunciation. Not satisfied with my attempts to correct myself, she repeated her correct variant several times and then diverted her attention switching to another activity. Even though English was not her family language she confidently exposed her awareness of her English competency, making it a part of her "self".

The above examples demonstrated Annemarii's negotiation of identity through her language choice signifying her positioning in communicative situations and her appropriation of the language(s) in her linguistic repertoire.

\section{Summary of Findings}

Through the analysis of interviews, ethnographic observations, talk-aloud contemplations of "language selves" in language ego-maps, and mother's trip-journal, I investigated the family's language ideologies and practices, at the individual and family level, and derived principles of family language policies.

The family perceived language as a tool, as a resource, as a social practice, extending these qualities to multilingualism. Each language in their linguistic repertoire was assigned global and local functions in their relation to the life of the family and each family member: the global function encompasses the status of the language in the world and the environment where the family lives and resources available through that language, the local function includes the family's individual interpretation of the language meaning for themselves. Thus, Estonian becomes the language of their linguistic and cultural heritage and citizenry, there is more 
strategic meaning in Russian for children's intellectual and cognitive development, and overall multilingual and multicultural agenda, and English is the language of global communication and access to global resources. Parents also appropriated the languages in their repertoire through their good proficiency, and did not perceive non-nativeness as a problem for becoming the models for their children's language acquisition.

With regard to beliefs about language learning, parents perceived family language as a foundational platform for children's language socialization, and valued and exercised rich language input, communicative strategies for language exposure and practice imbedded into their family language "system” of OPOL. They also envision literacy traditionally within the frameworks of reading and writing and encouraged the development of those skills, as fundamentals of language learning, in their family languages Estonian and Russian. The parents' language learning beliefs reflected their own experiences with language learning.

The analysis of naturally occurring conversations and mother's trip journal illustrated that parents' and children's multilingual language behaviors were directed towards developing and maintaining multilingualism. The parents' language behavior was characterized by active translanguaging, which was not supported in children, and diverse multilingual practices. Parents supported "monolingual multilingualism" in their children, focusing on strengthening of language command in each of the languages in the children's repertoire, but preventing the language mix. To develop multilingualism the parents employed both family and community resources. Among the most common practices were indexing, labeling, corrections, linguistic bordering, linguistic brokering, and multisensory input. Moreover, the parents tend to apply the following strategies expressed guess, adult repetition, and move on (Lanza, 1992). The first two strateges allowed the parents to provide more input of a linguistic structure for the children, and 
the third one made the communication flow without interruption, focusing on the act of communication rather than the form.

The analyses of all data sources revealed that parents" "languaged" their identity and the identity of their children, negotiating multiple "selves" through language choices and language practices. Among the identities they clearly identified and distinguished were language and cultural identity, heritage identity, citizenship identity, local identity, parent-of-a-multilingual child identity, identity of a multilingual intellectual, and transnational identity. Annemarii, little as she was, also used her language practices with limited, but developing proficiency to negotiate her identity as a competent language speaker and an interlocutor.

The analysis also revealed the dynamic character of family ideologies and practices: they appeared to be not set-in-stone beliefs and attitudes, but context sensitive and susceptible to change over time and across space. Language, cultural, ideological, and identity spaces created in the family, were not fixed, but intertwined or diverged, changed its shape and constituents to different degrees responding to the family's interpretation of their needs in a particular space and time. 


\section{CHAPTER 5: DISCUSSION, CONCLUSION, AND CONTRIBUTIONS}

\section{Discussion}

The guiding inquiry of the study was to describe the ecology of language use in a multilingual transnational family in the U.S. by exploring cultural, linguistic, ideological, and identity spaces in which the family navigated and which it constructed, and consequently to understand family language policies established and followed by the family. Therefore, the study addressed four substantive areas: 1) family language beliefs and attitudes, 2) family language and cultural practices, 3) language policy, and 4) family identities. After reviewing theoretical and empirical scholarly literature, and describing the methodology of the study, I provided a datadriven discussion of the findings following the order of the guiding questions, starting with the portrait of the whole family and the profile of each family member.

Part of this dissertation was also meant to understand the relationship between three different frameworks: an anthropological framework of language socialization (Ochs \& Schieffelin, 1982), a linguistic framework of Spolsky’s (2004) family language policy (FLP), and a sociological framework of transnational social space (Faist, 1998). In the discussion section I will theorize from the findings of the study by first providing the family portrait, reviewing the Kiisk's FLP, and examining how the family conceptualize heritage, first and family language, and notions of place and space. Then I will show how the three frameworks relate to one other to address the complexity of the language socialization in the contemporary globalized world. In this concluding chapter I will discuss what a story of this family tells us about the role of language in a person's being, becoming, and belonging in the contemporary gobalized world. Further, I will discuss the empirical, methodological, and theoretical 
contributions, and implications of this study with regard to the findings and the overall process of the project.

\section{Family Portrait}

The findings showed that the Kiisks are a transnational multilingual family with occasional translingual practices, who are not and do not consider themselves immigrants, but rather sojourners. Following Canagarajah's (2017) distinction between translingualism and multilingualism - multilingualism "postulates languages maintaining their separate structures and identities even in contact, translingualism looks at verbal resources as interacting synergistically to generate new grammars and meanings, beyond their separate structures" (p. 1) - I suggest the Kiisks have translingual and transcultural identities, as their selves transcend spaces, but multilingual language practices, as family languages are kept mostly autonomous and are directed to children's monolingual multilingualism. Ideally, they want their children to acquire monolingual competence in many languages, and have the ability to speak several languages without mixing them.

In this family, Russian is conceptualized as a heritage language in two generations, for Kristina and for her daughters. As for Estonian, it is heritage if looked through the lens of a longer stay in the U.S. dominant context, but a home language and more functional than English for the purposes of the family. Language socialization in the Kiisks' family is "hypercomplex" (Lefebvre, 1991) and goes beyond the maintenance of the heritage languages for the purposes of know-your-roots philosophy and intergenerational communication, as usually reported by the majority of HL socialization empirical literature (see Review of literature). This process embraces multiple languages and cultures, and transcends family physical places. The Kiisks' whole approach to their family language policy is shaped by multifaceted ideologies about 
language, individual languages, and language learning, which reflect parents' personal language experiences, imbedded in socio-cultural, socio-historical, socio-political, and socio-economic contexts, together with their interpretation of the demands of the contemporary world. The findings sowed that the ideologies could overlap and conflict.

Observing OPOL +1 policy for the home languages, the parents focused on providing access to various linguistic resources for multilingual development of their children, always keeping the equation of at least three: two family languages, Russian and Estonian, and the third is the language of the environment, English. The English language appeared to occupy a special status in the family language agenda across spaces, and it was shown to be the embodiment of its high global status, and the role it played in parents' intellectual and social maturing. The data demonstrated that mediational practices orchestrated by the parents were actively and strategically shaped by interaction of parents' language ideologies and the relevant contexts. Despite observing OPOL, the parents allowed themselves to encourage their children to speak English with their guests, and even corrected the children's English pronunciation and helped to find words for the response. Raising their children primarily as multilingual Estonians, the parents recognized their children's multiculturalism and transculturalism - the influence of all cultural contexts the children had been engaged in since birth - and described their children as "citizens of the world".

The study also revealed that socialization context of the Kiisk's family was complex, and the borders between the heritage and host domains, as the data showed, were more porous and flexible. Observing overpowering globalization processes in the contemporary world, it is hard to underestimate the influence of the specific global domain in family language ideologies and practices; and rapid advancement of technology has generated new digital forms of 
communication which allow interlocutors to transcend material space, and connect to different linguo-cultural contexts (e.g., Kwon, 2017; Lam \& Warriner, 2012). The Kiisk's frequent skyping sessions with Estonia, or with other multiple points on the globe, let the family participate in various cultural momentums, being in two physically and time-wise distant places simultaneously. Therefore, I suggest the family context should not be perceived as the common juxtaposition of home (or heritage) and host (or dominant) settings often employed by the Heritage Language socialization literature.

Another parameter that the family was engaged in was time. Kristina traveled discursively not only in space, cross the boundaries of nation states, but in time. Either reminiscing about her childhood language practices, living in Estonia in the Soviet times and in the newly independent state, or reminding Annemarii about the events of their last trip to Estonia, she was bringing together the time and making it salient at the moment. Her memories were an integral part of her language beliefs and translated into her language practices and family language polices.

It is hard to keep the emerging transnational space unnoticed, the idiomatic sum of all the engaged domains, representing the exact context in which transnational families live. Further, I will discuss the notions of multilingualism, transnational space, heritage, and transnational identity in more detail as revealed by the study.

\section{The Kiisks' Family Language System}

The data showed that in the family's perception, they were following OPOL policy (one parent - one language family policy), giving Estonian and Russian the status of family languages, therefore eagerly providing the children with linguistic resources, which were not offered, or had limited presence in the dominant English-speaking environment. Yet, OPOL 
policy in reality turned into OPOL +1 , and translanguaging, using three languages - Estonian, Russian, and English - was a strong feature of the parents.

The parents eagerly promoted multilingual competence in their family, believing that their children would and should become "global elites" who are culturally and socially flexible thanks to their multiple language skills (Bae \& Park, 2016). Russian is different from the other two; Estonian is the language of the citizenry, and English is a must in the global world. Pursuing primarily instrumental values in language learning, and conceptualizing multilingualism as a tool, as a resource, and a social practice, the language knowledge in the family was commodified (Piller, 2001). Thus, Kristina and Meelis demonstrated that their family language policy, which centered on the acquisition of three languages naturally and simultaneously despite Kristina's poor, in her words, proficiency in Russian, and not-native, but good command of English, was a careful management and investment into economic and social benefits of their children.

Although English was not granted the status of the family language in the U.S., it carried certain importance in the family language policy and children's language socialization routine. It was clearly gaining importance throughout the period of my observation, moving from the language of the beyond family environment to an integral part of children' language practices. The presence of English was supported by parents' "Estonglish" practices and through various socializing activities. First, focusing on the two languages as family languages directed to children, parents still sprinkled their mutual communication with English. Directly referring to their common language as "Estonglish" and listing an impressive variety of activities associated with English, as shared in their language ego-maps, Kristina and Meelis emphasized the significance of English in their personal and professional life. Mixing is "a multilingual norm of 
language use" (Cruz-Ferreira, 2010). Although the parents mixed, children did not mix. Keiriin mixed Russian and Estonian at the beginning, and the scaffolding of her parents turned her into more monolingual multilingual: she became cleaner in Russian and Estonian, and more confidently switched between interlocutors.

The family acknowledged that language learning is a crucial socializing experience for their children. They undertood that children use language for building relations, learning about the world, exchanging information, playing wth words, communicating their needs (HardingEsch \& Riley, 2003). The parents tried to provide the children with various socializing opportunities, during which language learning was unavoidable. Because the family believed in naturalness and inevitability of language acquisition at the presence of rich input, the parents supported the children's access to literacy events in the English language through library story times, music and movie sessions, the number of which grew exponentially when the family made a decision to return to Estonia.

The change of context during the summer trip to Estonia did not affect the family language policy. The lack of the English input was improved by the visit of the family friend from France, who spoke neither Russian, nor Estonian. However, the parents discussed the change of OPOL structure, in particular the inclusion of English, upon returning to Estonia, for a lengthier period. The decision was made primarily based on the children's language development and maturing.

The parents planned to continue OPOL +1 language policy in Estonia. The change of space and context for language resources is expected to influence family language policy in a new place. On several occasions both parents highlighted that they wanted to maintain threelanguage access for their children with two family languages and the third would be the language 
of the environment - even returning back to Estonia, or "wherever we end up being". Thus, upon their return to Estonia they were planning to introduce English as one of family OPOL strategies, shifting the responsibility of further Estonian language development onto the dominant environment: external family, school, and community socializing domains. Moreover, in the Kiisk's language policy, the English language acquired the status of a family language not through ius sanguinis, and even bigger than ius soli, but through the route of its global importance, ius mundi.

As was illusrated in the study, such an instrumental view of the language, as a tool and as a valuable resource, advances into seeing multilingualism, or functional command of multiple languages, as a necessary tool and an essential resource of successful functioning in the contemporary world, and also as a social practice. The Kiisks praised multilingualism and invested in it, not limiting OPOL to promoting their native languages, but adjusting OPOL to their pragmatic needs; being multilingual themselves (Kristina was bilingual from childhood and had acquired a native-like proficiency in English through learning, and Meelis was fluent in English), the parents seized the opportunity to equip their children with access to a multiple language resources early and were eager to continue investing into it. They also held a strong belief that multilingual language development was a necessary component of overall cognitive development of the child.

\section{Heritage, first, or family language?}

By illustrating diverse conceptualizations of language and cultural heritage by individual members of the family, the findings of this case study challenged the principles of nationalist language ideology, according to which nation, language, culture, people, and identity are mapped one onto another, and represent one another by default (Woolard, 1998). Kristina identified 
herself across muitple languages and cultures, and all of them became a fundamental part of her being either by birth or by her choice of learning. By accepting the fact that for her daughters the U.S. and the English language could become an integral part of their perceived "heritage" one day, she strengthened a more liberal ideology of allowing multiple identifications, when nation, language, culture, and people were seen as different underpinnings of identity. It was a matter of acting them out; when, where, why, and how were situational. "Identity inheres in action" and are situations themselves (Bucholtz \& Hall, 2004, p. 376).

To advance the previous argument, this study also problematizes the terminology choice for the heritage language, or first language, or family language, or mother tongue, or minority language. This finding corroborates Blackledge and Creese' (2008) statement that language and heritage are contested terms. Refering to Smith (2007) the researchers claim "rather than being a static entity, "heritage" is a "process or performance that is concerned with the production and negotiation of cultural identity, individual and collective memory, and social and cultural values" (in Blackledge and Creese, 2008, p. 537). Then, as was demonstrated in this work, the notions of "first" and "mother tongue" are also contested, performative and case-senstive.

Heritage Language scholarship frequently uses these terms interchangeably and mainly focuses on the maintenance of the heritage language within next generations, factors, practices, and identity of HL learners. However, as was demonstrated in the analysis section, the Kiisks distinguished between and assigned different meanings to the heritage, first, and family language, stating that they encompassed different expressions of the speaker's language identity and language practices. Kristina illustrated this point by speculating on what language would define her heritage, Russian or Estonian, and comparing herself to her children's scenario of choosing between Estonian and English. For example, the status of Russian in Kristina's life was 
changing, from the first language she spoke (her first words were in Russian) to a family language (when Estonian began to prioritize her socialization), to a foreign language (she was taking Russian as a foreign language in school), to one of her family languages again (the language she chose to speak with her daughters). Culturally, Russian is heritage for her, but linguistically, not as much. In Estonia, Russian is spoken by about $30 \%$ of the population, so it is still a functional language. In the U.S. context, both Estonian and Russian could be assigned a function of "heritage" for Kristina and her daughter, but again, for the Kiisks they are not, they are fully functional family languages. Two significant factors are at large in this debate: (1) the dominant language during early stages of socialization, despite the bilingual language context, and (2) the role of a beyond-the-family socializing context, as an inevitable participant in individual's language socialization. Therefore, describing her case, Kristina referred to Estonian as her first language, for the purpose of the functional importance, but not for the order of acquisition, and to Russian as her family language, but not the first language. To illustrate the second point, Kristina perceived English as the heritage language for her daughters, because they were born in an English-speaking country, and English language socialization was an integral part of their growth and development, despite the Estonian and Russian OPOL policy at home and the lack of the parents' affiliation to this country. Such classification of languages into first, home, and heritage raises an important question: What processes build into our notion of affiliation and identity through language? It may be blood affiliation, the country of citizenship or maturing, the family's language practices, or function in the speaker's life. This study is unable to predict the ways in which Annemarii and Keiriin will define their language selves in the future, through their future language practices; I can only assume, following Kristina's classification, living in Estonian the children's first language will be Estonian, family language 
Russian or English, and heritage language English. Moreover, in this case study the parents did not entirely focus on HL identity development as their primary reason for maintaining Russian, but focus on Russian being a tool, a resource, a commodity. The same qualities were attributed to English.

The parents' instrumental view of language and multilingualism, supported by the language practices, corroborates the view of languages as social and historical "inventions" (Makoni \& Pennycook, 2007). Because speaking the language is instrumental, speech communities become just idealizations of distinctiveness (Chomsky, 1980 in MacSwan, 2017), therefore should not be associated with any identity affiliation per se, only depending on how the language plays out in the particular context. Kristina's family language was Russian, she spoke Russian fluently and wanted her children acquire good competence in Russian. Although she unconsciously estranged herself from Russian affiliation and stayed controversial about her Russian heritage, she followed the social "invention" of commodification of the language knowledge, and invested herself emotionally and physically into teaching her children Russian. The historical "invention" grain sprouted when Kristina uses Russian in Estonia: despite her Russian heritage, she chose her use of Russian in Estonia to signify multilingualism, which diverged from the use of Russian in the U.S. where she referred to all Russian speakers as "our people”. Thus, her inventions about Russian had different socio-historical grounds depending on the context of use.

Finally, understanding individual conceptualizations of "heritage" is important for heritage language education. Recognizing no direct alignment and a very complex relationship between the language we speak since birth and our cultural and citizenship heritage, we can assume that not everyone who speaks a certain language since birth would feel affiliation to the 
culture and the country which speaks this particular language. Heritage language curriculum, primarily in post-secondary instututions, and one particular educational resource are worth attention here. Having been engaged in building the curriculum for a Russian course for Heritage learners myself, I was grateful to the efforts of Kagan, Akishina, and Robin for creating "Russian for Russians” textbook (“Русский для русских"). It is one of very limited up-to-date resources that is comprehensive for a Heritage speakers course. In the process of data collection for this research I looked at the title of the book more critically. Not everyone opening and using this book with an intention to study Russian would identify herself with being Russian; in the light of the latest geopolitical sifts it might be even uncomfortable. The Russian-speaking population is diverse, as there is no one-to-one correspondence among language identity, cultural identity, and national identity. Thus, the title of the book does raise a critical issue of national labeling and stereotyping. I do not have a title to suggest, and after all this book is a well-developed educational resource, so, the questions requires further discussion.

Thus, it is important to distinguish between heritage, first, and family languages, and acknowledge the speaker's individual perception of the language and its role in her personal language history and language practices.

\section{Place vs. Space}

Sociolinguistic scholars (Blommaert, 2010; Canagarajah, 2017; Pennycook, 2010) have already been advocating for the shift towards theorizing the context of language ideology and language practices in spacio-temporal terms, recognizing that every language practice is "situated, holistic, networked, mediated, and ecological, thus integrated with diverse conditions, resources, and participants" (Canagarajah, 2017, p. 3). The analysis of the Kiisks' family language ideologies, language behavior, and the parents' understanding of their own and their 
children's linguistic and cultural selves, as transnationals, vividly demonstrated that language and cultural practices, and identity are not limited to the physical and conventional lingo-cultural borders, but exist in and are constructed by a space or multiple spaces, which are not only geographical, but historical, political, temporal, virtual, etc. Through language practices and interaction with material objects (e.g., video and print media, digital synchronous means of communication etc.), the family lived simultaneously across multiple places (e.g., books from Japan, Slovenia, France, etc.) and times (e.g., Kristina was showing her children the cartoons from her childhood, and reading the seminal Soviet children books); and at the same time those practices are organized by and embedded into a particular social sphere (Blommaert, 2015). Thus, for example, heritage linguo-cultural spaces can be available without border-crossing as it can be created by the parents, and parents, based on their ideologies, decide whether to create and maintain those heritage spaces or not. This theorization of the context is similar to Lefebvre's conceptualization of "social space" as "a product and a means of production". (Lefebvre, 1991, p. 86). Illustrating how by creating particular linguo-cultural, ideological, and identity spaces the parents provided the means of nurturing children's multilingualism, multiculturalism, and multilingual Estonian identity, I argue that there is a need to reconsider the notion of context in language socialization framework and conceptualize it not as a linguocultural place but a linguo-cultural space, which is permeable, flexible, traversing spaciotemporal borders, and changing across time. The production of space is marked by the language and literacy practices, and the language and literacy practices are shaped by the historical production of that space.

I observed the Kiisks creating Estonian and Russian spaces living in the U.S., and heard them planning to create English-speaking space in Estonia, despite being native speakers of 
English. Those spaces are not exclusive, and may share features and overlap. For example, both parents pointed to the common system of values explaining their decision to enroll Annemarii into a Russian-speaking kindergarten, therefore the values system in Russian and Estonian spaces may coincide. The spaces were also created through material attributes of particular languages and cultures, i.e., magnet letters in Latin and Russian alphabet on the fridge, an Estonian flag on the wall, books, games, presents from Estonia or from all over the world, etc. "The places of social space are very different from those of natural space in that they are not simply juxtaposed: they may be intercalated, combined, superimposed - they may even sometimes collide" (Lefebvre, 1991, p. 88). Thus, daily experiences of a transnational multilingual family engage each of the family members in activation of available spaces, expanding them, traversing spaces, colliding or diverging them, sometimes creating new spaces. The spaces may expand and shrink depending on their relevance and importance across time, physical space, or the macro and family ideologies. Physical place becomes only a constituent of the space, and can participate in many spaces, for example, in the case of a translanguaging or multilingual environment.

Against the backdrop of the above discussion, an important issue comes to the fore: the bordering of countries, cultures, and language experiences becomes an artificial ideologicallydriven concept in the contemporary globalized world. Linguistic, cultural, identity, and ideological spaces are multiple and porous, and transcend the traditional physical places creating multidimensional "space". Recognizing the hypercomplexity of created spaces, and their permeable, flexible, and superimposing character, it is imperative to count and examine not only things in space, for example, literacy events or material objects directed to maintain the HL or support the development of the language of the host country, but their place, their function, their 
relationship to one another and a particular space, and the "space itself with the view of uncovering social relationships imbedded in it" (Lefebvre, 1991, p. 89).

This case showed that even though the spaces were divided by the means of language through parents' family language policies, in everyday family language practices, at the same time in reality, there was a tendency to merge, mix and mesh those various spaces through active interpersonal and intrapersonal translanguaging and transculturing, and physical and virtual transnationaling. They did it through traversing physical and virtual linguo-cultural-ideological borders, which allowed them to interact with diverse objects, people, values, ideas, compile them into one meaningful whole, as well as exercise a variety of identities. Time is also a crucial component of the space. Thus, Olga, Kristina's mother, shared "Kristina is not even Estonian now, she left home early pursuing her education abroad, ...time and life itself change things, they leave their footprint on us" (Olga, skype conversation, October, 2017).

In sum, in studying multilingualism and heritage language socialization we should not isolate languages and juxtapose home and host culture in relation to the children of transnational families' (both born in and out of the country they live now) language development and development of the language identity. Multilingualism, transnational experience, and what we call heritage are more complex processes of being and belonging. Any of linguistic, cultural, and ideological spaces are meaningful only in their relationship to the other spaces. They overlap, penetrate one another, and/ or exist in-between. A multilingual mind is not a sum of languages, but a harmonious whole, in which every language contributes to the whole with its existence. The language worlds are never demarcated in their mind, despite serving particular function and being the means of interaction with a particular interlocutor. On the ideological level they are not fractured - do not exist apart from each other - but are in the relationship, therefore 
multilingualism, - not a particular language - defines individual's linguistic, cultural, ideological, and identity practices. Experiences depend on the dynamics of the life experiences and needs. The imperative is not the language system itself but how the language as a social practice plays out in a certain time and space.

\section{Revised Language Socialization Framework}

The findings of the case study helped to illuminate the relationship between the guiding frameworks. Using the case study as an illustration, I propose to combine language socialization (LS), family language policy (FLP), and transnational social space (TSS) frameworks into one, bringing forward an idea that theoretically combined, they complement one other and help explain language socialization in transnational families in the contemporary world. Figure 12 illustrates the relationship between the frameworks. The three main constituents of Languge Socilization are (1) socializing agents, (2) mediational practices, and (3) socializing context, culture and language content of community of practice. I propose to theorize mediational practices - represented as a triangle - as embodied in the FLP and state that those practices are the product of parents' ideology about language(s), contexts, and language learning. I picture the socializing context - represented as a circle - not as a uniform homogeneous linguo-cultural place or a group of isolated linguo-cultural spaces, but as multidimensional and hypercomplex space, which is comprised of multiple domains, heritage, host, and global space, with flexible, porous, overlapping borders. Ideological, language, cultural, and identity experiences transcend all those spaces, and acquire new forms and meanings every time they manifest themselves in a certain time and place. Therefore, the notion of the heritage domain becomes idiosyncratic, and depends on all previous socio-cultural, linguistic, and ideological experiences of the each member of the family. Beliefs and attitudes about the language and language use, and the ways 
they translate into language practices, as well as identities, become a matter of relevancy of Kristna's "standing points" to the context. The momentum of the language choice, practice, identification lies in that one particular standing point, beyond which is multiplicity of other developing scenarios of language choices, practices, and identifications. The standing point grounds in either the land where someone is born or resides in (ius soli), or through the parents that come from a certain place (ius sanguinis), or the ways of being through languages one learns and speaks (ius lingue), or through developing a feeling of being a product of global world (ius mundi).

LANGUAGE SOCIALIZATION IN MULTILINGUAL CONTEXTS

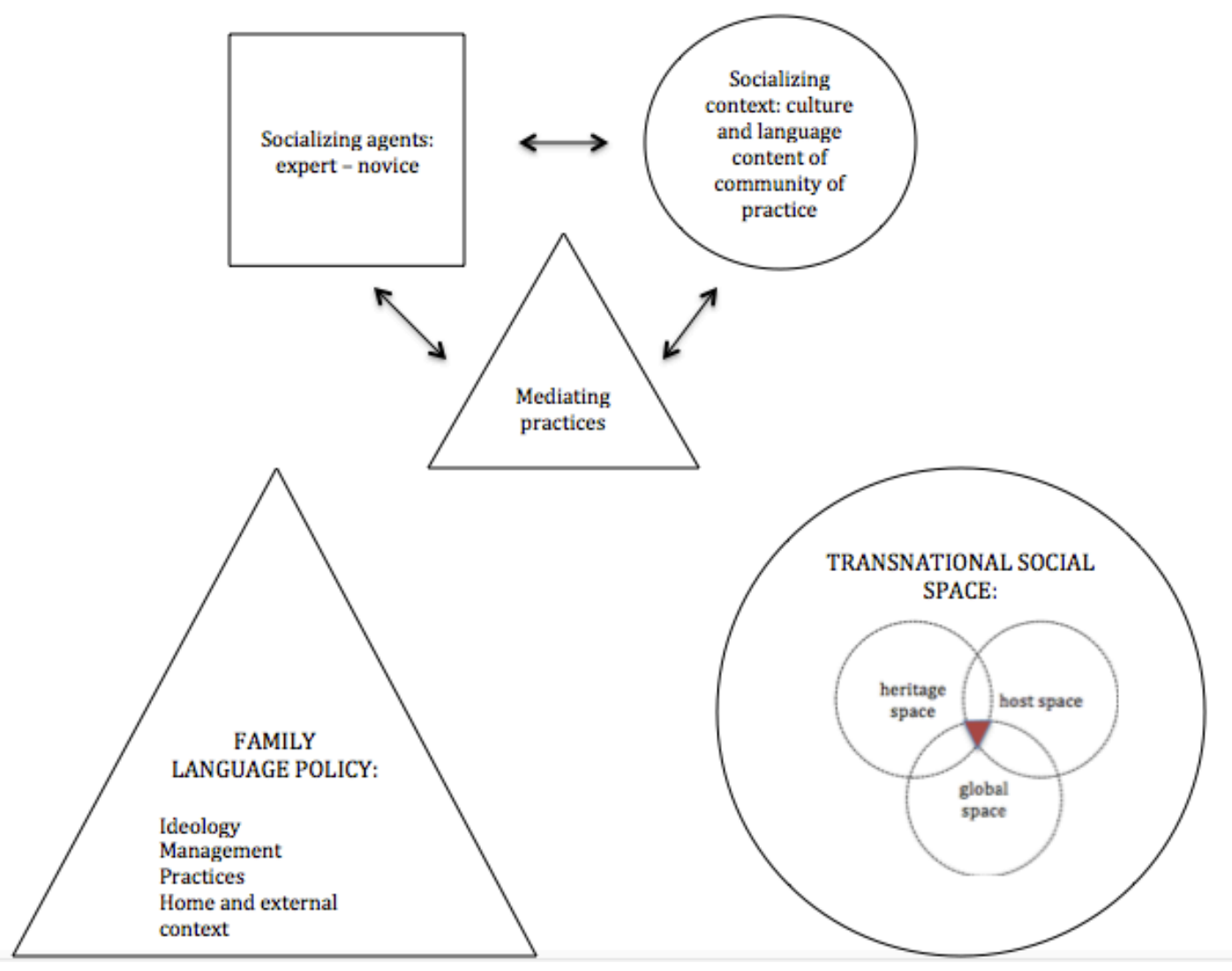

Figure 12 Revised framework for Language Socialization in multilingual contexts 


\section{Contributions}

The process and findings of this study suggest empirical, methodological, and conceptual contributions.

\section{Empirical Contributions}

Among empirical contributions, the following are worth discussing. First, although the number of studies on multilingual FLP and HL maintenance is still scant, the principles and strategies of children's language socialization in this study corroborated the findings of the reviewed literature on FLP and HL maintenance strategies in bilingual family contexts, with one language being the dominant language of the environment. In particular, OPOL was found the most natural and preferred family’s language policy (Piller, 2001; De Capua \& Wintergerst, 2009) especially at an early stage of children's language socialization as it was believed to provide access to quality (Döpke, 1992) natural input from the parents and to develop language awareness, diverging languages' paths and strengthening proficiency in each language. The parent believed in the success of the simultaneous language learning (cf. Chatzidaki \& Maligkoudi, 2013; Li, 2012). Similar to previous scholarship on heritage language maintenance (e.g., De Capua \& Wintergerst, 2009; Hua \& Wei, 2016; Jeon, 2008; Kwon, 2017), the Kiisks engaged children into a variety of literacy events, orchestrating children's interaction with languages through print media, video, music, transnational experiences, such as skyping with family in Estonia and annual trips to Estonia, community help, such as attending Russian kindergarten and play dates with other Russian speaking families. The parents also employed common for other bilingual families' strategies to develop children's proficiency (e.g., Liu, 2017) They corrected their children's pronunciation, used labeling and pointing techniques, and initiated narrating practices. Very often the parents were involved into formal language 
instruction (e.g., Kheirkhah \& Cekaite, 2015; Pease-Alvarez, 2003). Overall, the study strengthened our understanding of common multilingual family's approaches to language learning.

In addition, the study contributed to the existing body of literature by demonstrating how OPOL can function and be implemented in the multilingual context, and revealing that OPOL policy did not necessitate language nativeness, but primarily early and systematic exposure to languages. The Kiisks decision to include English as one of OPOL premises upon return to Estonia supports this point.

Second, the Kiisks articulated reasons to maintain the heritage language that were similar to the reviewed literature. Considering Russian as heritage, the family supported its maintenance for intergenerational communication (De Fina, 2012; Kirsch, 2012; Pavlenko, 2004; Sakamoto \& Kondon-Brown, 2006), overall cognitive development (Kirsch, 2012; Palvainen \& Boyd, 2013), and economic incentive (Kirsch, 2012; Park \& Sarkar, 2007; Palvainen \& Boyd, 2013). The parents also had positive bilingual experiences, similar to those reported by Kirsch (2012) and Moin, Schwartz, and Leikin (2013). However, the strongest - and unique - reason for this case study's family was to focus on multilingual development prompted by the linguistic differences between the available family language systems. Such a view reflected the parents' ideology about multilingualism as a tool, resource, and a social practice.

Although not being the focus of the study, the ethnography of the language ecology in a multilingual family cannot eschew the issue of language and emotions, making the findings the third contribution to the empirical literature. The present study supported and at the same time challenged Pavlenko's (2004) findings on emotions and language use among immigrant mothers with their children. Kristina's use of Russian with her daughters did not follow the reason of 
native language being the most natural and comfortable language to use with the children.

Kristina defines Russian as a family but not her first language, despite the fact that most of her childhood language interaction, prior going to school, was conducted in Russian. She explained, as discussed in the analysis section, that she constantly searched for words and expressions using Russian to talk emotions with her children, and looked forward to them being big enough so that she could began using her more comfortable language, English, with them. Whether the children accepted such a talk and how constitutes an empirical question, one that requires further attention. Thus, the present study elicited the importance of a speaker's individual perception of "nativism" in labeling a language and distinguishing it from "first language", and "family language”. Pavlenko’s conclusions, drawn from survey design, might have generalized a mother's language backgrounds and experiences; therefore, the further inquiries into the relationship between language and emotion in immigrant contexts can benefit from the findings of this project.

Fourth, the study supported Kenner's (2005) findings that the mother is a prominent language educator and a driving force of children's multilingualism. Kristina was the initiator of the family language policy of OPOL +1 , she suggested enrolling Annemarii into a Russian kindergarten, she orchestrated the most of the languages activities, and she even modified her husband's language behavior. Most of this arrangement was influenced by Meelis's role as the breadwinner, and Kristina being a stay-at-home mom.

\section{Methodological Contributions}

Methodological contributions of this study fall into two groups: first, using the existing methodology in new contexts, and second, the sample choice. 
First, my work demonstrated the value of a deep case analysis of heritage language socialization and family language policies through ethnography. Although language socialization literature widely employed ethnographic framework, the majority of previous studies on FLP and HL maintenance based their findings mostly on surveys and interviews, and lacked the nuances of illustrating how family language ideologies were created, developed, and instantiated in every day practices. As demonstrated by Fogle (2012) and Smith-Christmas (2015), the examination of bilingual family language behaviors benefits from ethnographic methodology and the analysis of naturally occurring conversations (NOCs). My work strengthened this point. Ethnographic observation in this study allowed me to notice the intricacies and complexities of transnational living, identification, affiliation, and decision-making. Constantly comparing and contrasting the observed family members' behaviors with their perceptions of those behaviors and themselves, I was able to construct a multidimensional picture of language choice, language use, and language development, and identity of my participants. The use of NOCs in this work elicited genuine language dynamics in the family, brought children's data into fore of the analysis of family language behavior, and compared the parents' perceptions of their language behavior with what they really do and say. Collecting NOCs longitudinally allowed me to notice and trace the changes of ideologies about language and language use over time. Through observations and NOCs I was able to reveal children's emerging identities constructed through their language use.

Second, the literature review showed that research on Russian heritage language maintenance did not fully considered "superdiversity" (Vertovec, 2006) of the Russian-speaking population and immigrant in the world, generalizing the participants' linguo-cultural and historical backgrounds and conditions for immigration. Therefore, this work contributed to the heritage language and family language policy scholarship with a more elaborated sample. The 
vast Russian-speaking world includes a diverse array of speakers originating from former-soviet republics. Although 30 years have passed after the dissolution of the Soviet Union, the 70 years of Soviet heritage with Russian as a lingua franca can not be easily erased by one language policy reform promoting the newly established independent republics' languages. My work revealed the importance of considering participants' linguo-cultural and historical background for the analysis of the beliefs and attitudes they construct around their language practices. For example, Kristina's choice of Russian was not dictated by her affiliation to the Russian community, but by her good command of Russian, as one of her childhood languages, and her connection to the Russian-speaking world through her mother. Although Kristina spoke Russian with her children, she did not consider it her first language, as many parents in heritage language socialization research assumed. The status of the Russian language in Estonia would qualitatively differ from that in Ukraine or Moldova or Kazakhstan. Therefore, the system of values, language ideologies, practices and identities of the Russian speakers should be treated and presented as "hypercomplex" (Lefebvre, 1991), and the former Soviet past still stays inevitably intertwined to a different degree into the fabric of the republic's life, linguistically and culturally.

Moreover, at the backdrop of abundant ethnographic research on Spanish and Chinese heritage language socialization in the context of the U.S., the Russian heritage language scholarship is still limited. By focusing on Estonian speakers of Russian in the U.S, this study attempted to address this issue.

\section{Conceptual Contributions}

Among the conceptual contributions of my work the following are worth commenting on: the importance of interdisciplinary approach in examination of the multilingual family 
experiences; the conceptualization of the environment of language socialization as space, not a place; the existence of transnational identity,

First, recognizing the complexity of human experiences and life, I took an interdisciplinary approach to describe the life of a transnational multilingual family in the U.S. in its wholeness and depth and designed a study drawing on three theoretical frameworks: an anthropological view in Language Socialization, a linguistic view in Family Language Policy, and a sociological perspective in the framework of Transnational Social Space. Even though all of them describe, directly or indirectly, language experiences, only the process of the research and the findings of the study enabled me to establish connections between the elements of the three, enriching each of them with insight of the other two. As discussed above, I propose to embed FLP into mediational practices of LS and underline that socialization not as a transfer of knowledge from an expert to a novice, but as an intricate system of decisions about family language practices influenced not only by the context of socialization but family members' personal language experiences and their interpretation of ideological dynamics of the context or contexts that may change across time and space. I also detailed the context of LS with the notion of transnational social space which is created in the process of multiple contexts working together, e.g., home context, heritage context, host context, global context, etc. Such theorization of language socialization in transnational families helps embody the complexity, dependence on local and global contexts, dynamism of the family language experiences and children's language socialization in their participation in physical and virtual movements.

Second, the study showed that family language practices transcend physical places and occur in multidimensional spaces created by parents for their children to achieve the goal of multilingual development or by affordances of contemporary life itself. Literacy objects and 
literacy events, as well as various means of communication, including virtual and face 2 face, become doorways to a variety of spaces, distant geographically, linguistically, culturally, and even ideologically. Therefore, bringing in the concept of "space" into heritage language socialization scholarship provides a deeper insight into multilingual's life and help understand that complexity of experiences. Those spaces can share elements, merge, expand, and shrink according to their importance and relevance in time and place. The borders are not distinct, but porous and fluid.

Third, the findings of the study necessitate the recognizing and distinguishing of transnational identity of multilinguals (cf. Buchotz \& Hall, 2010). Despite acknowledging translanguaging in practices of multilinguals, HL scholarship often juxtaposes heritage language identity, celebrating the roots, to the host country language identity, the place they grew up. Although multilinguals are able pragmatically differentiate among the languages and cultures and use them skillfully, the processes of the personal identification and affiliation are more complex, demanding, and involved, than demonstration of language proficiency, or the place of maturing. Looking at identity not only locally — the languages we speak, the country we grew up in - but globally — involving the global social space and all the linguo-cultural experiencesKristina herself defined identity as "standing points", not necessary roots. The process of identifying those "standing point(s)" is personal, and a group of "standing points" encompass the transnational identity that evolves in a transnational social space.

Fourth, the study provided deeper insight into understanding of the language and language identity, heritage language, multilingualism and multilingual practices in a family. Family multilingualism is not limited to the number of languages the person speaks, but how 
they help her to function in the society, and how they define her being, beyond the notion of "multi", into the notion of translanguaging, trans-culturing practices, trans-identity.

\section{Directions for Further Research}

The discussion section and the sections on the limitation of the analysis already suggested some areas that would require further research. In this section I will detail research areas that could enrich our understanding of ideology of multilingual practices, language socialization in transnational families, linguistic, cultural, and heritage identities, and language ideology at a macro and micro levels.

The study revealed that an ethnographic approach helped catch some contradictions between what participants reported in the interview and what language practices looked like in reality. What would be needed therefore in future research on HL maintenance and FLP is a case study design and greater engagement of naturally occurring conversations data and observation practices into the examination of individual family language practice.

As the study elicited the change in parents' goals, beliefs and perceptions of their language practices over time, further longitudinal observations of this family are important to understand how FLP is influenced by different life events, the change of the family's linguocultural context of living, children's aging and their progress with languages, and the expanding socialization of children. I observed that the parents' orientations to languages and, therefore, children's language practices, are not limited to the scope of the family, but embedded into a broader macro-level ideology (e.g., community, country), and constitute a part of continuous negotiating process (cf. Buchotz \& Hall, 2010). Therefore, they can be deeper understood through a broader temporal-spacial framework. By saying this, I propose to continue 
ethnographic observations, the collection of NOCs, and interviews with the parents and later with the children.

The longitudinal approach is a very promising further step for this case study. It will allow me to enrich the current case with new data on the younger child, Keiriin, when she reaches the similar age as Annemarii during the study, and cross examine the sisters' language practices, comparing FLPs, contexts, and spaces, at different time frames.

The family's return to Estonia might also prompt various trajectories of the FLP in the family. Although this study did not elicit any drastic changes in language behavior of the family members during their two months summer trip to Estonia, the family determination to include English into their FLP upon return to Estonia will expectedly affect the dynamics of the family language socialization: reshaping of language and cultural spaces, parents and children's language behavior and language practices. Moreover, as the children mature, their socialization domains broaden, so do their language needs, bringing new dynamics into their language behavior worth exploring.

Another direction for further investigations is a deeper exploration of each of the practices in the family, for example, closer examination of the nature and features of parents' questions and answers in conversations with children during different literacy events, or siblings' language interaction during socio-cultural role-plays.

Longitudinal approach will also allow me to move to a more child-centered approach in the study of multilingual practice and identity. As the children grow and mature, they will become a source of valuable perspectives on their own language practices and linguo-cultural affiliations. I will be able to compare the parents' goals for their FLP and the outcomes in the children's language behavior. 
Moreover, this study examined language socialization in one individual family with a particular linguo-cultural, socio-historical background in a particular context. It would be overstretching an argument to overgeneralize the findings to all multilingual families, or even to Estonian transnational families residing in the U.S., which have Russian as an element of their FLP. I have to return to the notion of "superdiversity" (Vertovec, 2006), to emphasize that each individual family would develop a particular pattern and trajectory of FLP and identities. Similar ethnographic case study of another Estonian or any other immigrant or sojourn family of similar profile, with post-Soviet multilingual background, will provide better understanding of how family language policy is negotiated. In the same vein, it is also necessary to continue examination of non-Estonian, multilingual families in immigrant and sojourn contexts strives to not classify people as attributed to their nationality, or place of origin, but recognizing the richness of their experiences. 


\section{AFTERWORD}

After I terminated official data collection for this project in September, I continued to receive Kristina's messages with pictures of the girls' literacy products: drawings, writings, or some remarkable stories of their language behavior and creativity. In those stories, she enthusiastically compared her daughters' quality of language production at different levels, such as vocabulary size, grammar, pronunciation. She noticed that Keiriin was cleaner in her grammar than Annemarii, but not as good with articulation at the same age. She also enjoyed comparing equivalents for different words and phrases that Annemarii and Keiriin were inventing.

I also had a chance to spend a couple of days with the family during Thanksgiving week and occasionally visited the family at their place when I was traveling. I enjoyed listening Kristina's new stories, observations and reflections on their participation in the whole project and how it had been affecting her approach to language practices in the family since then. She shared she had become more cognizant of her children's language behavior and her own language practices and multilingual parenting actions. She could not stop analyzing their family "system", her decisions and language choices, her short-term and long-term plans for her daughters' language development, as well as theorizing about language, languages, and language learning, about the place of each in her own life and their family life. Over the course of our further meetings and discussions, she ideologically elaborated and somewhat reconsidered the reasons for Russian language maintenance and the status of English. I rejoiced when during our conversation she, suddenly for me, confessed that all her actions directed to her daughter's Russian language socialization were mostly instrumentally motivated, and the connection to her Russian heritage was just a little part of it. 
Since I stopped my data collection, the girls have been maturing linguistically. Keiriin is more talkative now, having rapidly improved her vocabulary and complexity of discourse both in Estonian and Russian; she impresses her parents with the amount and speed of her speech. Very quickly "Madame Nyet" has turned into a chatterbox and began commenting on everything she sees around her. She developed her metacommunicative skills and better differentiates between situation for Estonian and Russian now. Keiriin also picks up English. Annemarii improved in all three languages, Russian, Estonian, and English.

Approaching the day when they will embark on their Estonian life-time trip, Kristina said they started transitioning more into the use of English in their family language practices. They evaluate the affordances of the contexts, and design their behavior accordingly. Interestingly, such a switch is not always welcomed by the children. Annemarii resisted it openly, requesting not to speak like this, “Мама, не говори со мной по-английски” (Eng: “Mama, don't speak English with me"). What trajectory will the transition towards English as a home language take in Estonia? How will the children's reactions develop or change?

Unfortunately, many valuable episodes of the children's language socialization and parents' language practices were left unobserved. The language ecology of the family is richer and more complex than life enabled me to observe the surface of their behavior, and many practices were left behind the scenes ether intentionally, perhaps, partially because Kristina was monitoring her behavior and her audio data collection, or unintentionally, for the lack of cues my ability to interprete the data was limited. Despite trying to be invisible, my persona was influencing the whole family's routine. If sometimes my presence allowed me to open the doors to most genuine behaviors, on the other hand it was constraining my access to it, by modifying it with my presence. 
The Kiisks are not an exceptional family, but I still grant it the right to be unique in its own sense, for each particular multilingual becoming and being constitutes a phenomenon. My observation of the two sisters' differences in their language behavior and development is illustrative in this sense. Those girls will grow, and who knows, maybe they will find another language to be appropriate for their identification. I wonder where their language experiences will take them, and where they will direct their language selves.

When this study was still in the nascent state I came across an ad on Facebook. It featured an energetic Polish grandfather who ordered a teach-yourself-English book, put stickers with English words on everything around, and spoke English with his dog. The ads pulled tears out of the most stonehearted and pragmatic individual with its heartfelt denouement, revealing that the grandfather's English learning effort was intended to prepare him to introduce himself to his two-year old Anglophone granddaughter who lived in the $\mathrm{UK}^{15}$. The concomitant comments for the ad were also revealing and deserve attention. Facebook users' reactions to the video did not lack an emotional touch: "you'll laugh and you'll cry", "get tissue handy", "this is what walking an extra mile mean" (commented a grandmother of four), "bilingual families will empathize" (commented a graduate student of linguistics from Spain studying in the US). The popularity and sentiments the video evoked - brought into relief the complex socio-economic, linguistic, and demographic landscape of our contemporary superdiverse (Vertovec, 2007) society, one that featured increasing population mobility, language and culture contacts, and number of multilingual and multicultural families. Reflecting on this commercial, I state that it goes beyond commentary on the economic and demographic situation in Europe, and the world, e.g., that people become more mobile in search of better job opportunities and, consequently, families are

\footnotetext{
${ }^{15}$ Link to the commercial: https://www.youtube.com/watch?v=7D3WJB5Yikw
} 
sadly split. There are divergent popular views on this multinational, multicultural, and multilinguistic phenomenon. Some viewers might respond to the ad by suggesting "why don't they teach some Polish to their little girl, it's a part of her heritage", while others would assert, "yes, it's good for the child to be immersed in one language environment, she is not going to live in Poland after all, and English has more power". These are all very relevant discussions that represent important discourses, both among and about transnationals', that abound in both faceto-face interactions and virtual spaces. A number of transnationals' virtual communities and blogs focus on issues related to the importance and maintenance of heritage language and culture, finding space for heritage in the family, and integrating into the host environment.

I find confirmation of the relevance and importance of these topics in my own experience of living in the U.S. for the past nine years. I have met families who have made a range of diverse decisions relating to heritage language maintenance: immigrant families who raised children bilingually, those who selected English-only environments, and those whose children attended English-instruction schools, but maintained their native language at home. As a member of several virtual communities (e.g., "Russian mothers USA," "Russian Mothers Boston," "Russians of DC Area"), I have read transnationals' posts in which they share experiences, concerns, questions, and opinions about their children being exposed to two or even three different languages, coping with the challenges of dominant language schools, and fearing low proficiency in either English or in the family tongue. Yet many of those posts are written in English, it being the most comfortable language for communication. I wish I could hear the children's voices, what they call their most comfortable language(s) and why. Do parents acknowledge the complexity of their language experiences living in those transnational spaces? Many questions are left unexplored. 
Although multilingual behavior has been attracting attention in linguistic and language pedagogy scholarship over a century, it is, nevertheless, underrepresented. Each language and culture is treated in their purity, and scholars focus mainly on siloing languages, cultures, experiences, heritage, citizenship, belonging, and being, measuring the progress in each, protecting the right of heritage. There is a need to acknowledge and scrutinize the complexity and in-betweenness of transnational experiences, the shift of ideological, cultural and language borders over time, the existence of transnational space where translanguaging, trans-culturing, trans-identity, and trans-experiences emerge and take place. 


\section{REFERENCES}

Ahearn, L. M. (2001). Language and agency. Annual review of anthropology, 30(1), 109-137.

Aronin, L., \& Laoire, M. Ó. (2004). Exploring multilingualism in cultural contexts: Towards a notion of multilinguality. In Hoffmann, C., \& Ytsma, J. (Eds.), Trilingualism in family, school, and community (Vol. 43) (pp. 11-29). Multilingual Matters.

Atkinson, J. M., \& Heritage, J. (1984). Structures of social action. Cambridge University Press.

Auer, P. (Ed.). (2013). Code-switching in conversation: Language, interaction and identity. Routledge.

Auer, P., \& Wei, L. (Eds.). (2007). Handbook of multilingualism and multilingual communication (Vol. 5). Walter de Gruyter.

Bae, S., \& Park, J. S. Y. (2016). Becoming Global Elites Through Transnational Language Learning?: The Case of Korean Early Study Abroad in Singapore. L2 Journal, 8(2).

Baker, C. (2011). Foundations of bilingual education and bilingualism (Vol. 79). Multilingual matters.

Bakhtin, M. M. (1981). The dialogic imagination: Four essays by mm bakhtin (m. holquist, ed.; c. emerson \& m. holquist, trans.).

Barron-Hauwaert, S. (2004). Language strategies for bilingual families: The one-parent-onelanguage approach (No. 7). Multilingual Matters.

Bayley, R., \& Schecter, S. R. (Eds.). (2003). Language socialization in bilingual and multilingual societies: edited by Robert Bayley and Sandra R. Schecter (Vol. 39). Multilingual Matters.

Bialystok, E. (2001). Bilingualism in development: Language, literacy, and cognition. Cambridge University Press. 
Blackledge, A. \& Creese, A. (2012). Multilingualism and pedagogy. Paper presented at the Birmingham/ Melbourne Summer School in Applied Linguistics, University of Birmingham.

Blackledge, A., \& Creese, A. (2014). Heteroglossia as practice and pedagogy. In Heteroglossia as practice and pedagogy (pp. 1-20). Springer, Dordrecht.

Blackledge, A., Creese, A., Baraç, T., Bhatt, A., Hamid, S., Wei, L., ... \& Yağcioğlu, D. (2008). Contesting 'language'as 'heritage': Negotiation of identities in late modernity. Applied Linguistics, 29(4), 533-554.

Blommaert, J. (2010). The sociolinguistics of globalization. Cambridge University Press.

Blommaert, J., \& Dong, J. K. (2007). Language and movement in space. Working papers in language diversity/Department of Languages; 1.

Blum-Kulka, S. (1997). Dinner talk. New Jersey: Lawrence Erlaum Associates.

Bourdieu, P. (2017). Habitus. In Habitus: A sense of place (pp. 59-66). Routledge.

Bourke, B. (2014). Positionality: Reflecting on the research process. The Qualitative Report, $19(33), 1-9$.

Brandt, D. (1997). The Sponsors of Literacy. Report Series 7.12.

Braun, A. (2012). Language maintenance in trilingual families-a focus on grandparents. International Journal of Multilingualism, 9(4), 423-436.

Brosig, M. (2008). A Plan for the Future-The Estonian State Integration Programme on National Minorities 2000-2007. JEMIE, 7, 1.

Brubaker, R. (1996). Nationalism reframed: Nationhood and the national question in the new Europe. Cambridge University Press.

Bucholtz, M., \& Hall, K. (2010). Locating identity in language. Language and identities, 18-28. 
Canagarajah, A. S. (2008). Language shift and the family: Questions from the Sri Lankan Tamil diaspora. Journal of Sociolinguistics, 12(2), 143-176.

Canagarajah, A. S. (Ed.). (2013). Literacy as translingual practice: Between communities and classrooms. Routledge.

Canagarajah, S. (2017). Translingual practice as spatial repertoires: Expanding the paradigm beyond structuralist orientations. Applied Linguistics. Retrieved from https://academic.oup.com/applij/article/39/1/31/4626948

Carreira, M. (2004). Seeking explanatory adequacy: A dual approach to understanding the term “heritage language learner.” Heritage Language Journal, 2(1), n1.

Carreira, M., \& Kagan, O. (2011). The results of the National Heritage Language Survey: Implications for teaching, curriculum design, and professional development. Foreign Language Annals, 44(1), 40-64.)

Chatzidaki, A., \& Maligkoudi, C. (2013). Family language policies among Albanian immigrants in Greece. International Journal of Bilingual Education and Bilingualism, 16(6), 675-689.

Chen, S. H., Kennedy, M., \& Zhou, Q. (2012). Parents' expression and discussion of emotion in the multilingual family: Does language matter?. Perspectives on Psychological Science, 7(4), $365-383$.

Cho, G. (2000). The role of heritage language in social interactions and relationships: Reflections from a language minority group. Bilingual Research Journal, 24(4), 369-384.

Coleman, J. S. (1988). Social capital in the creation of human capital. American journal of sociology, 94, S95-S120. 
Cook-Gumperz, J. (1985). Keeping it together: Text and context in children's language socialization. Georgetown University Round Table on Languages and Linguisticodeswitching, 337-356.

Copland, F., \& Creese, A. (2015). Linguistic ethnography: Collecting, analysing and presenting data. Sage.

Cruz-Ferreira, M. (2010). Multilinguals are...?. London: Battlebridge Publications.

Curdt-Christiansen, X. L. (2009). Invisible and visible language planning: Ideological factors in the family language policy of Chinese immigrant families in Quebec. Language Policy, 8(4), $351-375$

Curdt-Christiansen, X. L. (2014). Family language policy: Is learning Chinese at odds with learning English? In Curdt-Christiansen, X. L., \& Hancock, A. (Eds.). (2014). Learning Chinese in diasporic communities: Many pathways to being Chinese (Vol. 12). (pp. 35-55). John Benjamins Publishing Company.

Curdt-Christiansen, X. L. (2016). Conflicting language ideologies and contradictory language practices in Singaporean multilingual families. Journal of multilingual and multicultural development, 37(7), 694-709.

Danjo, C. (2015). A Critical Ethnographic Inquiry into the Negotiation of Language Practices among Japanese Multilingual Families in the UK: Discourse, Language Use and Perceptions in the Hoshuko and the Family Home (Doctoral dissertation, Northumbria University).

Darvin, R., \& Norton, B. (2014). Transnational identity and migrant language learners: The promise of digital storytelling. Education Matters: The Journal of Teaching and Learning, 2(1). 
De Costa, P. I. (2010). Reconceptualizing language, language learning, and the adolescent immigrant language learner in the age of postmodern globalization. Language and Linguistics Compass, 4(9), 769-781.

DeCapua, A., \& Wintergerst, A. C. (2009). Second-generation language maintenance and identity: A case study. Bilingual Research Journal, 32(1), 5-24.

De Fina, A. (2012). Family Interaction and Engagement with the Heritage Language: A Case Study. Multilingua: Journal of Cross-Cultural and Interlanguage Communication, 31(4), $349-379$.

De Fina, A., \& Perrino, S. (2013). Transnational identities. Applied Linguistics, 34(5), 509-515.

De Houwer, A. (1999). Environmental factors in early bilingual development: The role of parental beliefs and attitudes. Bilingualism and migration, 75-96.

De Houwer, A. (2004). Trilingual input and children's language use in trilingual families in Flanders. Trilingualism in family, school and community, 118-135.

De Houwer, A. (2007). Parental language input patterns and children's bilingual use. Applied psycholinguistics, 28(03), 411-424.

de la Pedra, M. \& Romo, Harriett. (2003). Collaborative literacy in a Mexican immigrant household: the role of sibling mediators in the socialization of the pre-school learners. In Bayley, R., \& Schecter, S. R. (Eds.). (2003). Language socialization in bilingual and multilingual societies. (Vol. 39). Multilingual Matters.

Derry, S. J., Pea, R. D., Barron, B., Engle, R. A., Erickson, F., Goldman, R., ... \& Sherin, B. L. (2010). Conducting video research in the learning sciences: Guidance on selection, analysis, technology, and ethics. The Journal of the Learning Sciences, 19(1), 3-53.

Deuchar, M., \& Quay, S. (2000). Bilingual acquisition. Theoretical implications of a case. n/a 
Dittmar, N., Spolsky, B., \& Walters, J. (1998). Language and identity in immigrant language acquisition and use: A framework for integrating sociological, psychological and linguistic data. Contemporary approaches to second language acquisition in social context: Crosslinguistic perspectives, 124.

Döpke, S. (1992). One parent one language: An interactional approach (Vol. 3). John Benjamins Publishing.

Edwards, J. (2002). Multilingualism. Routledge.

Ehala, M. (2015). Ethnolinguistic Vitality. In Tracy, Sandel, \& Ilie. (Eds.), The International Encyclopedia of Language and Social Interaction (pp.1-7). John Wiley \& Sons,

Elias, N., \& Shoren-Zeltser, M. (2006). Immigrants of the world unite? A virtual community of Russian-speaking immigrants on the web. Journal of International Communication, 12(2), $70-90$

Emerson, R. M., Fretz, R. I., \& Shaw, L. L. (2011). Writing ethnographic fieldnotes. University of Chicago Press.

Faist, T. (1998). Transnational social spaces out of international migration: evolution, significance and future prospects. European Journal of Sociology, 39(02), 213-247.

Feldman, G. (2005). Culture, state, and security in Europe: The case of citizenship and integration policy in Estonia. American Ethnologist, 32(4), 676-694.

Fogle, L. W. (2012). Second language socialization and learner agency (Vol. 87). Multilingual Matters.

Fuller, J. M. (2007). Language choice as a means of shaping identity. Journal of Linguistic Anthropology, 17(1), 105-129. 
Gafaranga, J. (2010). Medium request: Talking language shift into being. Language in Society, $39(2), 241-270$.

García, O. (2009). Education, multilingualism and translanguaging in the 21 st century. Social justice through multilingual education, 140-158.

García, O. (2011). Bilingual education in the 21st century: A global perspective. John Wiley \& Sons.

García, O., \& Flores, N. (2012). Multilingual pedagogies. In M. Martin-Jones, A. Blackledge \& A. Creese (Eds.), The Routledge Handbook Of Multilingualism (pp. 232-246). London: Routledge.

Genesee, F., Boivin, I., \& Nicoladis, E. (1996). Talking with strangers: A study of bilingual children's communicative competence. Applied psycholinguistics, 17(4), 427-442.

Giles, H., \& Johnson, P. (1987). Ethnolinguistic identity theory: A social psychological approach to language maintenance.

Glaser, B.G., \& Strauss, A. (1967). Discovery of grounded theory. Strategies for qualitative research. Chicago: Aldine Pub. Co.

Goodz, N. S. (1994). Interactions between parents and children in bilingual families. Educating second language children, 61-81.

Gounari, P. (2006). Language policy in the United States: Uncommon language and the discourse of common sense. Belgian Journal of English Language and Literatures, 4, 39-50.

Greenhill, A. (2000). SHOSHANA BLUM-KULKA, Dinner talk: Cultural patterns of sociability and socialization in family discourse. Mahwah, NJ: Erlbaum, 1997. Pp. ix, 306. Language in Society, 29(03), 420-423. 
Gregory, E. (2005). Guiding lights: Siblings as literacy teachers in a multilingual community. Portraits of literacy across families, communities, and schools: Intersections and tensions, $21-40$

Grosjean, F. (2010). Bilingual. Harvard University Press.

Gumperz, J. (2009). The speech community. Linguistic anthropology: A reader, 1, 66.

Gyogi, E. (2015). Children's agency in language choice: a case study of two Japanese-English bilingual children in London. International Journal of Bilingual Education and Bilingualism, $18(6), 749-764$.

Hall, S. (1990). Cultural Identity and Diaspora. In Rutherford, J. (Ed.). Identity: community, culture, difference. Lawrence \& Wishart.

Halliday, M. A. (1978). Language as social semiotic. London.

Harding-Esch, E., \& Riley, P. (2003). The bilingual family: A handbook for parents. Cambridge University Press.

Hardman, J. (2013). Literacy and Bilingualism in. Literacy Development in A Multilingual Context: Cross-cultural Perspectives. In Durgunoglu, A. Y., \& Verhoeven, L. (Eds.). (2013). Literacy development in a multilingual context: Cross-cultural perspectives (pp.51-81). Routledge.

Hartley, J. (2004). Case study research. Essential guide to qualitative methods in organizational research, 323-333.

ten Have, P. (1990). Methodological Issues in Conversation Analysis1. Bulletin of Sociological Methodology/Bulletin de Méthodologie Sociologique, 27(1), 23-51.

He, A. W. (2006). Toward an identity theory of the development of Chinese as a heritage language. Heritage Language Journal, 4(1), 1-28. 
He, A. (2010). The heart of heritage: Sociocultural dimensions of heritage language learning. Annual Review of Applied Linguistics, 30, 66-82.

He, A. (2011). 25 Heritage Language Socialization. The handbook of language socialization, 587.

Hornberger, N. (1998). Language policy, language education, language rights: Indigenous, immigrant, and international perspectives. Language in society, 27(04), 439-458.

Hornberger, N. (2003). Multilingual language policies and the continua of biliteracy: An ecological approach. Bilingual Education and Bilingualism, 315-339.

Hua, Z. (2008). Duelling languages, duelling values: Codeswitching in bilingual intergenerational conflict talk in diasporic families. Journal of Pragmatics, 40(10), 17991816.

Hua, Z., \& Wei, L. (2016). Transnational experience, aspiration and family language policy. Journal of Multilingual and Multicultural Development, 37(7), 655-666.

Hymes, D. (1972). On communicative competence. sociolinguistics, 269293, 269-293.

Irwin, V. (2009). More Than Just Ethnic: Negotiation of Ethnicity through Language among Russian German Re-Settlers and Jewish Refugees from the Former Soviet Union in Germany. (Doctoral Dissertation). University of Michigan. Retrieved from http://hdl.handle.net/2027.42/62426

Jeon, M. (2008). Korean Heritage Language Maintenance and Language Ideology. Heritage Language Journal, 6(2), 54-71.

Joseph, J. (2003). Language and identity. Palgrave Macmillan Limited. 
Kagan, O. (2012, September). Intercultural competence of heritage language learners:

Motivation, identity, language attitudes, and the curriculum. In Proceedings of Intercultural Competence Conference September (Vol. 2, pp. 72-84).

Kagan, O., Akishina, T., \& Robin, R. (2003). Russian for Russians: Textbook for heritage speakers. Bloomington, IN: Slavica.

Kagan, O., \& Dillon, K. (2006). Russian heritage learners: So what happens now?. The Slavic and East European Journal, 50(1), 83-96.

Kagan, O. \& Dillon, K. (2010). Russian in the USA. Potowski, K. (Ed.). (2010). Language diversity in the USA (pp.179-194). Cambridge University Press.

Kasatkina, N. (2010). Analyzing Language Choice among Russian-Speaking Immigrants to the United States. (Doctoral Dissertation). University of Arizona. Retrieved from http://hdl.handle.net/10150/193622

Kenner, C. (2005). Bilingual families as literacy eco-systems. Early years, 25(3), 283-298.

Kemppainen, R., Hilton, S., \& Rannut, Ü. (2015). Ethnic Identification and School Language of Russian-speaking Students in Estonia. Journal of Language, Identity \& Education, 14(5), $336-353$

Kheirkhah, M., \& Cekaite, A. (2015). Language Maintenance in a Multilingual Family: Informal Heritage Language Lessons in Parent-Child Interactions. Multilingua, 34(3), 319-346.

Kibler, A., Palacios, N., Simpson-Baird, A., Bergey, R., \& Yoder, M. (2016). Bilingual Latin@ children's exposure to language and literacy practices through older siblings in immigrant families. Linguistics and Education, 35, 63-77.

King, K. A., \& Fogle, L. W. (2013). Family language policy and bilingual parenting. Language Teaching, 46(2), 172. 
King, K. A., Fogle, L., \& Logan-Terry, A. (2008). Family language policy. Language and Linguistics Compass, 2(5), 907-922.

King, K., \& Fogle, L. (2006). Bilingual parenting as good parenting: Parents' perspectives on family language policy for additive bilingualism. International Journal of Bilingual Education and Bilingualism, 9(6), 695-712.

King, K. A., \& Mackey, A. (2007). The bilingual edge: Why, when, and how to teach your child a second language. New York, NY: Collins.

Kirsch, C. (2012). Ideologies, struggles and contradictions: An account of mothers raising their children bilingually in Luxembourgish and English in Great Britain. International Journal of Bilingual Education and Bilingualism, 15(1), 95-112.

Kondo, K. (1998). The paradox of US language policy and Japanese language education in Hawaii. International journal of bilingual education and bilingualism, 1(1), 47-64.

Kopeliovich, S. (2010). Family language policy: A case study of a Russian-Hebrew bilingual family: Toward a theoretical framework. Diaspora, Indigenous, and Minority Education, $4(3), 162-178$.

Koven, M. (2006). Feeling in two languages: A comparative analysis of a bilingual's affective displays in French and Portuguese. Pavlenko, A. (Ed.). (2006). Bilingual minds: Emotional experience, expression, and representation (pp.84-117). Multilingual Matters.

Kramsch, C. (Ed.). (2003). Language acquisition and language socialization: Ecological perspectives. Bloomsbury Publishing.

Kwon, J. (2017). Immigrant mothers' beliefs and transnational strategies for their children's heritage language maintenance. Language and Education, 31(6), 495-508. 
Labov, W. (1972a). Some principles of linguistic methodology. Language in society, 1(01), $97-$ 120.

Labov, W. (1972b). The study of language in its social context. Sociolinguistic patterns, 183259.

Lam, W. S. E., \& Warriner, D. S. (2012). Transnationalism and literacy: Investigating the mobility of people, languages, texts, and practices in contexts of migration. Reading Research Quarterly, 47(2), 191-215.

Lamarre, P., \& Dagenais, D. (2004). Language practices of trilingual youth in two Canadian cities. Trilingualism in family, school and community, 53-74.

Lanza, E. (1992). Can bilingual two-year-olds code-switch?. Journal of child language, 19(03), 633-658.

Lanza, E. (1997). Language contact in bilingual two-year-olds and code-switching: Language encounters of a different kind? International Journal of Bilingualism, 1(2), 135-162.

Lanza, E. (2007). 2. Multilingualism and the family. Handbook of multilingualism and multilingual communication, 5, 45.

Lao, C. (2004). Parents' attitudes toward Chinese-English bilingual education and Chineselanguage use. Bilingual Research Journal, 28(1), 99-121.

Lauristin, M., Kaal, E., Kirss, L., Kriger, T., Masso, A., Nurmela, K., ... \& Vihalemm, T. (2011). Estonian Integration Monitoring 2011. Estonian Ministry of Culture.

Lave, J., \& Wenger, E. (1991). Situated learning: Legitimate peripheral participation. Cambridge university press.

Lefebvre, H., \& Nicholson-Smith, D. (1991). The production of space (Vol. 142). Blackwell: Oxford. 
Lemke, J. L. (2011). Analyzing verbal data. na

Liebkind, K. (1999). Social Psychology//Handbook of Language and Ethnic Identity/Ed. By Joshua A. Fishman.

Li, L. (2012). How do immigrant parents support preschoolers' bilingual heritage language development in a role-play context?. Australasian Journal of Early Childhood, 37(1), 142.

Li, W. (2011). Moment analysis and translanguaging space: Discoursive construction of identities by multilingual Chinese youth in Britain. Journal of Pragmatics 43(5), 1222-35.

Li, W., \& Zhu, H. (2013). Translanguaging identities and ideologies: Creating transnational space through flexible multilingual practices amongst Chinese university students in the UK. Applied Linguistics, 34(5), 516-535.

Liu, L. (2017). "It's just natural": A critical case study of family language policy in a 1.5 generation Chinese immigrant family on the west coast of the United States. In M. Siiner, F. Hult \& T. Kupisch (Eds.), Bridging language acquisition and language policy. New York, NY: Springer Science + Business Media LLC.

Lo-Philip, S. W. Y. (2010). Towards a theoretical framework of heritage language literacy and identity processes. Linguistics and Education, 21(4), 282-297.

Luo, S. H., \& Wiseman, R. L. (2000). Ethnic language maintenance among Chinese immigrant children in the United States. International Journal of Intercultural Relations, 24(3), 307324.

Luykx, A. (2003). Weaving languages together: Family language policy and gender socialization in bilingual Aymara households. In Bayley, R., \& Schecter, S. R. (Eds.). (2003). Language socialization in bilingual and multilingual societies. (Vol. 39). Multilingual Matters. 
Luykx, A. (2005, April). Children as socializing agents: Family language policy in situations of language shift. In ISB4: Proceedings of the 4th International Symposium on Bilingualism (pp. 1407-1414). Somerville, MA: Cascadilla Press.

Macedo, D., Dendrinos, B., \& Gounari, P. (2015). Hegemony of English. Routledge.

MacSwan, J. (2017). A multilingual perspective on translanguaging. American Educational Research Journal, 54(1), 167-201.

Makoni, S., \& Pennycook, A. (2005). Disinventing and (re) constituting languages. Critical Inquiry in Language Studies: An International Journal, 2(3), 137-156.

Moin, V., Scwartz, L., \& Leikin, M. (2013). Immigrant parents' lay theories of children's preschool bilingual development and family language ideologies. International Multilingual Research Journal, 7(2), 99-118.

Montrul, S. (2010). Current issues in heritage language acquisition. Annual Review of Applied Linguistics, 30, 3.

Moore, E. L. (2012). Language and Social Identity Construction: A study of a Russian Heritage Language Orthodox Christian School. (Thesis). UCLA. Retrieved from http://www.escholarship.org/uc/item/6c84k7t5

Norton, B. (2013). Identity and language learning: Extending the conversation. Multilingual matters.

Ochs, E., \& Schieffelin, B. (1995). The impact of language socialization on grammatical development (pp. 73-94). na.

Ochs, E., \& Schieffelin, B. (1995). Language acquisition and socialization: Three developmental stories and their implications. In Blount, B. G. (Ed.), Language, culture, and society: A book of readings (pp.470-512). Waveland PressInc. 
Ochs, E., \& Schieffelin, B. (2001). Language acquisition and socialization: Three developmental stories and their implications. Linguistic anthropology: A reader, 2001, 263-301.

Ochs, E., \& Schieffelin, B. (2008). Language socialization: An historical overview. In Encyclopedia of language and education (pp. 2580-2594). Springer US.

Olshtain, E., \& Nissim-Amitai, F. (2004). Being trilingual or multilingual: Is there a price to pay. Trilingualism in family, school and community, 30-50.

Orellana, M. F. (2009). Translating childhoods: Immigrant youth, language, and culture. Rutgers University Press.

Palviainen, Å., \& Boyd, S. (2013). Unity in discourse, diversity in practice: The one person one language policy in bilingual families. In Successful Family Language Policy (pp. 223-248). Springer: Netherlands.

Park, C. (2008). One Person-One Language (OPOL). In J. González (Ed.), Encyclopedia of Bilingual Education (pp. 636-638). Thousand Oaks, CA: Sage.

Park, H., Tsai, K. M., Liu, L. L., \& Lau, A. S. (2012). Transactional associations between supportive family climate and young children's heritage language proficiency in immigrant families. International Journal of Behavioral Development, 36(3), 226-236.

Park, S. M., \& Sarkar, M. (2007). Parents' attitudes toward heritage language maintenance for their children and their efforts to help their children maintain the heritage language: A case study of Korean-Canadian immigrants. Language, culture and curriculum, 20(3), 223-235.

Pavlenko, A. (2004). 'Stop Doing That, Ia Komu Skazala!': Language Choice and Emotions in Parent-Child Communication. Journal of multilingual and multicultural development, 25(23), 179-203. 
Pavlenko, A. (2005). Emotions and multilingualism. New York, NY: Cambridge University Press.

Pavlenko, A. (2006). Russian as a lingua franca. Annual Review of Applied Linguistics, 26, 7899.

Pease-Alvarez, L. (2003). Transforming perspectives on bilingual language socialization. In Bayley, R., \& Schecter, S. R. (Eds.). (2003). Language socialization in bilingual and multilingual societies. (Vol. 39). Multilingual Matters.

Pennycook, A. (2010). Language as a local practice. Routledge.

Peterson, S. S., \& Heywood, D. (2007). Contributions of families' linguistic, social, and cultural capital to minority-language children's literacy: Parents', teachers', and principals' perspectives. Canadian Modern Language Review, 63(4), 517-538.

Phinney, J. S. (1990). Ethnic identity in adolescents and adults: review of research. Psychological bulletin, 108(3), 499.

Piller, I. (2001). Private language planning: The best of both worlds. Estudios de sociolingüística, 2(1), 61-80.

Pratt, M. L. (1991). Arts of the contact zone. Profession, 33-40.

Preece, S. (Ed.). (2016). The Routledge handbook of language and identity. Routledge.

Petersoo, P. (2007). Reconsidering otherness: constructing Estonian identity. Nations and nationalism, 13(1), 117-133.

de la Piedra, M., \& Romo, H. D. (2003). Collaborative literacy in a Mexican immigrant household: The role of sibling mediators in the socialization of pre-school learners. Bilingual Education and Bilingualism, 44-61. 
Quay, S. (2008). Dinner conversations with a trilingual two-year-old: Language socialization in a multilingual context. First language, 28(1), 5-33.

Ren, L., \& Hu, G. (2013a). A comparative study of family social capital and literacy practices in Singapore. Journal of Early Childhood Literacy, 13(1), 98-130.

Ren, L., \& Hu, G. (2013b). Prolepsis, syncretism, and synergy in early language and literacy practices: a case study of family language policy in Singapore. Language policy, 12(1), 6382.

Richter, M. (2012). Researching transnational social spaces: A qualitative study of the Spanish second generation in Switzerland. In Forum Qualitative Sozialforschung/Forum: Qualitative Social Research 3(13).

Rubin, H. J., \& Rubin, I. S. (2011). Qualitative interviewing: The art of hearing data. Sage. Ruiz, R. (1984). Orientations in language planning. NABE journal, 8(2), 15-34.

Ryazanova-Clarke, L. (Ed.). (2014). The Russian Language Outside the Nation: Speakers and Identities. Edinburgh University Press.

Sakamoto, M., \& Kondo-Brown, K. (2006). Balancing L1 maintenance and L2 learning: Experiential narratives of Japanese immigrant families in Canada. Heritage language development: Focus on East Asian languages, 33-56.

Saldaña, J. (2015). The coding manual for qualitative researchers. Sage.

Scenters-Zapico, J. (2013). Translingual Literacy Sponsors and Gateways on the United StatesMexico Borderlands. p.182-194. In Canagarajah, A. S. (Ed.). (2013). Literacy as translingual practice: Between communities and classrooms. Routledge.

Schieffelin, B. \& Ochs, E. (1982). Language Acquisition and Socialization: Three Developmental Stories and Their Implications. 
Shannon, S. M. (1995). The hegemony of English: A case study of one bilingual classroom as a site of resistance. Linguistics and education, 7(3), 175-200.

Shohamy, E. G. (2006). Language policy: Hidden agendas and new approaches. Psychology Press.

Smagulova, J. (2017). Ideologies of language revival: Kazakh as school talk. International Journal of Bilingualism.

Smith-Christmas, C. (2015). Family language policy: Maintaining an endangered language in the home. Springer.

Soler, J., \& Zabrodskaja, A. (2017). New spaces of new speaker profiles: Exploring language ideologies in transnational multilingual families. Language in Society, 46(4), 547-566.

Song, J. (2009). Bilingual creativity and self-negotiation. Beyond Yellow English: Toward a Linguistic Anthropology of Asian Pacific America, 309-324.

Song, K. (2016). “Okay, I will say in Korean and then in American”: Translanguaging practices in bilingual homes. Journal of Early Childhood Literacy, 16(1), 84-106.

Spolsky, B. (2004). Language policy. Cambridge University Press.

Spolsky, B. (2007). Towards a theory of language policy. Working Papers in Educational Linguistics (WPEL), 22(1), 1.

Stake, R. E. (1995). The art of case study research. Sage.

Stone, E., Gomez, E., Hotzoglou, D., \& Lipnitsky, J. Y. (2005). Transnationalism as a motif in family stories. Family process, 44(4), 381-398.

Suarez, D. (2002). The paradox of linguistic hegemony and the maintenance of Spanish as a heritage language in the United States. Journal of Multilingual and Multicultural Development, 23(6), 512-530. 
Super, C. M., \& Harkness, S. (1986). The developmental niche: A conceptualization at the interface of child and culture. International journal of behavioral development, 9(4), 545569.

Tse, L. (2001). Resisting and reversing language shift: Heritage-language resilience among US native biliterates. Harvard Educational Review, 71(4), 676-709.

Tsuda, Y. (2008). The hegemony of English and strategies for linguistic pluralism. The global intercultural communication reader, 167-178.

Tuominen, A. (1999). Who decides the home language? A look at multilingual families. International journal of the sociology of language, 140(1), 59-76.

Valdés, G. (2001). Heritage language students: Profiles and possibilities. In J. K. Peyton, D. A. Ranard, \& S. McGinnis (Eds.), Heritage languages in America: Preserving a national resource (pp. 37-80). Washington, DC \& McHenry, IL: Center for Applied Linguistics \& Delta Systems.

Vertovec, S. (1999). Conceiving and researching transnationalism. Ethnic and racial studies, $22(2), 447-462$.

Vertovec, S. (2007). Super-diversity and its implications. Ethnic and racial studies, 30(6), 10241054.

Vihalemm, T. (1999). Estonian language competence, performance, and beliefs on acquisition among the Russian-speaking inhabitants of Estonia, 1989-1997. International journal of the sociology of language, 139(1), 69-86.

Vu, J. A., Bailey, A. L., \& Howes, C. (2010). Early cases of code-switching in Mexican-heritage children: Linguistic and sociopragmatic considerations. Bilingual Research Journal, 33(2), 200-219. 
Walker, D., Bigelow, K., Harjusola-Webb, S., Small, C., \& Kirk, S. (2004). Strategies for promoting communication and language of infants and toddlers. Kansas City, KS: Juniper Gardens Children's Project.

Wei, L. (2017). Translanguaging as a practical theory of language. Applied Linguistics. Retrieved from https://academic.oup.com/applij/article/39/1/9/4566103

Woolard, K. A. (1992). Language ideology: Issues and approaches. Pragmatics, 2(3), 235-249.

Yamamoto, M. (2001). Language use in interlingual families: A Japanese-English sociolinguistic study (Vol. 30). Multilingual Matters.

Yin, R. K. (2003). Case study design. Sage

Zentella, A. C. (1997). Growing up bilingual: Puerto Rican children in New York. WileyBlackwell. 


\title{
APPENDIX A
}

\section{IRB Approval Letter}

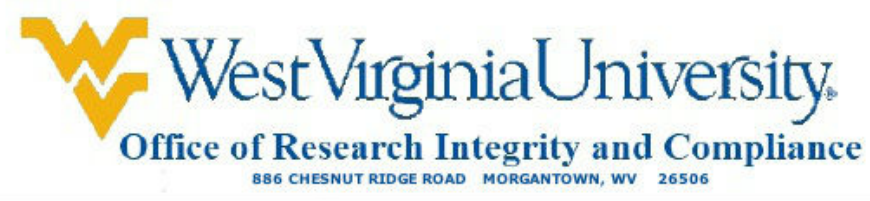

Approval Letter Expedited

\author{
Action Date \\ $04 / 28 / 2017$ \\ To \\ Malayna Bernstein \\ From \\ WVU Office of Research Integrity and Compliance \\ Approval Date \\ $04 / 28 / 2017$ \\ Expiration Date \\ $04 / 27 / 2018$ \\ Subject \\ Protocol Approval Letter \\ Protocol Number \\ 1702459662 \\ Title \\ Family Language Policy: a case study of a transnational family in the US
}

The above-referenced research study was reviewed by the West Virginia University Institutional Review Board IRB and was approved in accordance with 46 CFR $46.101 \mathrm{~b}$.

It has been determined that this study is of minimal risk and meets the criteria as defined by the expedited categories listed below:

- Category 6. Collection of data from voice, video, digital, or image recordings made for research purposes.

- Category 7. Research on individual or group characteristics or behavior (including, but not limited to, research on perception, cognition, motivation, identity, language, communication, cultural beliefs or practices, and social behavior) or research employing survey, interview, oral history, focus group, program evaluation, human factors evaluation, or quality assurance methodologies. [NOTE: Some research in this category may be exempt from the DHHS regulations for the protection of human subjects. See Exempt Categories and 45 CFR 46.101(b)(2) and (b)(3). This listing refers only to research that is not exempt.]

Documents reviewed and/or approved as part of this submission:

IRB response 4.19.17.docx: 2017-04-25-04:00

Procedures.docx: 2017-04-25-04:00

RUSS_interview protocol_grandparents.docx: 2017-04-25-04:00

validation of translation_consent.pdf: 2017-04-25-04:00 


\section{APPENDIX B}

\section{Interview protocol (parents)}

"I am going to have a conversation with you about language life in your family. You can stop if you do not want to address certain questions, and we'll proceed to the next, or stop the interview"

Major themes and prompting questions:

- (1) Background of the family and their story of coming to the US

- Tell me about the history of your young family before coming to the US

- When did you come to the US and under what circumstances? Why did you decide to stay?

- Why did you decide to raise your children here in the US?

- (2) Linguistic and cultural background of parents and their own language identities

○ What do you consider your first language? Do you consider yourself bi/multilingual? What does it mean to you to be bilingual/ multilingual? Bicultural/ multicultural?

- Which language(s) do you use most for reading/ writing/ speaking? In which domains?

- When did you start speaking/ reading/ writing those languages?

- How many languages do you speak and how? When did you study them and why? For how long? And why?

- What kinds of texts do you read / write in each language?

- Do you feel that reading/ writing/ speaking in different languages are different for you? How?

- Is your home country multilingual? What do you think about multilingualism in America?

- What language did you communicate with each other when you lived in Estonia? And now?

- What languages do you use in everyday life more often and in which circumstances?

- (3) Parents' attitudes and beliefs about multilingualism, HLs maintenance ideology and perceived identities of their children

○ Why do you think it's important to know your heritage language(s)? multiple languages?

- What language(s) do you use with your children? Are there situations when you prefer the one over another? When did you decide on what language to use with your children?

- What is the nationality of your children? 
- (4) Family language policy and practices:

Language Practices:

- What language(s) do you speak at home? Do you speak differently to different family members (parents, your husband, daughter I and daughter II)?

- Who do you speak to in languages other than English? Why do you choose that/ those languages?

- Who do your children speak to in languages other than English?

- When did you start thinking about languages in the family? How did you plan it?

- Do you help your child learn languages? How do you do that?

- What do you read at home? And what do you write? In what language? Do you read to or with your children?

- In what language was your children's first word?

- What do you think about heritage language kindergartens/ schools?

- How did you make your choice?

Ideologies:

○ How important is it to you that your children speak Estonian/ Russian/ English? Why?

D Do you want your children to be more proficient in one of the family language? Why?

- What is language for you?

Management:

- Do you have any established language policies in your family? What are those? How did they develop?

- What is a typical day in your family like?

- (5) Transnational practices in the family and the use of languages in the family and in the environment

- How often if ever do you visit your home country? And how long you usually stay there? Where do you stay and who do you usually visit?

- Do you talk with your relatives on skype? Who do you usually talk to? Do your children participate in those skype sessions?

- What language do you use predominantly when you travel to your home country and why?

- What holidays do you celebrate in your family? Did any of them originate here in the US? Which ones? 


\section{APPENDIX C}

\section{Trip-journal Guiding Questions}

During your trip to Estonia and back, and while you are there, try to register, or recall, and reflect on your (you, our husband, your children) language behavior and thoughts about those experiences.

\section{During the trip:}

- What language(s) you use with your husband/ wife, your children when you feed them or go explore the airport, when you cross the border, etc.

- Why do you think the particular language was prioritized?

\section{In Estonia:}

- What language(s) you use with your children when are at your husband's/ wife's family, your family.

- What language(s) does your elder daughter use interacting with other family members, her cousins, and her peers at the playground. Give examples, what have you observed.

- Have you noticed any changes in your children's language behavior since they came to Estonia? What are those?

- Why do you think the particular language was prioritized?

\section{Traveling back:}

- What language did you use with your children in the airport on your way back to the U.S.? Give examples.

- In what language children responded to you the most? Give examples.

- What language did your husband/ wife use on the way back to the U.S.?

- Why do you think the particular language was prioritized?

Please share any interesting moment related to languages and language behavior in your family during your trip to Estonia. 


\section{APPENDIX D}

\section{Essay Questions for Grandmothers}

"Please respond to the following questions as fully as you wish."

1. How many languages do you speak and how? When did you study them and why? For how long? And why?

2. What do you read at home? And what do you write? In what language?

3. Do you interact with the Russian speaking community? On what occasion? What language do you speak then?

4. What language do you speak to your grandchildren? How often do you speak to your grandchildren? In which context?

5. How important is it to you that your grandchildren speak Estonian/ Russian/ other languages?

Why?

6. Do you want your grandchildren to be more proficient in one language? Why?

7. What is language for you? 


\section{APPENDIX E}

\section{Skype Interview Protocol (Russian speaking grandparent)}

1. Let's talk more about the family you were born into. You were born at the border

2. Did you study a FL at school?

3. Describe your family language

4. What other languages, besides Russian, were present in your family when Kristina was born and was growing?

5. When Kristina whent to the kindergarten, what kindergarten that was language wise, Estonian or Russian? How did you make that decision?

6. Do you remember Kristina encountered any language problems in the Estonian kindergarten?

7. Who taught Krstin read and write? And what langauge was it?

8. What are your thoughts about Kristna's multilingualism? Did you support her language learning?

9. What is Kristina's linguistic and cultura identity in your opinion?

10. Do you think Kristina is more Estonian or Russian?

11. Comment on the status of the Russian language in Estonia, nd how it has been changing, if it is a case, over the recent years. 


\section{APPENDIX F}

\section{Interview with the Elder Child}

"Let's play a journalist game, shall we?... We'll be asking each other questions. I'll start and then your turn"

(The list of questions for different sessions)

- What language do you speak?

- Does you dad speak differently than your mom?

- What language am I speaking right now? (ask both in English and in Russian at different sessions)

- What is your favorite book? What's its name?

- What language do you speak to you grandmothers? 


\section{APPENDIX G}

\section{Language Ego-maps Protocol (parents)}

Researcher: You will be drawing your language-map. I will be giving you instruction and will bee asking you different questions along the way. Think loud as much as you wish.

1. Think about what languages are important to you in your life and list them down

2. Look at your list and try to order them in the matter of importance for you.

3. Look at this circle-map, the center of it is you.

4. Divide the circle-map into sectors representing the languages you listed and providing the space for each language sector according to its importance.

5. Look at each piece of your language pie and think about functionality of each language in your life and what connects you to this language (e.g., people, places, areas of use etc.).

6. Using concentric circles indicate how important each function of a particular language to you. Do it with each language. You can use various figures while drawing.

R: Comment on your map, please.

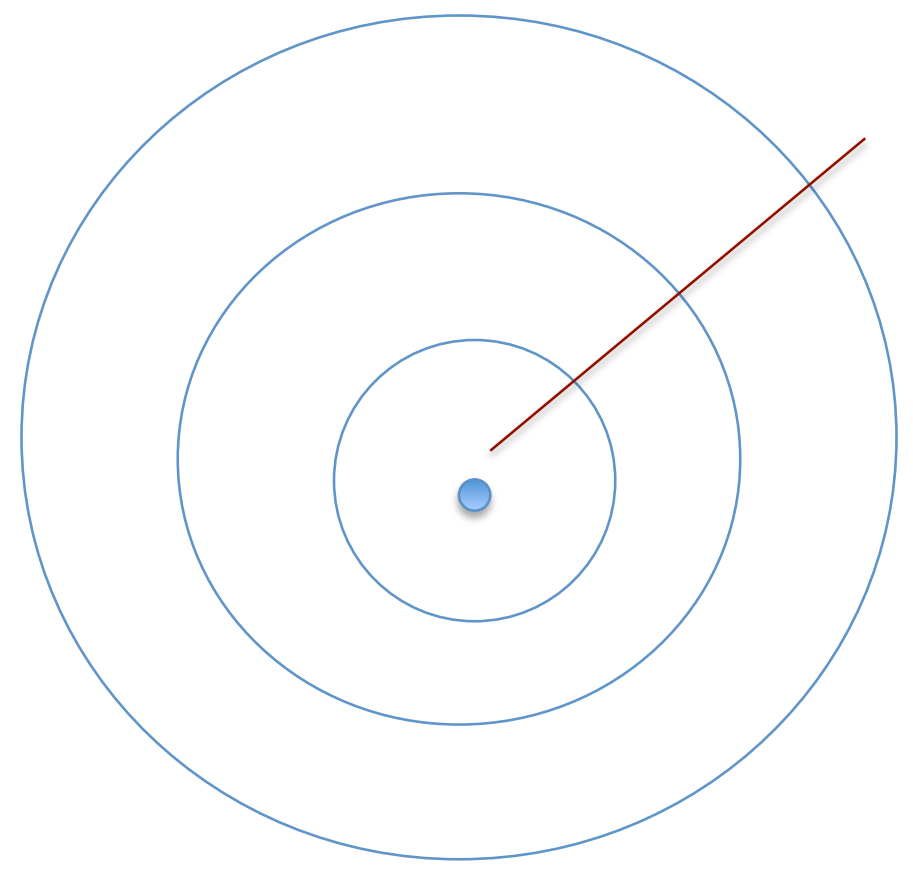




\section{APPENDIX H}

\section{Parents' Ego-maps}
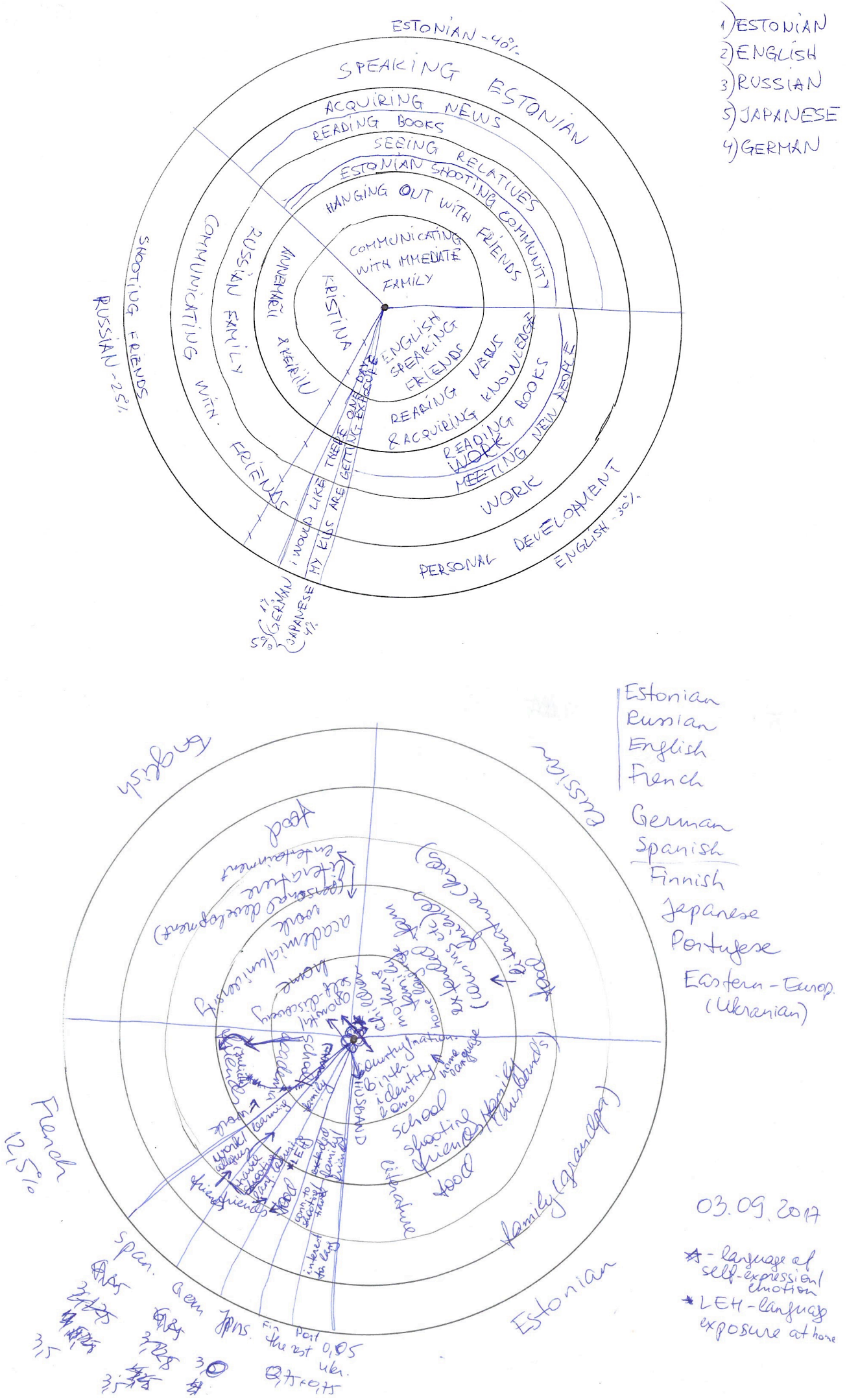


\section{APPENDIX I}

\section{Emergent Themes}

\section{BELIEFS ABOUT LANGUAGE(S)}

Language as a tool

Language as a resource

Language as communication

Language as a social practice

Language as culture and heritage

Multilingualism as a tool

Multilingualism as a resource

Multilingualism as a social practice

Appropriating the language through proficiency

- Non-nativeness is normal

English prevails

\section{PARENTS' INDIVIDUAL LANGUAGE PRACTICES}

Parents' Translanguaging

- Estonglish

Multilingual practices

- Reading

- Music

Self expression

- Differences in expressing self in Russian, Estonian, English

Child directed language use

Markedness of English

\section{PARENTS TEACHING}

Home language-Pragmatic choice Input

- Various outdoor activities

- Multilingual resources

- Multisensory input

- Russian-speaking community
BELIEFS ABOUT LANGUAGE LEARNING

Distribution of language input

- Rich input

Family language as a foundational platform

Good parenting

Natural language acquisition

The earlier the better

"system" and determination

Literacy is conceptualized as writing and reading

- Traditional literacy practices are fundamental for language learning

Parents' personal experiences

\section{CHILDREN'S LANGUAGE PRACTICES}

Differentiated language use

- Use of English

- Use of Russian

- Use of Estonian

Language awareness

- Differentiating between interlocutors

- Language structure (phonetics)

Multilingual socio-dramatic role plays

- Russian

- English

- Estonian

Siblings interaction

- Russian

- English

Imaginative language

Creating with the language

Asking for Translation

LANGUAGE MANAGEMENT

Language management as a family duty

Support of multilingualism 
Practices

- Rich Reading practices

- Multilingual Music practices

- Story times in the library

Parents language

- Adapting language for the children

- Parents' Questions and parents Answers

Expanding language knowledge

- Indexing and labeling

- Parents' brokering

- Teaching narration

Bordering languages

- Assigning functions to languages

- Preventing language mix

- Linguistic bordering of languages

Mother's role

- Mother scaffolding

- Initiated and regulate by mother

Literacy practices as defined by the parents

- Writing letters and words

- Reading letters and words

- Focus on proficiency

\section{DYNAMIC CHARACTER OF}

MULTILINGUAL IDEOLOGIES AND

\section{PRACTICES}

Change over time

Context sensitivity

Spaces are not fixed
Linguistic management

Communicative management

System approach

\section{LANGUAGING IDENTITY}

Heritage identity

Citizenship identity

Local identity (here and now)

Language identity

- Multilingual self

- Multilingual Intellectual

Cultural identity

Mother as an educator

Transnational identity

\section{LANGUAGE DIMENSIONS}

First language

Home/ family language

Academic language

Heritage language

Foreign language

Traveling

Sports and international competitions

Transnational life 


\section{APPENDIX J}

\section{Ethnography of Place (visuals)}

\section{English language space}
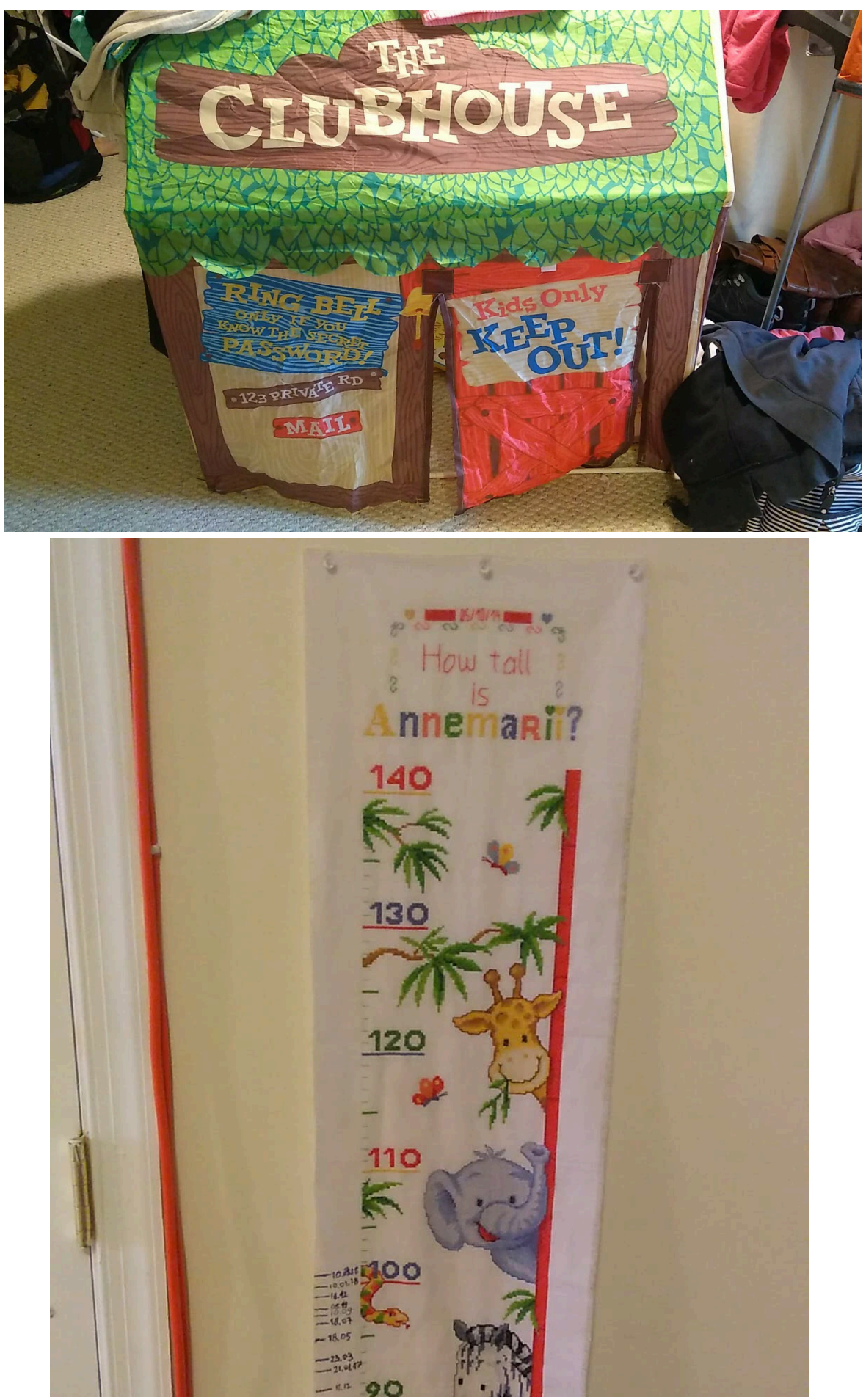
The girls' names in Japanese script

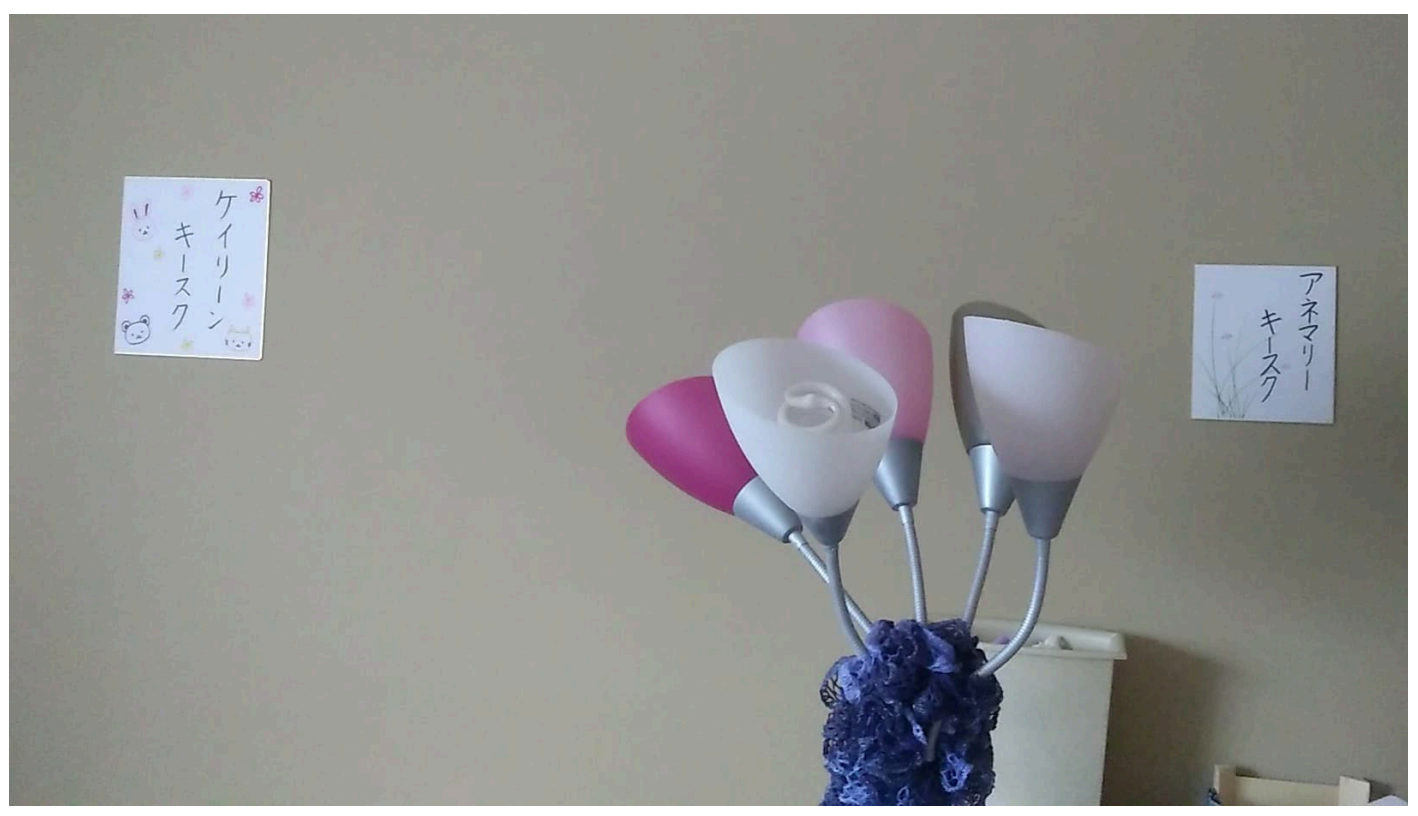

Russian cyrillic script letters are mixed up with Latin script letters

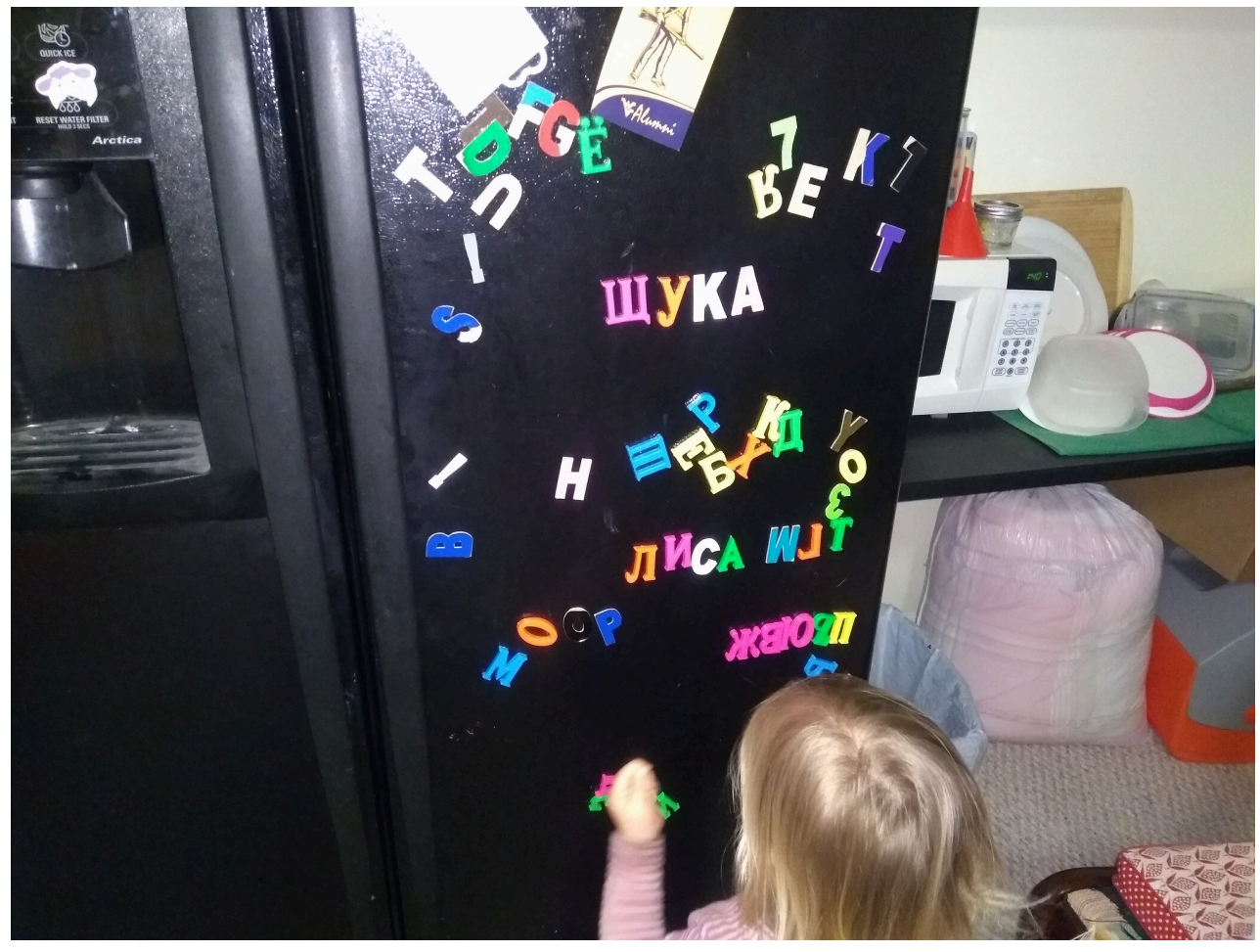


Reading space

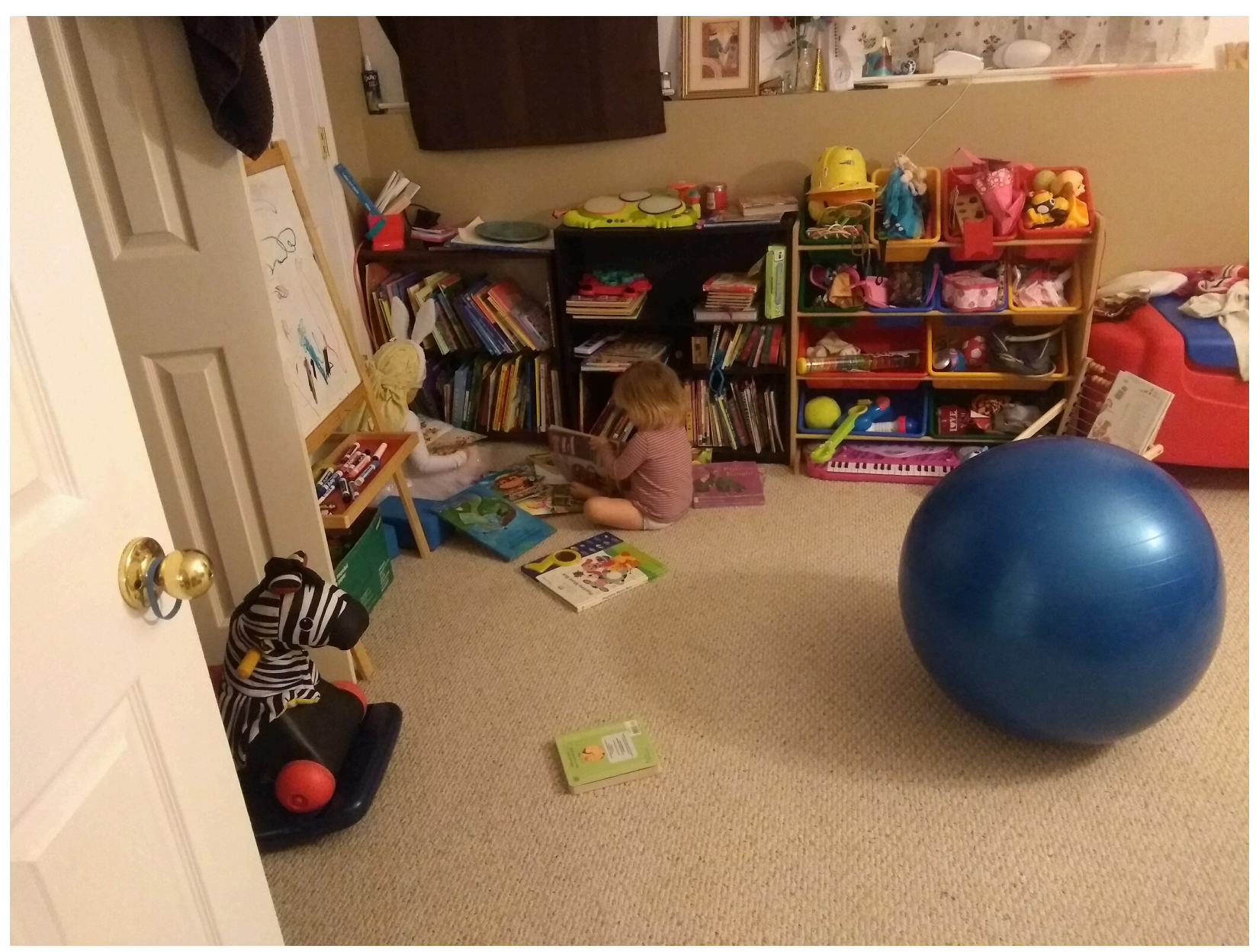

